\title{
DIFFUSE FLOW FROM HYDROTHERMAL VENTS
}

\author{
by \\ D. ANDREW TRIVETT \\ B.Eng., Technical University of Nova Scotia (1986) \\ SUBMITTED IN PARTIAL FULFILLMENT OF THE REQUIREMENTS \\ FOR THE DEGREE OF \\ DOCTOR OF SCIENCE \\ at the \\ WOODS HOLE OCEANOGRAPHIC INSTITUTION \\ and the \\ MASSACHUSETTS INSTITUTE OF TECHNOLOGY
}

June 1991

스 D. Andrew Trivett, 1991

The author hereby grants to WHOI and MIT permission to reproduce and distribute copies of this thesis document in whole or in part.

Signature of Author

Joint Program in Oceanographic

Engineering WHOI/MIT

Certified by

Albert J. Williams III Thesis Supervisor

Accepted by

W. Kendall Melville

Chairman, Joint Committee for Oceanographic Engineering,WHOI/MIT 



\title{
DIFFUSE FLOW FROM HYDROTHERMAL VENTS
}

\author{
by \\ D. ANDREW TRIVETT
}

Submitted to the Woods Hole Oceanographic Institution / Massachusetts Institute of Technology Joint Program in Oceanographic Engineering in June, 1991 in partial fulfillment of the requirements for the degree of Doctor of Science.

\begin{abstract}
The effluent from a collection of diffuse hydrothermal vents was modelled to determine the fate of this source of flow under typical environmental conditions at seafloor spreading centers. A laboratory simulation was conducted to test an analytic model of diffuse plume rise. The results showed that diffuse plumes are likely to remain near the seafloor, with their maximum rise height scaled with the diameter of the source of diffuse flow. The entrainment of ambient seawater into these plumes is limited by the proximity to the seafloor, thus slowing the rate of dilution.
\end{abstract}

The model of diffuse plume behaviour was used to guide the design and implementation of a scheme for monitoring the flow from diffuse hydrothermal vents in the ocean. A deployment of an array at the Southern Juan de Fuca Ridge yielded measurements of a variety of diffuse plume properties, including total heat output.

Two distinct sources of hydrothermal flow were detected during the field deployment. The larger source was $1-1.5 \mathrm{~km}$ north of the instrument array, and its energy output was $450 \pm 270 \mathrm{MW}$. A smaller source was located $100 \mathrm{~m}$ east of one instrument in the array. The energy output of this source was $12 \pm 8 \mathrm{MW}$. The rise heights of the centerlines of these plumes were $45 \mathrm{~m}$ and $10 \mathrm{~m}$, respectively. 


\section{Acknowledgements}

The stereotype of science as an exact, impersonal endeavour is complete hogwash. I have been fortunate to meet some wonderful, inspiring personalities while working on the research for this thesis. In fact, I would never have been able to present this work to you, dear reader, without their generosity.

The ideas contained herein grew from the guidance $I$ have received from Sandy Williams, Joe Cann, and Gene Terray. They have been Advisors, in the best sense of the word, and they have been true friends.

Education is much more than study, it is apprenticeship. Dick Edwards has shown me kindness, generosity, and dedication in addition to giving me the benefit of his awesome skill and experience. Al Bradley, Richard Koehler, Paul Boutin, Al Morton, Sarah Little, Craig Dorman, and Tom Gross have been both inspirational, and instrumental in making my field research possible. Steve Liberatore, Al Duester, John Kemp, Rod Catanach, Rick Chandler, Al Gordon, Dudley Foster, Karlen Wannop, Laurel Moore, and Judy White have both helped me do things, and have just gone ahead and done them for me. The WHOI security staff, Ron Craft, Joe Motta, Bill Cruwys, Dave MacDonald, J.C. Coddington, J.C. Williams, Ron Woods, and Nadine Athearn made it possible to work late, and get home dry (not to mention keeping me sane, or at least as sane as them). I have tremendous respect for all of these fine people. They make WHOI a great place to do research, and they make it a delightful experience.

My work has involved going to sea on the NOAA ship Discoverer, and the R/V Atlantis II. My thanks go to the excellent crews of both these vessels. Scientists at NOAA-PMEL have given me a chance to deploy my equipment on their cruises. I acknowledge the help and support given by Gary Massoth, Bob Embley, Chris Fox, Glenn Cannon, Ed Baker, and Hugh Milburn. Peter Rona at NOAA-AOML has also been a generous and helpful collaborator. Walter Frick kindly gave me guidance in using his EPA numerical plume model.

Mark McDonald, Phil Hammer and Wayne Crawford from SIO did a marvelous job of navigating the deployment of my instrument array during VENTS90. Jay Fay, Ken Melville, Jack Whitehead and Karl Helfrich gave me the impetus and facilities to perform the flow models discussed in this thesis. The readers of this thesis were Bob Weller, Jerome Milgram, Tim Duda, Joe Cann, Al Bradley, Gene Terray, Sandy Williams, Meg Tivey, and Laura Praderio. Thank you all for your constructive criticisms.

The Ocean Ventures Fund has supported my work. I thank C.D. Hollister, and Jake Peirson of the WHOI education office for making these funds available to students. My research has also been supported by the WHOI Fiends of Vents, with a grant from the Mellon Foundation, by the WHOI SeaGrant (NA86-AA-D-SG090, WHOI project number R10-11-PD), and by the National Science Foundation (OCE-8917448). If someone else wasn't paying, I always knew Jake Peirson and the Education office would take care of me.

Finally, I thank my friends and family, especially Markku Santala, Sarah Greene, Greg Cohen, Franz Hover, Chris Bradley, Josko Catipovic, Josh Hoyt, Harry Jenter, Paul Snelgrove, Sarah Little, Abbie Jacskon, Jane Smith, and Cindy VanDover. My wife, Lana Beth Barkhouse, and both our sets of parents have sustained me through this work. 
I dedicate this thesis to Lana Beth, who is just plain wonderful.

Let's hear a laugh for the man of the world who thinks he can make things work.

He tried to build a new Jerusalem, and ended up with New York.

Bruce Cockburn 


\title{
DIFFUSE FLOW FROM HYDROTHERMAL VENTS
}

\author{
D. ANDREW TRIVETT
}

\section{Table of Contents}

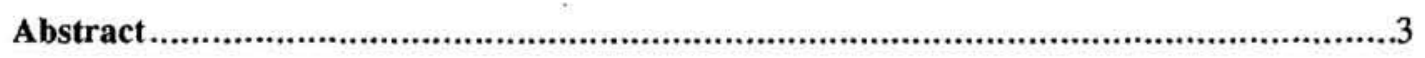

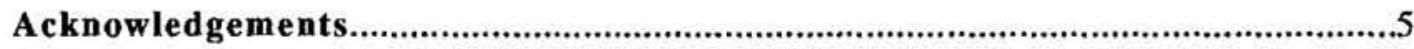

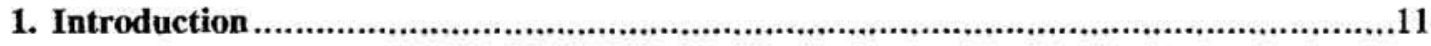

2. A Model of Diffuse Hydrothermal Flow ................................................................15

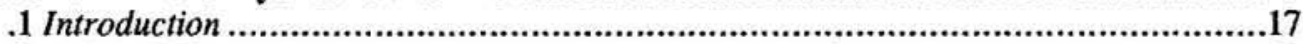

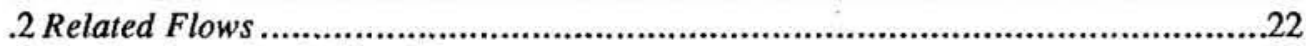

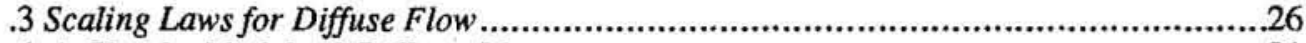

.4 A Simple Model of Diffuse Flow.............................................................................

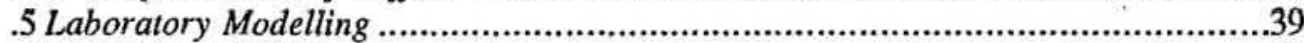

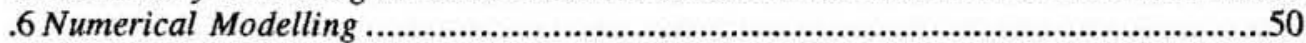

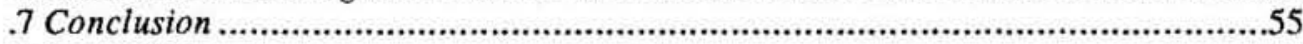

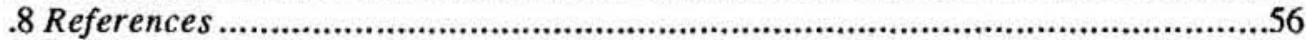

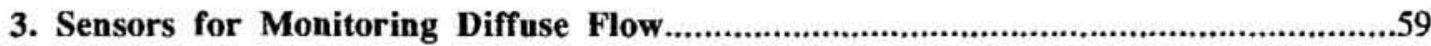

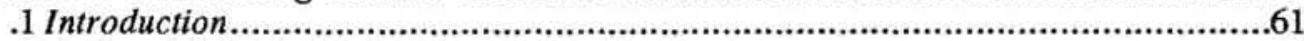

.2 A Vent Field Acoustic Tomography Array.........................................................62

.3 An Array of Temperature and Velocity Sensors ....................................................68

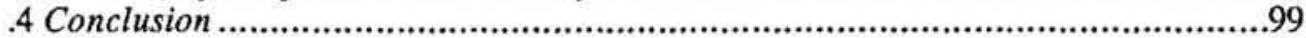

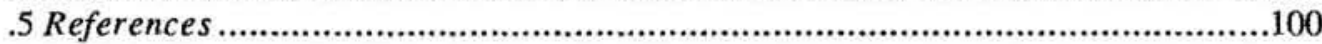

4. Field Measurements at the Southern Juan de Fuca Ridge...........................................103

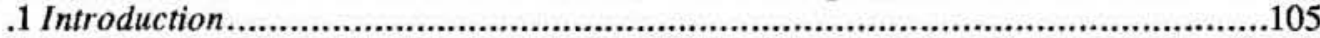

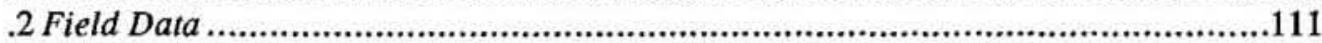

. 3 Interpretation of Field Measurements ..................................................................129

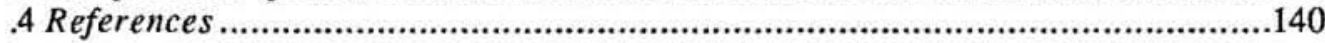

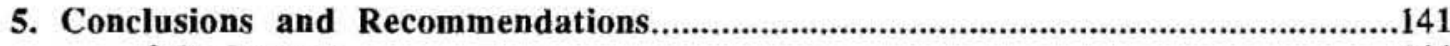

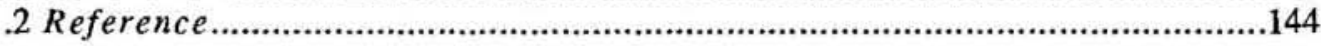

Appendix A: Discrete and Diffuse Heat Transfer at ASHES Vent Field...................................145

Appendix B: Error Analysis of an Acoustic Current Meter...............................................175

Appendix C: Time-Series and Cross-correlations from VENTS90......................................209 


\section{Section 1}

\section{Introduction}

This thesis describes an engineering research project. I spend the majority of it embroiled in issues of sensitivity and accuracy, deployment strategy and power budget. Despite attention to technological concerns, my overwhelming priority is to obtain a scientifically relevant measurement of an oceanic process. The scientific challenge in the work is found in sensing flow from deep-sea hydrothermal vents. The engineering challenge lies in realizing this scientific goal in the simplest, most practical manner possible.

Hydrothermal venting occurs on oceanic ridge crests due to circulation of seawater through hot rock below the ridge axis. Seafloor expression of this flow ranges from intense jets called black smokers, to diffuse flow emanating from tiny cracks and fissures between rocks. Both types of flow are typically observed in a single hydrothermal field.

Energy output by diffuse hydrothermal flow has never been measured over the scale of a vent field. Diffuse hydrothermal flow is characterized by extensive patches of small temperature and velocity anomalies caused by geothermal heating of water below the seafloor. Patches of diffuse flow are found at virtually every oceanic ridge-crest spreading 
center explored to date (RIDGE, 1988). The spatial variability in these flow patches can be dramatic. Videotape records from DSV Alvin show a cold desert of seafloor basalt, punctuated by oases of shimmering water around which are huddled a community of strange creatures. These patches of warmth and life may cover massive mounds and spires, as in the TAG field in the North Atlantic (Rona et al.), or just tiny clumps along a jumbled crack, such as the Cleft Segment of the Juan de Fuca ridge (Embley, et al, 1990).

How can we monitor these scattered oases of heat? Are they merely insignificant patches that we can ignore, or does the sum of their effect add up to something significant to the heat balance of the world ocean? Are they constant in time, or do the patches build and die in relation to some geologic or thermodynamic events? None of these questions can be answered without making initial field measurements.

To measure diffuse hydrothermal flow, I needed to understand the behaviour of idealized flow sources. This was accomplished by modelling the large-scale effects of diffuse flow in a laboratory setup. The modelling is described in Section 2.

From an engineering perspective, the measurement of diffuse flow is a challenging one. Not only is the target of the measurements spread out in discontinuous patches, but the magnitude of the temperature and velocity anomalies at these patches are potentially very small. The resolution of the instruments, and spatial sampling strategy must be carefully considered in order to successfully monitor this subtle, patchy flow. Section 3 addresses the design and implementation of a field-deployable array based on the lessons learned from the laboratory model.

Section 4 shows results from a deployment of this array at the southern Juan de Fuca ridge in 1990 (figure 1.1 shows a map of the location of this vent system). The quality of the data was sufficient to distinguish two different sources of hydrothermal flow, and estimate the energy output from each source.

Conclusions and recommendations for improvement of the monitoring technique are presented in Section 5 . 


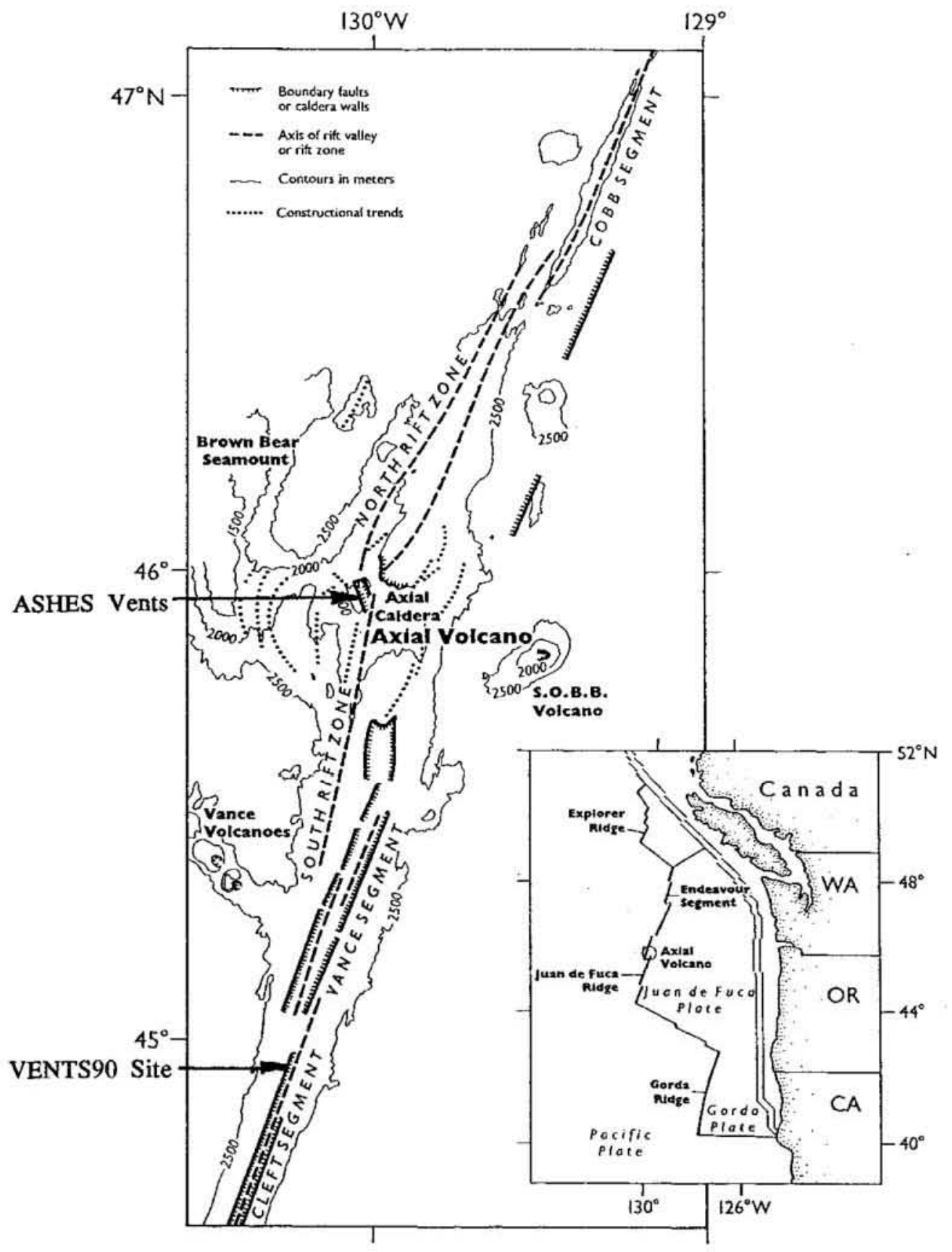

Figure 1.1: A map (inset) showing the location of the Juan de Fuca ridge with respect to the coast of the Pacific Northwest United States. The Juan de Fuca ridge is shown in detail, pointing out the principal segments which have been studied to date. The ASHES vent field (North) is the site of measurements described in Appendix A of this thesis, while the Cleft Segment of the Southern Juan de Fuca ridge was the location of measurements presented in Section 4 of this thesis. (from Embley, Murphy and Fox, 1990) 


\title{
Section 2
}

\section{A Model of Diffuse Hydrothermal Flow}

\author{
Table of Contents
}

2.1 Introduction: A Physical Description.....................................................17

Previous Attempts at Measurement ......................................................................18

The Need to Understand the Fate of Diffuse Flow....................................................19

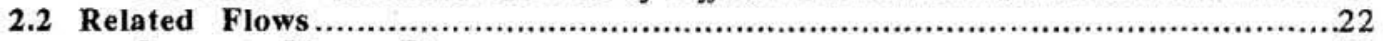

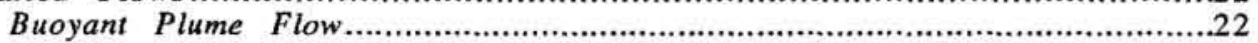

Buoyant Plume Flow from Multiple Sources......................................................23

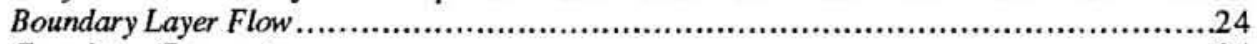

Gravity Currents....................................................................................24

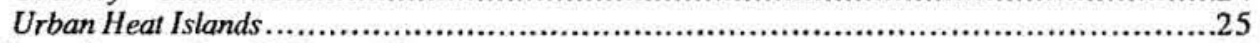

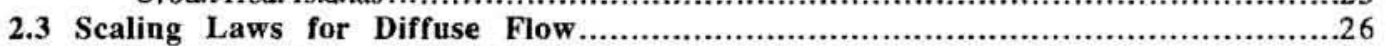

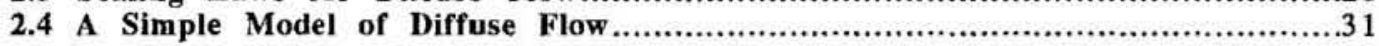

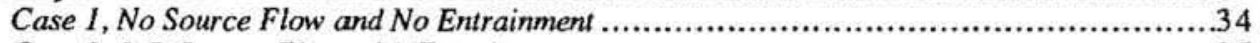

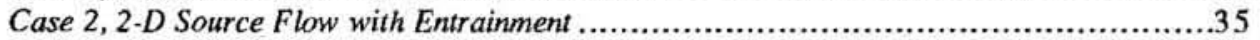

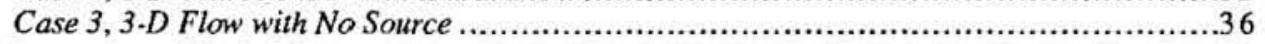

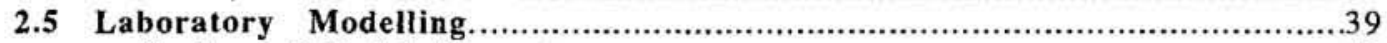

Scaling of Model Parameters.........................................................................4

Experimental Procedure ............................................................................43

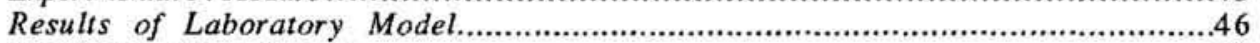

Discussion of Lab Results ..............................................................................48

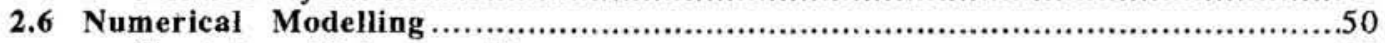

Simulation of Laboratory Flows ..............................................................52

Comparison between UMERGE and the Analytic Solution ...................................54

2.7 Conclusion: A Qualitative View of Diffuse Plumes..........................................55

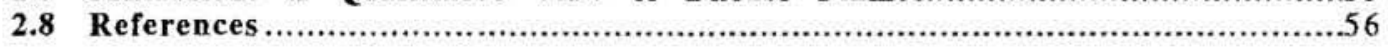




\section{Introduction: A Physical Description}

Figure 2.1 shows a cartoon of one presently held view of a hydrothermal system

(Cann, 1987). Cold bottom water circulates in the hot crust, where it extracts heat and reacts chemically with the rock. This heated fluid, containing a substantial quantity of dissolved minerals, rises toward the seafloor through pores or fissures in the rock. Black smokers occur if the hot solution remains concentrated until it mixes with cold seawater in the water column, and subsequently precipitates sulfide particles in a vigorous buoyant plume. This flow often forms tall chimneys of precipitated sulfides around the vent orifice, deposits sediment on the seafloor downstream of the source, and is a large contributor to dissolved minerals in the ocean.

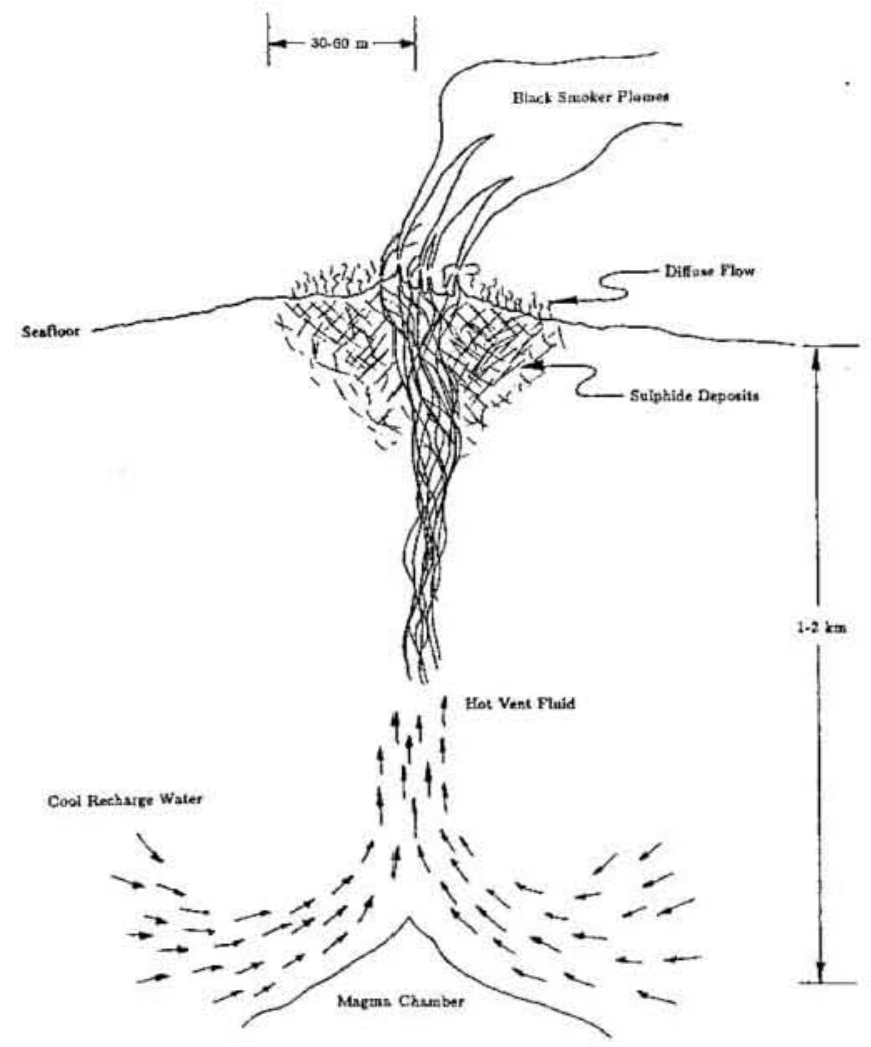

Figure 2.1: A representative cross-section of a hydrothermal vent field showing cool recharge water being heated by a shallow magma chamber $1-2 \mathrm{~km}$ below the seafloor. The heated water absorbs minerals from the rock as it rises through cracks and fissures in the rock. Some of the water reaches the seafloor directly, whereas some of it reaches the seafloor through a tortuous path, possibly being diluted by seawater, or cooling from contact with surrounding rock. This fluid forms diffuse hydrothermal plumes. (After Cann, 1987) 
Diffuse hydrothermal flow results if hot vent fluid is diluted with cold water, or is conductively cooled, before reaching the seafloor (Cann and Edmond, 1987; Cann, Strens and Rice,1985). Beneath diffuse vent fields, sulphides are deposited in the rock structure rather than precipitating in the water column. Diffuse flow has been proposed as the primary process for deposition of commercially important metallic sulphide deposits (Cann, 1989). Patches of diffuse flow are much more extensive in area than are smoker chimneys. For this reason, it may be that the energy flux from diffuse flow is greater than that from smokers in a vent field. Previous attempts to quantify heat flow from vents have focused on the smokers or discrete sources. In this thesis, I address the problem of measuring heat flux from the diffuse vents.

\section{Previous Attempts at Measurement}

The total heat flux from a diffuse hydrothermal vent region and its temporal variability have not been measured to date. Little et al., (1987) attempted to measure this quantity using a towed thermistor chain, but were only able to estimate the energy flux from a single black smoker plume. The integrated heat flux from diffuse vents was thought to be of the same order of magnitude as that from the black smokers (Little, 1988b).

Baker and Massoth (1987) conducted a survey in the water column above the Juan de Fuca ridge using a tow-yo vehicle. They estimated the total heat flux from all sources which produced plumes in the water column to be $580 \pm 351 \mathrm{MW}$. Their towed survey did not include plumes which were very near the bottom (less than $20-40 \mathrm{~m}$ ). Similar work was done by Crane et al. (1985) using a thermistor chain streaming below a towed vehicle. Their heat flux estimate over the same area as Baker and Massoth was $2,096 \mathrm{MW}$, or $30,240 \mathrm{MW}$, depending on the model used in the calculation. The site of both the above studies was the same as that where instruments were deployed in the field study to be discussed in this thesis. However, the previous measurements focussed on anomalies which were more than $30 \mathrm{~m}$ above the seafloor. 
On the scale of a few meters, diffuse venting appears as a distribution of tiny microplumes which individually look very similar to large buoyant plumes. These microplumes were sampled by several investigators ( Converse et al., 1984; Monfort and Schulz, 1988). Extrapolating these measurements of a single micro-plume, which is $1 \mathrm{~cm}$ in diameter, to the behaviour of an entire patch of diffuse venting $30-50 \mathrm{~m}$ in diameter gives a very questionable estimate of total heat output. A patch of diffuse hydrothermal flow is too variable for small-scale point measurements to be used for estimating total output.

Observations of micro-plumes indicate vertical velocities of less than $1-10 \mathrm{~cm} / \mathrm{s}$ above a small source (Converse et al.,1984), and source temperatures typically less than $20^{\circ} \mathrm{C}$ (Hessler and Smithey,1983). Ambient current can be as great as $20 \mathrm{~cm} / \mathrm{s}$ (Cannon and Pashinski, 1988). Under such conditions, the warm fluid will be convected $20 \mathrm{~m}$ downstream before it rises more than $10 \mathrm{~m}$ off the bottom. Clearly, the horizontal advection of diffuse venting will be crucial to interpretting any measurements. Little et al. (1988) analyzed a temperature record from a diffuse vent site in the Guaymas Basin, and concluded that currents must be measured in order to interpret any diffuse field data.

\section{The Need to Understand the Fate of Diffuse Flow}

The heat from black smokers rises up to 300 meters into the water column, thereby converting heat energy into potential energy by modifying the density profile above a ridge axis. Evidence of such behaviour has been well documented by the NOAA VENTS programme (Baker and Massoth, 1987). If diffuse flow contributes as much energy to the ocean as do black smokers, then we must ask, where does this energy go?.

To answer this question, I have set out a large-scale model of diffuse hydrothermal flow in this section. If we look some distance downstream from a vent field, we can consider the diffuse flow as coming from an individual source rather than from thousands of micro-plumes. I will outline scaling parameters relevant for determining how large the plume will be, and how its physical properties will vary a function of distance from the source.

Figure 2.2 shows a laboratory plume simulation of a black smoker in the middle of a diffuse vent field (scaled to dimensions expected in the field). The two sources stabilized 
to different heights in the tank, and behaved quite independently from each other. The diffuse plume did not rise more than a height approximately similar to the diameter of the source of venting ( $20-100 \mathrm{~m}$ in the field). In this thesis, I will test the hypothesis that energy from diffuse flow is trapped in the bottom $50-100 \mathrm{~m}$ layer of water, and instruments for monitoring the diffuse flow must therefore be located on or near the seafloor.

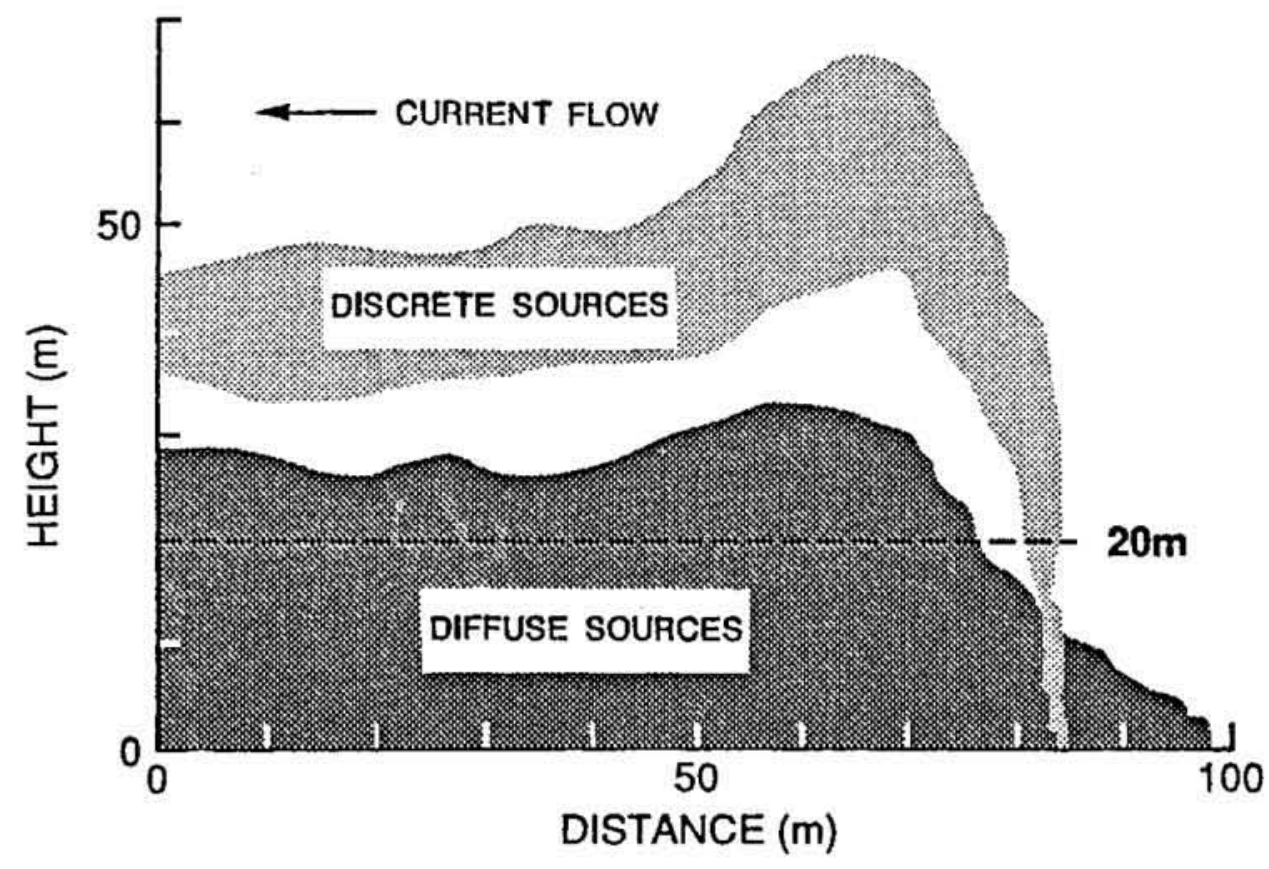

Figure 2.2: Outline of the trajectory of a black smoker plume within a diffuse vent field. The horizontal current is flowing from right to left, and the plume effluent is advected downstream. Discrete sources penetrate higher into the water column than do diffuse plumes, resulting in little interaction between the two, unless the boundaries of the effluents are close enough in vertical distance to entrain flow from each other (from Appendix A). 
The laboratory model described in this section is compared to a more complicated (but no more relevant) numerical model. Conclusions from the models are used to guide a field measurement strategy. 


\section{Related Flows}

To characterize large-scale diffuse flow, I consider the similarity of this problem to other flows. Following a discussion of previously solved problems, I will introduce an analytic solution to the flow from a patch of diffuse venting.

\section{Buoyant Plume Flow}

A buoyant plume results from a point source of heat in a still, uniform environment. Turner (1973) and List (1982) have reviewed this model. More complex models have been created for flow from point sources in a cross-flow; in a stratified environment; and in a combination of the two (List, 1982). A sketch of the flow considered in those models is shown in figure 2.3.

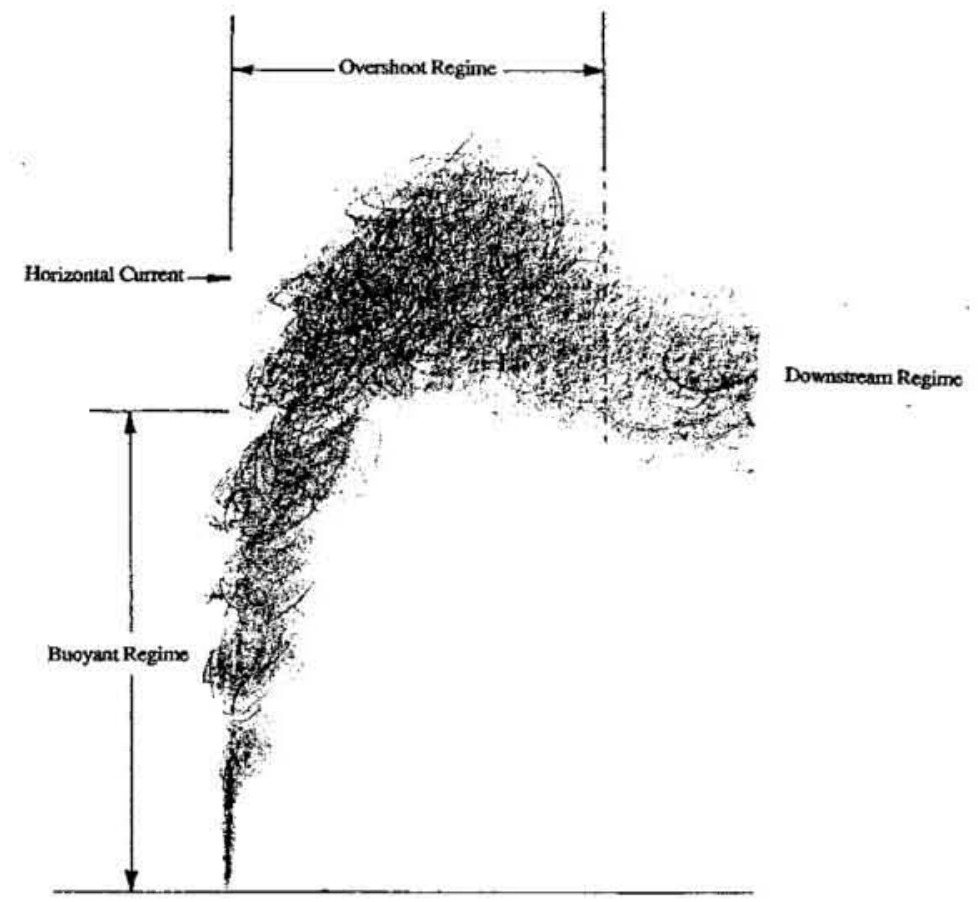

Figure 2.3: An idealized plume in a stably stratified flow where the rise height is many times larger than the source diameter. The three regimes in this figure are: buoyant rise, where the entrainment velocity is a constant fraction of the vertical velocity, The overshoot region where the buoyant fluid rises above the height where its density is equal to the surroundings, and the downsteam region where ambient turbulence dilutes the plume, and stratification flattens the effluent to a layer where its density is equal to the surroundings. 
Near the region of maximum rise, or the plume cap, the vertical dimension and the diameter of a plume become similar in scale, as shown in figure 2.3. The plume cap is more similar to diffuse hydrothermal flow than the region of rising flow. The diameter of a diffuse hydrothermal field is on the order of $30-100 \mathrm{~m}$, while the rise height is the same order of magnitude (Appendix A: Discrete and Diffuse Heat Transfer at ASHES Vent Field, Axial Volcano, Juan de Fuca Ridge). Classical models of plume flow consider only the rising portion of a plume. The plume cap is not considered. Thus, classical buoyant plume models should not be expected to predict the behaviour of diffuse vents.

Modelling hydrothermal flow using buoyant plume theory is applicable for intense black-smoker plumes rather than for weak, but extensive diffuse flow. Little et al., (1987) have used standard relations for a plume in a still, stratified environment to interpret field measurements and calculate the source heat flux from a black smoker field.

\section{Buoyant Plume Flow from Multiple Sources}

A hydrothermal field consists of many individual micro-plumes with a broad range of source intensities. From video-tape recordings (for example,DSV Alvin,1990), a diffuse hydrothermal vent field appears as patches of small micro-plumes. The spacing between individual sources varies widely, but a reasonable mean estimate is between 1$5 \mathrm{~m}$.

Briggs (1974) used observations of a collection of separate, but nearby cooling tower plumes in a crossflow to justify an empirical relation for the rise height of interacting plumes. The relation was intended to predict behaviour from a group of 2 to 30 equal strength plumes. He observed that the plumes would combine on a downstream scale which was equal to the horizontal spacing between sources.

Based on Briggs' conclusions for cooling tower plumes, micro-plumes in a diffuse vent should coalesce within a length-scale of $10 \mathrm{~m}$ (approximately twice the spacing between

micro-plumes). Beyond this distance, variability due to individual micro-plumes should be negligible. 


\section{Boundary Layer Flow}

If buoyant plume flow is an extreme case where hydrothermal fluid rises very far into the water column, then the opposite case occurs when flow stays very close to the seafloor. Townsend $(1965 \mathrm{a}, \mathrm{b})$ investigated the effect of a change in surface heat or roughness in a boundary layer flow. He also considered the effect of a line source of heat or roughness (such as a fence perpendicular to wind). He assumed the boundary layer thickness to be greater than the thickness of the disturbed layer. This assumption is not applicable to hydrothermal flow. Typical thickness of the benthic boundary layer is on the order of $10 \mathrm{~m}$ (Gross, et al.,1986), while the penetration thickness of diffuse flow may be $10-100 \mathrm{~m}$.

If the boundary layer is on the order of $10 \mathrm{~m}$ thick, then the top of a diffuse plume will be above the boundary layer turbulence. Thus, mixing at the plume top will be driven by buoyancy and ambient turbulence. At the bottom of the plume, heat transport between the plume and the seafloor will be governed by the turbulent boundary layer.

The full scale benthic boundary layer incorporates turbulent eddies with dimensions from centimeters up to tens of meters. To model mixing processes in the laboratory, the smallest eddy scales would have to be smaller than could be generated from reasonable model parameters. I chose not to simulate the boundary layer in model experiments because of the difficulty in attaining hydrodynamic similarity between mixing scales in the field and in the laboratory.

\section{Gravity Currents}

Britter and Simpson (1978) studied the mixing of a dense intrusion of fluid into horizontal boundary layer flows. The upstream velocity profile had a profound effect on the character of the density current downstream. In flow with no vertical velocity gradient, regular internal waves were observed at the interface between the ambient fluid, and the underlying layer of dense water. When they introduced a boundary layer, the waves were no longer observed. 
The laboratory model presented later in this section did not include any velocity gradient. Internal waves similar to ones observed by Britter and Simpson were observed for model runs where the plume rise height was very much less than the vent field diameter. The waves were an artifact of the model, and should not occur in the field because a bottom boundary layer retards the oscillations, as Britter and Simpson observed.

\section{Urban Heat Islands}

On land, large urban centers generate flow patterns which are analogous to diffuse venting in the ocean. Stable atmospheric stratification traps heat released above cities, creating a lens of warm air which is advected along the ground by wind (Garstang et al., 1975). The spatial scales of urban heat islands $(1-10 \mathrm{~km})$ are comparable to those of diffuse hydrothermal systems $(20-100 \mathrm{~m})$, given the relative difference in viscosity, density and heat capacity between water and air.

All of the general solutions reviewed (Atwater, 1972, 1975, 1977; McElroy, 1973; Yu and Wagner, 1975; Myrup, 1969; Bornstein, 1975; Gutman and Torrance, 1975) rely upon two-dimensional numerical modelling of the flow. The observational studies have each concentrated on particular cities or oceanic islands. Garstang et al., (1975) reviews literature containing field observations of the urban and oceanic heat islands. No analytical approach simple enough for a first-order solution to diffuse hydrothermal venting has been suggested for the urban heat island. A numerical model is far too complicated given the lack of observations of diffuse plumes.

I will present a simple set of relations in the next sub-section which will be instructive in understanding the flow characteristics of diffuse hydrothermal venting. 


\section{Scaling Laws for Diffuse Flow}

Figure 2.4 shows idealized flow from a large collection of diffuse hydrothermal micro-plumes in the presence of a horizontal current. The relevant variables are noted in the figure. The variables to be used in the remainder of this section are listed in table 2.1 .

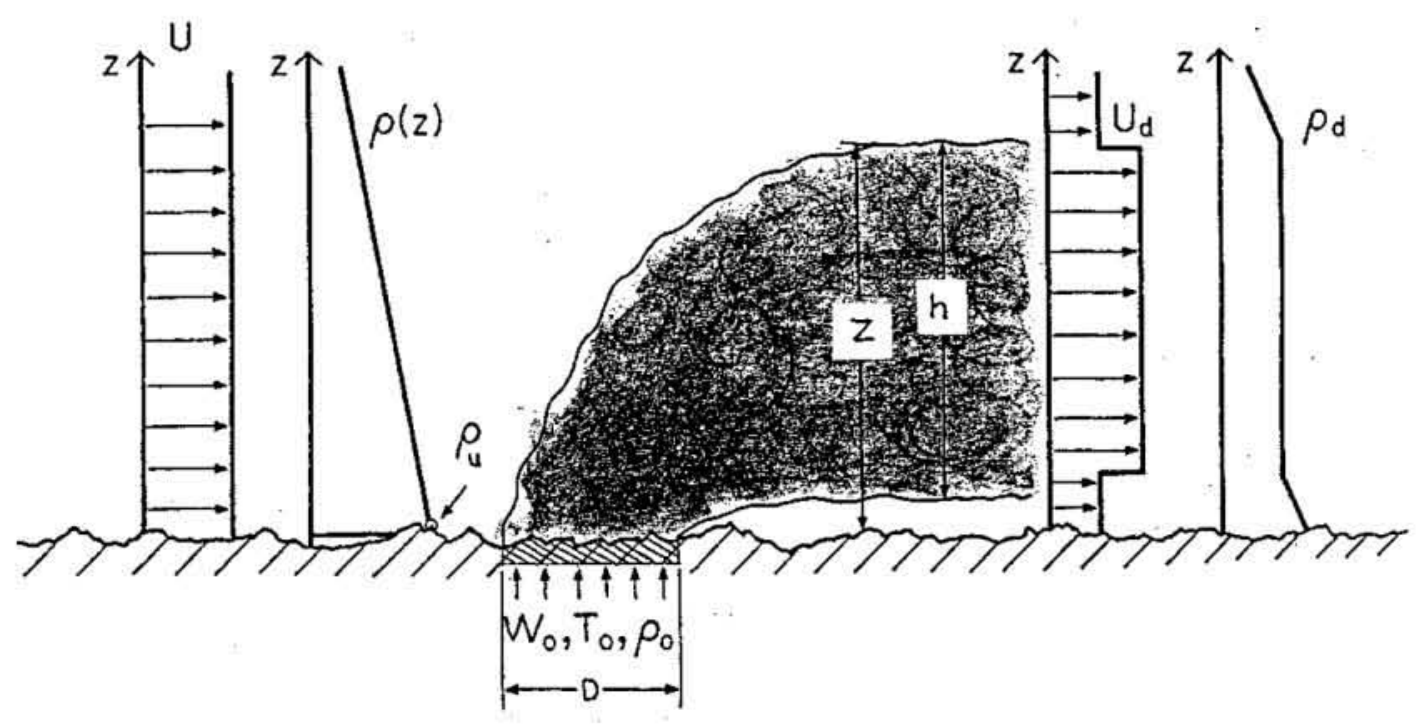

Figure 2.4: Parameters to be used in scaling diffuse hydrothermal flow. The symbols are also defined in table 2.1. The assumptions in this model are that the upstream flow (on the left) is stably stratified, and there is no vertical velocity shear. The plume downstream (to the right) is well-mixed, so that properties are constant within it. 


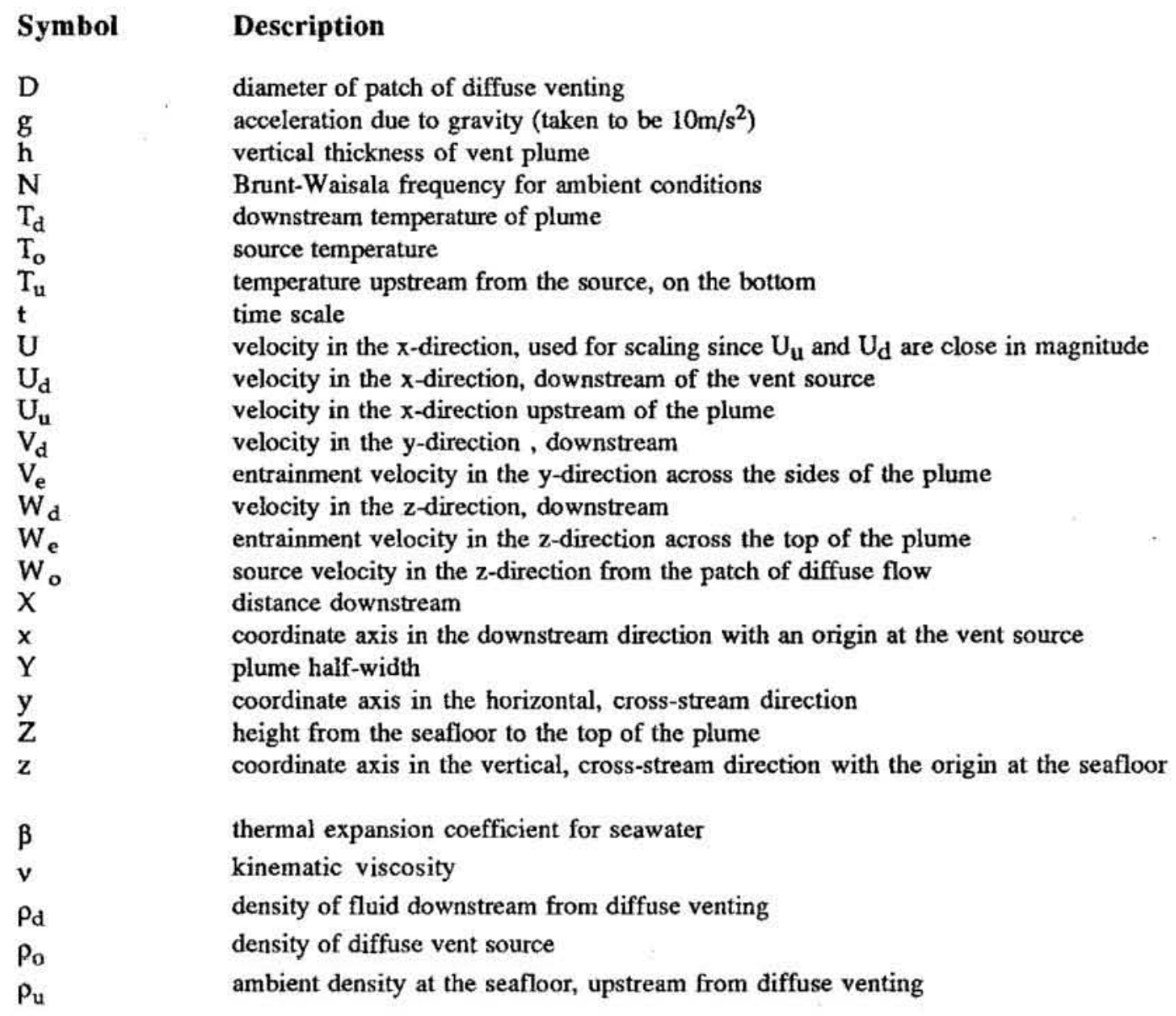

Table 2.1: Definition of symbols used in the remainder of this section

Using the variables shown in the table 2.1, I have created the relevant nondimensional parameters:

$$
\begin{aligned}
& \mathrm{w}_{\mathrm{o}}^{*}=\frac{\mathrm{W}_{\mathrm{o}}}{\mathrm{U}}, \mathrm{w}_{\mathrm{e}}^{*}=\frac{\mathrm{W}_{\mathrm{e}}}{\mathrm{U}}, \mathrm{v}_{\mathrm{e}}^{*}=\frac{\mathrm{V}_{\mathrm{e}}}{\mathrm{U}^{\prime}} \\
& \mathrm{Y}^{*}=\frac{\mathrm{Y}}{\mathrm{D}^{\prime}} \mathrm{Z}^{*}=\frac{\mathrm{Z}}{\mathrm{D}^{\prime}} \\
& \rho_{\mathrm{d}}^{*}=\frac{\left(\rho_{\mathrm{u}}-\rho_{\mathrm{d}}\right)}{\rho_{\mathrm{u}}}, \rho_{\mathrm{o}}^{*}=\frac{\left(\rho_{\mathrm{u}}-\rho_{\mathrm{o}}\right)}{\rho_{\mathrm{u}}}, \\
& \mathrm{S}^{-1}=\frac{\mathrm{Ut}}{\mathrm{D}}, \mathrm{Re}_{\mathrm{e}}^{*}=\frac{\mathrm{UD}}{\mathrm{v}},
\end{aligned}
$$




$$
\mathrm{F}_{\mathrm{r}}^{*}=\frac{\mathrm{ND}}{\mathrm{U}}, \mathrm{G}^{*}=\frac{\mathrm{g}}{\mathrm{N}^{2} \mathrm{D}}
$$

$S$ is the Strouhal number, $R_{e}$ is the Reynolds number, $F_{r}$ is related to the Froude Number, and $\mathrm{W}^{*}, \mathrm{Z}^{*}, \mathrm{Y}^{*}$ are geometrical scale factors.

$G^{*}$ and $\rho^{*}$ are not common dimensionless parameters. They can be interpretted by examining the momentum equation in the vertical $(\mathrm{z})$ direction (2-dimensional) for a infinitesimal fluid element:

$$
\frac{d v}{d t}+u \frac{d v}{d x}+v \frac{d v}{d z}=v\left(\frac{d^{2} v}{d x^{2}}+\frac{d^{2} v}{d z^{2}}\right)-g\left(\rho-\rho_{u}\right)
$$

The last term in this equation is the buoyancy force acting on a fluid element. For an element in a linearly stratified flow, such as encountered upstream of a diffuse hydrothermal vent, the buoyancy term is:

$$
F_{\text {upstream }}=g\left(\rho_{u}-\rho_{u} \frac{N^{2} z}{g}-\rho_{u}\right)=-\rho_{u} N^{2} Z
$$

The buoyancy of the plume downstream of a vent source is:

$$
F_{\text {downstream }}=-g\left(\rho_{u}-\rho_{d}\right)
$$

The ratio of these two forces, $F_{\text {downstream }}$ and $F_{\text {upstream, indicates the relative }}$ magnitude of the upstream stabilizing force compared with the buoyancy force in a plume. This ratio is written (with $\mathrm{Z}$ replaced by $\mathrm{D}$ since they are the same order of magnitude):

$$
\frac{F_{\text {downstream }}}{F_{\text {upstream }}}=\frac{g\left(\rho_{\mathrm{u}}-\rho_{\mathrm{d}}\right)}{\rho_{\mathrm{u}} \mathrm{N}^{2} \mathrm{D}}=\mathrm{G}^{*} \rho_{\mathrm{d}}^{*}
$$

Similarly, the ratio at the source of venting is:

$$
\frac{F_{\text {source }}}{F_{\text {upstream }}}=\frac{g\left(\rho_{u}-\rho_{\mathrm{o}}\right)}{\rho_{u} N^{2} D}=G^{*} \rho_{o}^{*} \text {. }
$$


The ratios defined in 2.4 and 2.5 are similar, with 2.5 actually being an upper bound on 2.4. In other words, the plume buoyancy is reduced from its maximum value at the vent source by entrainment of cool seawater into the plume. The height $(Z)$ has been replaced by $D$, which is the primary length scale in the problem. All other lengths are related to $\mathrm{D}$ through the dimensionless scales given above.

If the buoyancy force associated with diffuse flow is larger than the stabilizing buoyancy from upstream stratification, the ratio in equation 2.5 will be greater than unity. A plume that will rise above the seafloor will result. For $G^{*} \rho_{0}^{*}>1$, diffuse hydrothermal flow modelled in the lab breaks away from the boundary to form a buoyant plume (results of this laboratory model are presented in section 2.5 ). If $G^{*} \rho_{0}^{*}<1$, the plume effluent will not have sufficient buoyancy to lift above the bottom, and it should form a thin layer of warm flow along the seafloor.

$G^{*} \rho_{0}^{*}=1$ in the field corresponds to (using stratification data from Massoth, 1988):

$$
\begin{aligned}
& \mathrm{N}=.00196 \mathrm{~s}^{-1} \text { ， } \\
& \rho_{\mathrm{u}}=1026.8 \mathrm{~kg} / \mathrm{m}^{3}, \\
& \mathrm{D}=50 \mathrm{~m}, \\
& 1=\frac{g\left(\rho_{u}-\rho_{0}\right)}{\rho_{u} N^{2} D}-\frac{g\left(\rho_{u}-\rho_{0}\right)}{0.197}, \text { thus } \\
& \left(\rho_{\mathbf{u}}-\rho_{\mathrm{O}}\right)=0.020 \mathrm{~kg} / \mathrm{m}^{3} \text {. }
\end{aligned}
$$

Assumimg the coefficient of thermal expansion for seawater is $\beta=-1 \times 10^{-5} \mathrm{o}^{-1}$, then

$$
\left(\mathrm{T}_{\mathrm{o}}-\mathrm{T}_{\mathrm{u}}\right)=\frac{\left(\rho_{\mathrm{u}}-\rho_{\mathrm{o}}\right)}{\beta \rho_{\mathrm{u}}}=2.0^{\circ} \mathrm{C} .
$$

Temperature anomalies on the order of $0.3^{\circ} \mathrm{C}$ were measured by Rona at the ASHES vent field (Appendix A). Measurements were made approximately one meter above the seafloor where the diffuse flow was diluted with ambient seawater. Variability in 
source conditions, or undersampling of the vent field made source anomalies on the order of $0.1-5.0^{\circ} \mathrm{C}$ conceivable. Thus, $\mathrm{G}^{*} \mathrm{P}^{*}-1$ is a reasonable field parameter.

The behaviour of plumes with $G^{*} \rho_{o}^{*} 1$ is different from traditional buoyant plumes. This point was made in a qualitative way during the discussion of the classical plume model. I will use a simple analytic model to show that diffuse plumes obey a different spreading law than classical plume theory would indicate. 


\section{A Simple Model of Diffuse Flow}

In order to model diffuse hydrothermal flow, I construct a system of governing equations for the control-volume shown in figure 2.5. The goal of this model is to relate rise height, effluent density, and velocity anomaly to the source intensity and upstream ambient conditions. By doing so, I will have a way to predict the height to which a given diffuse source will rise, and the expected downstream density or temperature anomaly.

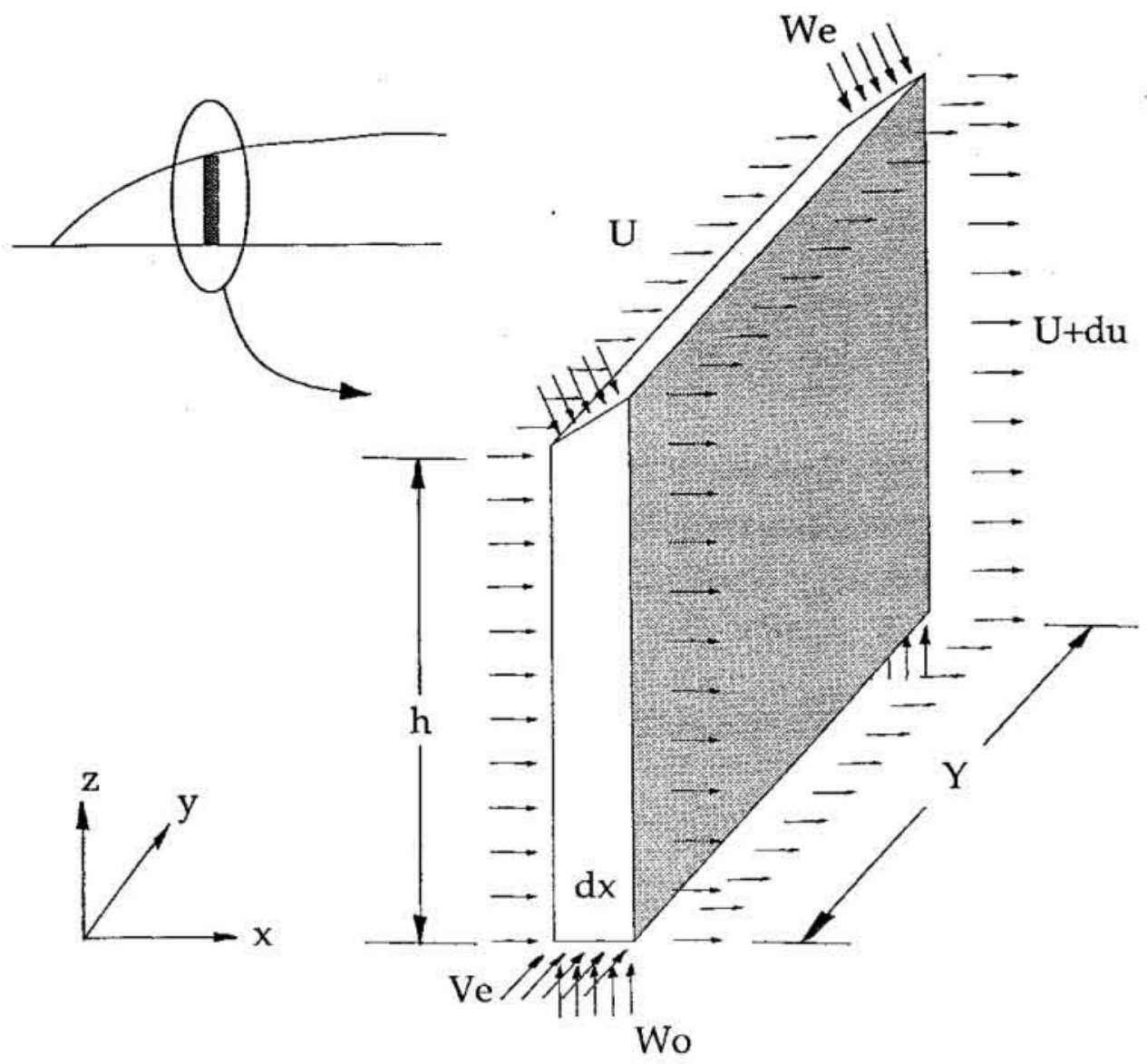

Figure 2.5: An elemental control-volume for modelling diffuse plume rise. The properties within the element are assumed to be constant. The boundaries of the elemental slice coincide with the boundary of the plume. The downstream direction is to the right. 
Flow is considered inviscid, and second-order terms are discarded in this analysis. The standard Boussinesq approximation is used when writing the governing equations (density gradients are only important in the buoyancy term of the momentum equations). Within the plume slice of figure 2.5, properties are assumed uniform. The appropriate governing equations are:

2.6 Continuity: $U Y h+W_{o} Y d x+W_{e} Y d x+V_{e} Z d x=(U+d U)(Y+d Y)(h+d h)$,

$2.7 \quad \mathrm{X}$-momentum: $\mathrm{U}^{2} \mathrm{YZ}=(\mathrm{U}+\mathrm{dU})^{2}(\mathrm{Y}+\mathrm{dY})(\mathrm{h}+\mathrm{dh})$

$2.8 \quad$ Y-momentum: $W_{\mathrm{o}}^{2} \mathrm{Ydx}-\mathrm{We}_{\mathrm{e}}^{2} \mathrm{Ydx}=\frac{\mathrm{d}}{\mathrm{dx}}(\mathrm{UWYh})+\frac{\mathrm{B}}{\rho^{\prime}}$

where B is the buoyancy, a body force acting on the whole element:

$$
B=-g Y\left[\int_{Z-h}^{Z} \rho-\left(\rho_{u}-\frac{N^{2}}{g} Z\right) d Z\right] d x,
$$

The ambient density gradient is assumed to be linear, and the there is no vertical velocity shear. I approximate the conservation of energy equation for the control-volume by considering only potential energy. This yields;

$$
\begin{gathered}
\rho g U\left(Z-\frac{h}{2}\right) h Y+g V_{e}\left(\rho_{u}-\frac{N^{2}}{g}\left(Z-\frac{h}{2}\right)\right)\left(Z-\frac{h}{2}\right) h d x+g W_{e}\left(\rho_{u}-\frac{N^{2} Z}{g}\right) Z Y d x= \\
g(\rho+d \rho)(U+d U)\left(Z+d Z-\frac{h+d h}{2}\right)(h+d h)(Y+d Y) .
\end{gathered}
$$

The left-hand side of 2.10 represents potential energy of flow entering the control-volume of figure 2.5. The right-hand side represents the energy of fluid exitting the volume.

I will also impose the condition;

$$
W=U \frac{d Z}{d x}-\frac{U d h}{2} \frac{d x}{d}
$$


which implies that the rise of the plume centerline is equal to the vertical velocity $\mathrm{W}(\mathrm{x})$. In order to simplify the governing equations, I assume that;

$$
\mathrm{W}_{\mathrm{e}}, \mathrm{W}_{\mathrm{o}}<\mathrm{U}
$$

Applying these assumptions to equations 2.6-2.9 and simplifying them yields useful forms of the governing equations:

2.13 Continuity : $\frac{d}{d x}(U h Y)=\mathrm{YW}_{\mathrm{O}}+\mathrm{YW}_{\mathrm{e}}+\mathrm{hV} \mathrm{e}$ ，

$2.14 \quad \mathrm{X}$-momentum: $\frac{\mathrm{d}}{\mathrm{dx}}\left(\mathrm{U}^{2} \mathrm{hY}\right)=0$

$2.15 \quad Y$-momentum: $\frac{d}{d x}(W h Y)=-\frac{g h Y}{U}\left[\frac{N^{2}}{2 g}(2 Z-h)+\rho^{*}\right]$

2.16 Energy: $\frac{d}{d x}\left(\rho U h^{2} Y\right)=2 Y W_{e}\left(\rho_{u} \frac{N^{2} Z}{g}\right)+h V_{e}\left(\rho_{u}-\frac{N^{2}}{2 g}(2 Z-h)\right)$

Replacing 2.13 into 2.16 and writing the densities in non-dimensional form leads to:

2.17 Energy: $2 \mathrm{YW}_{\mathrm{e}}\left(\rho^{*}+\frac{\mathrm{N}^{2} \mathrm{Z}}{\mathrm{g}}\right)+\mathrm{hV} \mathrm{e}\left(\rho^{*}+\frac{\mathrm{N}^{2}}{2 \mathrm{~g}}(2 \mathrm{Z}-\mathrm{h})\right)=2 \mathrm{Y} \mathrm{W}_{\mathrm{o}}\left(\rho_{\mathrm{o}}^{*}-\rho^{*}\right)$

I have used two vertical coordinates in the above equations, $h$ and $Z$. If $Z>h$, the plume has separated from the seafloor. If $\mathrm{Z}=\mathbf{h}$, the bottom of the plume must be in contact with the seafloor. The latter case is of more interest for modelling diffuse plumes. Setting $h=Z$ in equation 2.15 , and replacing $W$ with the definition in equation 2.11 allows me to re-write 2.15 as a second-order ordinary differential equation for $Z$ in terms of $\mathrm{x}$;

$$
\frac{d^{2} Z}{d x^{2}}+\left(2 \frac{W_{e}+W_{O}}{U Z}+2 \frac{V_{e}}{U Y}\right) \frac{d Z}{d x}+\frac{N^{2}}{U^{2}} Z=-\frac{2 g}{U^{2}} \rho^{*}
$$


The density anomaly present in the forcing term of 2.18 is approximated from the energy equation (2.17). Thus, I expand 2.18 into;

$2.19 \frac{\mathrm{d}^{2} \mathrm{Z}}{\mathrm{dx}^{2}}+2\left(\frac{\mathrm{W}_{\mathrm{e}}+\mathrm{W}_{\mathrm{o}}}{\mathrm{UZ}}+\frac{\mathrm{V}_{\mathrm{e}}}{\mathrm{UY}}\right) \frac{\mathrm{dZ}}{\mathrm{dx}}+\frac{\mathrm{N}^{2}}{\mathrm{U}^{2}} \mathrm{Z}=\frac{2 \mathrm{~g}}{\mathrm{U}^{2}}\left[\frac{\mathrm{Ve}^{\frac{\mathrm{N}^{2} \mathrm{Z}^{2}}{2 g}+2 \mathrm{We}^{\frac{N^{2} Z Y}{g}}-2 W_{\mathrm{o}} Y_{\rho_{\mathrm{o}}}}}{V_{\mathrm{e}} Z+2 W_{\mathrm{o}} Y+2 W_{\mathrm{e}} Y}\right]$.

The coefficient of damping, and the forcing function in 2.19 are complicated functions of $\mathrm{Y}$ and $\mathrm{Z}$. I have solved some simple examples of this equation, and will use these solutions to infer the first-order plume behaviour.

\section{Case 1, No Source Flow and No Entrainment}

By neglecting entrainment and source velocities, the governing equation 2.19 is reduced to:

$$
\frac{\mathrm{d}^{2} \mathrm{Z}}{\mathrm{dx^{2 }}}+\frac{\mathrm{N}^{2}}{\mathrm{u}^{2}} \mathrm{Z}=-\frac{2 \mathrm{gPo}}{\mathrm{u}^{2}}
$$

The solution for this second-order linear differential equation is:

$$
Z=A \cos \left(\frac{N}{U} x\right)+B \sin \left(\frac{N}{U} x\right)-\frac{2 g}{N^{2}} \rho_{o}^{*}
$$

where A and B are constant coefficients determined by appropriate boundary conditions. The third term is equal to $G^{*} \rho_{o}{ }^{*}$ as defined previously, where $\rho_{o}{ }^{*}$ is always a negative quantity. The corresponding solutions for $Y(x)$ and $\rho^{*}(x)$ show these to both be constant given the above set of assumptions. 


\section{Case 2, 2-D Source Flow with Entrainment}

Considering a two-dimensional problem where only $\mathrm{V}_{\mathrm{e}}$ is zero and $\mathrm{W}_{\mathrm{o}}>\mathrm{W}_{\mathrm{e}}$, the governing equation becomes:

$$
\frac{\mathrm{d}^{2} \mathrm{Z}}{\mathrm{dx^{2 }}}+2\left(\frac{\mathrm{W}_{\mathrm{e}}+\mathrm{W}_{\mathrm{o}}}{\mathrm{UZ}}\right) \frac{\mathrm{dZ}}{\mathrm{dx}}+\frac{\mathrm{N}^{2}}{\mathrm{U}^{2}} \mathrm{Z}=-\frac{2 \mathrm{~g} \rho_{\mathrm{o}}^{*}}{\mathrm{U}^{2}}\left(\frac{\mathrm{W}_{\mathrm{o}}}{\mathrm{W}_{\mathrm{o}}+\mathrm{W}_{\mathrm{e}}}\right)
$$

The linearized solution for this equation is a damped sinusoid:

$$
Z_{0}=-\frac{2 g}{N^{2}} \rho_{0}^{*}\left(\frac{W_{0}}{W_{0}+W_{e}}\right)+\left(A \cos \left(\frac{N}{U} x\right)+B \sin \left(\frac{N}{U} x\right)\right) \exp \left(-\frac{2 W_{e}+2 W_{0}}{U Z_{0}} x\right),
$$

which is the same as the rise height in Case 1, except for damping by the entrainment ratio. Thus, mixing dense ambient fluid into the diffuse plume will damp oscillations of the plume cap.

If $W_{0} \ll<W_{e}$, then the governing equation is:

$$
\frac{d^{2} Z}{d x^{2}}+2\left(\frac{W_{e}+W_{0}}{U Z_{0}}\right) \frac{d Z}{d x}-\frac{N^{2}}{U^{2}} Z=-\frac{2 g \rho_{o}^{*}}{U^{2}}\left(\frac{W_{0}}{W_{0}+W_{e}}\right)
$$

The solution for this equation is a sum of hyperbolic sine and cosine functions, with an exponential damping term. The particular solution (due to the forcing term) is identical to that shown above for $W_{0} \gg W_{e}$.

Qualitatively, the two solutions for 2-dimensional diffuse plume rise show that a vent must supply enough vertical velocity to keep the local mixing properties from diluting the effluent. Regardless of source temperature, if the vent flowrate is not great enough, it cannot produce a rising plume. 


\section{Case 3, 3-D Flow with No Source}

Finally, consider a three-dimensional flow which is well downstream of any source of buoyancy and flow $\left(W_{0}, \rho_{0}^{*}=0\right)$ :

$$
\frac{d^{2} Z}{d x^{2}}+2\left(\frac{V_{e}}{U Y}+\frac{W_{e}}{U Z}\right) \frac{d Z}{d x}+\frac{N^{2}}{U^{2}}\left(1-\frac{2 W_{e} Y+V_{e} Z}{W_{e} Y+V_{e} Z}\right) Z=0
$$

Assuming that $\mathrm{W}_{\mathrm{e}} \mathrm{Y} \gg \mathrm{V}_{\mathrm{e}} \mathrm{Z}$ (a very wide plume), the equation reduces to:

$$
\frac{d^{2} Z}{d x^{2}}+2\left(\frac{W_{e}}{U Z_{0}}\right) \frac{d Z}{d x}-\frac{N^{2}}{U^{2}} Z=0
$$

The solution of equation 2.26 is a sum of exponentials, similar to the second solution to Case 2. The slowest decaying term in the solution is:

$$
\left.Z(x) \approx(A) \sqrt{\frac{W_{e}^{2}}{U^{2} Z_{o}^{2}}+\frac{N^{2}}{U^{2}} x}\right)_{e}-\frac{2 W_{e}}{U Z_{o}} x .
$$

I approximate this for small distances $\left(x<<\frac{U Z_{0}}{2 W_{e}}\right)$ as:

$$
\begin{gathered}
\mathrm{Z}(\mathrm{x}) \approx \mathrm{Z}_{\mathrm{o}}+\frac{\mathrm{W}_{\mathrm{e}}}{\mathrm{U}} \zeta \mathrm{x}, \\
\text { where } \zeta=\left(-2+\sqrt{1+\frac{\mathrm{N}^{2} \mathrm{Z}_{\mathrm{o}}^{2}}{\mathrm{~W}_{\mathrm{e}}^{2}}}\right) .
\end{gathered}
$$

Solving for $\mathrm{Y}$ in terms of $\mathrm{Z}$ using equations 2.13-2.14 :

$$
Y \approx Y_{0}+\frac{V_{e}}{U} x
$$

This result can also be found by setting $V_{e} \gg W_{e}$. The governing equation becomes ; 


$$
\frac{d^{2} Z}{d x^{2}}+\frac{V_{e}}{U Y_{0}} \frac{d Z}{d x}=0
$$

The solution for which is

$$
\begin{aligned}
& Y \propto Z=A_{e} e^{-\frac{V_{e}}{U Y_{o}} x}+Y_{o} . \\
& Y \approx Y_{0}+\frac{V_{e}}{U} x
\end{aligned}
$$

Replacing these equations (assuming $\zeta=1$ ) into 2. 17, and expanding the result as a power series gives;

$$
\rho^{*} \approx \frac{W_{o} \rho_{o}^{*} Y_{o}-W_{e} \frac{N^{2}}{g} Y_{o} Z_{o}-V_{e} \frac{N^{2}}{2 g} Z_{o}^{2}}{W_{e} Y_{o}+V_{e} Z_{o}+W_{o} Y_{o}}-\frac{2 g V_{e} W_{o} \rho_{o}^{*}\left(W_{e} Y_{o}-V_{e} Z_{o}\right)}{4 U\left(W_{e} Y_{o}+V_{e} Z_{o}+W_{o} Y_{o}\right)^{2}} x+O\left(x^{2}\right)
$$

Keeping only the largest terms, this reduces to:

$$
\rho^{*} \approx \rho_{\mathrm{o}}^{*}\left[1-\frac{\mathrm{V}_{\mathrm{e}} W_{\mathrm{e}}}{\mathrm{UW}_{\mathrm{O}}} \frac{\mathrm{x}}{\mathrm{Y}_{\mathrm{O}}}\right]
$$

Summarizing the above linearized solutions:

$$
\begin{aligned}
& \begin{cases}\mathrm{Z} \approx \mathrm{Z}_{\mathrm{o}}+\frac{\mathrm{W}_{\mathrm{e}}}{U} \zeta \mathrm{x} & \mathrm{x}<<\frac{U \mathrm{U}_{\mathrm{o}}}{2 \mathrm{~W}_{\mathrm{e}}} \\
\mathrm{Y} \approx \mathrm{Y}_{\mathrm{O}}+\frac{\mathrm{V}_{\mathrm{e}}}{\mathrm{U}} \mathrm{x} & \mathrm{x}<<\frac{U \mathrm{Y}_{\mathrm{o}}}{\mathrm{V}_{\mathrm{e}}}\end{cases} \\
& \rho^{*} \approx \rho_{\mathrm{o}}{ }^{*}\left[1-\frac{\mathrm{V}_{\mathrm{e}} W_{\mathrm{e}}}{U W_{\mathrm{O}}} \frac{x}{Y_{\mathrm{O}}}\right], \\
& \text { where } \zeta=\left(-2+\sqrt{1+\frac{N^{2} Z_{o}^{2}}{W_{e^{2}}^{2}}}\right) \text {, and }
\end{aligned}
$$




$$
Z_{0}=-\frac{2 g}{N^{2}} \rho_{0}^{*}\left(\frac{W_{O}}{W_{O}+W_{e}}\right), Y_{O}=D
$$

These linear approximations to the behaviour of a diffuse plume are valid near the plume source, but not within the diffuse field. The downstream distance $(x)$ is limited to $\frac{U Z_{0}}{2 W_{e}}$, or approximately 5 source diameters (the spatial scale of a patch of diffuse venting, approximately $20-50 \mathrm{~m}$ ), assuming the entrainment velocity is $10 \%$ of the mean current.

Entrainment velocities $\left(\mathrm{W}_{\mathrm{e}}\right.$ andV $\left.\mathrm{V}_{\mathrm{e}}\right)$ determine the dilution rate of a plume. Large values of $W_{e}$ and $V_{e}$ result in rapid spreading, and dilution. These velocities are a function of turbulent mixing across the plume-seawater interface. An increase in upstream or downstream ambient turbulence will increase mixing, and thus dilution. Kennedy and Fordyce (1974) observed this effect in cooling tower plumes from thermal power plants. They determined that.downstream roughness, or turbulence caused by the cooling tower itself tended to retard the rise of a buoyant plume in cross-flow. There are no historical measurements on which to base an estimate of $W_{e}$ and $V_{e}$. The best estimate of a lower bound on the entrainment is the rate of momentum loss in a turbulent boundary layer. This is referred to by Tennekes and Lumley (1972) as friction velocity, and is typically on the order of $10 \%$ of the free-stream velocity.

When entrainment velocities are set equal to zero, the resulting solution for plume rise height $(\mathrm{Z}(\mathrm{x}))$ was an undamped sinusoid with a wavelength determined by the buoyancy frequency $(\mathrm{N})$ and the mean flow velocity $(\mathrm{U})$. This solution agreed with that for internal waves in a linearly stratified environment (Turner, 1971).

The most useful result from the preceding analysis was the determination of mean rise height $\left(\mathrm{Z}_{\mathrm{O}}\right)$. I compare this simple analytic result to a laboratory simulation, and a numerical model of diffuse flow in the next two sub-sections. 


\section{Laboratory Modelling}

Diffuse hydrothermal plumes were simulated in the Geophysical Fluid Dynamics Laboratory at the Woods Hole Oceanographic Institution. I scaled the laboratory setup to simulate parameters presented in section 2.3. Principal components of the experimental setup were:

- a $0.5 \times 0.5 \times 2.0 \mathrm{~m}$ glass tank filled with a linearly stratified salt solution,

- an inverted glass funnel covered with mesh and filled with glass beads through which dyed brine was pumped to simulate hydrothermal effluent,

- a tow carriage which moved the funnel along the surface of the water at a constant velocity,

- studio lights and an automatic camera to photgraph the trajectory of the dyed plume.

I chose to make plumes upside-down. The model-hydrothermal fluid was a salt solution that was denser than the surface-water in the tank. A pump forced the dense water through the inverted glass funnel, and down into the tank. It sank until it reached a depth where the density of the tank water was greater than the hydrothermal solution. This upside-down configuration was simple to build, and the dynamics were identical to a buoyant, rising plume.

This model did not reproduce any velocity shear, or a boundary layer. In the field, a boundary layer only influences the bottom of the plume, since the boundary layer thickness is on the order of $10 \mathrm{~m}$, while the plumes of interest are approximately $20-50 \mathrm{~m}$ thick. This uniform flow model was intended to simulate the simplest properties of diffuse plumes. The complication of attempting to model the benthic boundary layer would have been excessive in my first-order model.

Figure 2.6 shows one experimental run. The bottom half of the photograph is a sideview of the plume, while the top is an overhead view. A mirror was suspended above the tank at a $45^{\circ}$ angle to allow photographing of both views. Green and blue dyes show the trajectory of a black smoker centered in a model diffuse field. The carriage was moving to the left in the photo. A conductivity probe is seen in the foreground of the frame. This instrument was used in some runs to measure the density gradient in the tank. 


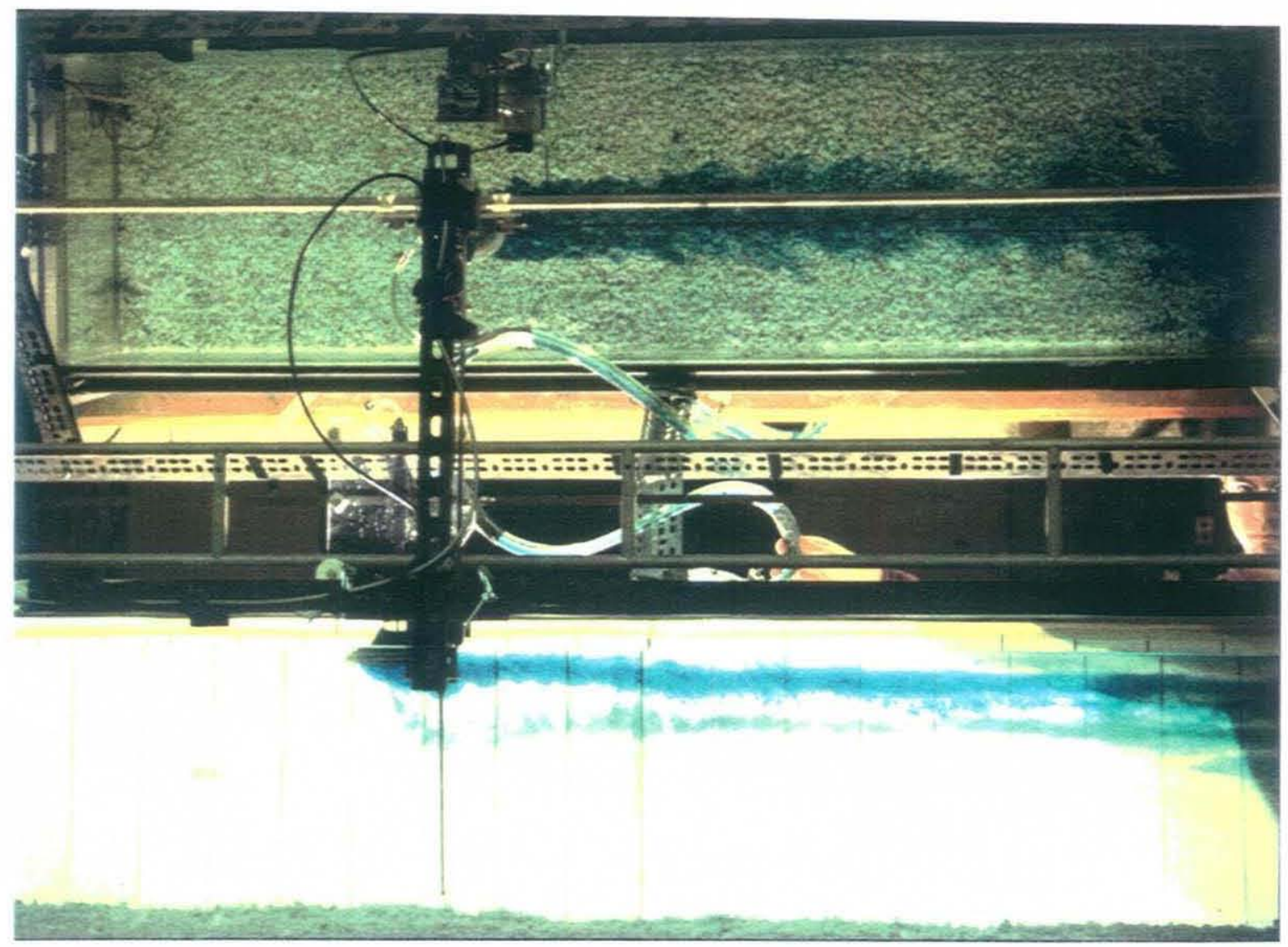

Figure 2.6: A typical laboratory run showing the test tank. In the foreground is the conductivity profiler. Its sensor tip is at the bottom of the vertical rod visible in the tank. The bottom of the photo shows the side view of the tank. Two dyed plumes are bring injected through a flow diffuser moving along a track above the tank. The top half of the photo is a top view of the tank as seen from a large mirror mounted at a $45^{\circ}$ angle. The original photos similar to this were projected onto a slide screen to measure the plume penetration into the tank.

Details of the laboratory model were chosen based on the scale parameters from section 2.3. I will describe model and field parameters, and the relevance of the laboratory simulation. 


\section{Scaling of Model Parameters}

In order to satisfy geometric and dynamic similarity between the model and the diffuse vents, I use the scale parameters presented in section 2.3 as guidelines. Ideally, it would be neccessary to meet the conditions:

$$
Z^{*}=\left(\frac{Z}{D}\right)_{\text {field }}=\left(\frac{Z}{D}\right)_{\text {model }} W_{o}^{*}=\left(\frac{W_{0}}{U}\right)_{\text {field }}=\left(\frac{W_{0}}{U}\right)_{\text {model }}
$$

$$
\begin{gathered}
\rho_{\mathrm{O}}^{*}=\left(\frac{\rho_{u}-\rho_{\mathrm{O}}}{\rho_{\mathrm{u}}}\right)_{\text {field }}=\left(\frac{\rho_{\mathrm{u}}-\rho_{\mathrm{O}}}{\rho_{\mathrm{u}}}\right)_{\text {model }} \mathrm{S}^{-1}=\left(\frac{\mathrm{Ut}}{\mathrm{D}}\right)_{\text {field }}=\left(\frac{\mathrm{Ut}}{\mathrm{D}}\right)_{\text {model }} \\
\mathrm{R}_{\mathrm{e}}^{*}=\left(\frac{\mathrm{UD}}{\mathrm{v}}\right)_{\text {field }}=\left(\frac{\mathrm{UD}}{\mathrm{v}}\right)_{\text {model }} \mathrm{Fr}_{\mathrm{r}}^{*}=\left(\frac{\mathrm{ND}}{\mathrm{U}}\right)_{\text {field }}=\left(\frac{\mathrm{ND}}{\mathrm{U}}\right)_{\text {model }} \\
\mathrm{G}^{*}=\left(\frac{\mathrm{g}}{\mathrm{N}^{2} \mathrm{D}}\right)_{\text {field }}=\left(\frac{\mathrm{g}}{\mathrm{N}^{2} \mathrm{D}}\right)_{\text {model }} \cdot
\end{gathered}
$$

Symbols are defined in table 2.1. Unfortunately, it is rarely possible to meet all scale parameters in a model study. It is very fortunate that we are not restricted to "the letter of the laws", but must abide only by their intent. I will describe how well each of the above conditions were met in the laboratory model.

The source model was $9 \mathrm{~cm}$ in diameter. If the diameter of a diffuse patch is taken as $50 \mathrm{~m}$, this corresponds to a geometric scale ratio of 1:550. The carriage velocity was set at $1.75 \mathrm{~cm} / \mathrm{s}$. In the field, the ratio of vertical velocity to horizontal current was $0.1-1(\mathrm{U}=5$ $15 \mathrm{~cm} / \mathrm{s}$ from Cannon, 1990, $\mathrm{W}_{\mathrm{O}}=1-10 \mathrm{~cm} / \mathrm{s}$ from Converse et al., 1984; Monfort and Schulz, 1988). For geometric similarity of plume velocity, the model velocity was set to 0.175 $1.75 \mathrm{~cm} / \mathrm{s}$.

Details of the flow diffuser were intended to approximate micro-plumes in the field. An inverted funnel was filled with glass beads which were on the order of $0.5 \mathrm{~mm}$ in diameter. A fine mesh was stretched and cemented over the funnel to hold the glass beads in place. Reynolds number based on the bead size and source velocity in the model was on the order of unity. The full scale size equivalent to the beads would be $0.3 \mathrm{~m}$. 
Full-scale Reynolds number based on $2 \mathrm{~cm} / \mathrm{s}$ velocity from a micro-plume and $0.3 \mathrm{~m}$ spatial scale is on the order of 400 . Both these indicate laminar flow from the full-scale and model micro-plumes.

Reynolds number of the model flow based on diffuse field diameter and carriage speed was 1400 , which was observed to be turbulent. The Reynolds number of the fullscale flow is approximately $2,500,000$ based on overall diameter $(D=50 \mathrm{~m}, U=5 \mathrm{~cm} / \mathrm{s}$, $v=1 \times 10^{-6} \mathrm{~m}^{2} / \mathrm{s}$ ). As in many model simulations, exact Reynolds' number equality was not possible at reasonable velocities between two flows of vastly different scales. Since both model and real flows were turbulent, viscous effects were negligible in both. Reynolds' number similarity was thereby sufficient for this model.

The inverse Strouhal number can be thought of as twice the number of vent diameters that the plume is spread over by one tidal cycle. For hydrothermal flow, this is from 10 to 40 field diameters ( $U=5 \mathrm{~cm} / \mathrm{s}, \mathrm{D}=50 \mathrm{~m}, \mathrm{t}=12$ hours). In a tank $200 \mathrm{~cm}$ long, with a source $9 \mathrm{~cm}$ in diameter, inverse Strouhal numbers up to 44 are possible. With such long excursions, the flow appears steady over most of the tidal cycle.

The buoyancy frequency $(\mathrm{N})$ above vents on the Southern Juan de Fuca ridge has been measured to be $0.00196 \mathrm{~s}^{-1}$ (Massoth, 1988). Buoyancy frequency for all of the tank experiments was $0.48 \mathrm{~s}^{-1}$. This stratification produced $5-40 \mathrm{~cm}$ plume penetration into the tank for reasonable salt concentrations in the diffuse source fluid. $\mathrm{F}_{\mathrm{r}}{ }^{-2}$ in the tank was thus $2.46\left(\mathrm{~N}=0.48 \mathrm{~s}^{-1}, \mathrm{U}=1.75 \mathrm{~cm} / \mathrm{s}, \mathrm{D}=9 \mathrm{~cm}\right)$. In the field, the parameter is 1 to 3 $\left(\mathrm{N}=0.00196 \mathrm{~s}^{-1}, \mathrm{U}=5 \mathrm{~cm} / \mathrm{s}, \mathrm{D}=50 \mathrm{~m}\right)$. Thus, similarity was achieved in Froude number.

The ratio of source density anomaly to ambient density in the field is estimated to be $0.00002\left(\rho_{0}^{*} \approx \beta\left(T_{0}-T_{u}\right), T_{u}=2^{\circ} \mathrm{C}, T_{0}=4^{\circ} \mathrm{C}, \beta=-1 \times 10^{-5}{ }^{\circ} C^{-1}\right)$. At the salt concentrations used in the model (400-25gm salt per 101 water), the density anomaly relative to fresh water was $0.032-0.0009$. For both model and field values, the density anomalies were much less than unity. Thus, the Boussinesq approximation presented in the preceding chapter is valid in the model and in the field.

The final important parameter in the lab model was $G^{*}$. In the field, $G^{*}$ is on the order of $50,000\left(\mathrm{~N}=.00196 \mathrm{~s}^{-1}, \mathrm{~g}=10 \mathrm{~m} / \mathrm{s}^{2}, \mathrm{D}=50 \mathrm{~m}\right)$. In the model, this parameter was only 
$480\left(\mathrm{~N}=.48 \mathrm{~s}^{-1}, \mathrm{~g}=10 \mathrm{~m} / \mathrm{s}^{2}, \mathrm{D}=9 \mathrm{~cm}\right)$. However, in section 2.3 this parameter was always discussed with $p_{0}^{*}$. The product $G^{*} p_{0}^{*}$ represents a ratio of source buoyancy to ambient stratification. Comparing the product of $G^{*}$ and $\rho_{0}^{*}$ for the model and the field plumes shows them both to be identical, $G^{*} \rho_{0}^{*}=1-10$. Thus, the buoyancy forces driving plume convection were similar in the field and the model.

The intent of scaling was to ensure that the important forces are dominant in the model, just as they are in the field. The forces were appropriately scaled in the laboratory model, based on the preceding discussion. Thus, the laboratory model reproduces the effects of buoyancy forces $\left(G^{*} p_{b}^{*}\right)$, while neglecting viscosity $\left(R_{e}\right)$ on the vent-field scale, flow acceleration $\left(\mathrm{S}^{-1}\right)$, internal waves $\left(\mathrm{F}_{\mathrm{r}}{ }^{-2}\right)$, and compressibility $(\rho$ ).

\section{Experimental Procedure}

Each simulation was set-up by filling two 45-gallon supply tanks with equal volumes of tap water the night before a run. $3.2 \mathrm{~kg}$ of salt was added to one supply tank, and it was stirred using a submersible pump for 15-30 minutes. The two supply tanks were covered to prevent evaporation, and left overnight to come to temperature equilibruim with the room. The test tank was then filled by pumping water from the fresh supply tank through a diffuser on the bottom of the test tank. As the level in the fresh supply tank dropped, a valve connecting the salty supply tank to the fresh tank was opened, and salty water was drawn into the fresh supply tank where it was mixed. The salinity in the fresh supply tank thus started out very small, and gradually increased as the level in both supply tanks dropped. This method of filling (the "Oster method") produced very reliable linear density gradients in the test tank.

The test tank had to be filled from the bottom very slowly to avoid destroying the stable stratification. After the test tank was completely filled, a procedure which took several hours, it was left for three hours to settle.

A bucket of water was taken from the fresh supply tank before the filling procedure for the test tank began. Hydrothermal solution was made by mixing salt $400-25 \mathrm{~g}$, depending on the desired density anomaly) into 10 litres of water. $5 \mathrm{ml}$ of liquid food 
colouring was added to this vent solution to make photos of the plume possible. A submersible pump was placed in the bucket and connected to the vent field diffuser via a large Tygon hose. A valve in the line kept the diffuser from siphoning water out of the test tank, into the hydrothermal solution, and onto the floor of the lab.

While the test tank was filling and settling, samples of the surface water, bottom water and hydrothermal source water were taken from the fresh supply tank and the bucket, respectively. The density of these samples was measured using a digital densitometer.

In some runs, a micro-conductivity probe was used as shown in figure 2.6. The probe was calibrated before each experiment by plunging it into beakers from which were drawn the densitometer samples. The probe was attached to a computer-controlled profiling device, and a C-program directed it to make repeated vertical profiles before, during, and after each experiment. The measurements were logged directly to a personal computer. A 12-bit analog-digital converter (A/D) digitized voltage output from the conductivity probe, as well as providing a signal to drive the profiling stepper motor. Each 12-inch profile took 90 seconds to complete for 100 sample points. The profile time limited the number of profiles possible for each run to one before, during and after the carriage traversed the tank. Figure 2.7 shows conductivity profiles from one experiment.

Photographs were taken during the experiments to show the rise height and character of the plumes. A $35 \mathrm{~mm}$ camera ( Canon T70) was set-up on a tripod at the same height as the plume source. A zoom lens ( $80-135 \mathrm{~mm}$ zoom) was used to permit variable resolution of the plume. Four studio lights were placed directly behind the tank so that they shone through a screen of white paper into the tank. This backlit arrangement provided the best pictures of the experiment. In later runs, a mirror was placed above the tank to provide a plan view of the plume as well as side views. In this way, both the horizontal spreading and the vertical penetration of the plume was observed. 


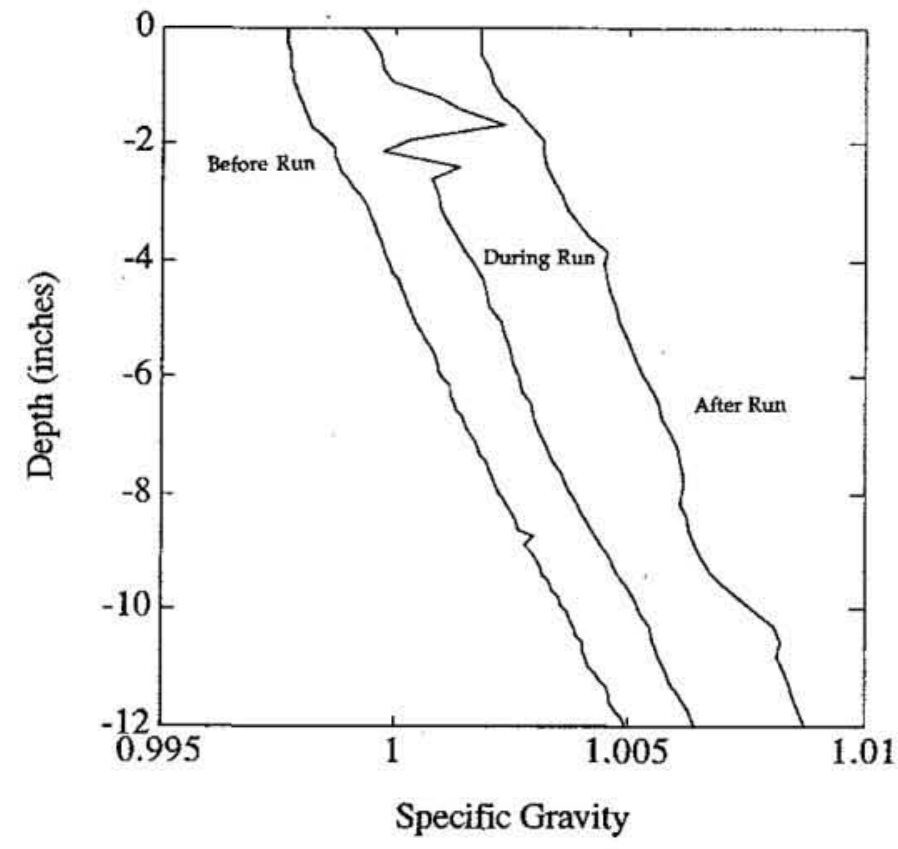

Figure 2.7: Conductivity profiles from an experiment run on January 31/89. These profiles were measured by the probe seen in figure 2.6. The three profiles shown; before, during and after the model run. The two curves on the right were offset to the right by adding a constant to each. The curves actually lie on top of one another. The density spike in the middle profile represents the plumes shown in figure 2.6. The profile made several minutes after the run shows two sharp peaks at depths of 2 and 4 inches. These were the depths to which the plumes penetrated in this particular run.

Photograph negatives (for black and white) or slides (colour) were projected on a screen, and plume penetration was measured as the distance between the bottom of the diffuser funnel and the top of the dyed plume (figure 2.6). This was normalized by the measured diameter of the funnel diameter in the projection to account for differences in magnification. 


\section{Results of Laboratory Model}

Results of the model runs are summarized in Table 2.2.

\begin{tabular}{|c|c|c|c|c|c|c|c|c|c|}
\hline Run & $U$ & $\mathrm{~N}$ & $w_{0}$ & $\rho \mathrm{u}$ & $\rho_{0}$ & Z/D & $\mathrm{w}_{\mathrm{o}}{ }^{*}$ & $\mathrm{~F}_{\mathrm{r}}^{*}$ & $G^{*} p_{u}{ }^{*}$ \\
\hline 1 & $1.76 \mathrm{~cm} / \mathrm{s}$ & $0.5 \mathrm{~s}^{-1}$ & $0.33 \mathrm{~cm} / \mathrm{s}$ & $1.0 \ddagger$ & $1.032 \ddagger$ & 3.3 & 0.19 & 2.56 & 14.2 \\
\hline 2 & 176 & 0.5 & 0.33 & 1.0 & 1.016 & 3.0 & 0.19 & 2.56 & 7.1 \\
\hline 3 & 1.76 & 0.5 & 0.33 & 1.0 & 1.007 & 2.5 & 0.19 & 2.56 & 3.1 \\
\hline 4 & 1.76 & 0.5 & 0.33 & 1.0 & 1.0035 & 1.5 & 0.19 & 2.56 & 1.6 \\
\hline 5 & 1.76 & 0.5 & 0.33 & 1.0 & 1.0018 & 0.48 & 0.19 & 2.56 & 0.8 \\
\hline 6 & 1.76 & 0.5 & 0.33 & 1.0 & 1.0028 & 0.57 & 0.19 & 2.56 & 1.2 \\
\hline 7 & 1.76 & 0.5 & 0.33 & 1.0 & 1.0034 & 1.5 & 0.19 & 2.56 & 1.5 \\
\hline 8 & 1.76 & 0.5 & 0.33 & 1.0 & 1.0044 & 2.2 & 0.19 & 2.56 & 2.0 \\
\hline $9 \mathrm{~A}$ & 1.96 & 0.49 & 0.68 & 0.9975 & 1.0009 & 0.40 & 0.35 & 2.25 & 1.6 \\
\hline $9 B$ & 1.96 & 0.49 & 418.0 & 0.9975 & 1.0042 & $80 \dagger$ & 210 & 0.063 & 110 \\
\hline $10 \mathrm{~A}$ & 1.96 & 0.53 & 0.65 & 0.9983 & 1.0009 & 1.0 & 0.33 & 2.43 & 1.0 \\
\hline $10 \mathrm{~B}$ & 1.96 & 0.53 & 345.0 & 0.9983 & 1.0042 & $130 \dagger$ & 175 & 0.068 & 84 \\
\hline $11 \mathrm{~A}$ & 1.96 & 0.50 & 0.65 & 0.9985 & 1.0004 & 1.3 & 0.33 & 2.30 & 0.85 \\
\hline $11 \mathrm{~B}$ & 1.96 & 0.50 & 46 & 0.9985 & 1.0043 & $70 \dagger$ & 24 & 0.064 & 93 \\
\hline $12 \mathrm{~A}$ & 1.96 & 0.37 & 0.65 & 0.9980 & 1.0009 & 0.51 & 0.33 & 1.70 & 2.4 \\
\hline $12 B$ & 1.96 & 0.37 & 46 & 0.9980 & 1.0052 & $40+$ & 23 & 0.047 & 210 \\
\hline $13 \mathrm{~A}$ & 1.96 & 0.35 & 0.65 & 0.9975 & 1.00012 & 0.56 & 0.33 & 1.61 & 2.4 \\
\hline $13 B$ & 1.96 & 0.35 & 46 & 0.9975 & 1.0048 & $35 t$ & 23 & 0.045 & 240 \\
\hline
\end{tabular}

Table 2.2: Summary of data from laboratory modelling of diffuse plumes

I used the maximum salt concentration $(400 \mathrm{gm}$ salt/101 water for the hydrothermal solution) in the first run, and reduced the concentration to a minimum value ( $25 \mathrm{gm}$ salt $/ 101$ water) in incremental steps. Transition to non-buoyant flow was observed at $40-50 \mathrm{gm} /$ 10l. After the transition point was determined by plotting rise height $(Z)$ versus $G^{*} \rho_{o}{ }^{*}$ (figure 2.8), runs near transition were repeated. 


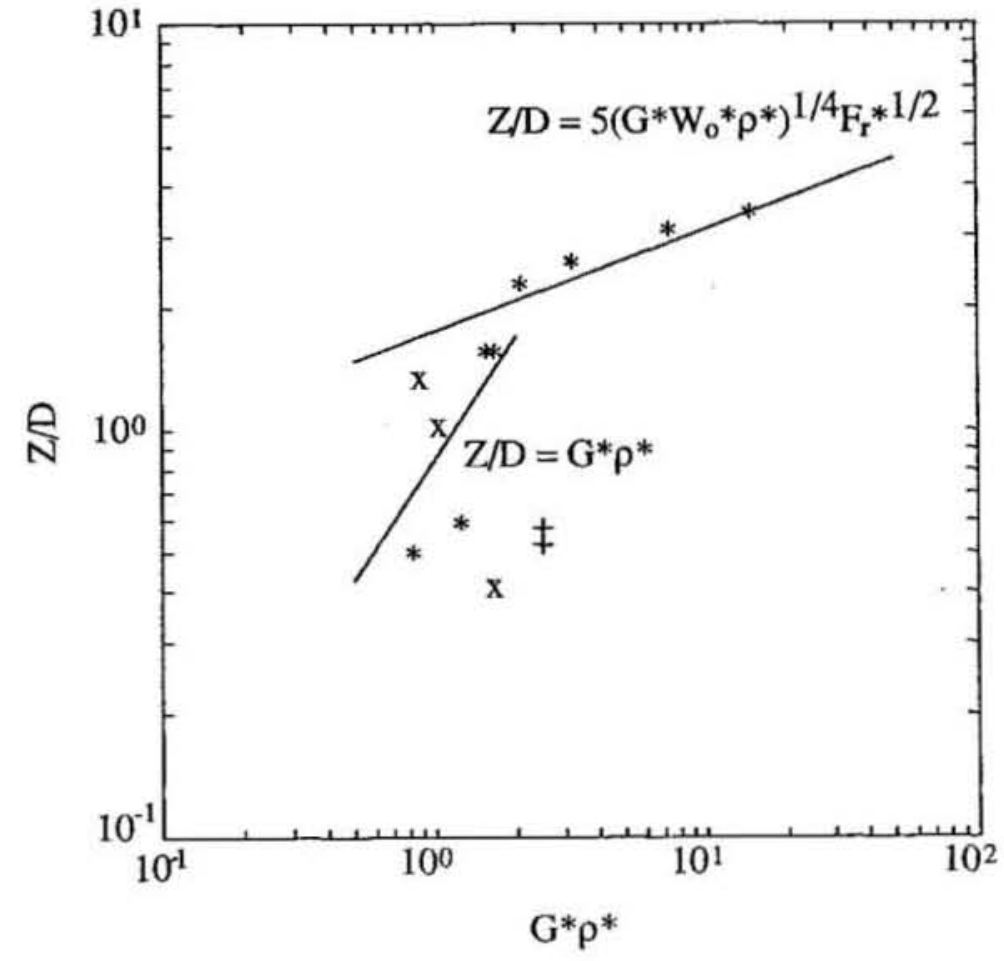

Figure 2.8: Plume rise height versus source intensity parameter from laboratory model data. The data points represent: $*$ runs $1-8, x$ runs $9 A-11 A,+$ runs 12,13 . The upper line is from Turner (1973, eqn 6.4.6, p198), re-written as equation 2.35, while the lower line is from equation 2.36 .

The source was modified to include a secondary fluid injected from a small diameter pipe at a different density and velocity from the diffuse flow. The secondary source simulated a black smoker present in the center of a diffuse field. In table 2.2, runs 9B, $10 \mathrm{~B}, 11 \mathrm{~B}, 12 \mathrm{~B}$, and 13B denote these black smoker plumes. Runs $9 \mathrm{~A}-13 \mathrm{~A}$ were the diffuse plumes which were measured in the same runs. Data from 9B-13B are not plotted in figure 2.8 . 


\section{Discussion of Lab Results}

The width of the plume did not change in the experiments. Based on the width relation in 2.33 , this was not surprising. The plume spreading was primarily dependant upon the horizontal entrainment velocity $\left(V_{e}\right)$. Runs were made at effectively the same carriage speed, which is the principal factor determining the turbulence levels in the plume (based on the scaling arguments presented in this section). $V_{e}$ is essentially a simplistic view of turbulent mixing. Since mixing was constant through the laboratory experiments, the horizontal spreading of the plume was also constant.

Turbulence levels in the laboratory were not intended to model the field, so there was no benefit in measuring the plume spreading in the laboratory. $V_{\mathrm{e}}$ in the field is dependent on more factors than were simulated in this simplistic laboratory model. Modelling these phenomena could be a subject for future work.

The model provided a basis for evaluating plume rise versus diffuse plume source intensity. In Turner (1973, eqn 6.4.6, p198), the maximum rise height of a classic buoyant plume is given as:

$$
\mathrm{Z}_{\max }=5.0 \mathrm{~F}^{1 / 4}\left(\mathrm{~N}^{2}\right)^{-3 / 8}
$$

where $\mathrm{F}$ is :

$$
\mathrm{F}=\frac{\mathrm{g}\left(\rho_{\mathrm{u}}-\rho_{\mathrm{o}}\right)}{\rho_{\mathrm{u}}} \mathrm{W}_{\mathrm{o}} \mathrm{D}^{2}
$$

replacing for the maximum rise height:

$$
\frac{Z_{\max }}{D}=5.0\left(G^{*} W_{O} \rho_{o}^{*}\right)^{1 / 4} F_{r}^{* 1 / 2}
$$

Turner notes that the coefficient must be found by direct experiment. I have plotted this equation over my laboratory measurements of plume rise in figure 2.8 . 
In the regime where $G^{*} \rho_{o}{ }^{*}$ is less than unity, the above functional form does not match model data. A better fit to these points is made with a linear function of $G^{*} \rho_{o}{ }^{*}$, rather than $\left(G^{*} \rho_{0}{ }^{*}\right)^{1 / 4}$. The model I presented in equation 2.33 showed the diffuse plume rise height would be:

$$
Z_{0}=-\frac{2 g}{N^{2}} \rho_{0}^{*}\left(\frac{W_{0}}{W_{0}+W_{e}}\right)=\left|2 G^{*} \rho_{0}^{*}\left(\frac{W_{0}}{W_{o}+W_{e}}\right)\right|,
$$

This function is also plotted in figure 2.8. The entrainment velocity $\left(\mathrm{W}_{\mathrm{e}}\right)$ was not known, so the velocity ratio above was considered as a constant coefficient. In the figure, the best fit was acheived if the ratio was assumed to be 0.5 (or $W_{e}=W_{0}$ ). The fit is better than the classic model in the regime where $G^{*} \rho_{0}^{*}<1$.

The slope of plume penetration $(Z)$ versus plume intensity $\left(G^{*} \rho_{0}{ }^{*}\right)$ is steeper for weak plumes than for intense buoyant plumes. A weak plume does not require much buoyancy to rise to a height approximately equal to its diameter. Intuitively, this implies that entrainment is limited by the presence of the bottom. If the plume continues to rise, dilution increases due to ambient seawater entrained from below the plume as well as above. If a vent is to penetrate high into the water column, the buoyancy flux must be sufficient to overwhelm this greater entrainment.

The simple model summarized in 2.33 does a better job of predicting the behaviour of weak plumes than classic buoyant plume theory. How will it compare to a standard numerical model of plume behaviour? 


\section{Numerical Modelling}

Muellenhoff et al. (1985) have developed a numerical model (UMERGE) for simulating sewage discharge into a stratified reservoir. The model has been compared extensively to laboratory and field data (Frick et al., 1990). I have used this model to simulate the laboratory plumes described in the previous sub-section, and to interpret field measurements obtained by Rona (Appendix A).

UMERGE is a two-dimensional model which calculates the behaviour of buoyant plumes in a stably stratified environment. The output parameters from the model are centerline rise height, plume radius, dilution ratio, vertical velocity $(W)$, horizontal velocity $(U)$, downstream coordinate $(x)$, centerline temperature $(T)$, density difference $\left(\rho^{*}\right)$, and time from start $(t)$.

UMERGE solves Lagrangian forms of the conservation equations of mass, momentum, energy and pollutant concentration. Temperature is treated in the same way as nonreacting pollutants. The Boussinesq approximations are invoked, implying that the density variations are small relative to the average density and thus are retained only in buoyancy terms, not in inertia terms of the momentum equations.

The model assumes inviscid flow. Dilution is the result of entrainment in accordance with the Taylor hypothesis (entrainment velocity is a constant fraction of the velocity shear) plus entrainment due to mean flow impinging upon the windward side of the plume (Frick, 1984).

UMERGE was intended for flows where the maximum rise height is larger than the plume diameter, and the source vertical velocity is greater than the horizontal current speed. These are the same limitations as all plume models based on the work of Morton, Taylor and Turner (1956). Neither of these conditions are satisfied by diffuse hydrothermal flow.

Despite its limitations, UMERGE is useful as a standard because it has been extensively compared against other numerical models, and field measurements by the EPA (Muellenhoff et al., 1985). The EPA has published a software set which allows the 
user to run a variety of different numerical plume models using a single input format (Frick, 1990; Muellenhoff et al., 1985). I input diffuse plume data to several of the other models (all of which are reviewed by Muellenhoff et al., 1985 ), and no significant differences were found. Therefore, I chose to compare UMERGE to the laboratory measurements and to the first-order analytic solution.

Frick wrote an interactive window environment to create the input for UMERGE (Frick, 1990). This environment greatly simplified my task of simulating numerous different diffuse flow cases. The neccessary inputs are:

- ambient density gradient,

- mean current profile,

- source diameter,

- source temperature,

- source salinity,

- ambient salinity,

- source vertical velocity.

In addition to the above data, the model needs to be given a limit on the distance downstream to carry the calculation. This is specified in terms of the number of oscillations of the plume centerline around the equilibrium height.

The output from UMERGE was in the form of an ASCII file of data. I loaded it into MATLAB for analysis and plotting. Figure 2.11 shows a plume centerline trajectory created using MATLABto manipulate data from UMERGE. I added the laboratory plume profile by exporting the MATLAB graph to ADOBE Illustrator 3.0 and tracing the plume from a photograph.

UMERGE can estimate conditions under which nearby plume sources merge (intended to simulate many sewage outlets along the length of a single pipe). UMERGE was run to simulate many small micro-plume sources having the same total buoyancy flux as a single source. The results showed no significant difference in rise height or dilution when compared with runs for a single source. UMERGE was used to directly simulate the scalemodel plumes created in the laboratory. The difference between numerical simulation 
and the observed model plumes indicated the effectiveness of UMERGE in simulating diffuse hydrothermal flow.

\section{Simulation of Laboratory Flows}

The conditions for each of the diffuse plumes made in the laboratory (table 2.2) were input to UMERGE. Figure 2.9 shows laboratory measurements of plume rise height. Plume centerline heights calculated by UMERGE are superimposed on the figure.

UMERGE assumes that a plume retains a circular cross-section as it is advected downstream. In unstratified flow, this is a valid simplification. In stratified flow, plumes tend to collapse in the vertical dimension, and spread horizontally. Thus, the vertical spreading predicted by UMERGE does not resemble the behaviour of a plume in stratified flow, but the plume centerline calculation is still valid. Frick (1990) has implemented a technique for modelling this evolution of the plume, but it has not been incorporated in UMERGE. Calculated centerline height is more relevant to the laboratory measurements of maximum plume rise.

Figure 2.10 shows the difference between measured rise heights, and centerline heights calculated by UMERGE. For plumes where $\mathrm{G}^{*} \rho_{0}{ }^{*}$ was greater than unity, the actual plume thickness was small compared to the rise height. The offset introduced by comparing measured plume top with calculated centerline height was insignificant. The measured and calculated rise heights were essentially identical.

For less intense plumes, the differences were much larger. UMERGE calculated centerline heights which were twice the laboratorymeasurements of maximum rise. Adding plume thickness to the calculated centerline makes the difference between the numerical model and the observations even worse. The analytic model (equation 2.33) is also compared to observations in figure 2.10. 


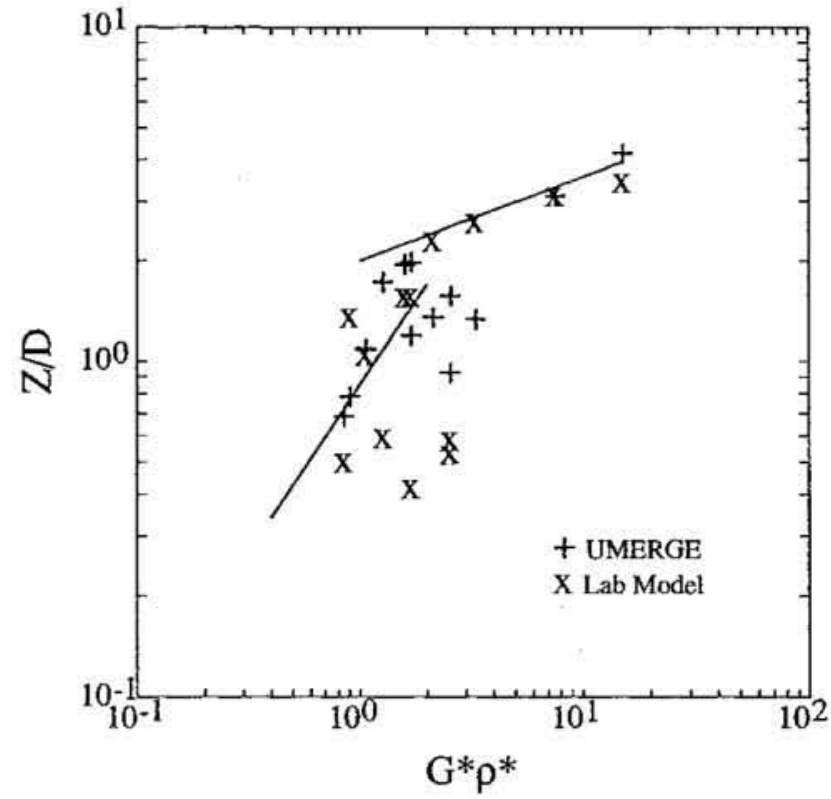

Figure 2.9: Rise height from laboratory simulations and from UMERGE model. This plot is identical to figure 2.8, except that the results from the numerical simulation are also shown. The $x$ symbol represents laboratory data, while the + symbol shows the numerical simulation results. The curves shown are the same as in figure 2.8

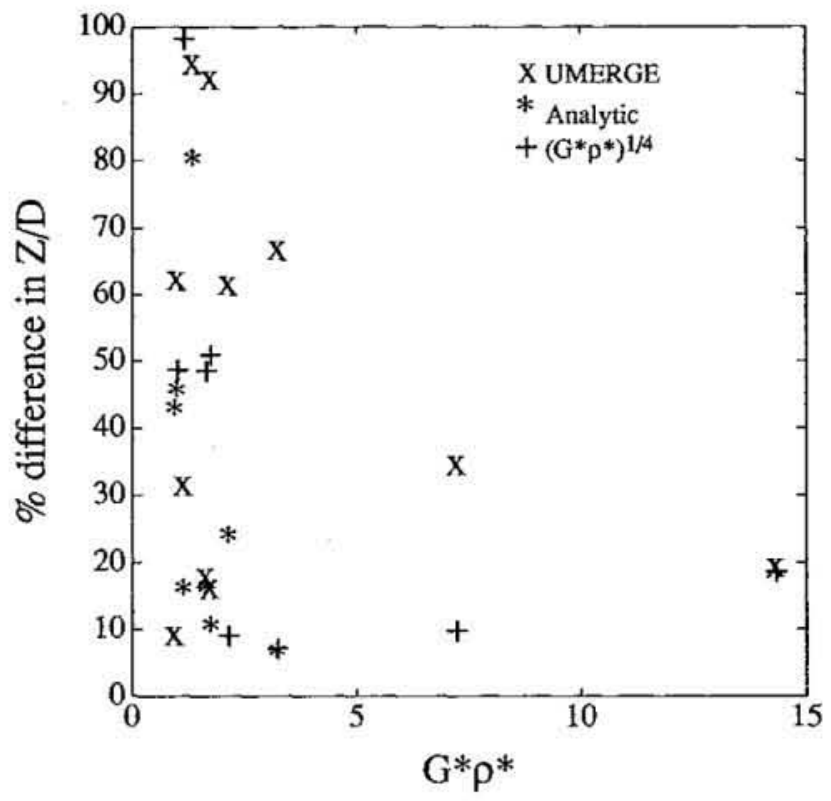

Figure 2.10 : Difference between rise height measured during each laboratory simulation and that calculated for each run from three models: UMERGE (x), the analytic model of equation 2.36 $\left(^{*}\right)$, and the classical buoyant plume relation from equation $2.35(+)$. 


\section{Comparison between UMERGE and the Analytic Solution}

Both UMERGE and the analytic model (equation 2.33) were used to simulate the laboratory plumes summarized in table 2.2. Figures 2.9 and 2.10 showed results from both model efforts. For plumes with $G^{*} \rho_{0}^{*}>1$, UMERGE did an excellent job of predicting plume rise, while the classic analytic model (after Morton et al.,1956) was also very close to the actual observations. Both models have been evaluated elsewhere for such plumes (Muellenhoff et al, 1985). For plumes with $G^{*} \rho_{0}^{*}<1$, UMERGE was no better than the analytic model (equation 2.33).

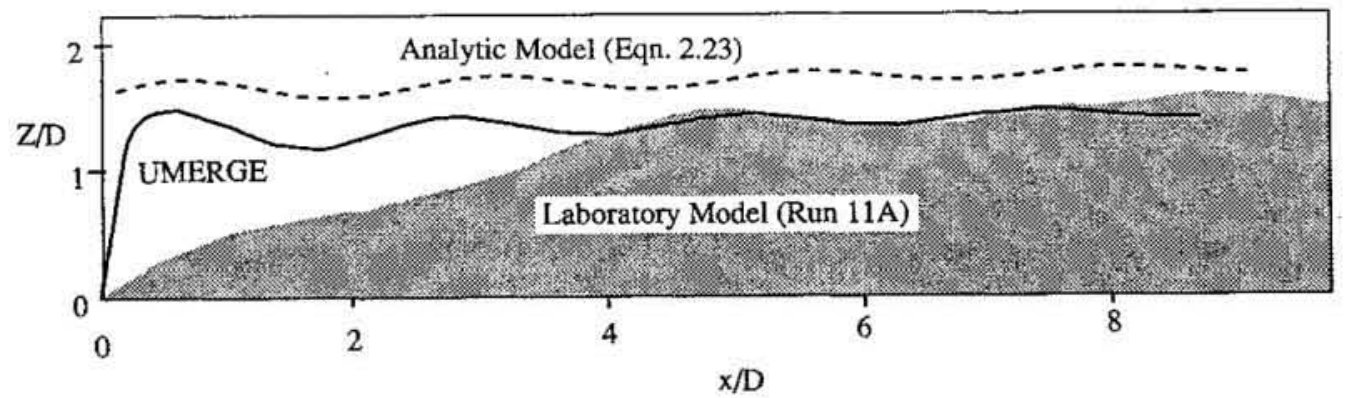

Figure 2.11: Trajectory of a laboratory plume predicted by UMERGE and by linear theory (equation 2.23)compared with the outline traced from a photograph during the laboratory simulation.

Figure 2.11 shows the simulations of laboratorymodel run \#11A. The analytic model came from equation 2.23. Both models predicted similar internal waves on the top surface of the plume. The oscillations are damped by entrainment in both models. The laboratorysimulation did not clearly show waves to be present on the top of the plume. By examining equation 2.22, it appears that an entrainment velocity $\left(W_{\mathrm{e}}\right)$ equal to or greater than the source velocity $\left(\mathrm{W}_{\mathrm{o}}\right)$ would effectively dampen the oscillations.

Neither the UMERGE model or the analytic model do a good job of predicting the plume behaviour near the source. They both successfully predict the maximum rise height. The analytic model is simplest to implement, and gives the ability to make "back-of-the-envelope" estimates of plume behaviour . 


\section{Conclusion: A Qualitative View of Diffuse Plumes}

The analytic model formulated in this section suggests an heuristic explanation for the difference in behaviour of diffuse plumes versus "classic" buoyant plumes. A diffuse plume which does not rise off the seafloor entrains water from the side and from above. A rising plume will entrain water from the sides, above and from below. In a linear density gradient, the water below a plume is denser than that above. A diffuse plume therefore entrains a smaller proportion of dense seawater than would a similar plume free from the seafloor. This makes the diffuse plume behave differently to changes in buoyancy than does the classic buoyant plume.

My goal in modelling has been to guide the design of an instrument suite for field measurements of diffuse hydrothermal flow. The analytic model presented in this section showed several key features which are important for designing a method to monitor diffuse hydrothermal flow. These principal insights are that:

- diffuse hydrothermal flow should merge into a single plume within a downstream distance scaled with the spacing between micro-plume sources,

- it should be advected along the seafloor for long distances, given typical source intensities, stratification, and horizontal current, and

- the rate of entrainment of ambient seawater into a plume determines its horizontal spreading and vertical thickening.

The next section will address the problem of design and implementation of a vent field monitor for diffuse hydrothermal flow. 


\section{References}

Alvin, DSV, videotapes from dives \#2067, \#2069, \#2267

Antonia, R.A., H.Q. Danh, A. Prabhu, Response of a turbulent boundary layer to a step change in surface heat flux, J. Fluid Mech., vol.80, part 1, pp.153-177, 1977

Atwater, M.A. , Urbanization and Pollutant Effects on the Thermal Structure in Four Climatic Regimes, J. Appl. Met., vol.16, pp.888-895, Sept. 1977

Atwater, M.A. , Thermal Changes Induced by Urbanization and Pollutants, J. Appl. Met., vol.14, pp.1061-1071, Sept. 1975

Atwater, M.A. , Thermal Effects of Urbanization and Industrialization in the Boundary Layer: A Numerical Study, Bound. Lay. Met., vol.3, pp.229-245, 1972

Baker, E.T. , G.J. Massoth, Characteristics of hydrothermal plumes from two vent fields on the Juan de Fuca Ridge, Northeast Pacific Ocean, Earth and Plan. Sci. Lett., 85, pp.59-73, 1987

Bornstein, R.D. , The Two-Dimensional URBMET Urban Boundary Layer Model, J. Appl. Met., Vol. 14, Dec. 1975, pp.1459-1477

Briggs, G.A. , Plume Rise from Multiple Sources, in Cooling Tower Environment - 1974, Energy Res. Dev. Agency, pp.161-179, 1974

Britter, R.E. , J.E. Simpson, Experiments on the dynamics of a gravity current head, $J$. Fluid Mech.,vol.88, part 2, pp.223-240, 1978

Cann, J.R., discussion during field expedition to Troodos Ophiolite, Cyprus, 1989

Cann, J.R., personal communication, Woods Hole, February, 1987

Cann, J.R. , J. Edmond, Sub-seafloor water-rock interactions, Report of NAS meeting on mid-ocean ridges, 1987

Cann, J.R. , M.R. Strens, A. Rice, A simple magma-driven thermal balance model for the formation of volcanogenic massive sulphides, Earth Plan. Sci. Lett., 76, pp.123134,1985

Cannon, G.A. , D.J. Pashinski, Circulation Near Axial Seamount, J. Geophys. Res., Vol.95, No. B8, pp. 12,823-12,828, 1990

Converse, D.R. , H.D. Holland and J.M. Edmond, Flow Rates in the Axial Hot Springs of the east Pacific Rise $21^{\circ} \mathrm{N}$ : Implications for the Heat Budget and the Formation of Massive Sulphide Deposits, Earth Plan. Sci. Lett., 69, pp.159-175, 1984 
Crane, K., Aikman, F., III, Embley, R.W., Hammond, S., Malahoff, A., Lupton, J., The Distribution of geothermal fields on the Juan de Fuca Ridge, J. Geophys. Res., 90, 727,1985

Embley, R.W., K.M. Murphy, C.G. Fox, High-Resolution Studies of the Summit of Axial Volcano, J. Geophys. Res., Vol.95, No. B8, pp. 12,785-12,812, 1990

Frick, W.E. , D.J. Baumgartner, C.G. Fox, C.A. Bodeen, Empirical Energy Transfer Function for Dynamically Collapsing Plumes, in prep., 1991

Frick, W.E., Non-Empirical Closure of the Plume Equations, Atmos. Env., Vol.18, No.4, pp.653-662, 1984

Garstang, M. , P.D. Tyson, G.D. Emmitt, The Structure of Heat Islands, Rev. Geophys. Space. Phys., Vol.13, No.1, pp.139-165

Gross, T.F. , A.J. Williams III and W.D. Grant, Long-term in situ Calculations of Kinetic Energy and Reynolds Stress in a Deep-Sea Boundary Layer, J. Geophys. Res., Vol.91, No.C7, pp.8461-8469, 1986

Gutman, D.P. , K.E. Torrance, Response of the Urban Boundary Layer to Heat Addition and Surface Roughness, Bound. Lay. Met., 9, pp.217-233 ,1975

Hessler, R.R. and W.M. Smithey jr., The Distribution and Community Structure of Megafauna at the Galapagos Rift Hydrothermal Vents, in Hydrothermal Processes at Seafloor Spreading Centers, P.A. Rona et al.,ed., Plenum, New York, 1983, pp.735-770

Kennedy, J.F. , H. Fordyce, Plume Recirculation and Interference in Mechanical-Draft Cooling Towers, in Cooling Tower Environment - 1974, Env. Res. Dev. Agency, pp.58-160, 1974

List, E.J. , Mechanics of Turbulent Buoyant Jets and Plumes, in Turbulent Buoyant Jets and Plumes, W. Rodi, ed., Pergammon Press, Vol.6, The Science and Applications of Heat and Mass Transfer, 1982

Little, S.A. , K.D. Stolzenbach, J.F. Grassle, Tidal Current Effects on Temperature in Diffuse Hydrothermal Flow: Guaymas Basin, Geophys. Res. Let., vol.15, No.13, pp.1491-1494, Dec. 1988

Little, S.A. , Ph.D Thesis, Woods Hole Oceanographic Institution / Massachussetts Institute of Technology, April, 1988

Little, S.A. , K.D. Stolzenbach, R.P. Von Herzen, Measurements of Plume Flow from a Hydrothermal Vent Field, J. Geophys. Res., Vol.92, No.B3, pp.2587-2596, 1987

Massoth, G.J., raw measurements from Seabird Conductivity-Temperature-Depth sensor carried aboard DSV Alvin during dives \#2075, 2077, 2094, 1988.

McElroy, J.L. , A numerical study of the nocturnal heat island over a medium sized midlatitude city (Columbus, Ohio), Bound. Lay. Met., Vol. 3, 1973, pp.442-453 
Monfort, M. , A. Schulz, Timeseries Measurements of Hydrothermal Vent Temperature and Diffuse Percolation Velocity: Results from an Alvin Submersible Program, Endeavour Segment, Juan de Fuca Ridge, AGU Fall Meeting, Poster session, Dec. 59, 1988

Morton, B.R. , Sir Geoffrey Taylor, J.S. Turner, Turbulent Gravitational Convection from Maintained and Instantaneous Sources, Proc. roy. Soc. A 234, 1-23, 1956

Muellenhoff, W.P. , A.M. Soldate Jr., D.J. Baumgartner, M.D. Schuldt, L.R. Davis, W.E. Frick, Initial Mixing Characteristics of Municipal Ocean Discharges: Volume 1: Procedures and Applications, EPA-600/3-85-073a, 1985

Myrup, L.O. , A numerical model of the urban heat island, J. Appl. Met., Vol. 8, Dec. 1969, pp.908-918

Townsend, A.A. , Self-preserving flow inside a turbulent boundary layer, J. Fluid Mech., vol.22, part 4, pp.773-797, 1965(a)

Townsend, A.A. , The response of a turbulent boundary layer to abrupt changes in surface conditions, J. Fluid Mech., vol.22, part 4, pp.799-822, 1965(b)

Turner, J.S. , Buoyancy Effects in Fluids, Cambridge Univ. Press, Cambridge, 1973

Yu , T. , and N.K. Wagner, Numerical Study of the Nocturnal Urban Boundary Layer, Bound. Lay. Met., vol. 9, 1975, pp.143-162 


\section{Section 3}

\section{Sensors for Monitoring Diffuse Flow}

Table of Contents

3.1 Introduction: Measurement Strategy .........................................................61

3.2 A Vent Field Acoustic Tomography Array .................................................62

Performance Requirements ......................................................................62

Theoretical Development ......................................................................63

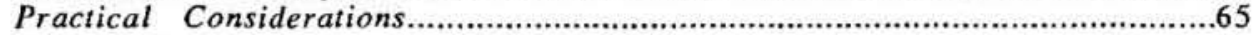

3.3 An Array of Temperature and Velocity Sensors...........................................68

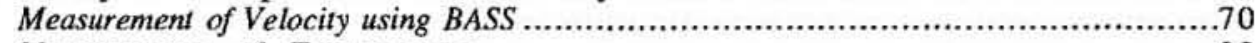

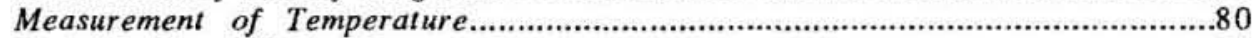

Turbulent Heat Diffusion Measurements .................................................95

Measurements of Turbulence using BASS ...................................................98

Ancillary Measurements......................................................................98

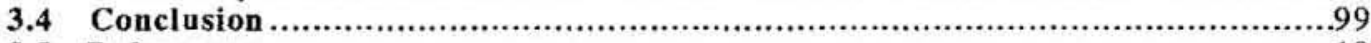

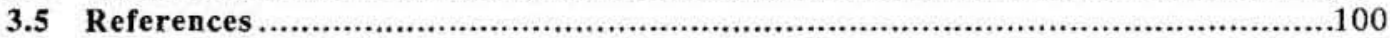




\section{Introduction: Measurement Strategy}

A suitable instrument array to monitor diffuse hydrothermal flow should be:

- simple to deploy and recover,

- capable of extended deployments,

- sufficiently reliable and rugged for use at a variety of vent sites .

The most direct technique to monitor diffuse hydrothermal venting involves placing flow sensors at the exit of one or more micro-plume orifices. To calculate the integrated heat flow, I would need to know something about the distribution of similar micro-plumes throughout the area of venting. The source distribution becomes critical. Only by repeated surveys similar to that described in Appendix A, could we observe the total output using a single sensor within the vent field. Such revisits to a site at a short enough time interval are not practical, except by autonomous vehicles.

Rather than extrapolating the details of near-field diffuse flow, I prefer to use the conclusions from the previous section, and determine a method of constraining large-scale (50-100 $\mathrm{m}$ scales) plume models. My approach requires measuring flow parameters far enough from the source of venting for local inhomogeneities to have been smoothed out by mixing, yet near enough that a detectable plume signature remains.

There are two possible approaches to making a monitor for large-scale measurement of diffuse flow:

- develop a remote sensing technique which can make a three-dimensional map of velocity and temperature near a source of hydrothermal flow,

- deploy an array of simple point sensors in a configuration that allows the important aspects of the flow to be observed.

The first approach would involve a small-scale acoustic tomography array. I decided that this technique required more development than seemed appropriate for the problem. The second approach requires an array of current and temperature sensors. This was the technique which I ultimately used.

In this section, I will discuss the theoretical and practical limitations of each of the approaches. A detailed discussion of the performance of the instruments used in my field deployment will be included in this section. 


\section{A Vent Field Acoustic Tomography Array}

The optimum monitor for diffuse flow would continuously measure the output of vents over a large section of seafloor ( $\sim 500 \mathrm{~m}$ diameter patch), and show the change in output from different segments of the measurement field. Acoustic tomography may provide a means to realize this goal. I will sketch its potential to monitor diffuse heat flux, and point out some major difficulties which made it impractical to implement in this research project.

Acoustic tomography is a technique where a field variable (such as temperature or sound-speed) is reconstructed from measurements of path integrals through the reconstruction field. The measurement gives information about some mean property along individual ray-paths. The process of inverting data from a collection ray-paths enables a space-dependent property to be mapped.

\section{Performance Requirements}

A useful tomography array should:

- resolve anomalies in temperature and velocity larger than $10-30 \mathrm{~m}$ in diameter,

- detect horizontal velocity anomalies of $.5 \mathrm{~cm} / \mathrm{s}$,

- observe temperature fluctuations of $0.005^{\circ} \mathrm{C}$, and

- monitor a $100-200 \mathrm{~m}$ diameter hydrothermal field .

In addition to these specifications, a tomography monitor for vents must endure deployments of 1 month to 2 years in duration. It must contain sufficient battery and data storage capacity for the entire mission.

Little (1988) and Rona and Trivett (Appendix A) demonstrated that horizontal current must be measured when observing diffuse flow. This is true for a tomography array as well as for point sensors. Mapping out velocity, a vector quantity, has some theoretical problems that are not encountered in tomographic inversion of a scalar field (such as temperature). I will consider the development of an acoustic array to measure flow velocity and temperature over $100-200 \mathrm{~m}$ scales. 


\section{Theoretical Development}

Tomographic inversion of acoustic travel-time measurements for temperature estimation has proven successful over large-scales in the ocean (Ocean Tomography Group,1982; Munk and Wunsch, 1979). A useful hydrothermal heat-flux monitor must map flow velocity as well as temperature.

Flow velocity is measured acoustically by transmitting sound in reciprocal directions along an acoustic path. The technique is described in Appendix B for small-scales. On the scale of $100-200 \mathrm{~m}$, the reciprocal travel-time technique is the same for measuring the integrated velocity.

Velocity is a vector quantity. Norton (1988) and Johnson et al., (1979) have investigated the problems inherent in attempting a tomographic inversion of a vector field. Johnson et al. presented examples of "invisible flow" from two-dimensional sources or sinks. Norton (1988) proved that information from line integrals alone (such as the traveltime along an acoustic ray) is not sufficient to reconstruct the irrotational component of flow, but it can uniquely determine the rotational component for 2-dimensional flow. The simple , irrotational velocity field in figure 3.1 cannot be detected by a tomography array.

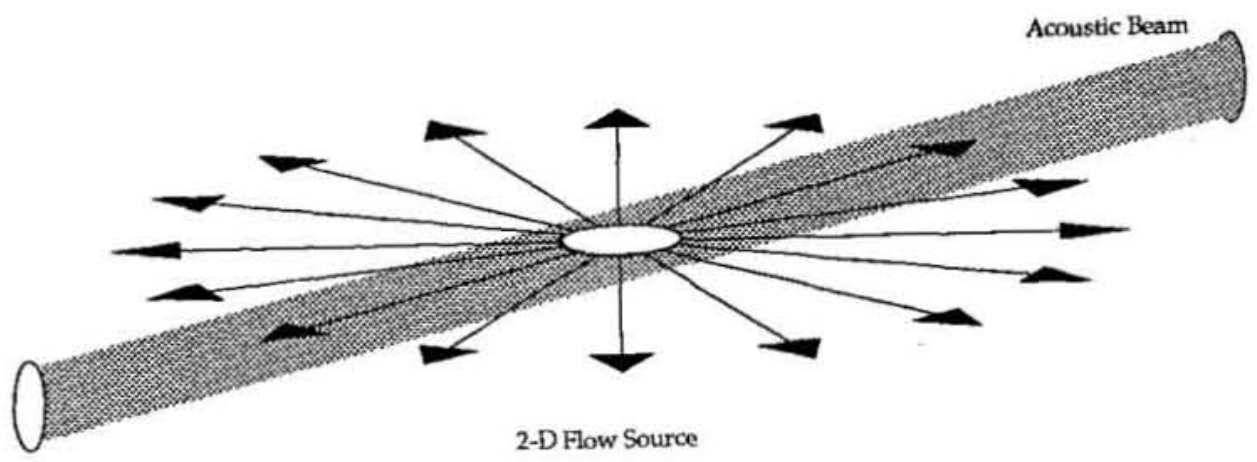

Figure 3.1 : An invisible velocity field: The velocity field, a two-dimensional source is centered so that an acoustic path passes though its center. The velocity produced by this source is indicated by arrows. The acoustic path represents one in an arbitrary number of paths to be used in a tomographic inversion of the velocity 
Consider the acoustic path which crosses through the eye of a flow source (figure 3.1). On one side of the source, the travel time will be reduced because the sound propagation is in the same direction as the radial flow from the source. On the opposite side, the travel time will be increased because the sound must go upstream. Since we must take the difference between travel times measured going in two directions to estimate velocity, it becomes clear that the symmetric effect of a source will cancel out, giving no net contribution to the travel time difference. This result can be generalized to paths which do not intersect the center of a flow source. The net effect of a source will cancel out over the entire region shown in figure 3.1 .

The inability of a tomography array to reconstruct a two-dimensional source is important in a hydrothermal field. Entrainment into a buoyant plume appears as a twodimensional sink when looking at a thin slice through the cross-section of a plume (figure 3.2). An acoustic tomography array will not detect the velocity field caused by a plume.

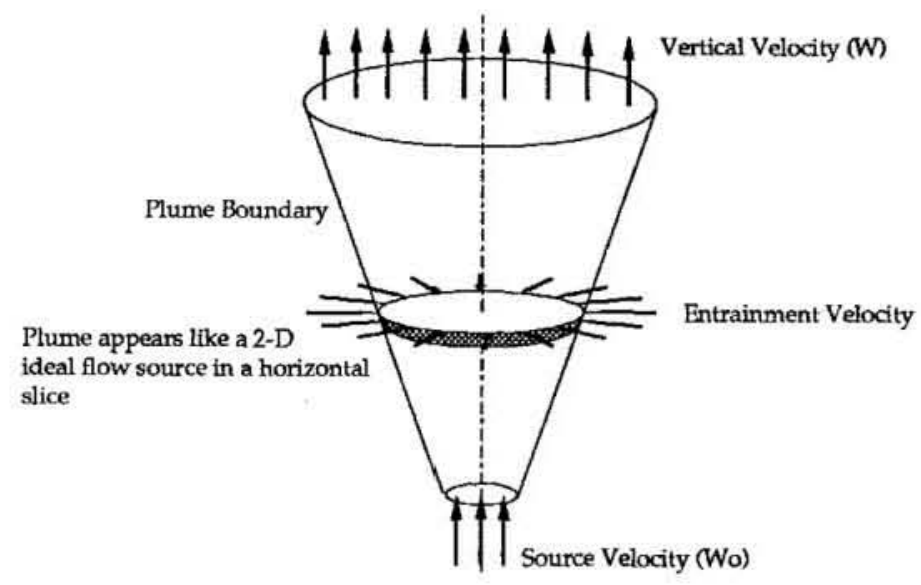

Figure 3.2: A plume appears as a vertical line sink due to entrainment of ambient fluid into the plume. At every elevation, a slice such as that shown resembles a two-dimensional sink, making observation of entrained velocity into a plume using acoustic tomography ambiguous.

If I assume that the diffuse hydrothermal flow to be reconstructed is predominantly two-dimensional due to its proximity to the seafloor, the measurement of velocity becomes possible. Norton has shown that both the path integrals of travel-time and the velocity across a bounding surface around the reconstruction area must be measured in order to solve 
for the complete two-dimensional flow (irrotational and rotational). In theory, we could map everything except flow sources and sinks.

The irrotational flow in a hydrothermal field includes the depth-averaged mean velocity, and steady flow from the hydrothermal sources. The rotational part of the flow field includes the boundary layer shear, mixing eddies created by the plume, and largescale vorticity due to coriolis force. The rotational flow (for two-dimensional geometries) can be reconstructed knowing only the travel times through the volume. Norton's result shows that the irrotational flow can be reconstructed by knowing only the velocity across a boundary enclosing the volume of interest. Thus, mapping irrotational flow need not involve a tomography array, since a collection of individual velocity sensors around a control-surface are all that are required.

I have not mentioned mapping of temperature anomalies in the above discussion. The inversion of a temperature field does not involve any new theoretical challenges. Munk and Wunsch (1979) showed the practicality of this technique over large scales. The theory of small-scale tomographic inversion is simpler than for large-scales in the ocean because the acoustic paths can be assumed to be nearly straight. Over large scales, refraction produces multiple sound paths between a source and receiver, and these must be identified before an inversion can commence (Ocean Tomography Group, 1982).

The decision to pursue development of an acoustic tomography monitor for vents must be based on an assessment of the value of knowing the rotational component of flow, as well as the need to map out the temperature field. The irrotational flow can be obtained from traditional velocity measurements alone.

\section{Practical Considerations}

The first-order decision to be made in evaluation of a vent-field acoustic tomography array is how many source/receiver pairs to use. The maximum number of direct paths $\left(\mathrm{N}_{\mathrm{P}}\right)$ for a given number of transducers $(\mathrm{N})$ in an array is: 


$$
N_{P}=\frac{N(N-1)}{2}
$$

where transducers both transmit and receive signals. I assumed in the above expression that every transducer communicates with every other transducer in the array. The average resolution of an inversion is proportional to the volume (or area in a two-dimensional array) of the reconstructed field, divided by the number of paths. The worst resolution will be proportional to spacing between transducers (figure 3.3). To build a twodimensional array that has better than $30 \mathrm{~m}$ resolution everywhere in a $100 \mathrm{~m}$ diameter vent field would require 10 transducers around the perimeter of the field. The same resolution over a $200 \mathrm{~m}$ diameter would require 20 transducers. Mean resolution in both these examples would be $13 \mathrm{~m}$.

The goal of measuring velocity over the vent field demands that we make differential travel-time measurements to an accuracy of $400 \mathrm{~ns}$ to get $0.5 \mathrm{~cm} / \mathrm{s}$ accuracy through $30 \mathrm{~m}$ patches. If we design the array having instruments run on independent clocks, synchronization and drift of the multiple time bases would be a daunting problem. A configuration where 20 transducer nodes are strung together on a cable carrying a common time-base could be one solution. This string could be deployed in a loop around the ventfield. Timing errors would then depend on the stability of a single clock.

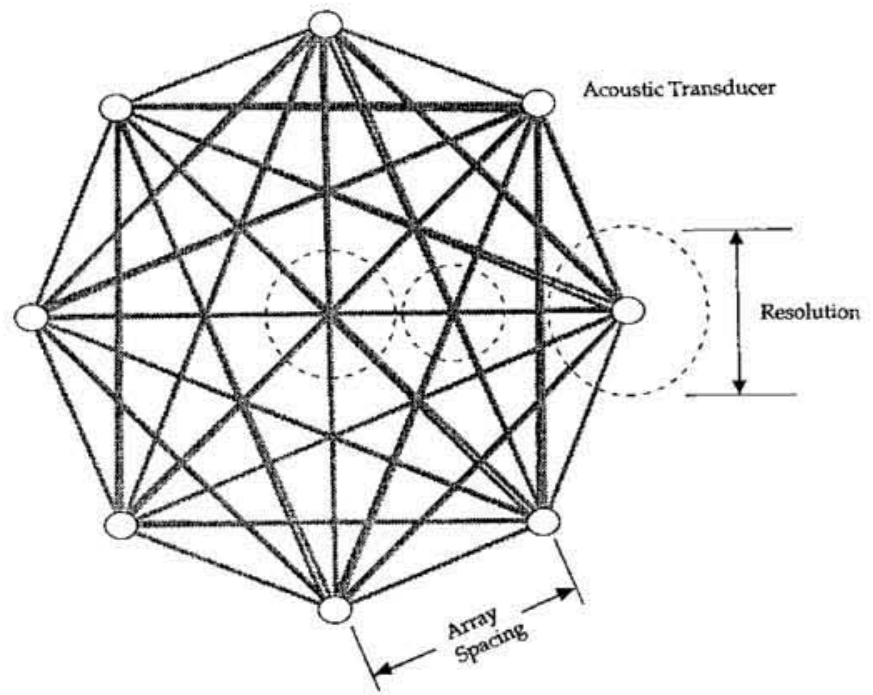

Figure 3.3: Resolution of a hypothetical tomography array showing eight transducers. The shaded lines represent acoustic paths in the tomography array. Each transducer would transmit and receive from every other transducer. The circles indicate the approximate resolution at three locations in the array. This resolution is not a constant over the field, but depends on the concentration of acoustic paths. 
Positioning the transducers may be a major challenge during the deployment of an acoustic array. Each hydrophone must be at least $20 \mathrm{~m}$ above the seafloor in order to avoid shadow zones due to upward refraction, and blockage from topography. The motion of the transducers must be analyzed to see how badly it will reduce the accuracy of travel-time measurements.

Another problem may be deciding where and how to store data. Should each transducer separately record when a transmission was received, and when it sent responses? This sort of data would require post-processing to work out the path integrals for the tomographic inversion. An alternative would be to transmit a coded signal with the transmission time included as part of the information. This could be received and decoded in a central location for storage.

There are many more challenges to be overcome in the design of a tomography array for hydrothermal vent fields, but the ones listed above are the most basic. Development of a system to make this measurement is a significant engineering task. I chose to find a measurement technique which would be simple, deployable, and would use existing hardware whenever possible. A simple array of point sensors which was deployed to monitor the irrotational flow will be presented in the next section. 


\section{An Array of Temperature and Velocity Sensors}

The analytic model presented in section 2.4 showed relations between plume rise height, downstream density anomaly, and source conditions under known ambient conditions. By measuring the inflow and outflow current and temperature over a diffuse vent field, the parameters (ambient current, upstream stratification, downstream temperature anomaly, and plume rise height) due to hydrothermal activity between measurement stations can be estimated. In figure 3.4, I show an "upstream" and "downstream" array of sensors. The upstream sensors will monitor the ambient stratification, temperature, and velocity. The downstream sensors will detect the same parameters in the wake of a plume.

The concept of "upstream" and "downstream" directions is somewhat arbitrary. At the southern Juan de Fuca ridge, current has been observed to reverse with the tidal cycle (Cannon and Pashinsky, 1988). The currents are primarily constrained to flow in a northsouth direction (Cannon and Pashinsky). Therefore, I attempted to deploy an array of sensors as shown in figure 3.4. The upstream and downstream sensors should be interchangeable, depending on the tidal phase.

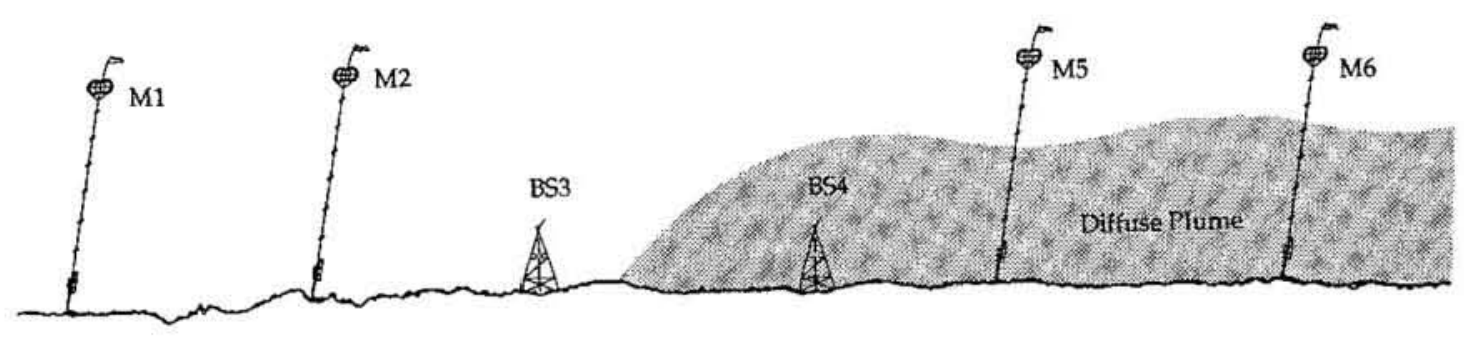

Figure 3.4: An array of point-sensors for diffuse plume monitoring showing four thermistor moorings (labelled M1-M6), and two BASS (Benthic Acoustic Stress Sensor labelled BS3 and BS4) tripods deployed upstream and downstream of a diffuse hydrothermal vent field. The current is flowing from left to right in the figure, and the plume is being advected to the right. 
The BASS velocity sensors are one order of magnitude shorter than the temperature sensors deployed. This is a practical constraint, since the velocity measurements (resolution to $0.3 \mathrm{~mm} / \mathrm{s}$ ) require a stable platform to avoid errors induced by sensor motion. In addition, velocity shear beyond five meters from the bottom is outside the logarithmic portion of the boundary layer for the flow velocities expected at the southern Juan de Fuca ridge.

Ideally, the sensor array would be designed to form a ring around the vent field. This would account for flow from all horizontal directions. It would also provide some measure of the plume width. Unfortunately, such an array would have been prohibitively expensive to build and to deploy for a first attempt at this measurement. In the deployment discussed in this thesis, I had to settle for two BASS (Benthic Acoustic Stress Sensor) tripods, each measuring profiles of velocity, temperature, speed of sound, Reynolds Stress, and turbulent heat diffusion. The BASS tripods were augmented by four temperature moorings, each having six thermistors. The measurements made by each of the sensors in the instrument array will be discussed in detail in the remainder of this section. 


\section{Measurement of Velocity using BASS}

BASS (Benthic Acoustic Stress Sensor) was originally designed to measure the benthic boundary layer (Tochko, 1978). The sensor cages described in Appendix B: Error Analysis of an Acoustic Current Meter (Trivett, Terray and Williams, 1991) are mounted in a vertical tower as shown in figures 3.5 and 3.6 .

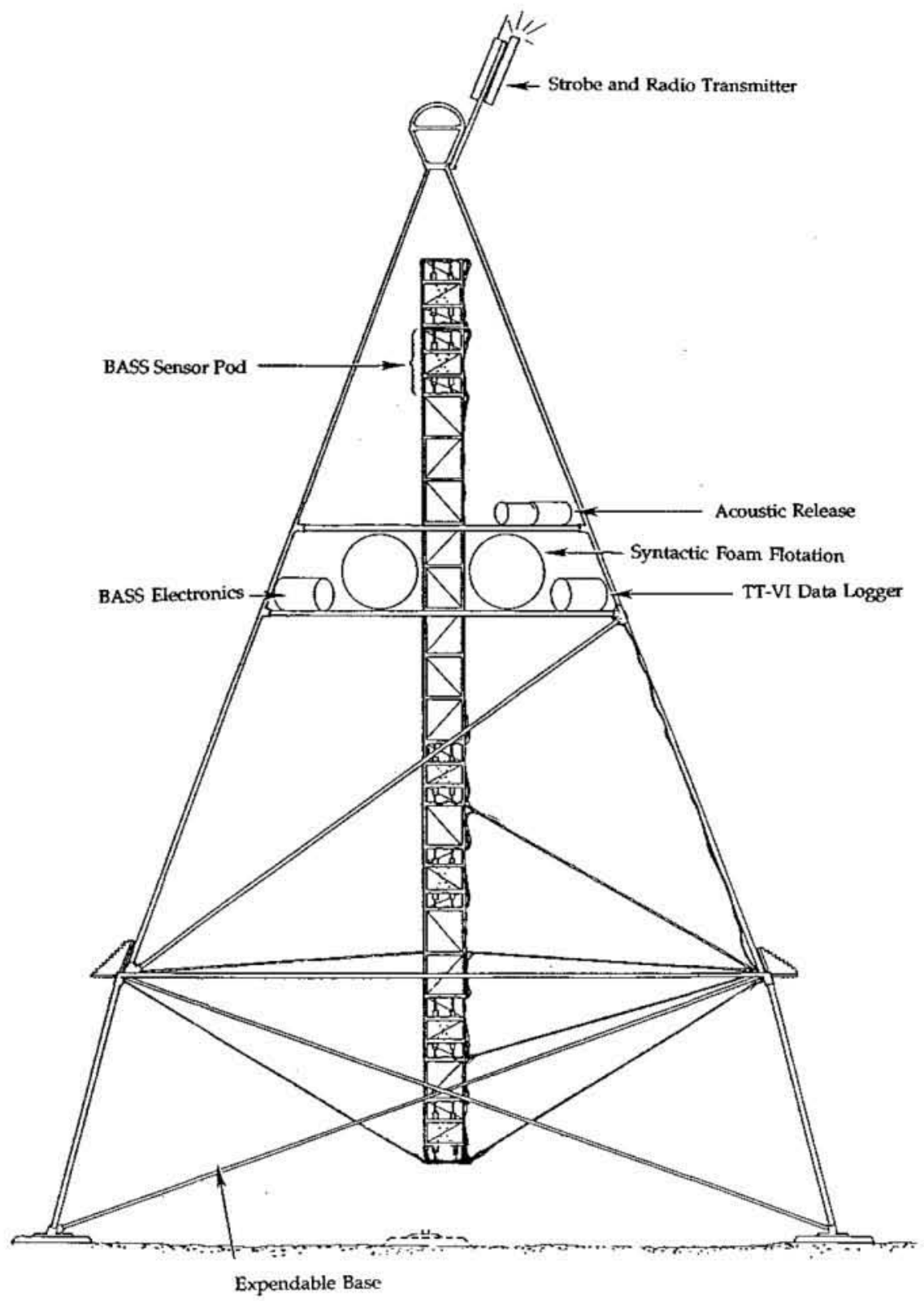

Figure 3.5 : Major components of a BASS tripod including sensor pods (6), BASS and Tattle-Tale electronics housings, syntactic foam flotation, acoustic release, and major dimensions of the tripod structure. 


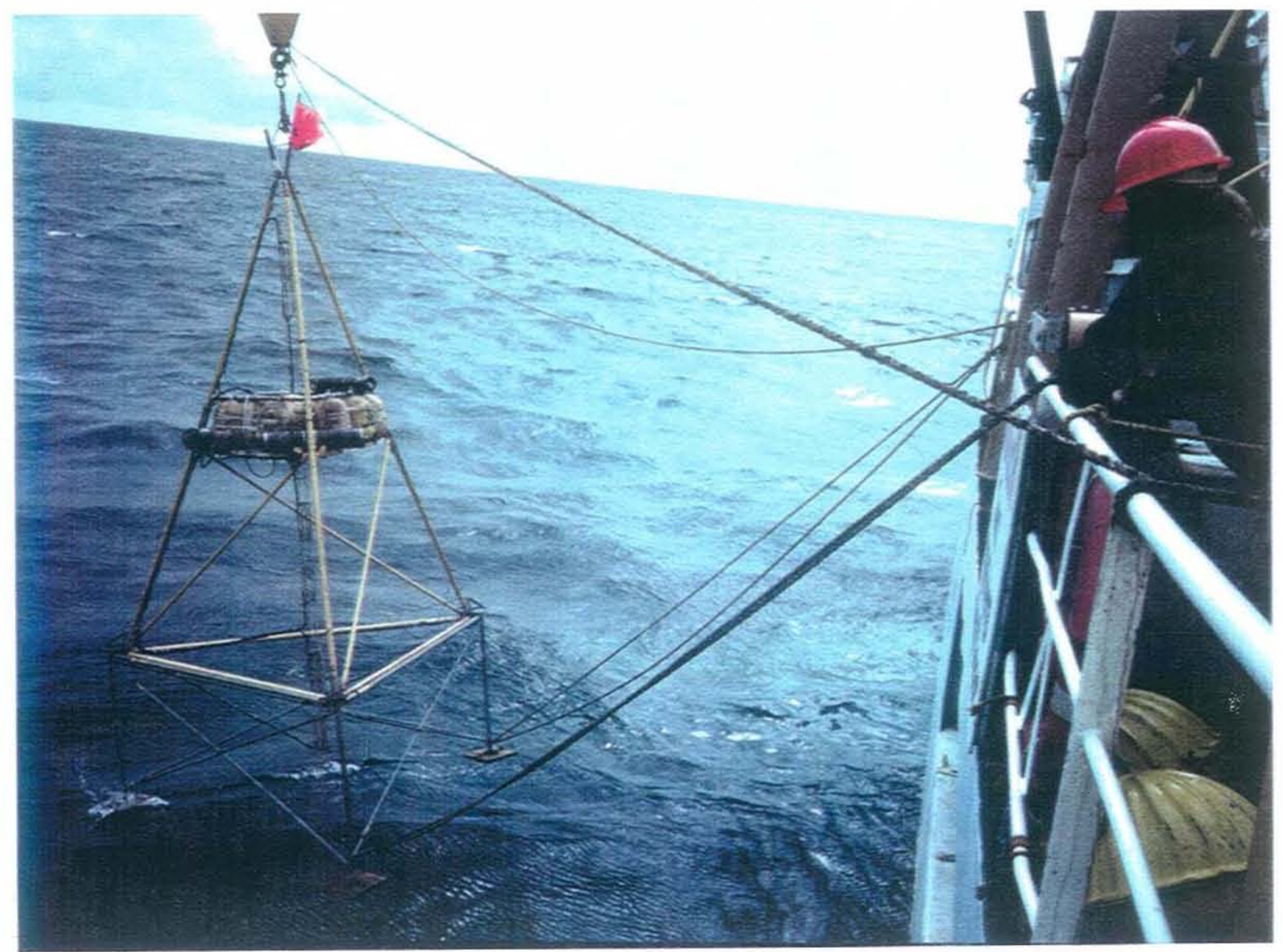

Figure 3.6 : A BASS tripod being deployed from The NOAA ship Discoverer in the VENTS90 cruise of August 1990. The yellow-painted structure is the recoverable part of the tripod. The grey steel base was left to corrode on the seafloor after the deployment. The black cylinders are electronics housings, the top one being the acoustic release. The nearest cylinder to the camera is the logger housing, and the other is the BASS electronics housing. The tag-lines attached to the tripod base are about to be cleared, and the slack line to the tripod peak will be pulled to trip a pelican-hook lift release. 
The height of sensor pods in the BASS towers for VENTS'90 were:

\begin{tabular}{|c|c|}
\hline Pod\# & Height $(\mathrm{m})$ \\
\hline \hline 1 & 0.58 \\
2 & 1.18 \\
3 & 2.03 \\
4 & 2.62 \\
5 & 4.46 \\
6 & 4.81 \\
\hline
\end{tabular}

Table 3.1 : Heights of BASS sensor pods above the seafloor

The height of each pod is plotted in figure 3.7 over a measured boundary layer profile. The heights were chosen to adequately define the logarithmic boundary layer, and to provide redundant sampling at the uppermost height. I expected to observe the most interesting temperature and velocity fluctuations at the top of the tripod. It was important to ensure that the measurements at that height were not lost due to a bad sensor pod, or bad axes in a pod. Thus, Pods 5 and 6 are closely spaced at the top of the array. Pod 1 was located $0.58 \mathrm{~m}$ above the bottom to give a reasonable clearance for deployment on very rocky or irregular bottoms.
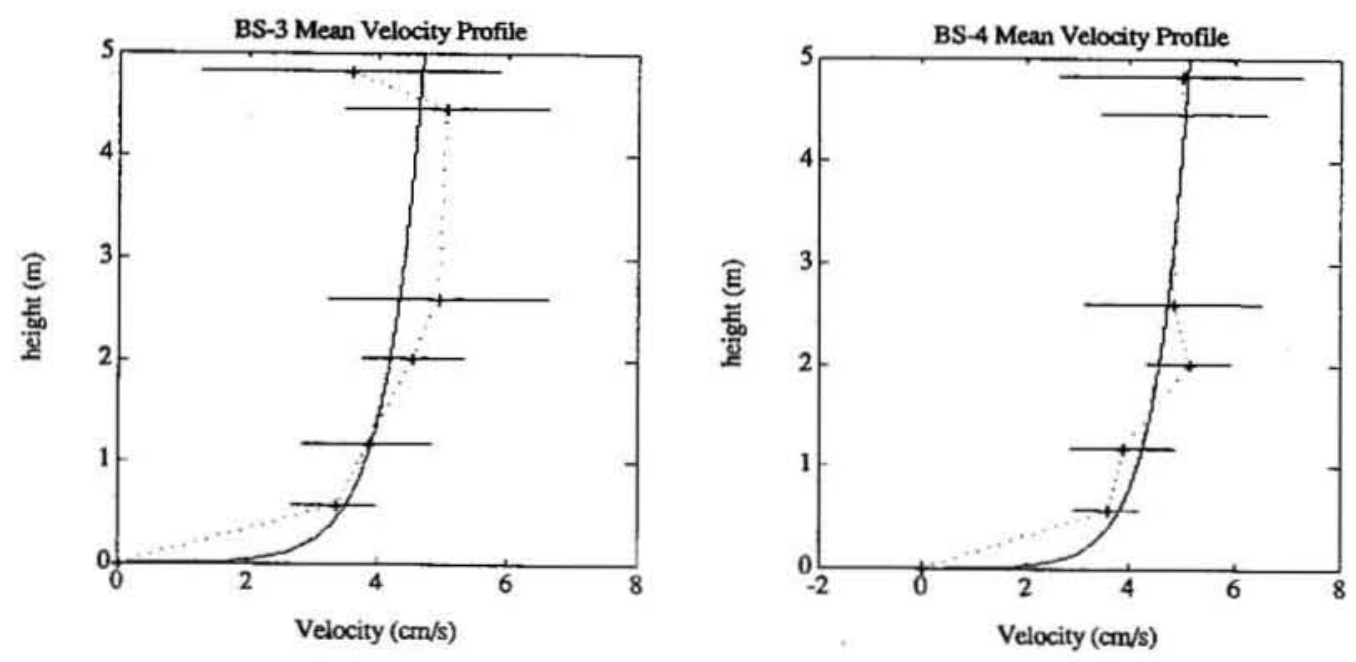

Figure 3.7 : Pod heights are shown in a mean boundary layer profile from VENTS90 data. The horizontal bars indicate calculated errors for $4 \mathrm{~cm} / \mathrm{s}$ flow at each pod. The dotted line represents a mean velocity profile averaged over 4 days of the field deployment at the southern Juan de Fuca ridge. The solid line is a logarithmic boundary layer fit to the data in a least-squares sense. 


\section{Error Estimation for BASS Velocity}

In Appendix B, we have performed a simple analysis of flow disturbance on an individual BASS sensor pod. The flow error has been broken down into three main sources; ideal flow blockage, wake velocity deficit, and vortex-induced oscillations. Error in the sound-speed used for the conversion from travel-time to velocity is also discussed. Soundspeed was measured directly, and did not fluctuate enough to effect the velocity scale factors. Zero offset calibration will be discussed separately for the VENTS90 deployment.

I have carried out a crude analysis to estimate the additional errors due to flow disturbance from the tripod structure. Figure 3.8 illustrates the flow disturbers for a typical BASS tripod.

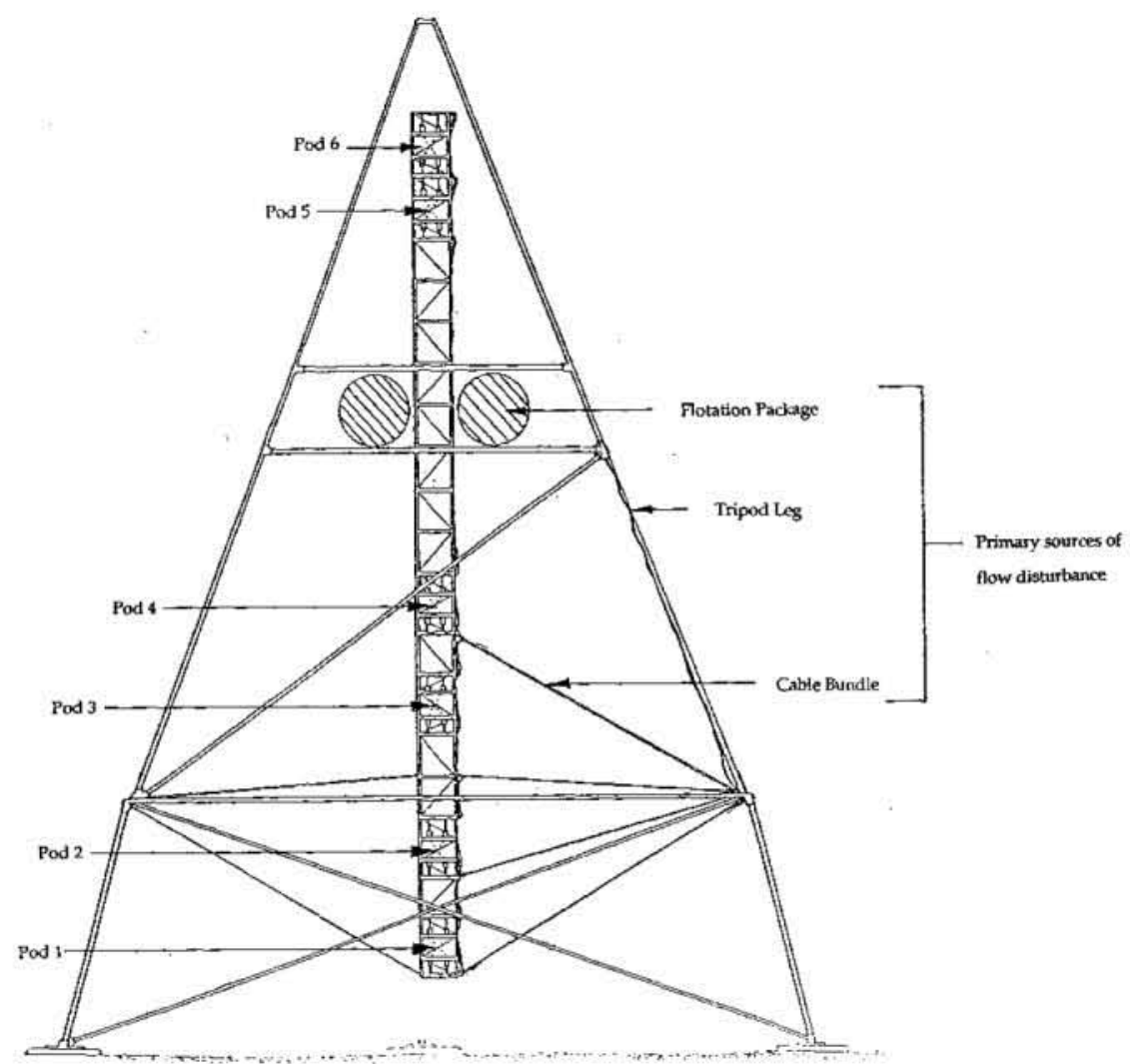

Figure 3.8: Schematic of a BASS tripod showing location of pods with respect to the primary sources of flow disturbance. During the VENTS 90 deployment, the flow was primarily parallel to the bottom at velocities never exceeding $10 \mathrm{~cm} / \mathrm{s}$. 
Bundles of transducer cables were laced along stays supporting the BASS tower. These bundles were almost $2 \mathrm{~cm}$ in diameter in some places. Assuming the bundle of cables behaves like a cylinder in cross-flow (Blevins, 1977), the vortex shedding frequency of this bundle should have been on the order of $0.6 \mathrm{~Hz}$ in a $6 \mathrm{~cm} / \mathrm{s}$ current. This was filtered out of the mean measurements, since BASS constructedthe mean values of velocity and temperature from 120 samples taken at $2 \mathrm{~Hz}$. The mean wake created by the bundles was in the same plane as the tripod legs, so I consider only the wake from the tripod legs, which were much larger in diameter.

The tripod legs entirely shadowed sensor pods when the flow came from directions where a leg was directly upstream of the sensors. The error in velocity measurement is thus equal to the wake velocity defect due to the tripod leg. Error due to ideal flow is relatively minor at the four lowest pods since the tripod legs are quite far away from them. The upper two pods were marginally influenced by ideal flow around the tripod legs. The relative magnitudes of errors from various types of flow disturbance are summarized in Table 3.2. The calculations used to formulate table 3.2 are explained in Appendix B for an individual sensor pod.

The buoyancy package shown in figure 3.8 was a major source of flow blockage. I have very crudely modelled it as a two-dimensional cylinder with its diameter equal to the height of the buoyancy package. The wake from the buoyancy package was not a problem, since flow was always horizontal, the wake was never advected into any of the sensor pods.

\begin{tabular}{|c|c|c|c|c|}
\hline Pod \# & $\begin{array}{c}\text { Error from } \\
\text { Leg Wake }\end{array}$ & $\begin{array}{c}\text { Ideal Flow Error } \\
\text { due to Leg }\end{array}$ & $\begin{array}{c}\text { Ideal Flow Error } \\
\text { due to Buoyancy }\end{array}$ & $\begin{array}{c}\text { Flow Error in } \\
4 \mathrm{~cm} / \mathrm{s} \mathrm{mean} \mathrm{flow}\end{array}$ \\
\hline \hline 1 & $-0.18^{*}$ & \pm 0.0010 & $0.011^{*}$ & $-0.7+0.04 \mathrm{~cm} / \mathrm{s}$ \\
2 & -0.20 & 0.0013 & 0.018 & $-0.8+0.07$ \\
3 & -0.22 & 0.0021 & 0.047 & $-0.9+0.19$ \\
4 & -0.24 & 0.0032 & 0.140 & $-1.1+0.56$ \\
5 & -0.42 & 0.04 & 0.088 & $-1.7+0.39$ \\
6 & -0.54 & 0.15 & 0.049 & $-2.3+0.63 \mathrm{~cm} / \mathrm{s}$ \\
\hline
\end{tabular}

* fractional error

Table 3.2 : Error estimates from different sources of flow disturbance and electronic offset for the BASS tripod: BS3. 
Two-dimensional equations for wake velocity defect and potential flow anomaly were used in the above error estimates (Appendix B). Wake induced errors always cause the velocity to be underpredicted, whereas the disturbance due to potential flow around the buoyancy package causes the horizontal velocity to be overpredicted.

I estimated zero-offset errors by comparing the pre- and post-cruise zero-velocity calibrations. Each BASS tripod was deployed off the dock with plastic bags taped over the sensors before and after the deep-sea deployment. The difference between the pre- and post-cruise calibrations were used as the zero-offset error. Measured offset errors for both BS4 and BS3 tripods are presented in table 3.3 along with the summarized errors from tripod flow disturbance in $4 \mathrm{~cm} / \mathrm{s}$ mean flow.

\begin{tabular}{|c|l|l|l|}
\hline Pod \# & $\begin{array}{c}\text { Flow Error in } \\
\text { 4 cm/s mean flow }\end{array}$ & $\begin{array}{c}\text { BS3 } \\
\text { Zero Offset }\end{array}$ & $\begin{array}{c}\text { BS4 } \\
\text { Zero Offset }\end{array}$ \\
\hline 1 & $-0.7 \pm 0.04 \mathrm{~cm} / \mathrm{s}$ & $0.15 \mathrm{~cm} / \mathrm{s}$ & $0.96 \mathrm{~cm} / \mathrm{s}$ \\
2 & $-0.8 \pm 0.07$ & 0.70 & 0.74 \\
3 & $-0.9 \pm 0.19$ & 0.18 & 0.34 \\
4 & $-1.1 \pm 0.56$ & 1.22 & 0.26 \\
5 & $-1.7 \pm 0.39$ & 0.38 & 0.76 \\
6 & $-2.3 \pm 0.63 \mathrm{~cm} / \mathrm{s}$ & $1.15 \mathrm{~cm} / \mathrm{s}$ & $0.40 \mathrm{~cm} / \mathrm{s}$ \\
\hline
\end{tabular}

$\dagger$ from calibration data

Table 3.3 : Error estimates from flow disturbance and electronic offset for each of the BASS tripods: BS3 and BS4. The flow error column is a summary of table 3.2, given a $4 \mathrm{~cm} / \mathrm{s}$ mean current. Zero offset for each pod comes from the RMS (root-mean-square) offset of all four axes in each pod. The data for this offset error was accumulated from pre-andpost-cruise zero velocity calibrations of the BASS tripods.

Figure 3.7 showed average velocity profiles from the BS3 and BS4 tripods. Error bars are shown on the plots to represent uncertainties based on the above table. The variablity of the profiles from a least-squares fit logarithmic profile is within reason for the error bars shown.

\section{Sampling Rate, Data Storage and Format}

BASS can make a velocity measurement from all axes at all pods in less than $40 \mathrm{~ms}$. For VENTS90, measurements were made once every 0.5 second, for a digital sample rate of $2 \mathrm{~Hz}$. 
Since data at $2 \mathrm{~Hz}$ over the course of the deployment would have been far too much data for the 20MByte storage medium, samples were averaged down to once per minute. A spectrum of the autocorrelation of velocity measurement is shown in figure 3.9. Notice that the behaviour of the spectrum from sample intervals shorter than 20 minutes $(0.05$ samples/minute) has a slope of $-5 / 3$, which implies that the sampling was sufficient to detect part of the equilibrium range of turbulence (Tennekes and Lumley, 1972). The spectrum decays monotonically at high frequency. Undersampling of velocity fluctuations was not a problem since there were no significant peaks or elevation of the spectrum at high frequencies.

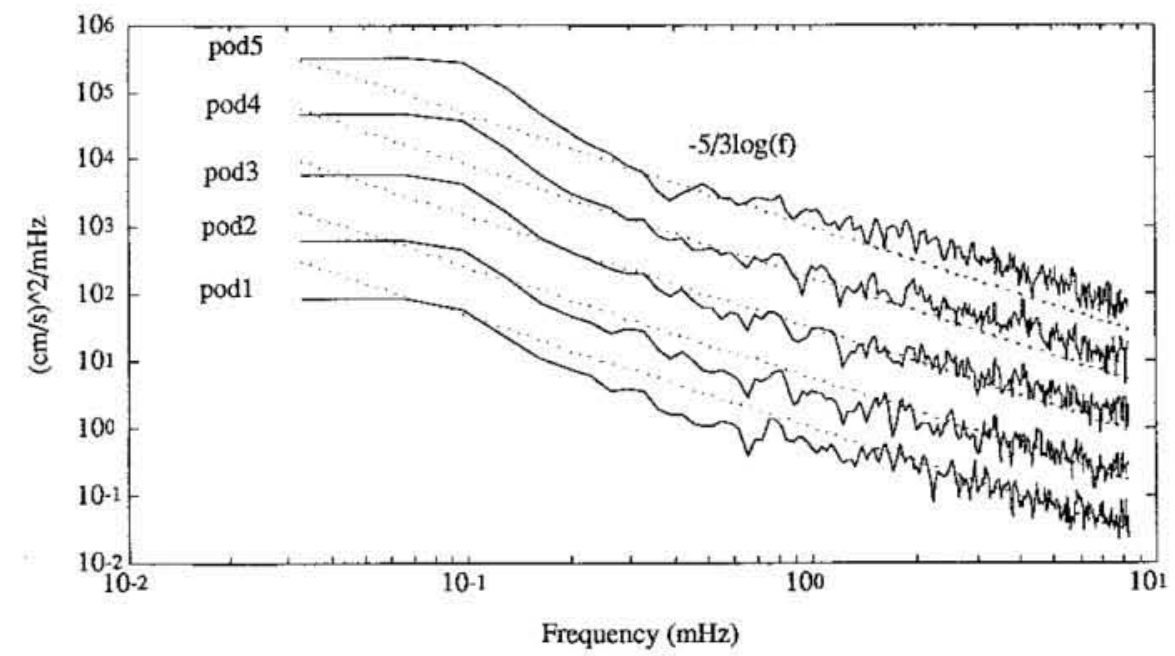

Figure 3.9: Power spectrum of horizontal velocity from BS3 during the first five days of the VENTS90 deployment at the southern Juan de Fuca ridge. The velocities were sampled at $2 \mathrm{~Hz}$, then averaged down to 1 sample per minute on the seafloor. The vertical scale refers to the spectrum of the bottom pod. All the others were given a vertical offset to separate them by $\log (10)$. The spectrum was constructed by averaging the squares of ten 512-point FFT's. More details about the spectra are presented in section 4.4 .

BASS recorded data using an Onset Tattle-Tale model VI computer (TT-VI) with a Conner 20MByte hard disk drive. BASS sent a block of 257 bytes of data to the TT-VI once each minute. The block contained average data for the minute (the average of 120 samples). The first six hexadecimal bytes in the data block represent date, hour and minute. This is followed by a six byte quality word. Each half-byte (nibble) of the quality word represents the performance of one of the six sensor pods over the 120 samples. When the hexadecimal nibble is converted to a four-bit binary representation, then each 
bit represents one axis in the pod. A "1" indicated that all 120 attempts by BASS to measure velocity were successful. " 0 " indicated that at least one of the acoustic pulse transmissions was not received. As an example, the quality word FF FD FF is translated to mean:

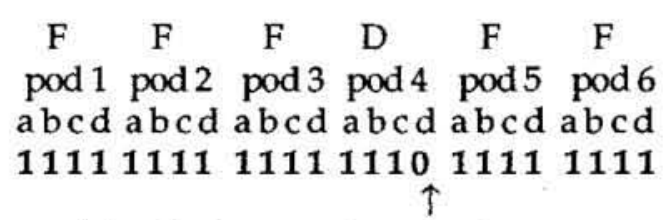

pod 4; axis d was not received

With this quality word, bad measurements could be sorted from good ones. In practice, bad quality words were extremely rare, and when they did occur, the measurement was usually still acceptable, since the quality word would be set to " 0 " if even one sample from 120 was not be received. The BASS sampling program was designed to average over only those samples which were good. If one sample (at $2 \mathrm{~Hz}$ ) was not received, then the 1minute average velocity was constructed from the 119 remaining samples, and the quality word for that pod was set to " 0 ".

Following the quality word were six sets of five two-byte words. Each set of five words consisted of the total travel-time measured in one pod, and the four velocity components along axes $\mathrm{a}, \mathrm{b}, \mathrm{c}$, and $\mathrm{d}$ for that pod (figure 3.10). Travel-time measurement will be discussed in the next chapter. The important point to mention here is that the travel-time was an average from all four axes in a pod. Unfortunately, this made the travel-time sensititive to the presence of even a single bad axis in a pod, since each travel-time measurement was the average of 120 samples of each of the four axes. If one axis gave a measurement which was incorrect, but not bad enoughto be detected by the quality word logic, the bad value contributed to one quarter of the average travel-time. This averaging was done to conserve data storage space.

Following the one-minute averages of velocity and travel-time were two-byte outputs from eight thermistors and two tilt-sensors. After this was a large block of cross-products of velocity and travel-time. The temperature was multiplied by each velocity component in turn. Each velocity component was multiplied with all axes within a pod to form a Reynolds stress tensor (Tennekes and Lumley, 1972). For each pod, there are fourteen two- 
byte cross-products. The last data byte stored in each one-minute output block was the compass heading.

The TT-VI logged six hours of one-minute samples from BASS on static RAM, then wrote the accumulated data to the hard-disk. Each time the hard disk was accessed, it had to be spun-up from rest. The motor to drive the disk required $2 \mathrm{~A}$ of current for $9 \mathrm{~s}$ to spin the disk up to its working speed. A single $12 \mathrm{~V}$ alkaline lantern battery provided power for the computer and disk drive.

The nominal capacity of the $12 \mathrm{~V}$ lantern batteries powering the TT-VI was $20 \mathrm{Ah}$ at $20^{\circ} \mathrm{C}$ (16Ah at $0^{\circ} \mathrm{C}$ from manufacturer's data). The disk was spun-up a total of 63 times from each battery. The power consumed was thus $0.4 \mathrm{Ah}$. The continuous drain on the batteries was $1.5 \mathrm{~mA}$ when the TT-VI was in sleep mode, resulting in $0.54 \mathrm{Ah}$ power consumption over the entire deployment. Total power taken from the battery should have been $0.94 \mathrm{Ah}$.

After recovery of BS3, I observed that two records were not written to disk (out of 63) on the last day of the deployment because the battery was unable to provide the $2 \mathrm{~A}$ current to spin-up the hard disk. Once the battery warmed up to ambient temperature on the deck of the Discoverer, it successfully wrote the final data record. The cold-temperature performance of the alkaline cells had been tested prior to deployment using fresh cells. Field performance of the BS3 battery was worse than observed in the lab. However, the battery for BS4 successfully supplied power to write all 63 data records, indicating that the problem lie in the $12 \mathrm{~V}$ battery or hard-disk on BS3. The rest of the power for the instruments was provided from a $22.5 \mathrm{~V}$ alkaline battery pack. Figure 3.10 shows a block diagram of the instrument systems onboard each BASS tripod.

The BASS tripods (BS3 and BS4) measured velocity profiles as well as turbulence properties, and temperature using two independent techniques (thermistors and acoustic travel-time). The four moorings (M1, M2, M5, M6) also measured temperature. The three temperature measurement techniques will be discussed in the next section. 


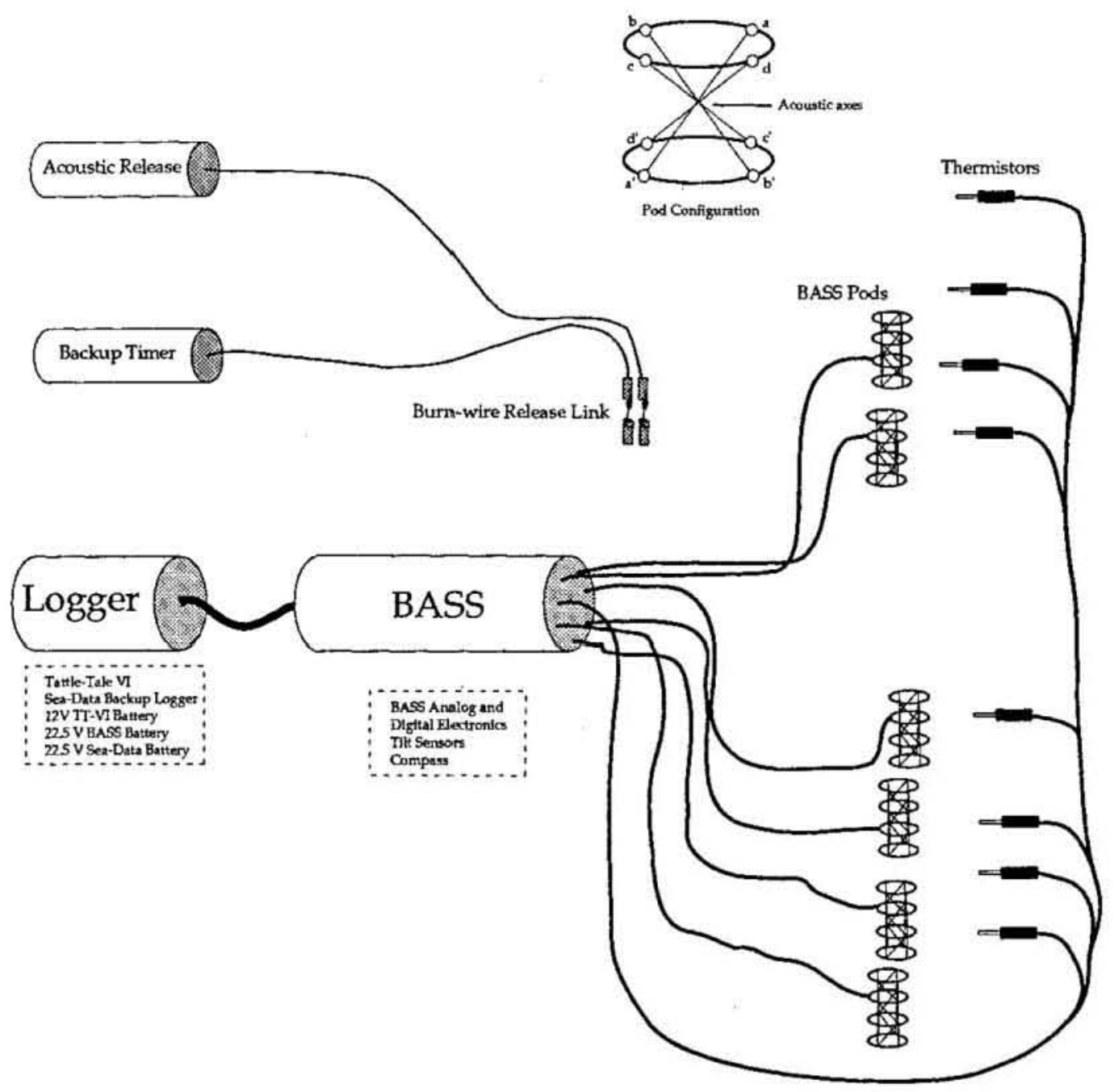

Figure 3.10: Schematic showing the instrument systems onboard each BASS tripod. Each of the pressure cases onboard a tripod is pictured here. The connections between pressure housings indicate the independence of the release system from the measurement system. Power was supplied for measurement and logging from three independent batteries housed in the logger case. The only electrical ground for the electronics was made in the BASS electronics case. 


\section{Measurement of Temperature}

I employed three sensing techniques to measure temperature in the VENTS90 experiment:

- metal clad thermistors on BASS tripods

- sound speed measurement in BASS

- internally recording thermistor packages (NOAA Miniature Temperature Recorders)

Each of these instruments was sensitive to temperature fluctuations smaller than 0.0005 ${ }^{\circ} \mathrm{C}$, with absolute accuracy of $0.005^{\circ} \mathrm{C}$. The detailed performance of each of the temperature sensors will be discussed in this section.

\section{BASS Metal Clad Thermistors}

Eight thermistors (YSI Inc. \#441005) were connected as ancillary sensors on each of the BASS tripods deployed during VENTS90. Six of them were taped to the BASS sensor pods, one was mounted at the top of the tripod, and one was mounted next to the BASS electronics housing. The range of measurement was from $0-32^{\circ} \mathrm{C}$, with the thermistor resistance measured in a Wheatstone bridge of precision (Vishay) resistors (Williams et al., 1987). A $2750 \Omega$ Vishay resistor in series with the thermistor linearized the output voltage around approximately $20^{\circ} \mathrm{C}$. Sensitivity over the range $\left(0-32^{\circ} \mathrm{C}\right)$ was $0.0005^{\circ} \mathrm{C} / \mathrm{bit}$. Figure 3.11 shows the result of pre-deployment calibration of all eight thermistors on both tripods BS3 and BS4.

Thermistors were housed in a stainless-steel sleeve with a small amount of heat-sink grease applied inside the tip. RG-316 cable (co-axial, teflon insulated with urethane jacket) was connected to the thermistor, and sealed by a molded urethane "hot-dog" around both the cable and the stainless steel sleeve. After the deployment, it was apparent that all of these molds had leaked at high pressure. Some of the thermistors survived for much of the deployment, but by recovery every one had failed. Those that did not completely short-circuit showed higher than normal noise levels ( figure 3.12). Dissection of one of these assemblies showed evidence of corrosion along the length of the copper conductors 
from the cable end of the hot-dog to the thermistor tip. This was confirmation that the failures were due to leakage of seawater.
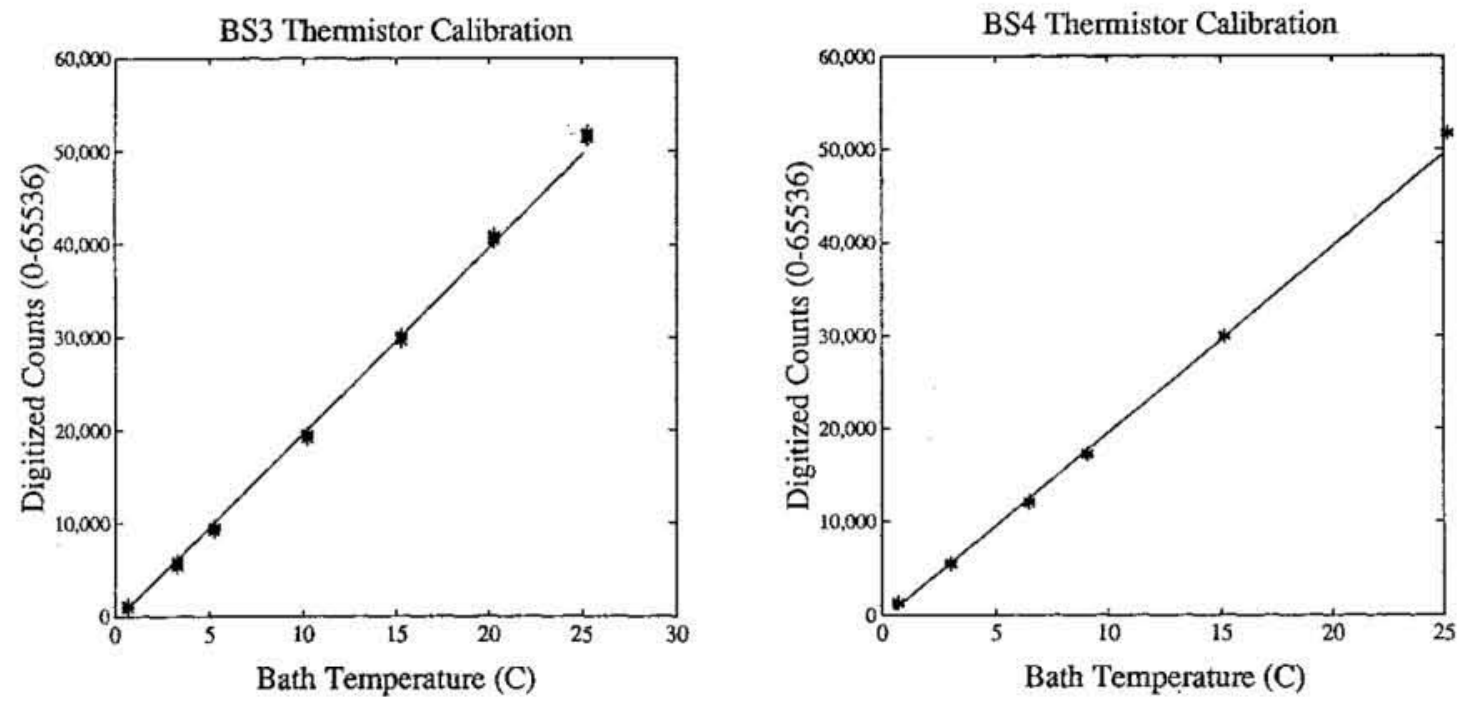

Figure 3.11: BASS thermistor calibration curves. The curves cannot be distinguished from each other over the entire range of calibration temperatures. The linearization of the output voltage (in digitized counts from 0-65536) is apparent in the figure (compare with the output from the non-linearized thermistors used in the MTR, figure 3.22). A post-cruise calibration over a narrower range would have been useful, but the thermistors all flooded before recovery.

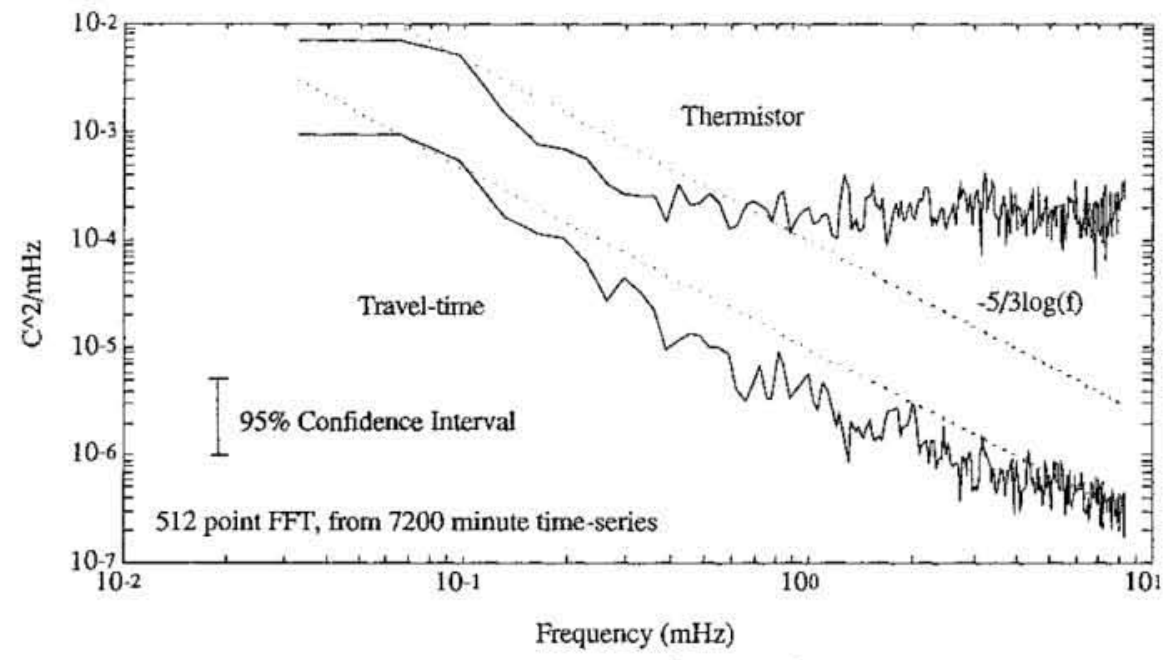

Figure 3.12 : Spectrum of a BASS thermistor prior to complete failure compared with a good measurement of temperature. The top spectrum is from a partially-flooded thermistor (BS4, pod 3) after the third day of the deployment. The spectrum has been offset vertically by multiplying the data by a factor of ten. The low-frequency appearance of the thermistor time-series was very similar to that of the the temperature estimate from acoustic travel-time (to be discussed in the next section). The bottom spectrum came from a reliable temperature record from the same time period and the same location. 
During the period when thermistors were functional, It was found that application of the calibration curves gave large inter-sensor offsets (on the order of $0.1-0.2^{\circ} \mathrm{C}$ ). The offsets were several orders of magnitude greater than any temperature gradients seen by other measurements in the same area (Baker, 1991). Figure 3.13 shows the temperature offsets between thermistor number 1 and the other thermistors during deployment. The temperature offset appeared to be constant during the drop below approximately $6^{\circ} \mathrm{C}$.

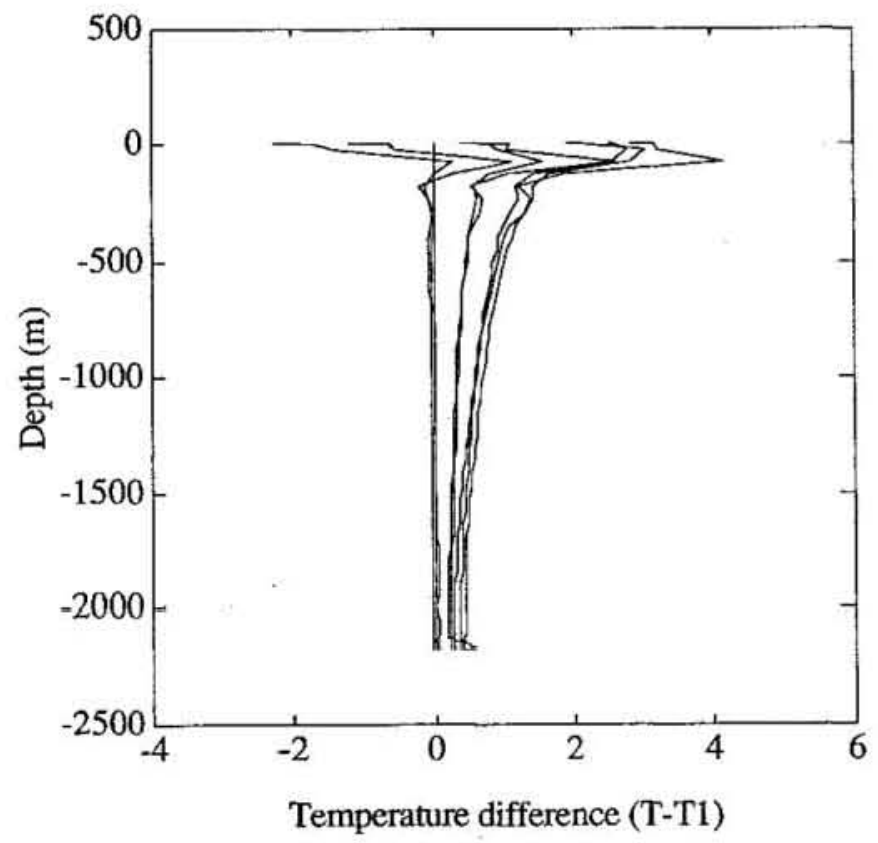

Figure 3.13 : Temperature measured by all thermistors on BS4 during its fall to the seafloor. The horizontal axis is measured temperature difference between thermistors (referenced to podl temp.) and the vertical axis is the log of the mean temperature, which decreases with depth from $20^{\circ} \mathrm{C}$ at the surface, to $2^{\circ} \mathrm{C}$ at the seafloor. It is clear that the offset between thermistors is constant at temperatures below $7^{\circ} \mathrm{C}$.

To correct the profiles, the offsets shown in this figure were subtracted from the thermistor output. An example of the uncorrected profile for BS4 is shown in figure 3.14. BS3 only had one working thermistor from the initial deployment, so no profiles were possible from its thermistors.

Justification for eliminating the offsets by subtracting the inter-thermistor difference can be found from two observations: The offsets were effectively constant over the entire data set; and Conductivity-Temperature-Depth (CTD) measurements by Baker (1991) show 
the background temperature gradient in the bottom $300 \mathrm{~m}$ of the water column to be on the order of $5 \times 10^{-5} \mathrm{o} \mathrm{C} / \mathrm{m}$. This would translate into a maximum difference between the top and bottom thermistor on a BASS tripod on the order of $0.00025^{\circ} \mathrm{C}$ when the tripod was not in the wake of a plume. This is less than the resolution of the 16-bit digitization of thermistors on BASS. Thus, the background temperature gradient should appear to be zero for the BASS thermistors.

Correction of the thermistor data by subtracting mean inter-sensor differences yielded reasonable temperature gradients $\left(0.003-0.005^{\circ} \mathrm{C} / 5 \mathrm{~m}\right.$ height $)$ during plume events when compared with other temperature sensors used in this experiment. This data will be presented in section 4.3 .

The alternate technique for measuring temperature on the tripods was through the measurement of sound-speed, and calculation of temperature fluctuations based on the equation of state for seawater. This technique will be discussed in the next section.

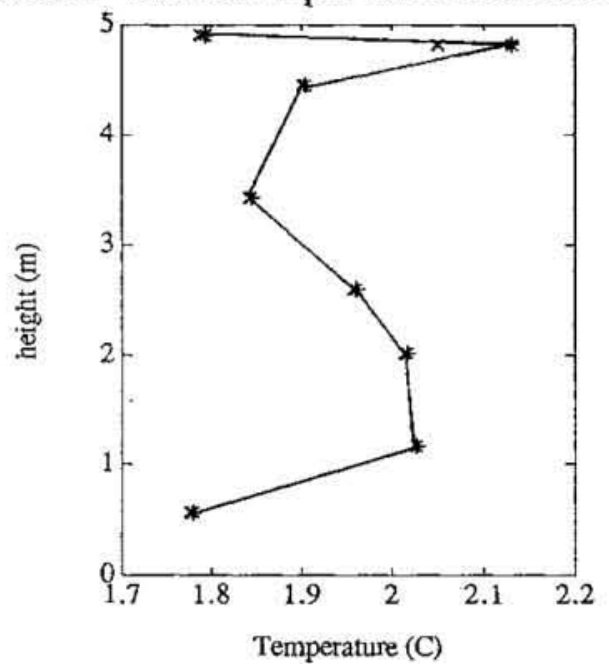

Figure 3.14 : Uncorrected mean temperature profile from BS4 averaged over the whole time it was on the seafloor. The temperature gradient observed by Baker $(1991)$ was $0.00025^{\circ} \mathrm{C}$ over the five-meter height shown in this figure. The offset between thermistors in the figure above is far to large to represent an environmental effect. This offset was also constant throughout the entire deployment.

\section{Temperature Estimation from BASS Sound Speed Measurement}

A sensor was needed which could monitor rapid changes in temperature in the same volume as velocity was measured by BASS, at the same time. Such a measurement would 
be ideal to use in calculation of convective heat flux. BASS already measured the difference in travel-time of sound transmitted in opposite directions. A simple way to obtain an appropriate estimate of temperature in a BASS pod was to modify BASS to measure the time for sound to traverse the $15 \mathrm{~cm}$ acoustic axes in each sensor pod. This estimate of speed-of-sound could be used as:

- an independent estimator for temperature through the sound speed equation, - a measure of temperature with very rapid time response,

- a temperature measurement that is correlated with velocity in space and time,

- an in-situ measure of sound-speed to be used in correction of velocity measurements.

The sound-speed equation relates the acoustic propagation speed $(\mathrm{c}, \mathrm{m} / \mathrm{s})$, to temperature $\left(\mathrm{T},{ }^{\circ} \mathrm{C}\right)$, pressure ( $\mathrm{z}$, expressed as depth in meters) and salinity $(\mathrm{S}, \mathrm{ppt})$ in seawater. A common example of this empirical relation can be found in Clay and Medwin (1977):

$$
c=1449.2+4.6 \mathrm{~T}-0.055 \mathrm{~T}^{2}+0.00029 \mathrm{~T}^{3}+(1.34-0.010 \mathrm{~T})(\mathrm{S}-35)+0.016 \mathrm{Z} .
$$

In VENTS90, I estimated temperature by solving the sound-speed equation for temperature, using the measured travel-time, path-length, and by assuming the depth and salinity were constant. The mean temperature was fit to the mean of the thermistor temperatures. Figure 3.15 shows a comparison between two time series of temperature estimates from the same pod on BS4. The magnitude of the temperature excursions is very similar for both methods of temperature measurement. There is no significant drift between the two temperature measurements over the full deployment.

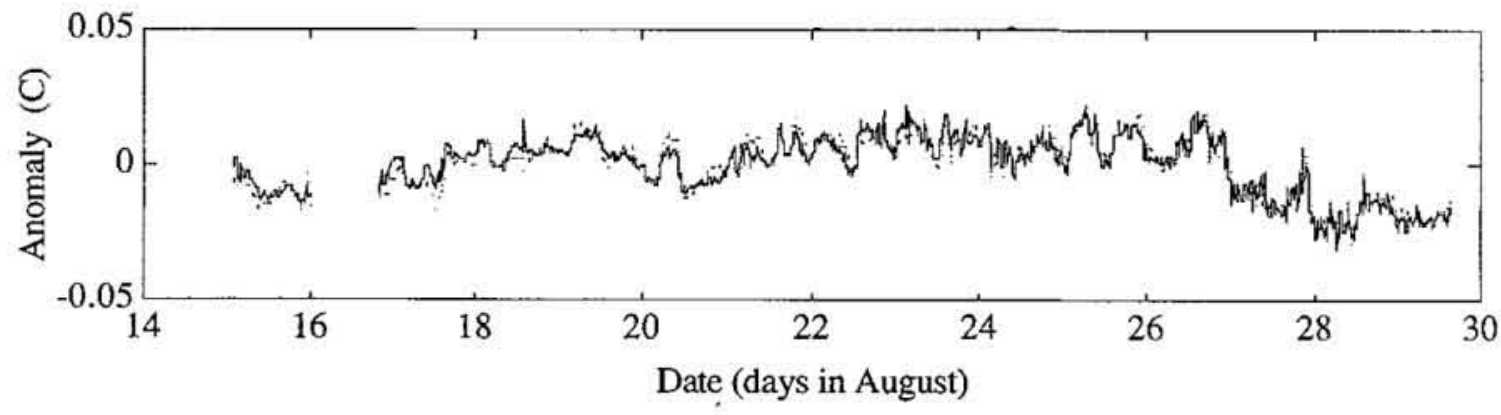

Figure 3.15: Comparison between BS4 thermistor and travel-time estimates of temperature. The solid line is the temperature from the thermistor at pod4. The dotted line is the temperature estimated by solving the sound-speed equation using travel-time information from pod 4 . The gap in the time-series on August 16 was due to the instrument surfacing prematurely, and having to be re-deployed. 
Figure 3.16 presents an analogous plot from BS3. There is a long-term oscillation producing a different temperature estimate from the two sensing techniques.

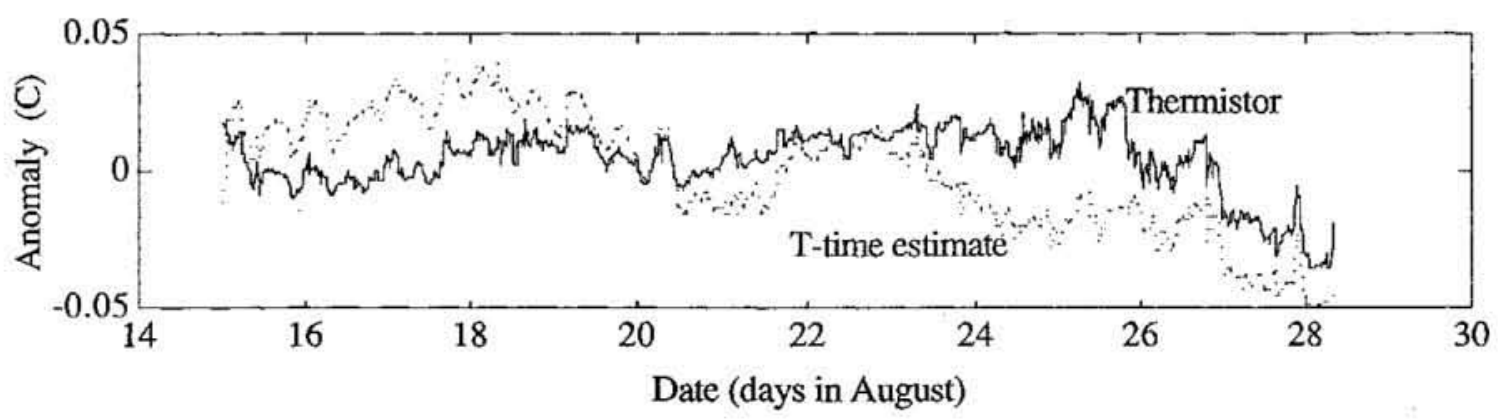

Figure 3.16 : Comparison between BS3 thermistor and travel-time estimate of temperature. The solid line is the temperature from the thermistor at pod5. The dotted line is the temperature estimated by solving the sound-speed equation using travel-time information from pod5, and assuming the salinity and pressure were constant.

It is possible that this long-term oscillation was due to salinity variations in either the bottom water, or the hydrothermal vent fluid. Figure 3.17 shows the hypothetical salinity fluctuation neccessary to produce the discrepancy shown in figure 3.16. One difficulty with this interpretation is that salinity does not seem to be correlated with temperature over the long-term. It is correlated with flow direction, since the beginning of the VENTS90 deployment showed southward flow, and the last several days showed northward.

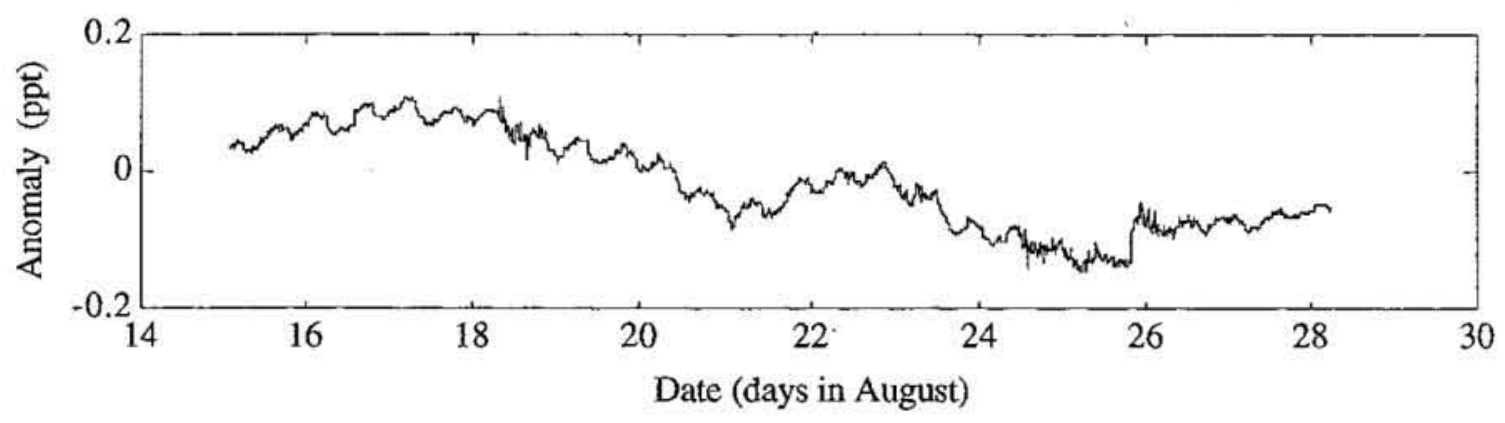

Figure 3.17 : Salinity Variation needed to produce offsets between BS3 thermistor and travel-time temperature estimates. The salinity anomaly was solved by solving for $S$ in equation 3.2 . This variation was low-pass filtered (as shown in the figure), and the result was used in calculation of a corrected temperature based on equation 3.2 . 
Removing this salinity variation from the temperature estimate of travel-time results in excellent agreement between the temperatures on BS3 and BS4. Figure 3.18 shows the relationship between the thermistor temperature measurements and the temperature estimated from sound-speed measurements using equation 3.2. The standard deviation was $0.0018-.0032^{\circ} \mathrm{C}$ (the lower value comes from BS4, the higher from BS3 without correction for salinity fluctuations) with the range of scatter on the order of $0.010^{\circ} \mathrm{C}$.

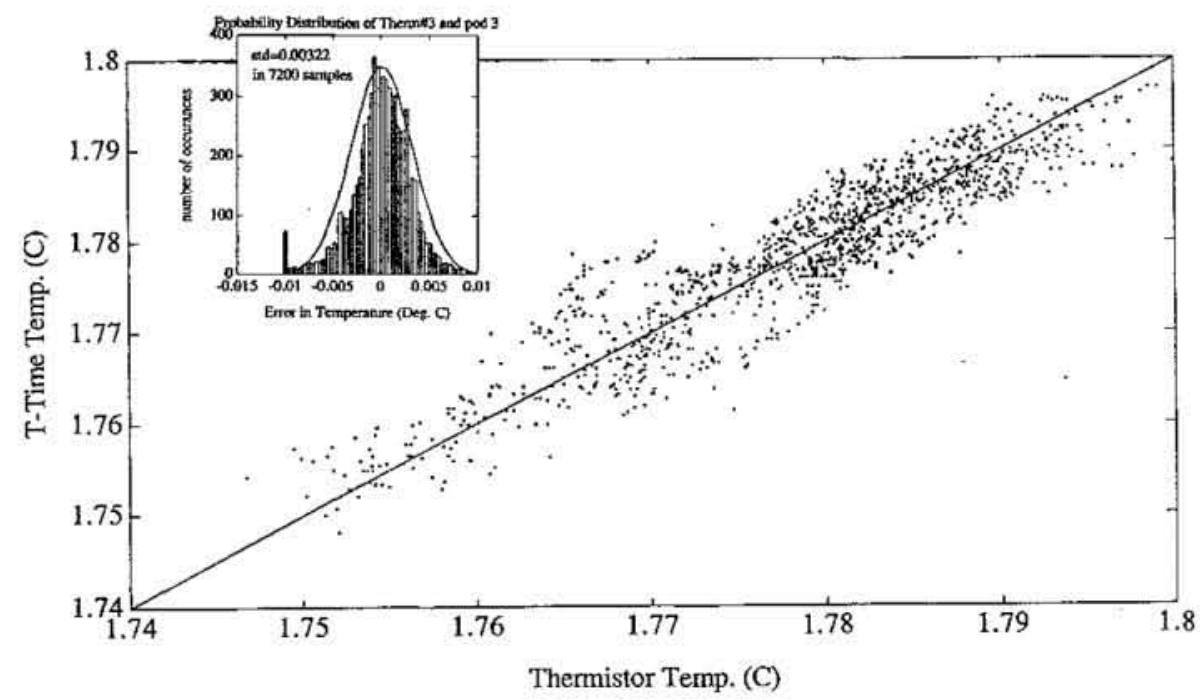

Figure 3.18: Correlation between BS4 thermistor and travel-time estimates of temperature for the entire VENTS 90 deployment. The data is from pod4; the only pod to have remained working until the last day of the deployment.

Fluctuations in pressure due to tides could account for the remaining noise in temperature estimates from sound speed. Pressure fluctuations on the order of $1.4 \mathrm{~m}$ of water could result in apparent $0.005^{\circ} \mathrm{C}$ temperature fluctuations. Fox (1990) recorded tidal pressure fluctuations using a bottom pressure recorder deployed near the site of my array of instruments on the southern Juan de Fuca ridge. The peak-to-peak pressure oscillation due to tides was $3 \mathrm{psi}$. This corresponded to $2 \mathrm{~m}$ of peak-to-peak change in depth. Thus, the fluctuations shown in figures 3.15-3.17 having 12.5-hour periods are probably due to tidal forcing.

Without making any correction for tidal pressure fluctuations, the performance of my estimate of temperature anomaly from speed-of-sound measurement is accurate to better 
than $\pm 0.005^{\circ} \mathrm{C}$. However, the temperature estimate based on travel-time was not useful for measuring mean temperatures, since there was no absolute calibration of sound speed, nor were there simultaneous, independent measurements made of salinity or temperature .

\section{Implementation of Travel-Time Measurement in BASS}

BASS was modified to make the measurement of acoustic travel-time in each sensor pod. It originally measured only the difference in sound transmitted in opposite directions. I designed and built electronics which fit within the existing BASS instrument rack, and which was used with minimal change to the BASS controller software. The technical implementation of this modification will be described in this section.

BASS can be divided into conceptual blocks as shown in figure 3.19. An RCA 1802 micro-processor orchestrates events by acting out a programmed cycle of activities, and by responding to interrupt signals. The 1802 initiates a transmit pulse from one of the acoustic transducer pairs, then a hardware counter waits a pre-determined number of clock cycles before the listening circuit is unclamped in preparation for receiving a pulse.

To make a measurement of velocity in BASS, a counter tests for the reception of the 14th zero crossing of the $1.75 \mathrm{MHz}$ acoustic pulse, and upon reception toggles a logic line to steer a constant current source, which begins to charge an integrating capacitor. When the acoustic pulse travelling in the opposite direction is received, a twin circuit does the same thing. After the second arrival (plus an added wait period for both capacitors), both current sources are steered away from the capacitors, and the voltages on these integrating capacitors are compared. The difference in voltage is proportional to the difference in travel-time in one direction versus the other. The resulting voltage is amplified and digitized using a 16-bit A/D (Williams et al., 1987).

This method of time interval measurement can detect delays as small as $40 \times 10^{-12} \mathrm{~s}$ reliably. This hardware implementation never measures any property of the total time taken for sound to travel from one transducer to another, since the absolute travel-times are differenced by analog electronics. Additional electronics were needed to measure the absolute acoustic travel-time. 


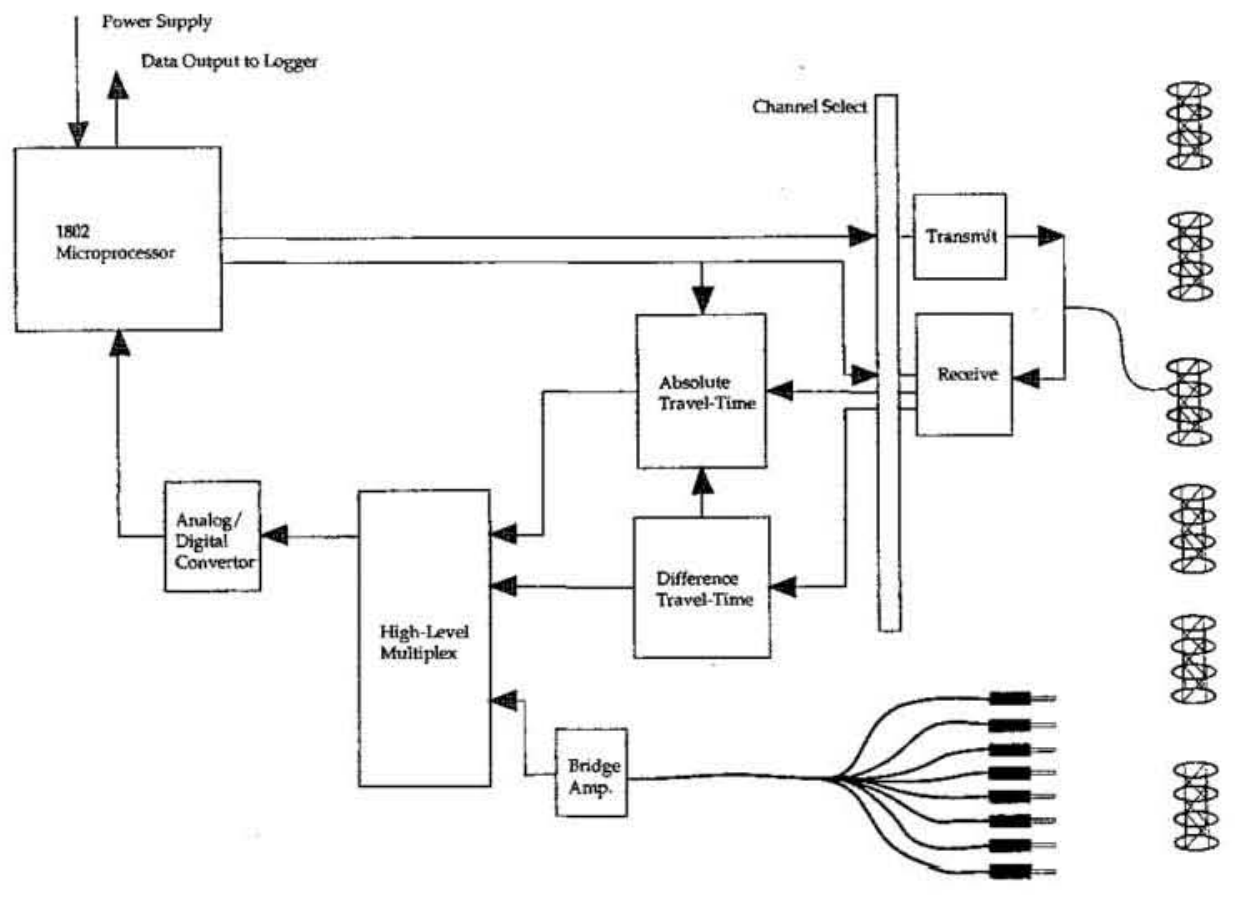

Figure 3.19 : Block diagram of the BASS measurement electronics showing major analog and digital components. The 1802 microprocessor orchestrates the measurements, and performs calculations on the data. The Channel Select card decodes a command indicating which sensor pod to use. The transmit and receive electronics gate a $1.75 \mathrm{MHz}$ signal to the transducers, and detect the received pulse. The Absolute and Difference travel-time cards work in parallel measuring time intervals based on the received signals, and clock pulses from the 1802. The high-level Multiplexor selects between thermistors, difference traveltime, or absolute travel-time. The Analog/Digital convertor interprets a voltage signal as a 16-bit binary word.

I opted to measure absolute travel-time using an identical analog technique, with the only changes being the selection of signals to trigger the integrating capacitor, and the time constant of integration. The signal which triggers time integration is the same one which arms the receiver circuit. This action is done on the precise timing of the micro-processor 
clock. The integrating capacitor is charged until pulses have been received from both directions. The range of time between pulse transmission and reception is on the order of 92.5-108 $\mu$ s. The "unclamp receiver" signal occurs $92.5 \mu$ s after pulse transmission. By starting measurement from this point, resolutions in travel-time on the order of 230ps are achieved (16-bit measurement of $15.5 \mu$ s maximum interval).

A diagram of the analog circuit which converts the time delay to a voltage is presented in figure 3.21. I tuned the circuit to a slightly higher gain in $\mathrm{V} / \mathrm{ns}$ than suggested above (figure 3.20). By adjusting potentiometers to vary the reference voltage on the output comparator, and by adjusting the output of the current source, the travel-time corresponding to 0 counts ( -5 Volts) was adjusted to an appropriate range based on calculations of the expected sound speed. The Volts/nanosecond gain was measured with a delay-line (Canberra model 2058, with .5 to 32 ns delay lines) which was connected between the "both channels received" signal and the absolute travel-time circuit.

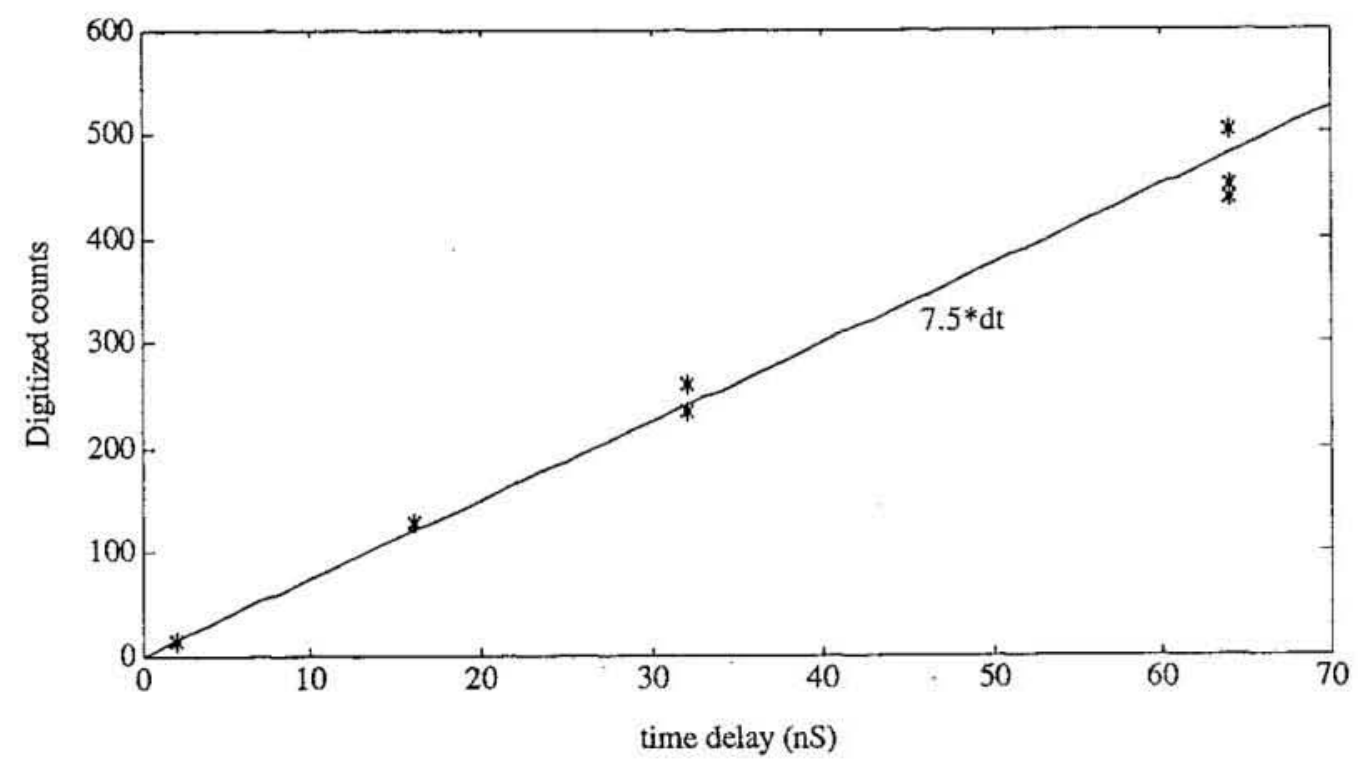

Figure 3.20: Gain of travel-time measurement circuit measured using a pair of switched delay-lines (Canberra model 2058) 


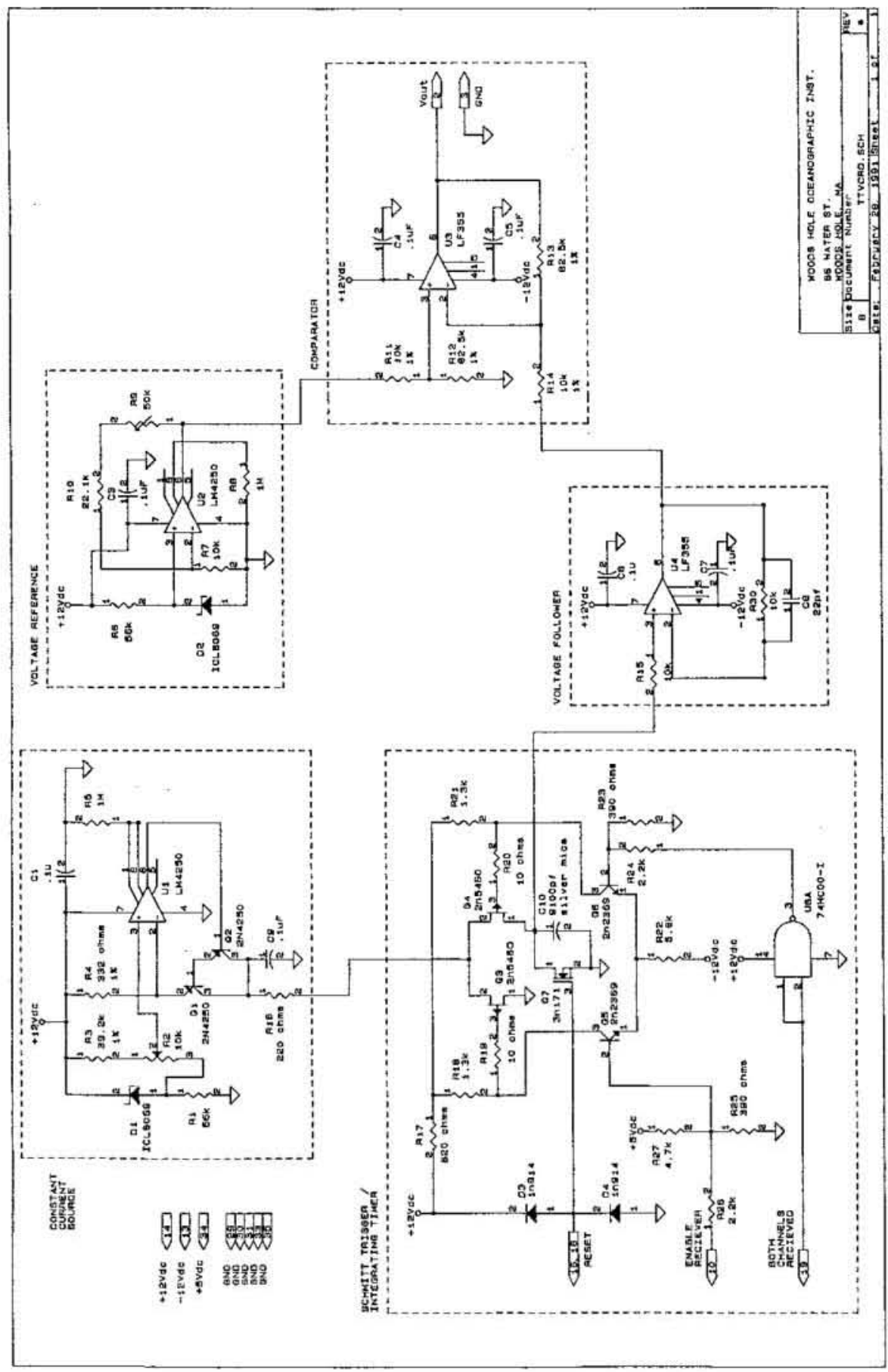

Figure 3.21 : Travel-time measurement circuit: as built in BS3 and BS4. The dashed boxes delineate five functional blocks of the analog time-measurement circuit. clockwise from left are: a constant current source for supplying current to the integrating capacitor, a voltage reference for the final stage of amplification and inverting the time-measurement, the comparator to invert the measured travel-time and adjust its zero-level, a voltage follower to detect the integrating capacitor voltage, a Schmitt trigger to steer the constant current supply to the integrating capacitor when at the appropriate timing signal (Enable Receiver steers current to integrating capacitor, Both Channels Received steers current to ground, and reset discharges capacitor voltage between measurements) 
A concern during testing of the travel-time measurement circuit was the sensitivity of the output to electronics temperature. The BASS electronics rack was moved from a $20^{\circ} \mathrm{C}$ room to a cold chamber kept at $2^{\circ} \mathrm{C}$ to observe the effect on output. After a series of modifications, it was determined that the electronics drifted by less than 80 bits for the step change from room temperature $\left(20^{\circ} \mathrm{C}\right)$ to $2^{\circ} \mathrm{C}\left(<0.0022^{\circ} \mathrm{C} /{ }^{\circ} \mathrm{C}\right.$ change in electronics temp.). The resulting travel time measurements were very stable over the entire VENTS90 deployment (figure 3.15).

\section{NOAA Miniature Temperature Recorders}

A newly developed temperature sensor built by the Engineering group at the National Oceanic and Atmospheric Administration Pacific Marine Environmental Laboratory (Milburn and McLain, 1990) was choșen as a small, inexpensive temperature sensor for the VENTS90 deployment.

The "Miniature Temperature Recorder", or MTR contains a YSI \#46006 thermistor inside a small titanium pressure housing. Within the pressure case is a complete measurement circuit with a $68 \mathrm{HC} 11$ microprocessor and 118.8 kilobytes of static RAM data storage. The instrument is powered for up to one year by two lithium 'AA' batteries, and a backup lithium cell for protection of the stored data and system software. Communications interface to the MTR is achieved by unscrewing the end-cap from the housing and connecting an RS-232 serial communications cable to the electronics (Milburn and McLain, 1990).

The MTR's cannot be linked together, so each must run according to its own internal clock. A source of error for sensors running on independent time bases is that samples can get out of synchronization. The sample interval of 3.75 minutes in this deployment gave a very comfortable cushion against synchronization errors. The instruments were initialized manually by watching the clock ticks on a common time reference. The accuracy of this sort of initialization was on the order of a few seconds.

The MTR versions used in VENTS90 were designed with a simple software clock which has subsequently proven to be relatively inaccurate. Due to a problem with the design of the data interface, I was only successful testing clock drift of two MTR's before and after the 
VENTS90 deployment. These two drifted by 1.4 and 0.7 minutes per month, respectively (drift less than 1:30,000). The maximum sample interval for the MTR is 3.75 minutes.

Cross-correlations were done between MTR's mounted on the same mooring, and no significant peak was observed to indicate any of the sensors were measurably out of synchronization. Thus, for a one-month deployment, clock drift was acceptable. It quickly becomes intolerable with longer deployments. Subsequent versions of the MTR incorporate an inexpensive hardware clock.

Temperature calibration of all the MTR's was performed by W.H. Horn at the WHOI calibration facility. A plot of the results of pre- and post-cruise calibration runs is shown in figure 3.22 . The pre-cruise calibration was done simultaneously with the BASS thermistors in the bath to get reasonable inter-calibration between the MTR moorings and the BASS tripods.

Just as with BASS thermistors, the temperature profiles estimated using only calibration data did not produce reasonable background profiles. Using the same logic as for the BASS thermistors, the mean inter-thermistor offset was subtracted from the data set. A sample of the resulting temperature profiles is shown in figure 3.23.
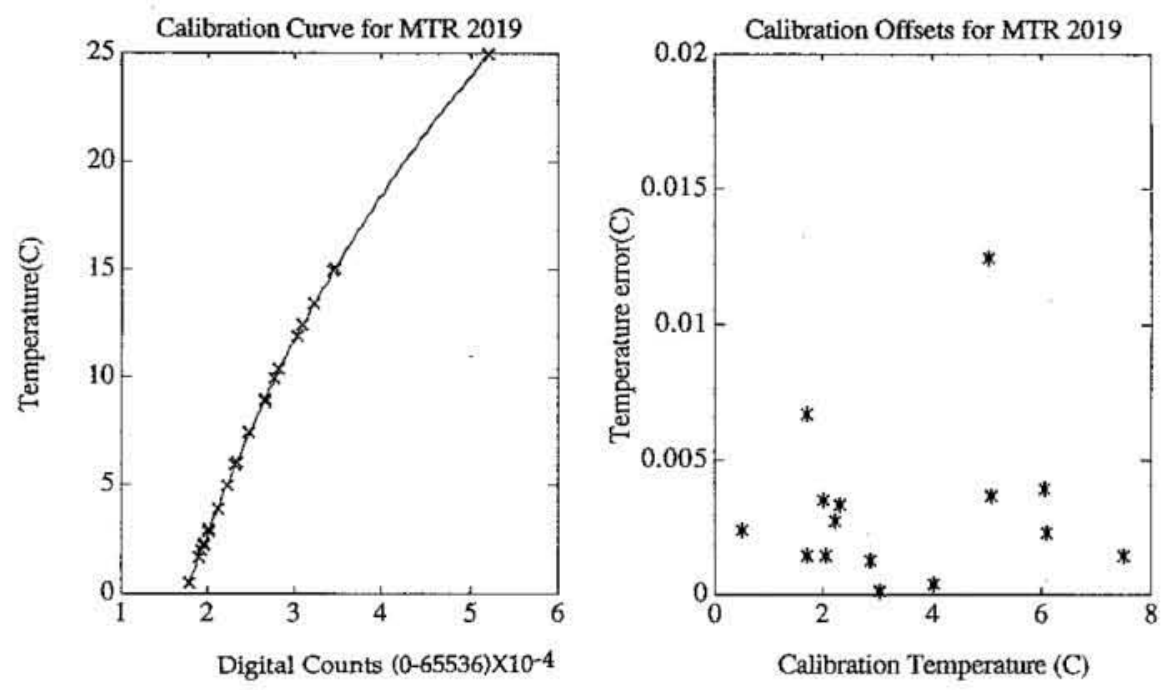

Figure 3.22: Calibration curve for MTR \#2019, representative of curves for all MTR's. The graph on the left is the calibration data with a calibration curve fit to the data points (the SteinhartHart equation, YSI Precision Thermistor guide, 1990). The graph on the right is the difference between the fitted curve and the calibration data points. This shows the error to be independent of temperature over the temperature ranges of interest. 


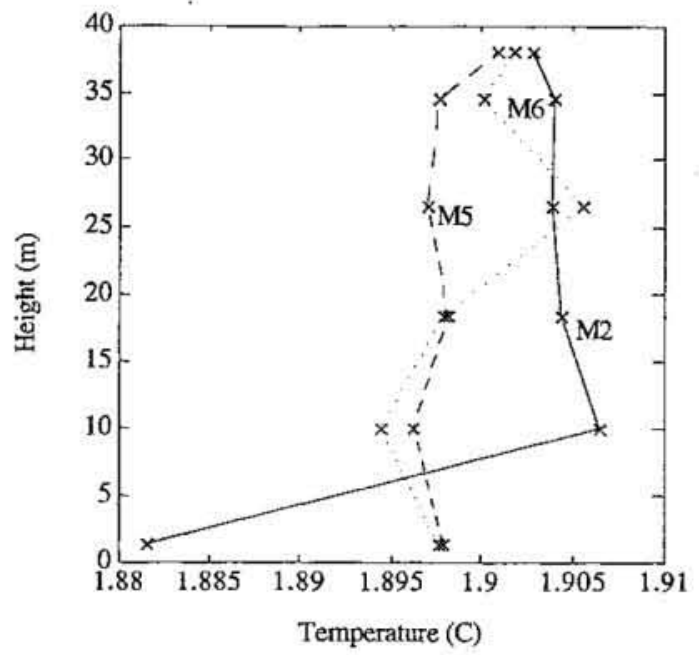

Figure 3.23 : Uncorrected temperature profiles from the MTR moorings. The solid line represents M2, the dashed line is M5, and the dotted line is M6. The background temperature gradient (Baker, 1991) was estimated from CTD casts to be $0.0022^{\circ} \mathrm{C}$ over the height of the mooring $\left(0.00005^{\circ} \mathrm{C} / \mathrm{m}\right)$. Such a small background gradient would not have been detected. Thus, the mean offsets shown in this plot were subtracted from the data set to make the corrected mean profiles constant with height.

The MTR's were deployed on $50 \mathrm{~m}$ tall moorings as shown in figure 3.24 . Three 17 inch Benthos glass floats at the top of each mooring provided buoyancy. The strength member for each mooring was $5 / 8$ inch braided nylon line. The anchor was approximately 100-200 lbs of steamer chain connected to the mooring through an acoustic release latch made by Oceanographic Instrument Systems of North Falmouth,MA. Six MTR's were attached to the mooring at equally spaced intervals from 1 to 45 meters above the release latch.
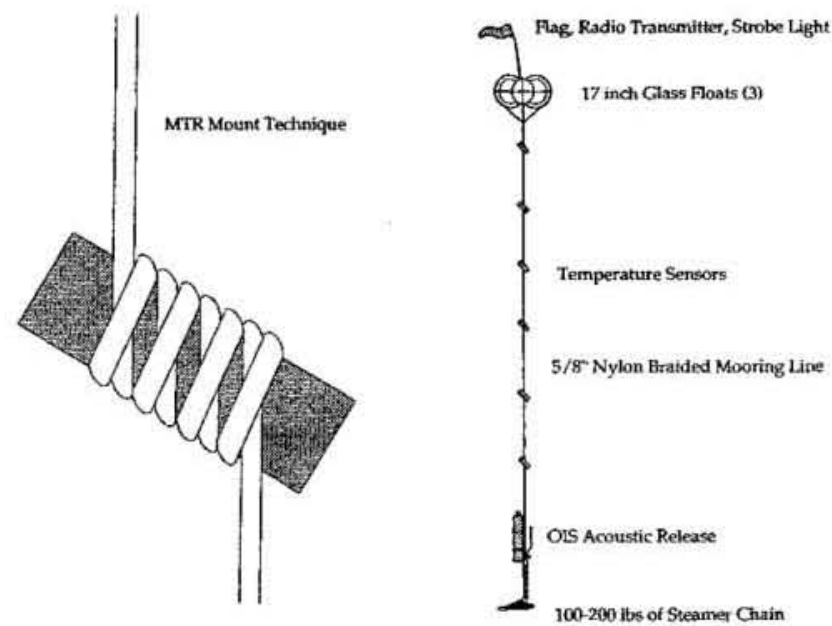

Figure 3.24 : Profile of one MTR thermistor mooring. The sketch on the left shows the way in which the MTR's were tied to the mooring line. Five half-hitch knots were snugged around each MTR on the mooring. The sketch on the right shows a profile of the assembled mooring. 
Attaching the MTR's to the mooring line was a challenge. They were not designed with any clamp or holder attachments. The smooth cylinders had to be exposed to water without any insulating material to slow their time response. I wrapped the mooring line in self-vulcanizing tape ( $3 \mathrm{M} \# 23$ black tape), and then tied five half-hitches around each MTR with the mooring line. The tape provided enough adhesion that the MTR did not slip when the line was slack. When tension was applied, the knot tightened around the MTR, holding it in place. The five half-hitches held the MTR at an angle which kept sharp corners of it away from the mooring line, thus preventing chafe on the line. The tape was extended far enough above and below the MTR to prevent stress concentrations on the line fibres, and to provide some small measure of chafe resistance. Fishing net was stitched and taped around each MTR to act as a backup in case the MTR were to slip out of the knot during deployment. All moorings were inspected closely after recovery, and none showed any evidence of chafe near the MTR's. No MTR's were lost from the three recovered moorings.

Each of the three independent ways of measuring temperature showed different quirks. The BASS thermistors flooded before the end of the deployment. The travel-time measurements were stable over the full deployment, but when temperature was estimated based on travel time, there was no direct way of finding the constant temperature offset without simultaneous thermistor data (which was available). The travel-time also included pressure and salinity effects, but it was possible to filter them out of the temperature signal since the pressure fluctuations were tidal, and salinity fluctuation seemed to have a two-week period. The MTR's suffered from clock drift, which was not a problem in the VENTS90 deployment, and from a program error which stopped data logging three days into the deployment. Despite the difficulties with each of the sensors, the redundancy that I designed into the VENTS 90 instrument array facilitated observation of diffuse hydrothermal flow.

There were other measurements made by BASS which helped to interpret the temperature and velocity data. I will describe these ancillary measurements in the remaining pages of this section. 


\section{Turbulent Heat Diffusion Measurements}

The primary goal of VENTS90 was to monitor the heat output from diffuse hydrothermal venting. Convective heat flux is broken into two parts; the mean transport represented by the average velocity and temperature of flowing water (over some arbitrary time scale), and the diffusion of heat due to turbulence or conduction. This is analogous to a patch of dye which is being carried along in a flow, and as it moves, it also spreads. The rate at which the center of the patch goes by is like the mean heat advection, while the rate at which the patch spreads out is like the heat diffusion. Measurements of mean velocity and temperature which have been discussed in detail already are suitable for calculation of the mean heat advection. I will present the details of an in situ estimate of heat diffusion in this sub-section.

Tennekes and Lumley (1972) define the heat diffusion per unit area and unit time in a turbulent flow as:

$$
Q_{j}=\rho c_{p}\left(\overline{\theta u_{j}}-\gamma \frac{\delta \Theta}{\delta x_{j}}\right) .
$$

The overbar represents a time averaged quantity. The symbols used in 3.3 and in the rest of this sub-section are summarized in table 3.4.

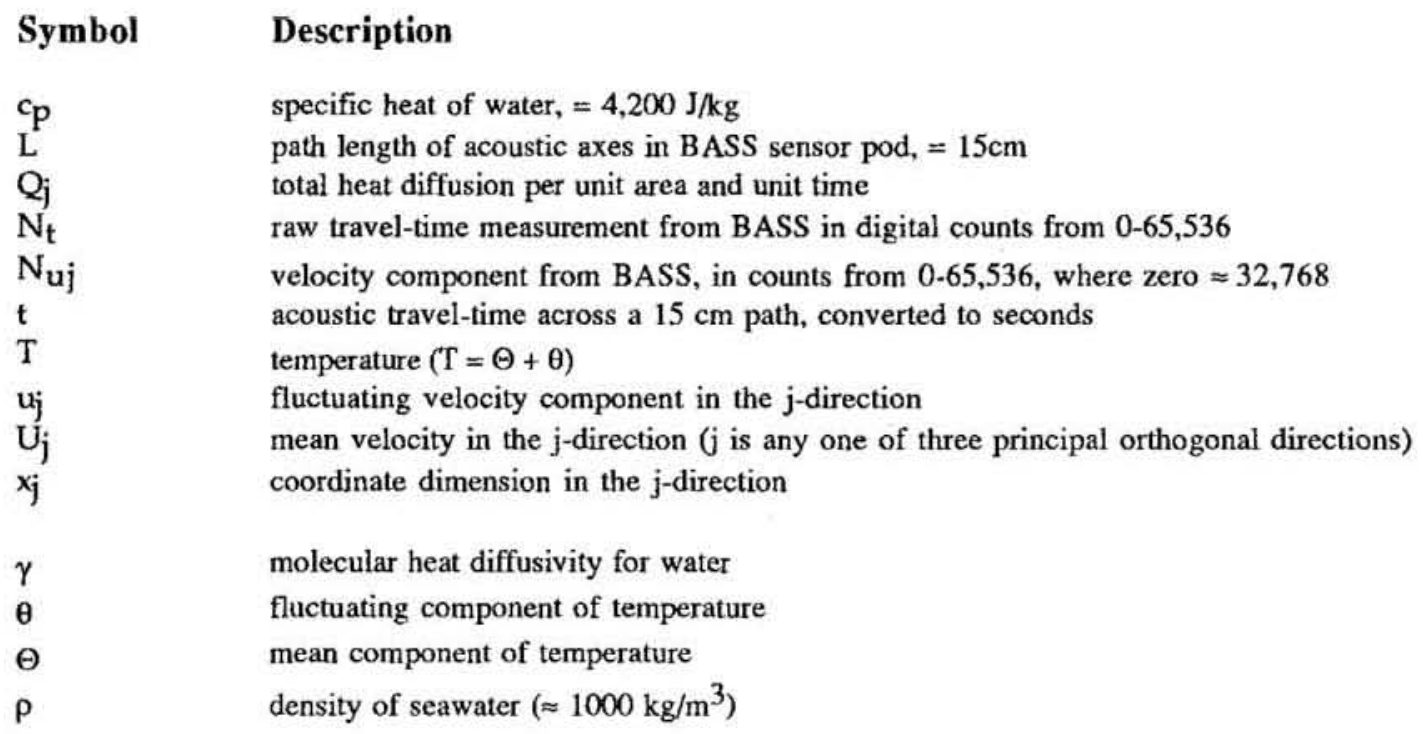

Table 2.1: Definition of symbols used in the remainder of this section 
To estimate $Q_{j}$, BASS performed in-situ calculation of the product $\overline{\left(U_{j}+u_{j}\right) T}$ from $2 \mathrm{~Hz}$ samples, and summed the result over one minute. At the end of each one-minute average period, the product of the mean $U$ and $\Theta$ measurements was subtracted from the $\overline{U_{j} T}$, producing the first term in equation 3.3:

$$
\overline{u_{j} \theta}=\overline{\left(U_{j}+u_{j}\right) T}-U_{j} \Theta .
$$

When the turbulent heat transport calculation was implemented in BASS, the digitized output in counts were proportional to the travel-time through the $15 \mathrm{~cm}$ BASS sensor pod. A close look at the scaling required to obtain heat flux in physical units is warranted.

Replacing depth and salinity in the sound-speed equation (equation 3.2) with approximate field values gives:

$$
\begin{gathered}
\frac{\mathrm{L}}{\mathrm{t}}=1449.2+4.6 \mathrm{~T}-0.055 \mathrm{~T}^{2}+0.00029 \mathrm{~T}^{3}+\left(1.34-0.010\left(\sim 2^{\circ} \mathrm{C}\right)\right)(34.611-35) \\
+.016(2250 \mathrm{~m})
\end{gathered}
$$

The linearized form of equation 3.5 is:

$$
\frac{\mathrm{L}}{\mathrm{t}} \approx 1484.6+4.6 \mathrm{~T} \text {. }
$$

Replacing $\mathrm{t}$, the acoustic travel time, with $\mathrm{N}_{\mathrm{t}}$, the travel-time measurement in digital counts leads to:

$$
\frac{\mathrm{L}}{103.175 \times 10^{-6}-140 \times 10^{-12} \mathrm{~N}_{\mathrm{t}}} \approx 1484.6+4.6 \mathrm{~T} \text {. }
$$

Simplifying gives:

$$
\mathrm{T} \approx \frac{316.1}{1-1.375 \times 10^{-6} \mathrm{~N}_{\mathrm{t}}}-322.76
$$

A linear expansion of this expression (since $N_{t}<65,536,1.375 \times 10^{-6} N_{t}<<1$ ) results in: 
The velocity measurement in BASS is related to the output counts via:

$$
\mathrm{U}_{\mathrm{j}} \approx 3.91 \times 10^{-3} \mathrm{~N}_{\mathrm{uj}}-128 \mathrm{~cm} / \mathrm{s} \text {. }
$$

Therefore, The product of $\mathrm{N}_{t}$ and $\mathrm{N}_{\mathrm{uj}}$ is:

$$
\overline{\theta_{u j}}=\overline{T U_{j}}-\Theta \overline{U_{j}}=1.70 \times 10^{-8}\left(\overline{N_{t} N_{u j}}-\overline{N_{t}} \overline{N_{u j}}\right)^{\circ} \mathrm{C} \cdot \mathrm{m} / \mathrm{s}
$$

Thus, the turbulent heat diffusion from equation 3.3 is:

$$
Q_{j, T}=\rho c_{p} 1.70 \times 10^{-8}\left(\overline{N_{t} N_{u j}}-\overline{N_{t}} \overline{N_{u j}}\right) \mathrm{W} / \mathrm{m}^{2}
$$

If I assume $\rho c_{p}=4.2 \times 10^{6} \mathrm{~J} / \mathrm{m}^{3}{ }^{\circ} \mathrm{C}$, the order of magnitude of the measured estimate of $\left(\overline{N_{t} N_{u j}}-\overline{N_{t}} \overline{N_{u j}}\right)=8$ counts, indicating the turbulent heat flux was $0.6 \mathrm{~W} / \mathrm{m}^{2}$. For comparison, the molecular diffusion term in equation 3.3 is :

$$
Q_{j, m}=-\rho c_{p} \gamma \frac{\delta \Theta}{\delta x_{j}}=-k \frac{\Delta \Theta}{\Delta x_{j}} .
$$

Temperature gradients on the order of $0.0001^{\circ} \mathrm{C} / \mathrm{m}$ were observed (Baker (1991) quotes $5 \times 10^{-}$ $5 \mathrm{o} \mathrm{C} / \mathrm{m}$ from CTD casts). I assume $\rho c_{p} \gamma=0.6 \mathrm{~W} / \mathrm{m}^{\circ} \mathrm{C}^{-1}$. The conductive heat transfer is on the order of $6 \times 10^{-5} \mathrm{~W} / \mathrm{m}^{2}$. Turbulent heat diffusion is thus much more significant than molecular diffusion.

The magnitude of turbulent heat flux was very small. One count corresponds to 0.07 $\mathrm{W} / \mathrm{m}^{2}$. Since this estimate comes from the product of the velocity and temperature measurements, the resolution limit is determined by resolution of those two measures. Increasing the gain of the heat flux calculation by multiplying by a constant before the averaging process would only have served to amplify digitization noise, not increase the resolution of turbulent heat diffusion. Despite its poor resolution, the heat diffusion measurements revealed interesting information about the diffuse hydrothermal plume. The measurements were compared to turbulence measurements made by BASS at the same 
time. The turbulence measurements have already been discussed in the literature (for example, Gross, Williams and Grant, 1986). I will briefly describe BASS measurements of turbulence in the next sub-section.

\section{Measurements of Turbulence using BASS}

BASS calculates turbulent Reynolds' stresses in situ (Gross, Williams and Grant, 1986). This calculation is made by multiplying each velocity axis with itself, and with every other axis in a pod each time a measurement is made (twice per second). The products are summed for 120 samples (one minute), then divided by the number of good samples. The product of the mean velocities averaged over the same period is subtracted from the total, and the result is stored as a two-byte value. This is denoted as;

$$
\overline{U_{i}^{\prime} U_{j}^{\prime}}=\overline{U_{i} U_{j}}-\overline{U_{i}} \overline{U_{j}},
$$

where $i, j$ denote axes $a, b, c, d$. The overbar denotes a quantity averaged over 120 samples. The resulting data is a filtered estimate of the turbulent Reynolds stress as defined by Monin and Yaglom (1971).

A discussion of this calculation is covered by Tochko (1979), and deep-sea measurements are presented by Grant et al. (1984), Gross et al. (1986), and by Williams et al. (1987). The measurements of Reynolds stresses during VENTS 90 were made using the same technique as discussed in the above references. The magnitudes were small (less than $\left.0.005 \mathrm{~cm} / \mathrm{s}^{2}\right)$ due to the small mean current $(1-4 \mathrm{~cm} / \mathrm{s})$.

\section{Ancillary Measurements}

BASS incorporates some necessary ancillary sensors. A compass is housed in the main pressure case to record the orientation of the tripod with respect to earth coordinates. The compasses were the same as used in the VMCM (Vector Measuring Current Meter), and have $3^{\circ}$ resolution. Data from the compass is stored as a one-byte word in the data record. 
Humphrey potentiometric tilt sensors were used to measure pitch and roll referenced to the BASS electronics rack. The range of these were $\pm 45^{\circ}$ from vertical, and the voltage output was digitized using the same 16-bit A/D as used for all other measurements in BASS ( Williams et al., 1987). The tilt sensors were calibrated for zero tilt before deployment by aligning the tower with a plumb-bob while on the dock. A six-hour record was then logged before the tripods were moved from this position.

\section{Conclusion: An Array of Velocity and Temperature Sensors}

I have discussed the measurement of velocity using BASS tripods, and the accuracy of those velocities. I have described three independent techniques for temperature estimation used in VENTS90. I have also described some unique measurements made by BASS for estimating the turbulent heat diffusion, and the Reynolds stresses. These measurements formed a complete monitoring system for diffuse hydrothermal flow. The instruments were shown to be sufficiently sensitive to detect subtle anomalies from diffuse venting. The remaining task to be covered in section 4 will be to present the measurements, and see if they point to a plausible picture of diffuse hydrothermal acitvity. 


\section{References}

Baker, E.T., telephone conversation and subsequent FAX of unpublished graphs of CTD data, February, 1991.

Blevins, R.D. , Flow Induced Vibration, Van Nostrand, 1977

Cannon, G.A. , D.J. Pashinski, Circulation Near Axial Seamount, J. Geophys. Res., Vol.95, No. B8, pp. 12,823-12,828, 1990

Clay, C.S. and H. Medwin, Acoustical Oceanography John Wiley \& sons, New York, 1977

Fox, C.G., Evidence of active ground deformation on the Mid-ocean Ridge: Axial Seamount, Juan de Fuca Ridge, April-June 1988, J. Geophys. Res., Vol.95, No. B8, pp.12,813-12,822, 1990

Grant, W.D. , A.J. Williams III, S.M. Glenn, Bottom Stress Estimates and their Prediction on the Northern California Continental Shelf during CODE-1: The Importance of Wave-Current Interaction, J. Phys. Oc., Vol.14, pp.506-527, 1984

Gross, T.F. , A.J. Williams III and W.D. Grant, Long-term in situ Calculations of Kinetic Energy and Reynolds Stress in a Deep-Sea Boundary Layer, J. Geo. Res., Vol.91, No.C7, pp.8461-8469, 1986

Johnson, S.A. , J.F. Greenleaf, M. Tanaka, and G. Flandro, Reconstructing ThreeDimensional Temperature and Fluid Velocity Vector Fields from Acoustic Transmission Measurements, ISA Transactions, Vol. 16, No. 3, pp.3-15, 1979

Little, S.A. , K.D. Stolzenbach, J.F. Grassle, Tidal Current Effects on Temperature in Diffuse Hydrothermal Flow: Guaymas Basin, Geophys. Res. Let., vol.15, No.13, pp.1491-1494, Dec. 1988

Milburn, H., P. McLain, Miniature Temperature Recorder Owner's Manual NOAA/PMEL, Seattle, WA, 1990

Monin , A.S. and A.M. Yaglom, Statistical Fluid Mechanics: Mechanics of Turbulence, Volume 1, The MIT Press, Cambridge, MA, 1971

Munk, W. and C. Wunsch, Ocean Acoustic Tomography: a Scheme for large-Scale Monitoring, Deep Sea Res., 26A, pp.123-161, 1979

Norton, S.J. , Tomographic Reconstruction of Two-Dimensional Vector Fields: Application to Flow Imaging, Geoph. J. Roy. Astr. Soc. vol.97,pp.161-168,1988

Ocean Tomography Group, A Demonstration of Ocean Acoustic Tomography, Nature, Vol.299, No.5879, pp.121-125, 1982

Tennekes, H. and J.L. Lumley, A First Course in Turbulence, The MIT Press, Cambridge, MA, 1972 
Tochko, J.S. , A Study of Velocity Structure in a Marine Boundary Layer : Instrumentation and Observations, Ph.D. Thesis, MIT/WHOI Joint Program in Oceanographic Engineering, 1978

Williams, A.J. III, J.S. Tochko, R.L. Koehler, W.D. Grant, T.F. Gross, C.V.R. Dunn, Measurement of Turbulence in the Oceanic Bottom Boundary Layer with an Acoustic Current Meter Array, J. Atmos. Oc. Tech., Vol.4, No.2, June 1987 


\title{
Section 4
}

\section{Field Measurements at the Southern Juan de Fuca Ridge}

\author{
Table of Contents
}

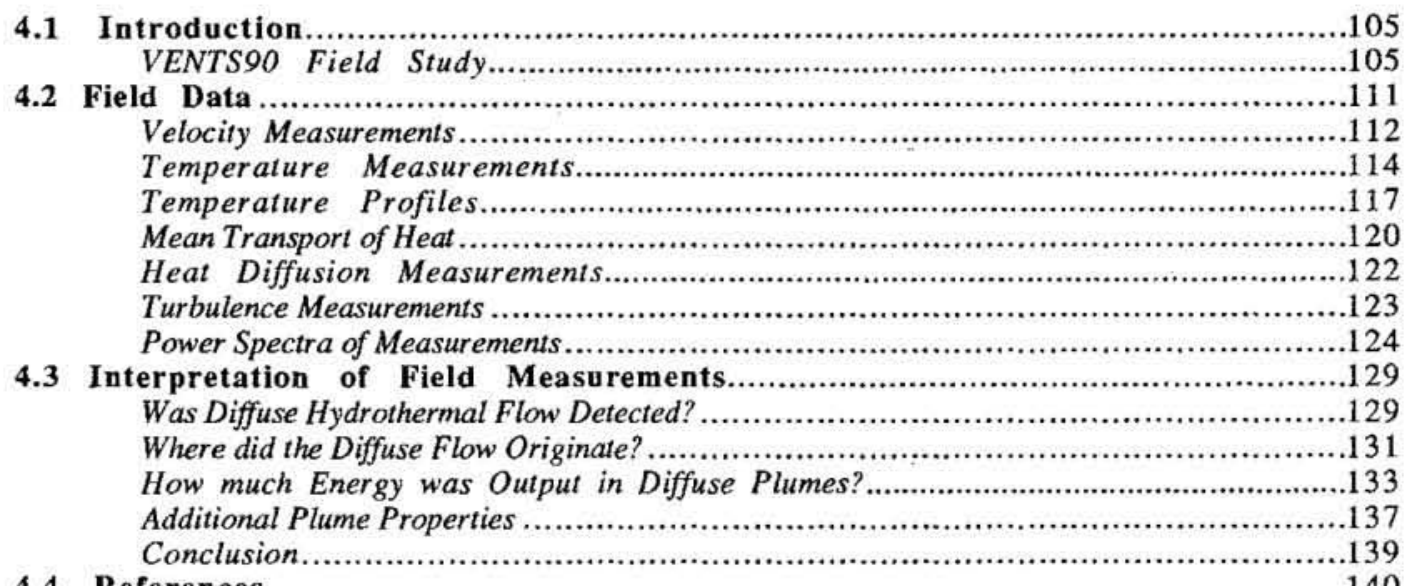

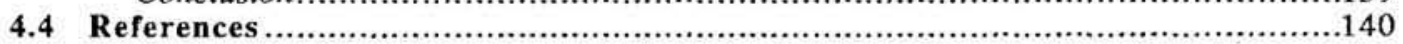




\section{Introduction: VENTS90 Field Study}

VENTS90 was a multi-disciplinary field program involving scientists from NOAA (National Oceanic and Atmospheric Administration), SIO (Scripps Institiution of Oceanography), WHOI, University of Washington, and others. During the summer of 1990, the NOAA Ship Discoverer returned to the southern Juan de Fuca ridge several times. During the month of August, both Discoverer and the R/V Atlantis II collected data from the South Cleft segment of the ridge (see location map, figure 1.1).

I deployed instruments to monitor diffuse hydrothermal flow during VENTS90. My intent was to deploy an array similar to the idealized one shown in figure 3.4. The site chosen for the deployment was centered around an area surveyed by DSV Alvin in 1988. A long crack with several patches of diffuse venting was mapped by Alvin and by towed camera surveys. I chose the most active of these patches for the locus of my field array.

Two BASS tripods (BS3 and BS4) and four thermistor moorings (M1, M2, M5, M6) were dropped from the Discoverer on August 14, 1991. Surface positions for the drop sites were determined using the Global Positioning System (GPS), or Loran-C navigation when GPS was unavailable. One of the tripods (BS3) and one of the moorings (M2) were observed on the seafloor by DSV Alvin (figures 4.2 and 4.3). The positions of M2 and BS3 were recorded in the submersible's acoustic navigation net, and plotted on the map shown in figure 4.1 (Embley, 1991).

Tripod BS4 prematurely surfaced at midnight local time on August 15. The navigator on the Discoverer , Ensign Neal Daboul, spotted the strobe light atop BS4 from several miles away, and the bridge watch tracked the tripod until dawn. It was recovered at 8:00 a.m., and re-deployed by noon. The location for re-deployment was navigated with Loran-C, since GPS was unavailable at the time. Thus, BS4's precise position on the seafloor was uncertain after August 15 because the navigation error for Loran- $\mathrm{C}$ was several hundred meters. In addition, the drift of BS4 as it fell through the water column was not neccessarily similar to that of instruments deployed on the first day. The position of BS4 on the first day of the deployment is shown in figure 4.1 as "BS4(A)", and the best estimate of its second location is "BS4(B)". 


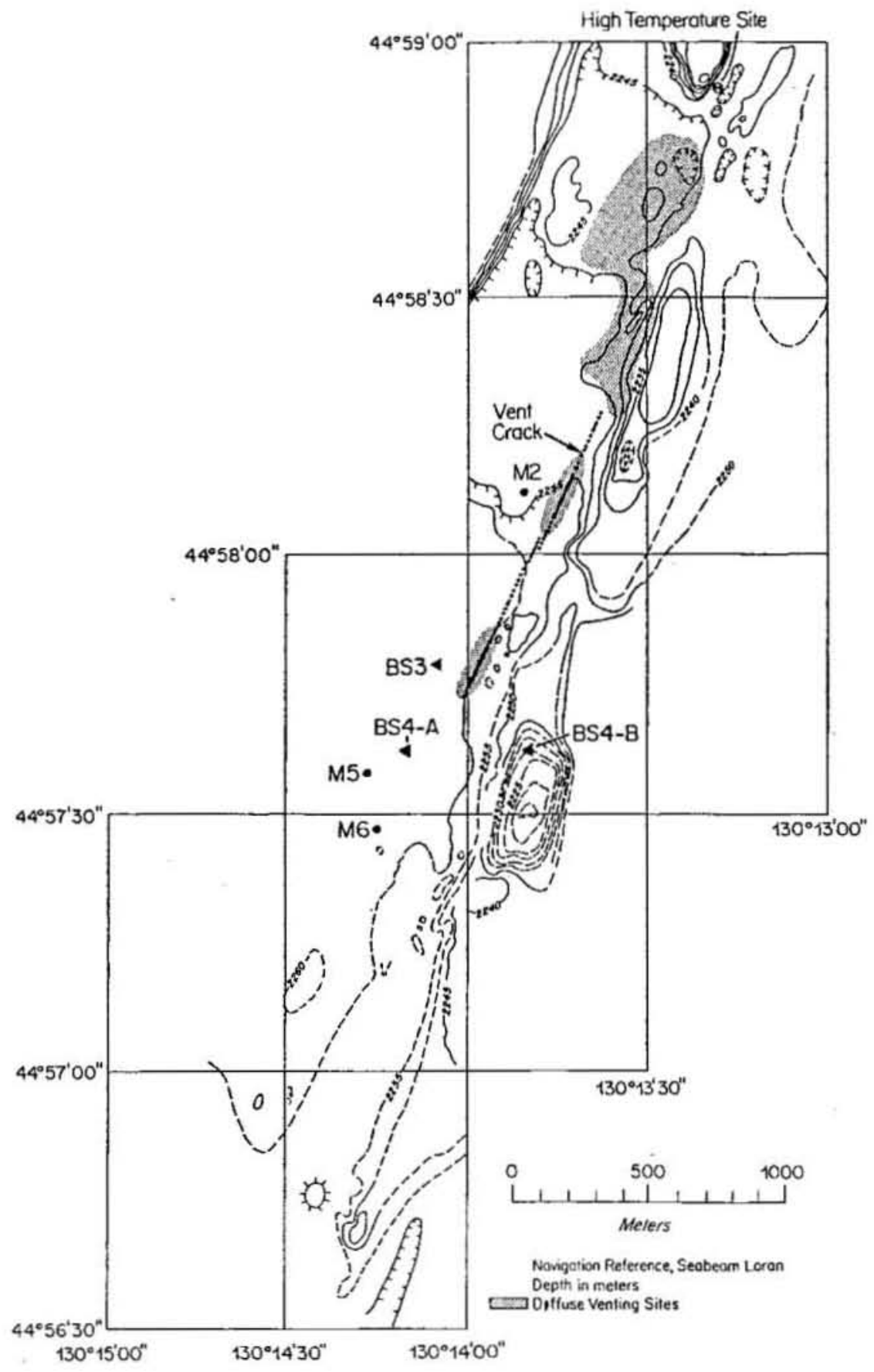

Figure 4.1: Map of the deployment site showing known locations of hydrothermal activity. The location of instruments is shown ( $\triangle$ BASS tripods, - thermistor moorings). BS4 was first deployed at site BS4A, and later at BS4B. Contours were drawn based on a sketch by Embley(1991) summarizing towed camera and submersible studies of the area. The shaded regions indicate known sites of diffuse hydrothermal venting as seen from the DSV Alvin in August 1990. 


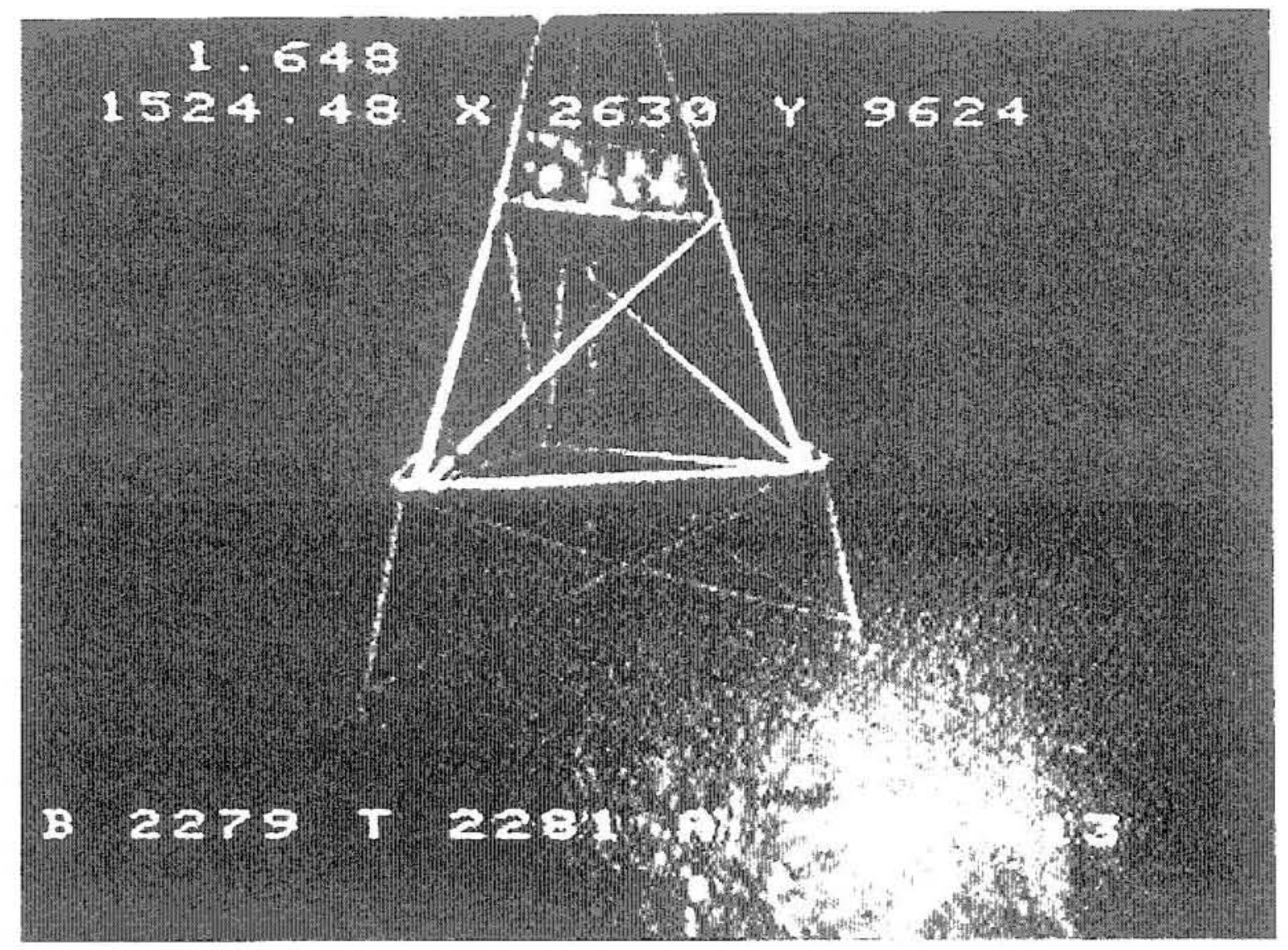

Figure 4.2: BS3 photographed by DSV Alvin on dive $\# 2265$. The numbers at the iop of the frame are: external temperature $\left({ }^{\circ} \mathrm{C}\right)$, time (IIHMM.SS), and position within the acousic navigation net $(X, Y$, in $m$ ). The bottom line shows: $B=$ depth to bottom skid on the submersible ( $m$ ), $T=$ total water depth $(m), A=$ attitude to pressure transducer $(m)$, and $H=$ compass heading in degrees. The poor resoltution of this photo is duc to the fact that it was reproduced from videotape. 


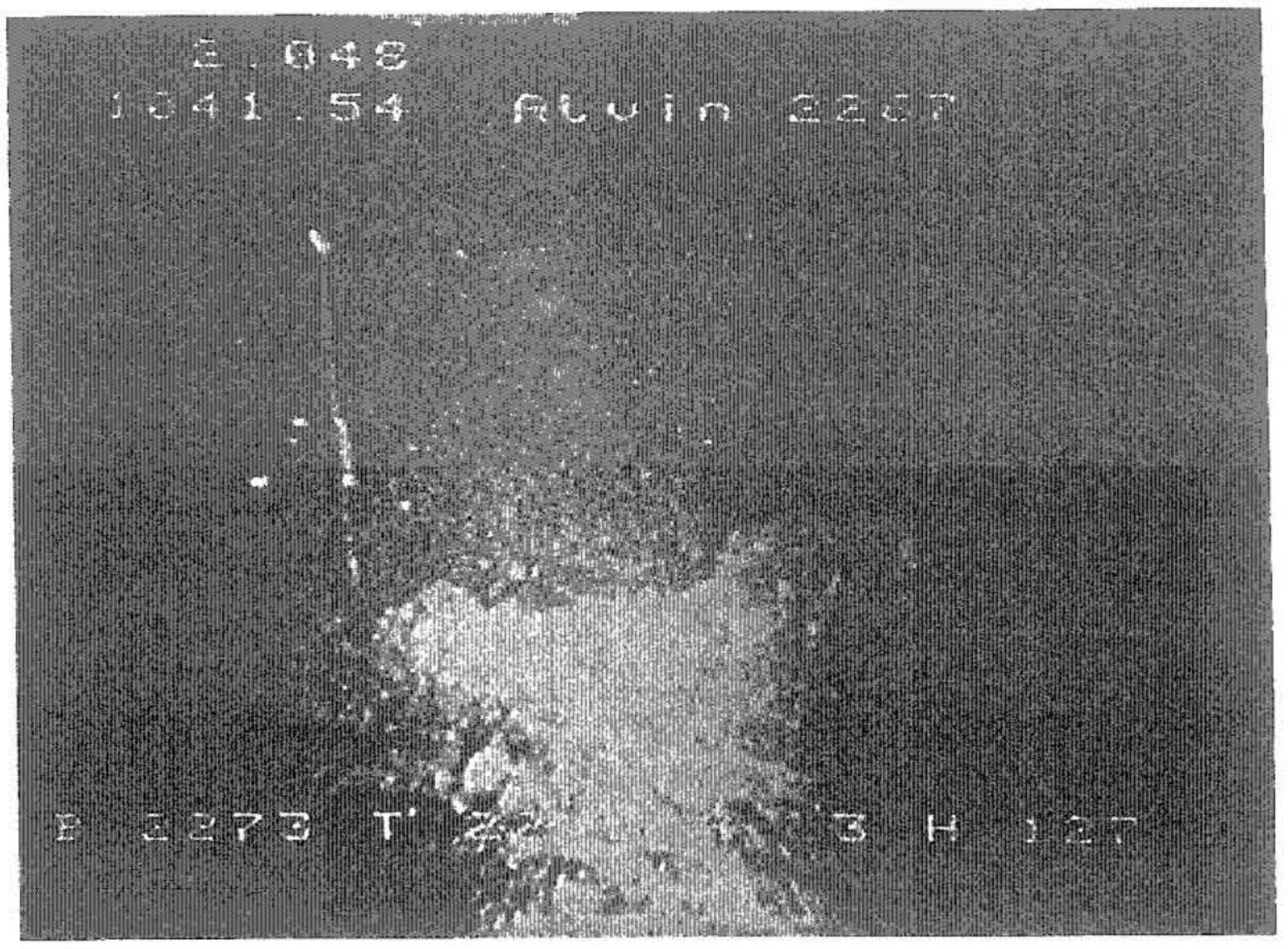

Figure 4.3:M2 photographed by DSV Alvin on dive \#2267. The cylinder visible on the mooring line is the electronics housing for the acoustic release. The bulge above that is the lowermost temperature sensor (MIR2016). The data shown on the screen is the same as in figure 4.2, except for the navigation data which has been replaced by the dive number in this photo. 
The travel-time measurement made by BS4 was essential in estimating the position of BS4B. Data from all the pods on BS4 show a constant offset in the sound speed versus the thermistor measurement of $0.1118^{\circ} \mathrm{C}$ (figure 4.4). This offset is constant over the remainder of the deployment. If the offset were due to a salinity change, the magnitude of the salinity difference would have been $0.388 \mathrm{ppt}$ (from equation 3.2 ). This magnitude of salinity offset has not been observed at the southern Juan de Fuca ridge (Baker,1991). I equate the sound-speed offset to depth dependence. If this is true, then BS4 was deployed $32 \mathrm{~m}$ shallower at site BS4B than BS4A. Examining the map in figure 4.1 reveals that there is only one large mound where the tripod could have landed. Therefore, I have placed BS4B as shown in figure 4.1.

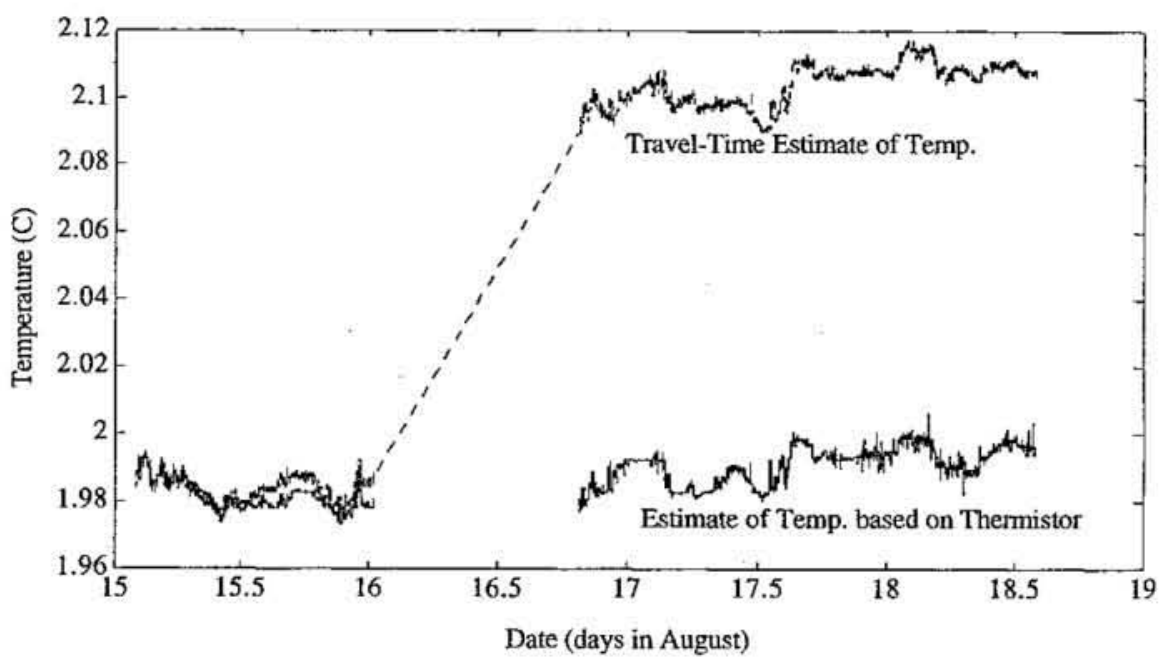

Figure 4.4: Temperature offset between first and second deployment of BS4. The upper data comes from calculating temperature using the sound-speed measurements with a constant built-in to match the temperature with the thermistors during the first day of deployment (August 15). After August 15, the travel-time estimate of temperature and the thermistor temperature measurement differed by $0.1118^{\circ} \mathrm{C}$. For the same period of time, BS3 thermistors tracked travel-time temperature very closely.

Of the four thermistor moorings that were deployed in VENTS90, three were recovered. M1 did not respond to acoustic commands after repeated attempts to communicate with it. It was equipped with a back-up timer set to release on the last day Discoverer was on station. Atlantis II was on station for several more days, and no sign of the mooring was found. M1 was deployed $150 \mathrm{~m}$ southwest of M2. Its loss was disappointing, but since M2 was so close, I did not expect the measurements at M1 to be much different from those at M2. 
The three moorings (M2, M5, M6) which were recovered had logged temperature data for only three days. They were initialized on July 17-18 in Woods Hole, and left running from that date. There was a software error which prevented the micro-processor from writing more than one month of data, so after 30 days, the logging stopped. The engineer at PMEL who wrote the software was able to identify the problem, and fix it in a matter of minutes after he was made aware of the problem. One MTR (\#2016) on M2 had been reinitialized later than the others, so it logged 10 days of field data. Even in the three day time-series from the moorings, very exciting evidence of diffuse hydrothermal flow was observed.

The BASS tripods both logged nearly complete data sets. BS4 missed one day during which it was being re-deployed (August 16), and BS3 missed twelve hours of data at the very end of the deployment because its battery failed at cold temperature. Otherwise, the quality of the data was excellent, and it has provided the first time-series of the largescale picture of diffuse hydrothermal flow.

In the remainder of this chapter, I will present time-series, vertical profiles, and power spectra from the VENTS 90 measurements. I will also show estimates of turbulence, heat diffusion, and salinity which were calculated from the field measurements. The measurements will be shown to have captured diffuse hydrothermal flow from two different diffuse patches, one small one within $100 \mathrm{~m}$ of $\mathrm{M} 2$, and another very large field $1000 \mathrm{~m}$ north of M2. I will conclude the chapter by using the field data to estimate the total heat output from these two diffuse flow sources. 


\section{Field Data}

In this section, I present field measurements from the two BASS tripods, and three thermistor moorings deployed during the VENTS90 cruise to the Cleft segment of the southern Juan de Fuca ridge. The location of the instruments was shown in figure 4.1.

I will show velocity measurements from the BASS tripods first, so that the reader will see where fluid is coming from, and going to, in the hydrothermal field. Once the general character of the flow has been established, I will show time series and vertical profiles of temperature measured at all five instruments.

I then use the simultaneous velocity and temperature measurements to make estimates of heat flux vectors for mean heat transport, and for turbulent heat diffusion. These measurements have allowed me to identify the probable sources of diffuse hydrothermal flow. They also permit application of my simple plume model (discussed in section 2) for estimating total diffuse hydrothermal energy output.

There are several other measurements made by the BASS instruments which warrant presentation, but which do not directly aid in estimating hydrothermal energy output. These additional measurements will be discussed at the end of this subsection. 


\section{Velocity Measurements}

Velocities measured by all pods on BS3 and BS4 were very similar. Figures 4.5, 4.6, and 4.7 show time series of Northward, Eastward and Upward velocities measured at pod 3 on BS3. This pod was representative of all the velocity sensors.

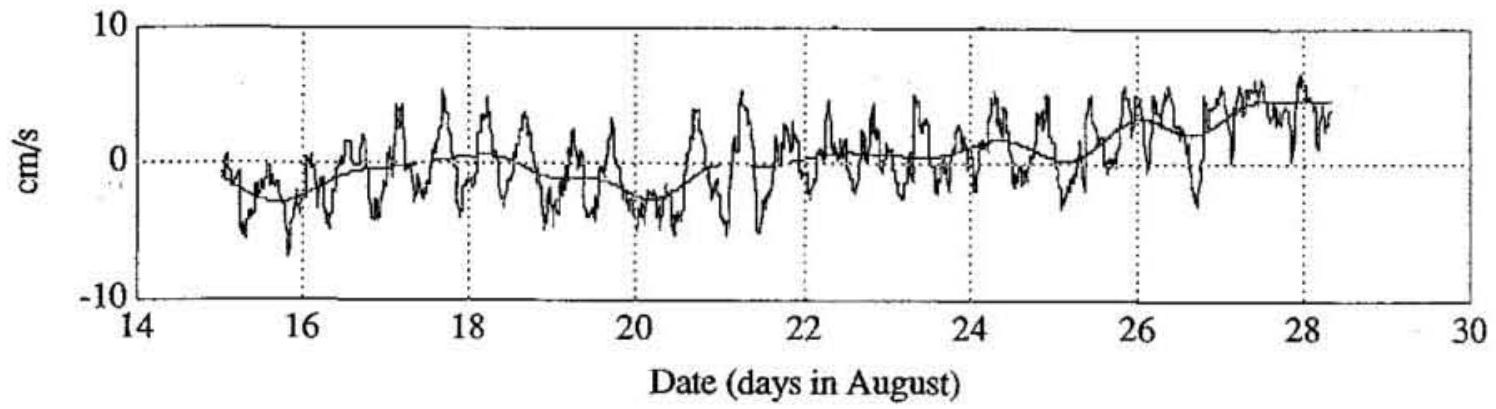

Figure 4.5 : Northward velocity measured at BS3, pod3

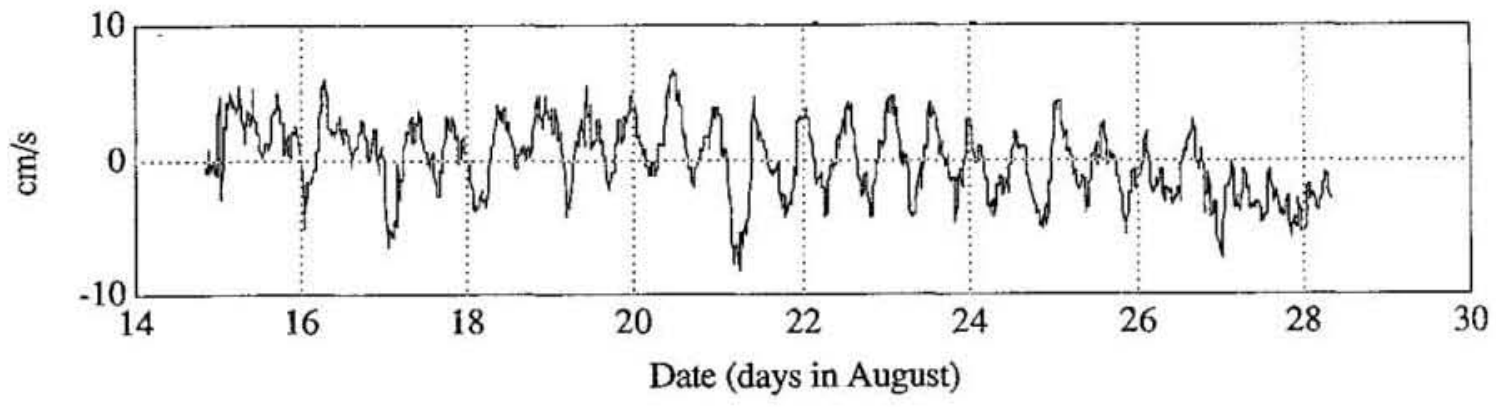

Figure 4.6: Eastward velocity measured at BS3, pod3

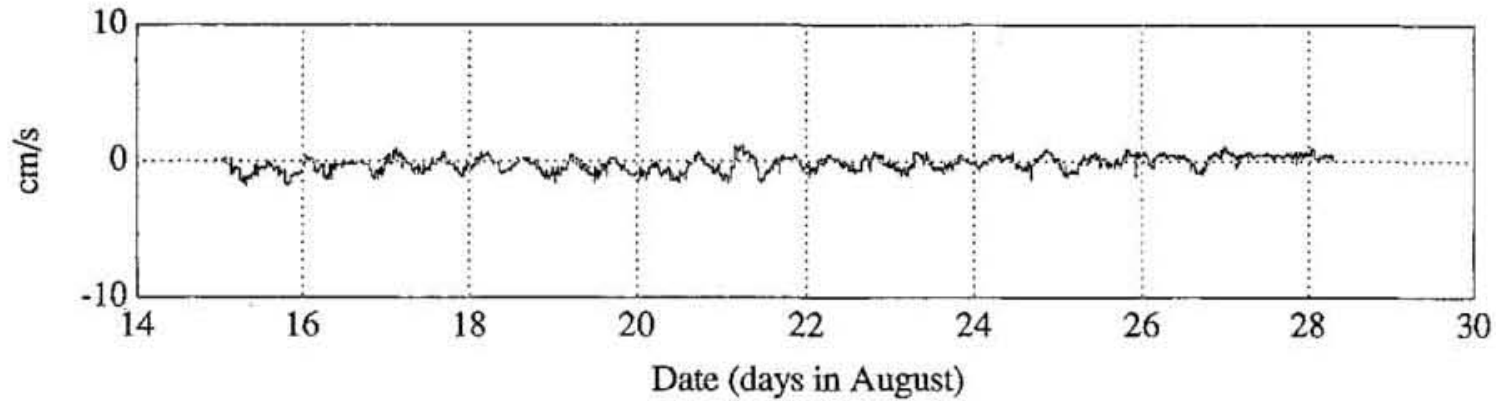

Figure 4.7 : Upward velocity measured at BS3, pod3 
A scatter plot of the direction and magnitude of velocity (figure 4.8 , in the horizontal plane only) shows a tidal ellipse which has its major axis in the direction of northwest to southeast. The highest currents are seen in these directions.

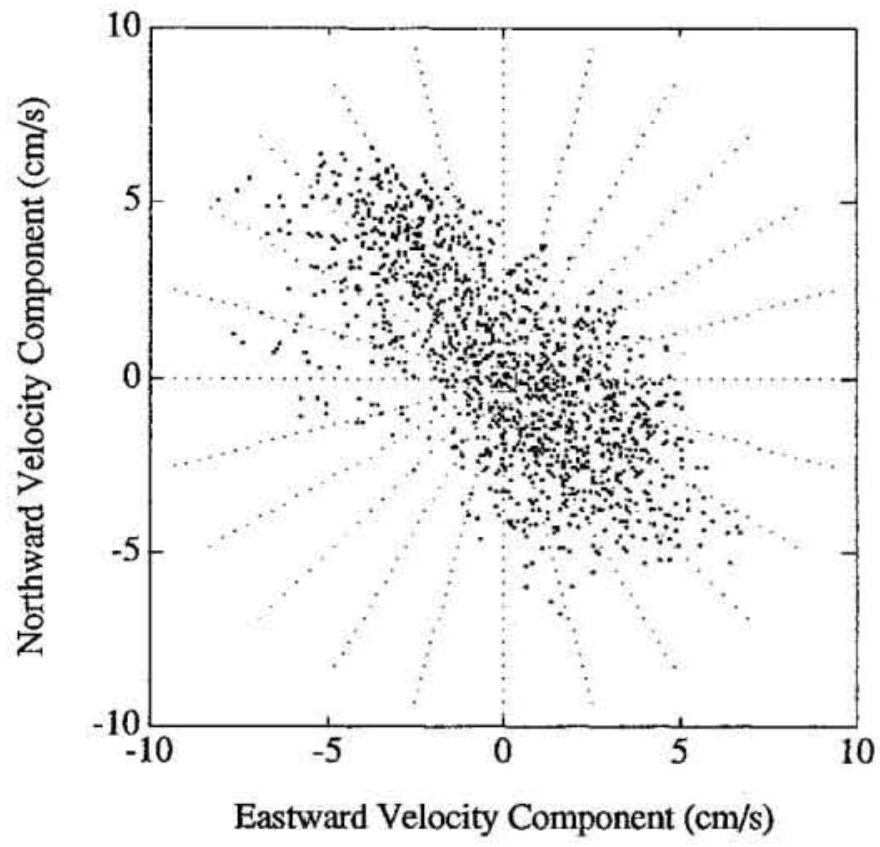

Figure 4.8 : Horizontal velocity measured at BS3, pod3. Each point represents a one-hour average of velocity measurements. The predominant flow direction was northwest-southeast, oscillating with tidal periods.

Cannon deployed several current meter moorings to the south of the vent field (Cannon, 1991). His current meters were much higher in the water column than were my BASS tripods. Cannon's measurements showed the mean flow to be in essentially the same direction as observed by BS3, and very similar in magnitude.

Cannon observed a four-day periodicity from moored current meter data in 1990 (Cannon, 1991), and in 1987-88 (Cannon, 1990). In figure 4.9, the four-day periodicity observed by Cannon is apparent in BASS measurements. This figure is a progressive current vector diagram where the curve can be thought of as the path of a particle released from the BS3 tripod on the first day of the deployment (assuming the flow over the entire field was uniform at every time sample). Each ' $x$ ' represents the position in 24 hour increments. The first two days showed consistent mean flow to the southeast. After the second day, the flow reversed for one day, then continued its southeast trajectory for four more days. At 
this time, the flow oscillated back and forth for three days, until it began a five day trend with a general drift to the northwest.

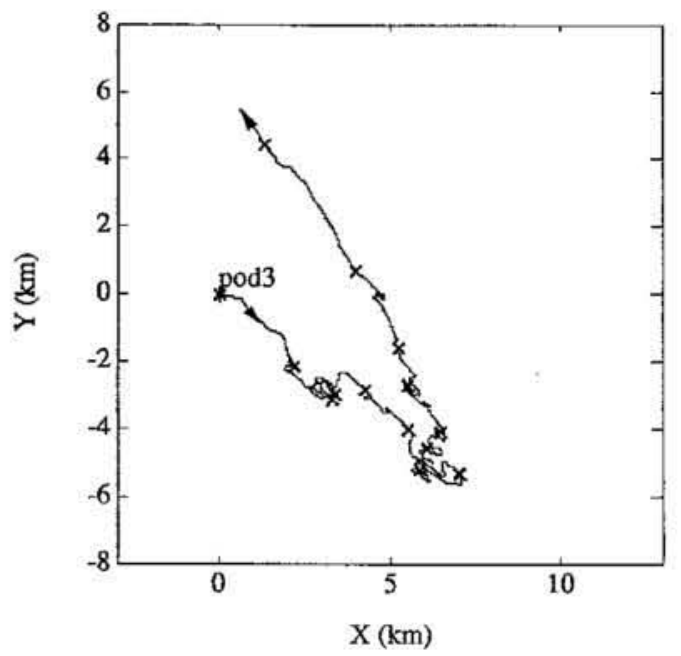

Figure 4.9 : Progressive-vector diagram from BS3. The curve represents drift of a hypothetical particle released from $B S 3$ on the first day of the deployment. The starting point is at coordinate $(0,0)$. The distance between ' $x$ ' marks represents the distance covered by the particle over one 24-hour period.

The velocity measurements indicate that over the first several days of the deployment, mean advection was to the southeast, after which time it reversed. During the course of the deployment, velocities from all directions were encountered, but the general trends were as shown in figure 4.9. This implies that any hydrothermal effluent detected in the first several days of the deployment had its origins to the north, while any detected later in the deployment probably came from the south.

\section{Temperature Measurements}

Temperature measurements were the means used in my array to detect the presence of hydrothermal fluid. Knowing something about the mean flow field from velocity measurements will ultimately permit me to suggest the location and character of the origins for observed temperature anomalies. 
Mean temperatures from the three moorings (M2, M5, M6) were 1.906, 1.898 and 1.901 ${ }^{\circ} \mathrm{C}$, respectively. The difference in mean temperatures between moorings are within 0.005 ${ }^{\circ} \mathrm{C}$ of each other after applying the Steinhart-Hart equation to the calibration data ( YSI Inc., 1990). Temperatures measured on the BASS tripods had mean values of 2.124 and 1.779 ${ }^{\circ} \mathrm{C}$ for BS3 and BS4, respectively. I attribute the difference in mean values between the MTR's and the BASS thermistors to the BASS thermistor calibrations (see section 3.2). The MTR's were extensively calibrated after the deployment at temperatures similar to those encountered in the field. The mean temperatures on BS3 and BS4 are corrected to match those of M2, M5, and M6.

The complete time-series of temperature from each of the instruments is presented in figure 4.10. Figure 4.11 shows the temperatures observed for the first three days of the deployment.

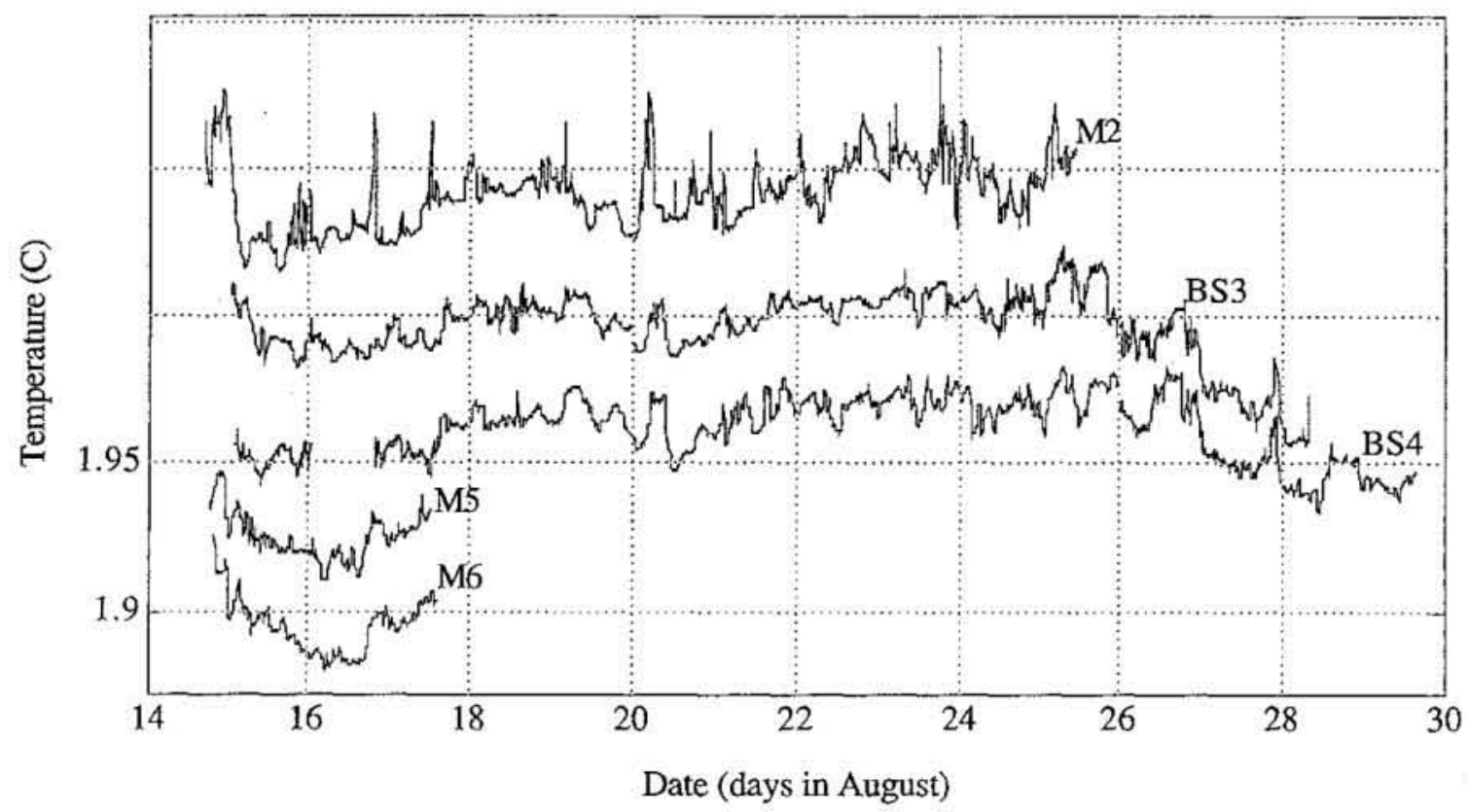

Figure 4.10: Time-series of temperature from the lowest sensor on each instrument for the duration of the deployment. Each of the time-series is vertically offset by $0.025^{\circ} \mathrm{C}$. The bottom curve for M6 shows the true mean level for all the curves. 


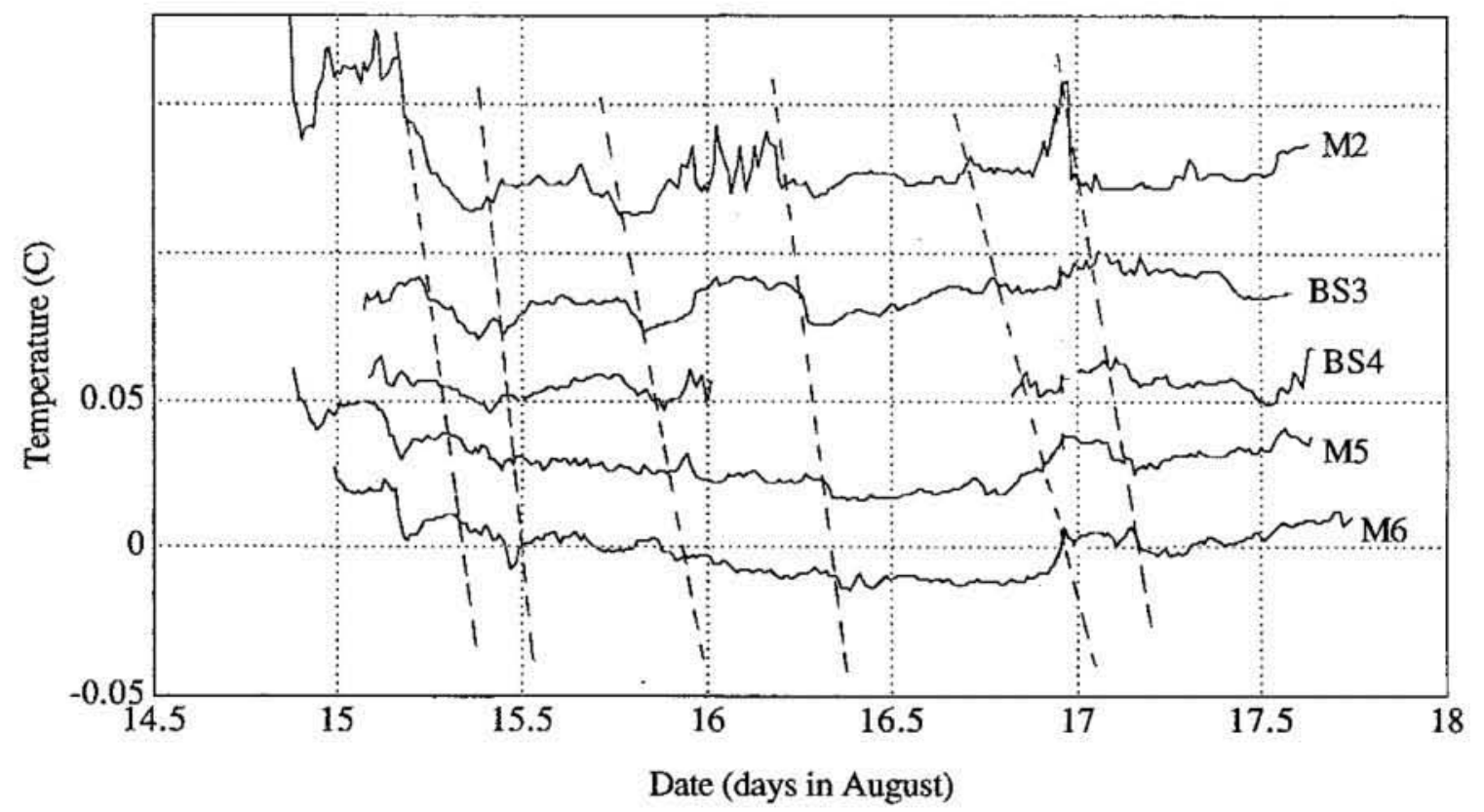

Figure 4.11: Time-series of temperature from the lowest sensor on each instrument for the first three days of the deployment. Each of the time-series is vertically offset by $0.025^{\circ} \mathrm{C}$. The bottom curve for M6 shows the true mean level for all the curves.Features which are correlated between the five instruments are illustrated by the dashed lines marking some of the most striking similarities.

The curves in both figure 4.10 and 4.11 are offset in the vertical in such a way that the top curve is M2, the northern-most instrument, and the bottom is the southern-most. The time series from M2 shows several significant temperature spikes.

Similar features between M2 and the other instruments are pointed out in figure 4.11. A time lag between peaks at M2 and those on the other instruments was measured from the time-series. I divided the distance between instruments by the time-lag between the temperature measurements obtained from cross-correlation between each of the moorings. The result is acharacteristic velocity scale. The velocity scales resulting from peaks in the 
correlation functions are summarized in Table 4.1. These velocities are similar to mean flow speeds measured by BASS.

The correlations between the most distant instruments, such as M6 and M2 are less realistic than those between the nearest instruments. The peak in the cross-correlations corresponding to a parcel of fluid being advected by two widely spaced instruments was not neccesarily the first peak (see Appendix C). In table 4.1, only the first correlation peak was used. The time-scale of current fluctuations was tidal (twelve hours). The time it would take a particle at M2 to reach M6 (assuming a mean velocity of $1.5 \mathrm{~cm} / \mathrm{s}$ ) is 26 hours. Thus, the flow would have changed before the temperature signal at M2 could be impressed upon M6. In the table 4.1, the most remote correlations are those in the upper right-hand corner of the table.

\begin{tabular}{|r||c|c|c|c|c|}
\hline & M2 & BS3 & BS4 & M5 & M6 \\
\hline M2 & 0 & 0.99 & 1.62 & 2.39 & 5.64 \\
BS3 & & 0 & 1.00 & 1.04 & 1.45 \\
BS4 & & & 0 & 1.37 & 1.39 \\
\cline { 1 - 2 } M5 & & & & 0 & 0.59 \\
\cline { 1 - 2 } M6 & & & & & 0 \\
\hline
\end{tabular}

all velocities in $\mathrm{cm} / \mathrm{s}$

Table 4.1: Velocity scales from cross-correlating instruments in the VENTS90 array. Each entry in the table corresponds to the cross-correlation between the instruments indicated along the border. For example, the velocity of $1.62 \mathrm{~cm} / \mathrm{s}$ at the intersection of $M 2$ and $M 5$ represents the distance between $M 5$ and $M 2$ divided by the correlation time between the temperature time-series from these two instruments.

\section{Temperature Profiles}

Figure 4.12 presents surface plots of the vertical temperature profiles at all five instruments during the first three days of the deployment (August 15-18). Since the tripods were only $5 \mathrm{~m}$ tall, and the moorings were $45 \mathrm{~m}$ in height, variations in the temperature gradient are not obvious on the time-series from BS3 and BS4. M2 shows several events where the temperature profiles are monotonically increasing with height. These events correspond to periods of southward flow. There are three events where the maximum temperature was observed at $10 \mathrm{~m}$ above the seafloor. These events correspond to the only three times during the first three days when the flow was directed towards the west. The different character of the temperature events when the flow comes from different directions is suggestive of two diffuse sources, one due east of $M 2$, the other well to the north of M2. 


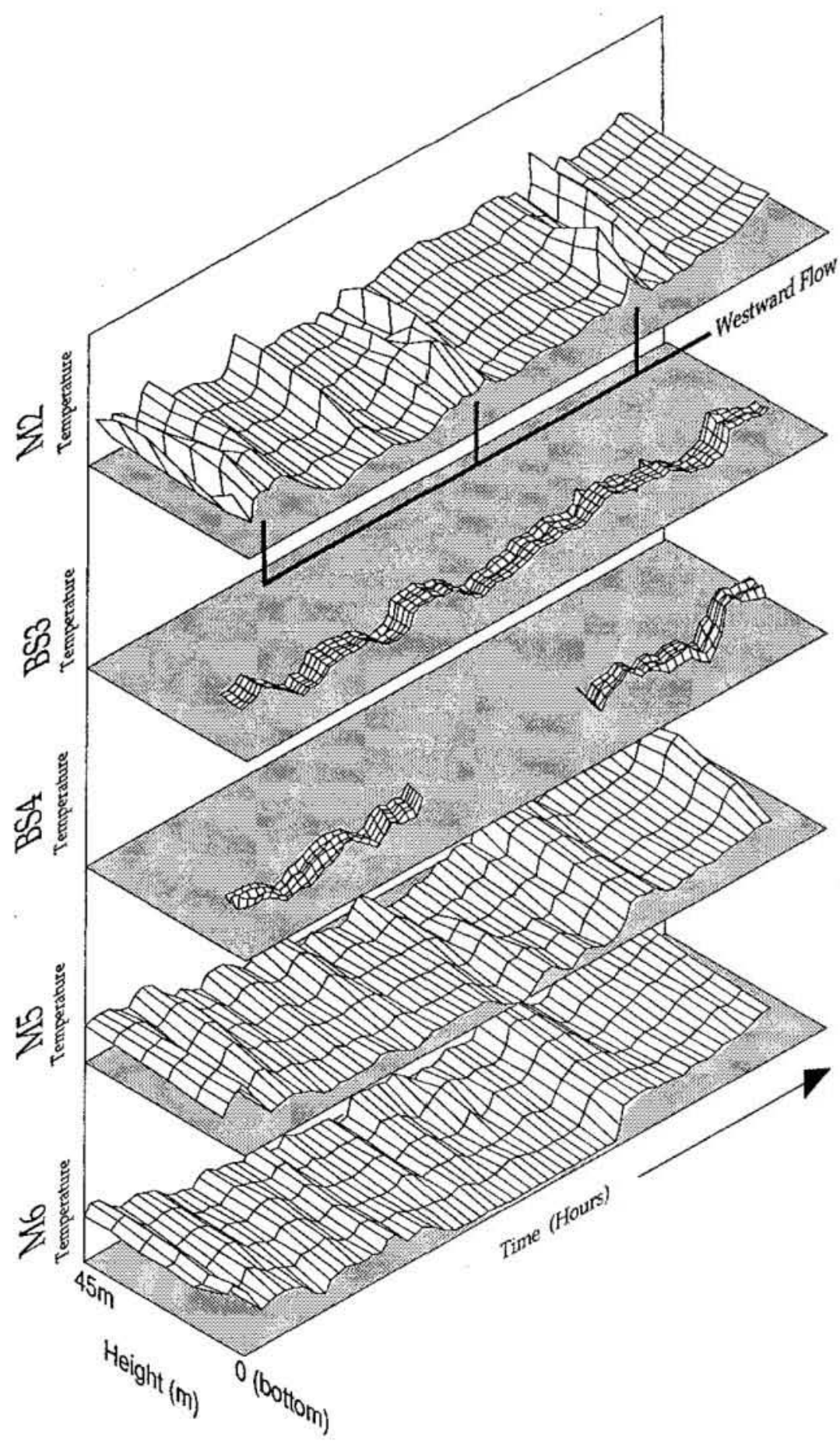

Figure 4.12: Vertical profiles of temperature expressed as surface plots. The fluctuating nature of the temperature profiles is evident in this presentation. On M2, there are several temperature events where the maximum temperature occurs at the top sensor. There are three events where the maximum temperature occurs at the $10 \mathrm{~m}$ elevation. These three events correspond to the only times when the flow was to the west. The profiles for BS3 and BS4 were only $5 m$ high, whereas the profiles from $M 2, M 5$, and M6 were $45 \mathrm{~m}$ high. 
Figure 4.12 does not give a good quantitative picture of the temperature profiles. Bottom temperature gradient was better for comparing the five instrument arrays. The temperature gradient at the bottom of each of the instrument arrays is plotted in figure 4.13.

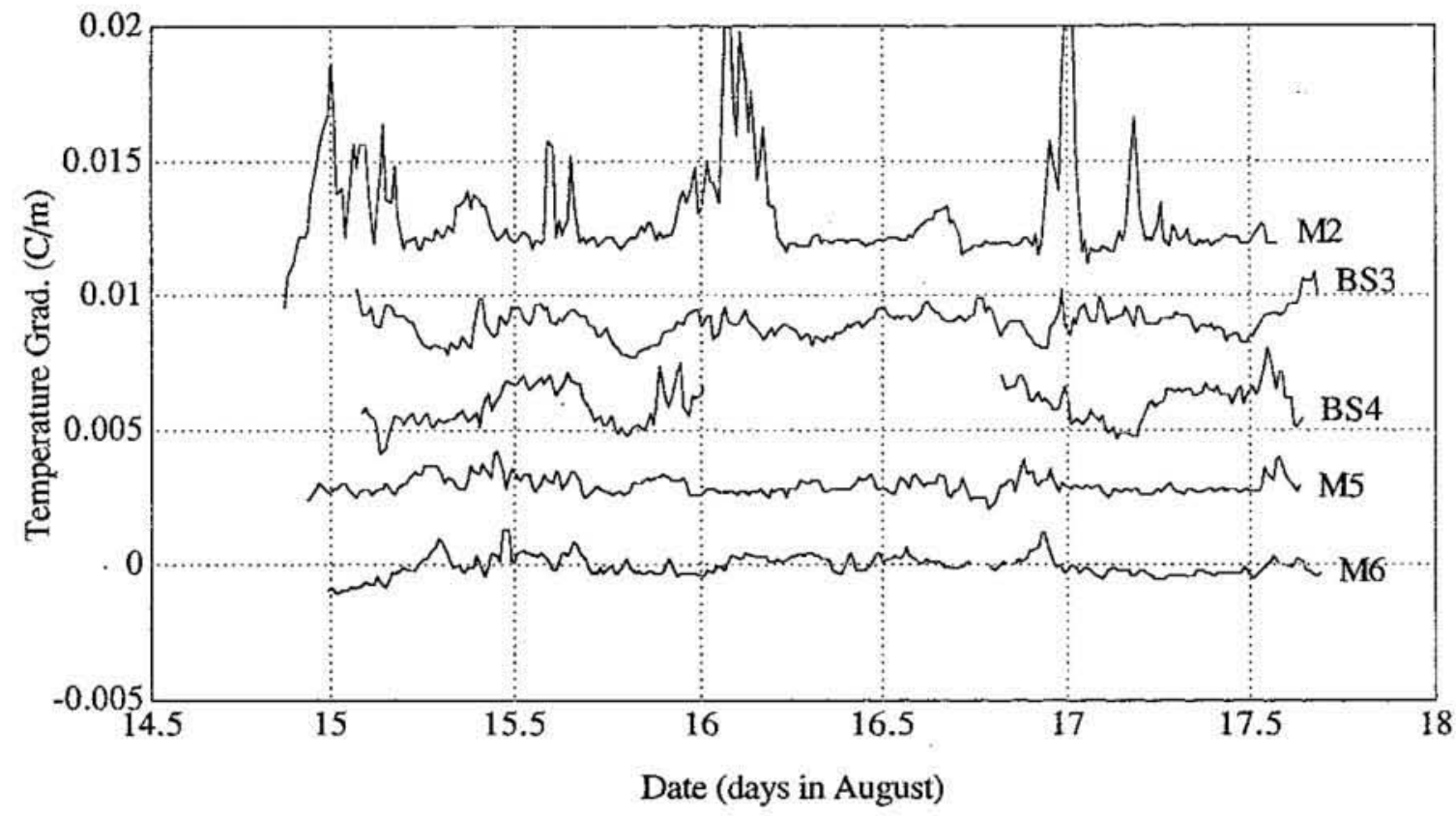

Figure 4.13: Temperature gradient at all instruments. The five time-series are vertically offset by $0.0025^{\circ} \mathrm{C}$ from each other. Their actual mean values are the same as that of $M 6$. The break in the temperature gradient record for BS4 was due to it surfacing and being re-deployed at that time.peaks which appear correlated are indicated in this figure.

There are several peaks in the times series which are correlated between instruments. Events showing the strongest correlation on all the instruments occured during southward flow. The events with the largest bottom temperature gradient, particularly on August 17, do not appear to propagate down the array. These events are the ones which occurred during westward flow (shown in 4.12). If they are indeed due to a small, near source, then it is no surprise that evidence of a temperature event at these times was only observed at M2. 


\section{Mean Transport of Heat}

The mean heat transport is the product of velocity and temperature anomaly (the constant $\rho c_{p}$ is assumed to be $4.2 \times 10^{6} \mathrm{~kg} \mathrm{~s}^{-2} \mathrm{~m}^{-1} \mathrm{o}^{-1}$ ). Figure 4.14 shows the flow direction superimposed over the M2 time-series. The periods when flow was southward and westward are high-lighted in the figure. These times correspond to most of the observed temperature spikes on M2.

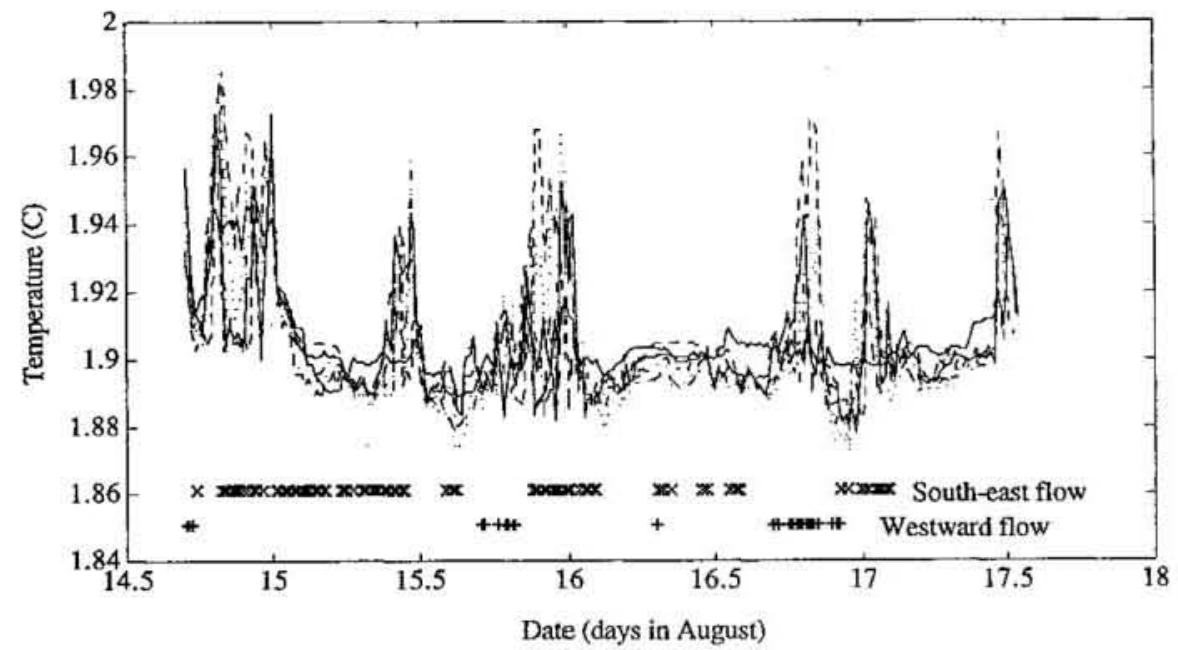

Figure 4.14 : Flow direction and temperature anomalies on M2. The bars along the bottom show peroids when the velocity was directed to the southward, and to the westward. The multiple curves shown are from the six temperature sensors at the six elevations on $M 2$

Figure 4.15 shows the advected heat flux calculated at each instrument. The technique used to make these estimates was to take the time-series of velocity at BS3, averaged over 15-minute intervals, and multiplied with the 15-minute average temperature anomaly at each of the other instruments. The temperature anomaly was conservatively estimated as the average difference between the maximum and minimum temperature on each vertical array. The resulting 15-minute interval time-series of heat flux was sorted into $5^{\circ}$ direction bins, and all of the measurements for a given direction were ensemble-averaged (figure 4.15). The resulting polar plot of heat flux for M2 shows two directions where the heat flux was several times larger than any other directions. The other moorings show an elevated heat flux for flows to the southeast. The true direction of this flow may have been different due to local magnetic anomalies influencing the compasses on BS3 and BS4. 


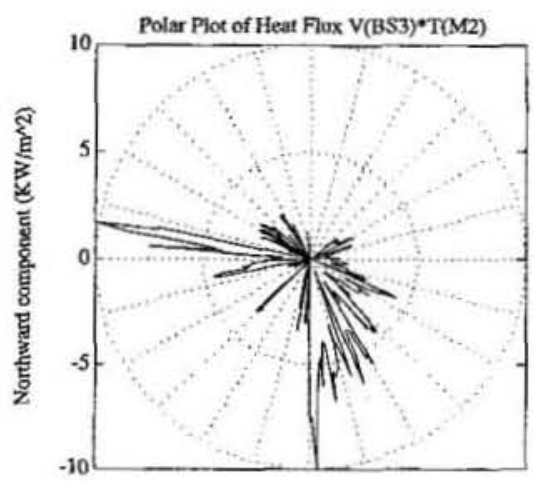

Eastward component $\left(\mathrm{KW} / \mathrm{m}^{\wedge} 2\right)$

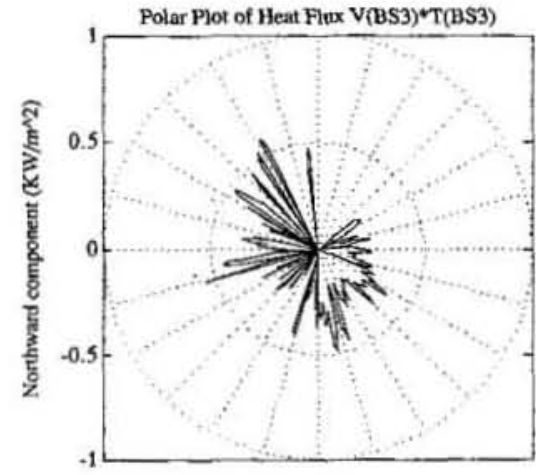

Eastward component (KW/m^2)

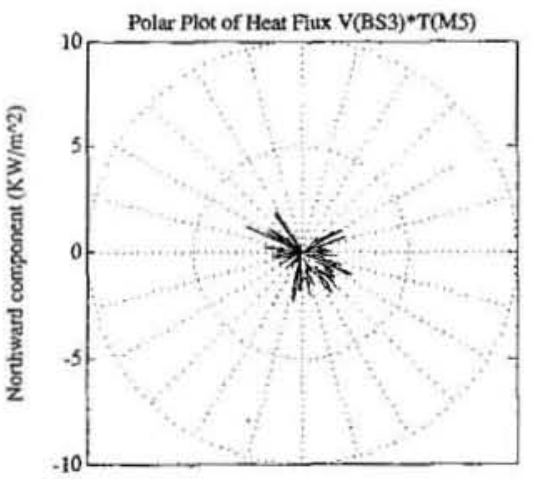

Eastward component $\left(\mathrm{KW} / \mathrm{m}^{\mathrm{N} 2}\right)$

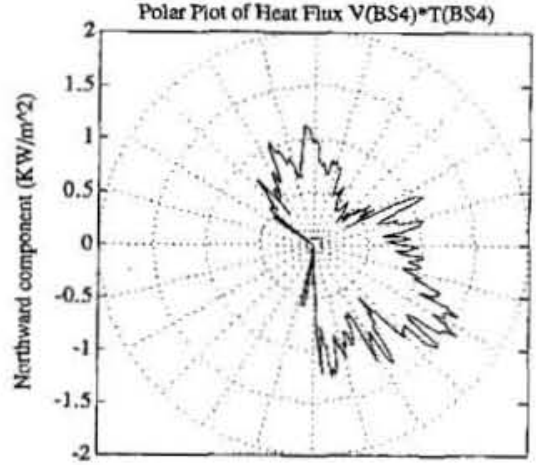

Eastwrard component $(\mathrm{KW} / \mathrm{mm} / 2)$

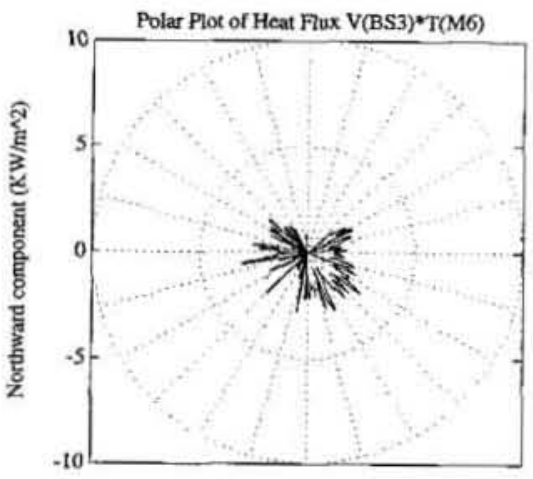

Eastward component $\left(\mathrm{KW} / \mathrm{m}^{\wedge} 2\right)$

Figure 4.15: Direction of convective heat flux at all instruments. The polar plots were made by sorting the heat flux time series (product of fifteen-minute averages of temperature and velocity and BS3) In thepolar plot for BS4, the velocity measured at BS4 is used. Note the different scales on the BASS tripods compared with the moorings. Since the moorings were taller, the observed temperature anomalies were larger, since the temperature fluctuations were larger above $5 \mathrm{~m}$ than below $5 \mathrm{~m}$ heights. 


\section{Heat Diffusion Measurements}

Turbulent heat diffusion as described in the previous section is shown for the entire deployment in figure 4.16. The time-series shows that there are spikes which correspond to peaks in turbulent kinetic energy. Figure 4.17 shows a scatter plots of the heat diffusion vector. In the horizontal plane, the diffusion was approximately isotropic, with a magnitude of $0.1 \mathrm{~W} / \mathrm{m}^{2}$. In the vertical plane, the diffusion was directed into the seafloor for most of the deployment. The downward heat diffusion was less than $0.6 \mathrm{~W} / \mathrm{m}^{2}$. This measure of heat diffusion gives an idea of the loss of heat from a plume into the bottom.

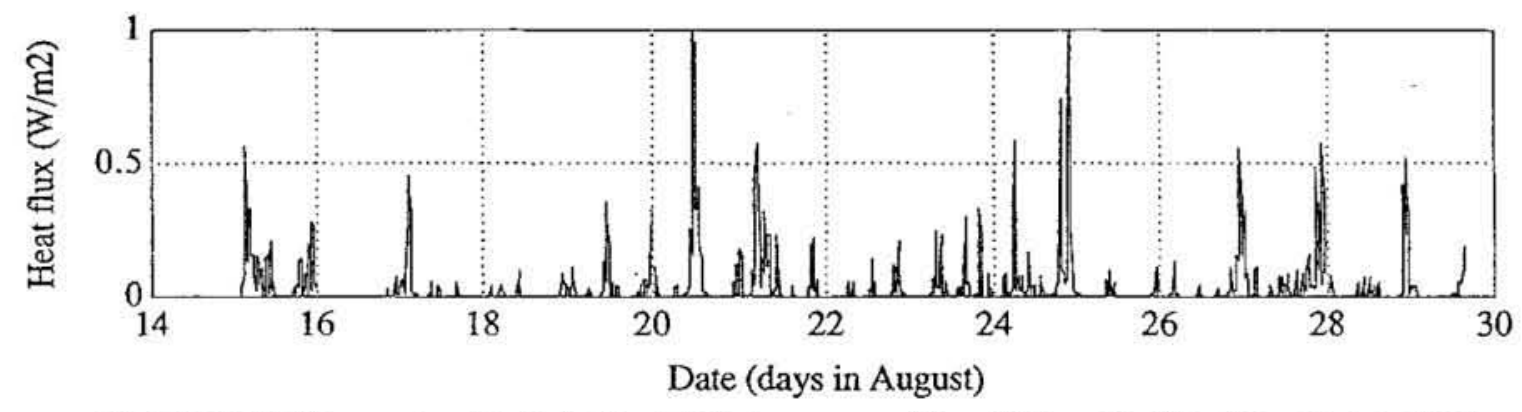

Figure 4.16: Time-series of turbulent heat diffusion measured from BS3, pod3. This data was calculated in situ by BASS, and shows times when the magnitude of heat diffusion was greatest.
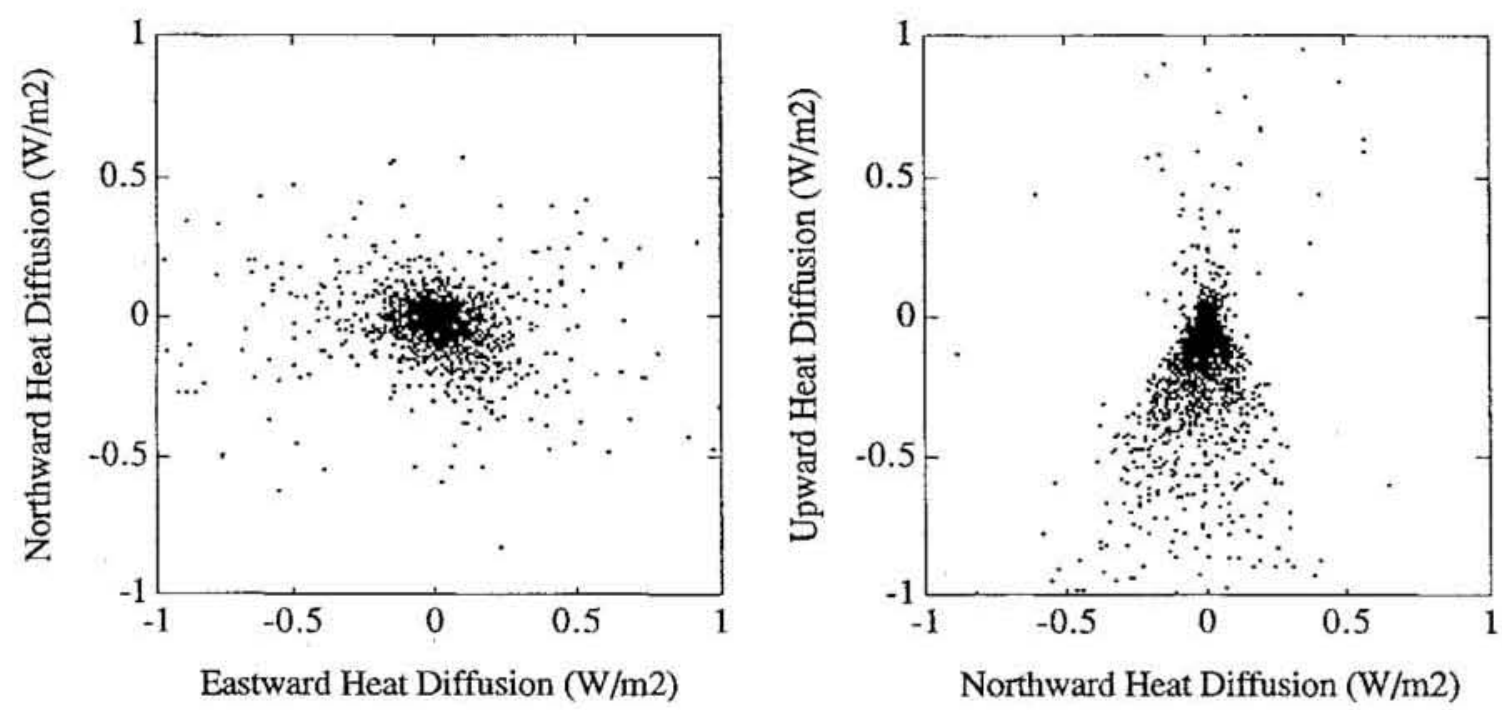

Figure 4.17: Scatter plot of horizontal and vertical heat diffusion vectors from BS3. The plot on the left shows diffusion in the horizontal plane. The plot on the right shows diffusion in the vertical plane. It is apparent that heat diffusion was primarily directed downward. This is plausible for warm flow over a cold bottom. 


\section{Turbulence Measurements}

Measurements of turbulent kinetic energy are presented in figure 4.18. The semi-diurnal periodicity of all the turbulent energy reflects the tidally forced currents. Figure 4.19 shows correlation between the square of the mean velocity and the turbulent energy.

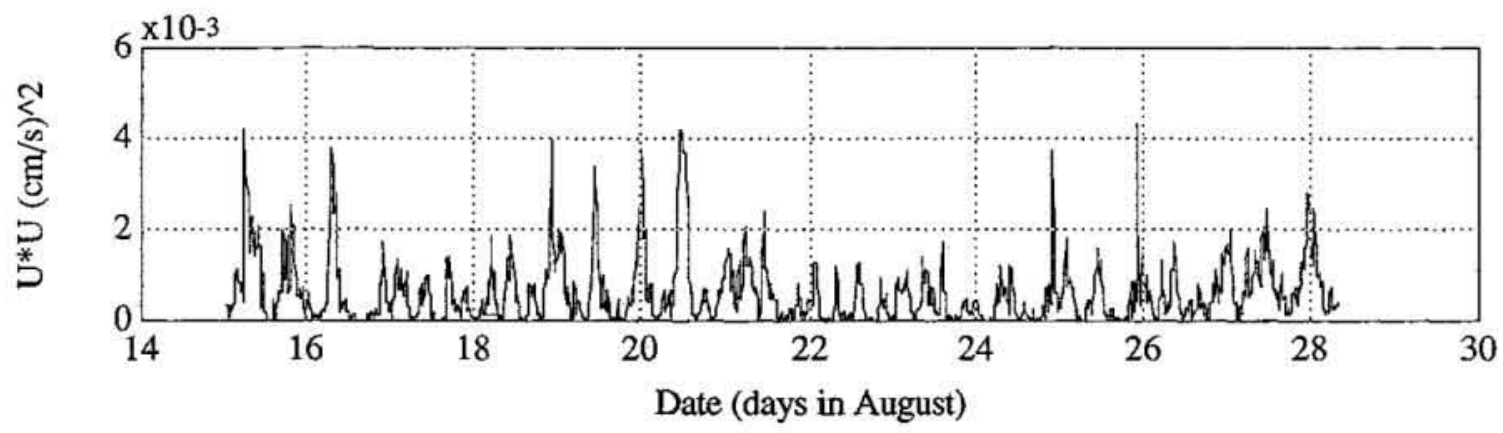

Figure 4.18: Time-series of turbulent kinetic energy measured from BS3, pod3

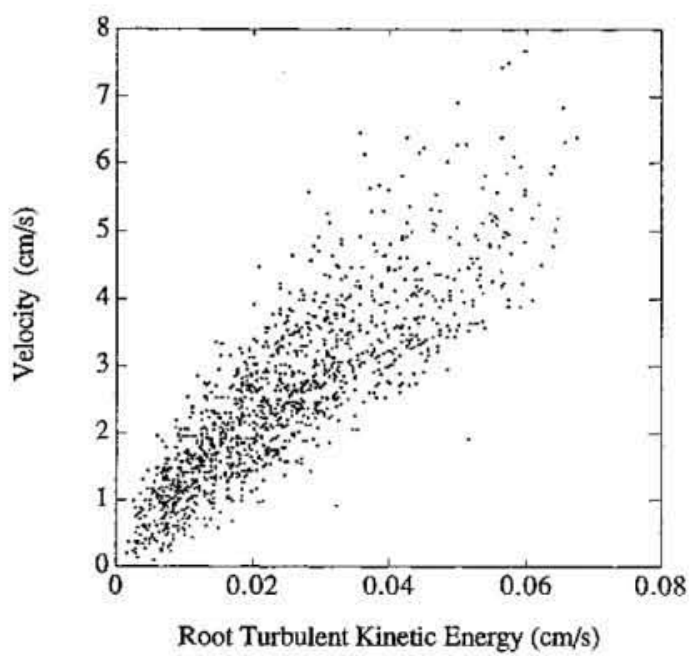

Figure 4.19: Correlation between turbulent kinetic energy and velocityfrom BS3, pod3

Vertical profiles of turbulent kinetic energy (figure 4.20) show that the mean levels were constant with height. The maximum turbulence events (turbulence intensity greater than $\left.0.005(\mathrm{~cm} / \mathrm{s})^{2}\right)$ show that the kinetic energy increased with height during times of high turbulence (figure 4.20 ). The profile of turbulent heat diffusion also shows a positive vertical gradient during high-energy periods. Figure 4.20 also shows the vertical profile of heat diffusion from BS4 and BS3. 

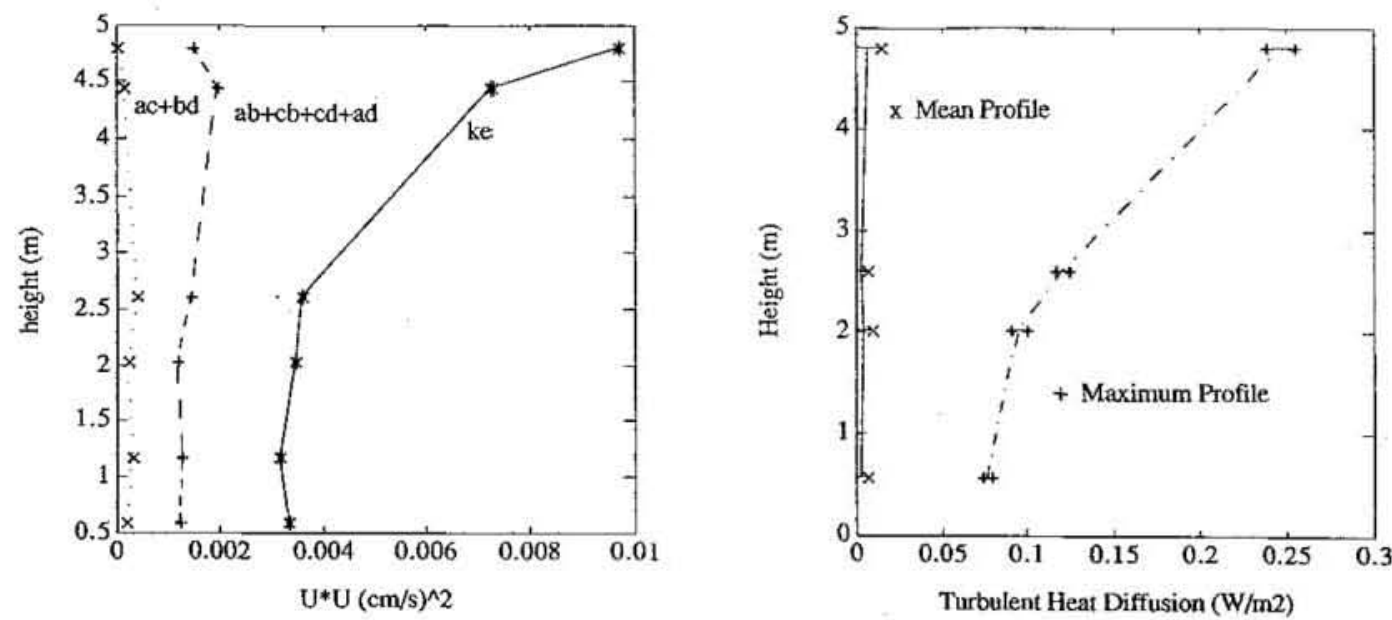

Figure 4.20: Turbulence and heat diffusion profiles for BS3 and BS4. The figure on the left shows the vertical profile of turbulence when the kinetic energy (figure 4.18) was larger than $0.005(\mathrm{~cm} / \mathrm{s})^{2}$. The three profiles are for kinetic energy (ke), Reynolds stresses of BASS axes $(a x b+c x b+c x d+a x d)$ which are in an inclined plane, and reynolds stresses $(a x c+b x d)$ which are in a vertical plane. The plot on the right shows a profile of turbulent heat diffusion for the same samples as the profiles on the left. The mean diffusion profile was effectively constant with height, while the maximum profile increases with distance from the bottom.

\section{Power Spectra of Measurements}

In environmental flow such as diffuse hydrothermal venting, turbulent eddies exchange energy from large-scale motion to scales where the energy can be dissipated through viscous friction. The process is referred to as the turbulent energy cascade. Measurements from VENTS90 show some interesting properties of the energy cascade.

At scales of motion smaller than the largest eddies, and larger than the scale of viscous dissipation, the energy present in any particular eddy size is proportional to $-5 / 3 \log (f)$, where $f$ is the frequency (or wavenumber) of the eddy scale (Tennekes and Lumley, 1972). The scales of turbulence should be visible in the power spectrum of any fluctuating, flow dependent variable such as velocity or temperature.

Power spectra of the velocities from BS3 and BS4 were calculated from the VENTS90 data. Figure 4.21 shows spectra estimated over the first 3.5 days of deployment for BS3. Figure 4.21 was obtained from an average of the squares of ten 512-point FFT's (at one sample per minute, 512 samples $=8.5$ hours) in accordance with Oppenheim and Schafer (1975). I also calculated spectra the hard way, by taking an FFT of the autocorrelation of 
the time-series. Both techniques produced comparable spectra. I used the MATLAB "Spectrum" function to implements the method of Oppenheim and Schafer (Little and Shure, 1988).

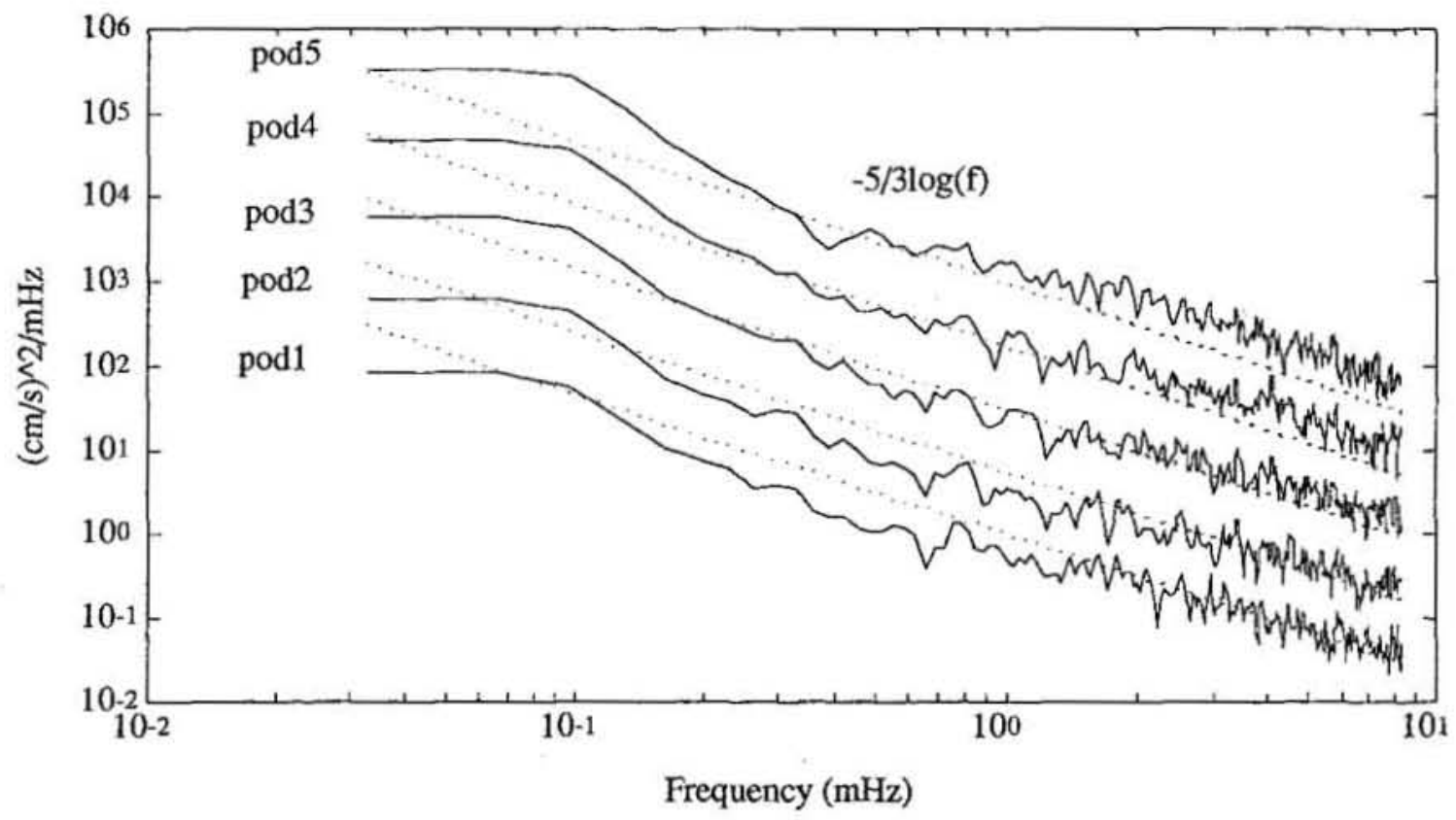

Figure 4.21 : Power spectrum of northward component of velocity from BS3. The dashed lines indicate the $-5 / 3 \log (f)$ slope. Each curve is offset vertically by one order of magnitude. The true level for all the curves is identical to that of pod1. Pod 6 was not plotted since one axis was bad.

The classical $-5 / 3 \log (\mathrm{f})$ slope of the spectrum is apparent in figure 4.23. The top curve represents data from the top sensor (pod5), and the bottom represents velocity measurements from the sensor pod nearest the boundary (pod1). The spectra have been offset for clarity, the spectral levels are actually the same for all curves in the figure. The approximate lowest frequency where the $-5 / 3$ slope is evident indicates the minimum frequency of the equilibrium range of turbulence. The minimum frequency of the equilibrium range can in turn be related to the largest-scale turbulent motion (Tennekes and Lumley, 1972) by:

$$
l \approx \frac{\mathrm{U}}{\mathrm{f}}
$$

where $U$ is the mean velocity, $f$ is the lowest frequency limit of the equilibrium range of turbulence, and $l$ is the largest turbulent eddy scale. In figure $4.21, \mathrm{f}$ is on the order of 
$0.0003-0.0008 \mathrm{~Hz}$ ( a time-scale of $55-20$ minutes), while $U$ is $3-4 \mathrm{~cm} / \mathrm{s}$. The large-scale eddy size should be on the order of $40-130 \mathrm{~m}$.

Figure 4.22 shows the spectra for vertical velocity at pods $1-5$ on BS3. The $-5 / 3$ slope is not as apparent as in spectra of horizontal velocities. The upper three pods (3-5) show indications of the $-5 / 3$ slope at frequencies higher than $0.004 \mathrm{~Hz}$. This frequency corresponds to an eddy scale of 6-10m The lower pods (1-2) do not show evidence of the $-5 / 3$ roll-off. This is to be expected, since eddy scales are proportional to the distance from the seafloor for simple boundary layer flow. The distance above the bottom where the boundary layer eddies were fluctuating too rapidly to be resolved by one-minute samples of velocity (at $3-4 \mathrm{~cm} / \mathrm{s}$ mean flow) is $1.8-2.4 \mathrm{~m}$. Pods 1 and 2 were 0.58 and $1.18 \mathrm{~m}$ above the bottom, respectively. Therefore, the high-frequency measurements (up to once sample per minute) agree with simple boundary layer behaviour.

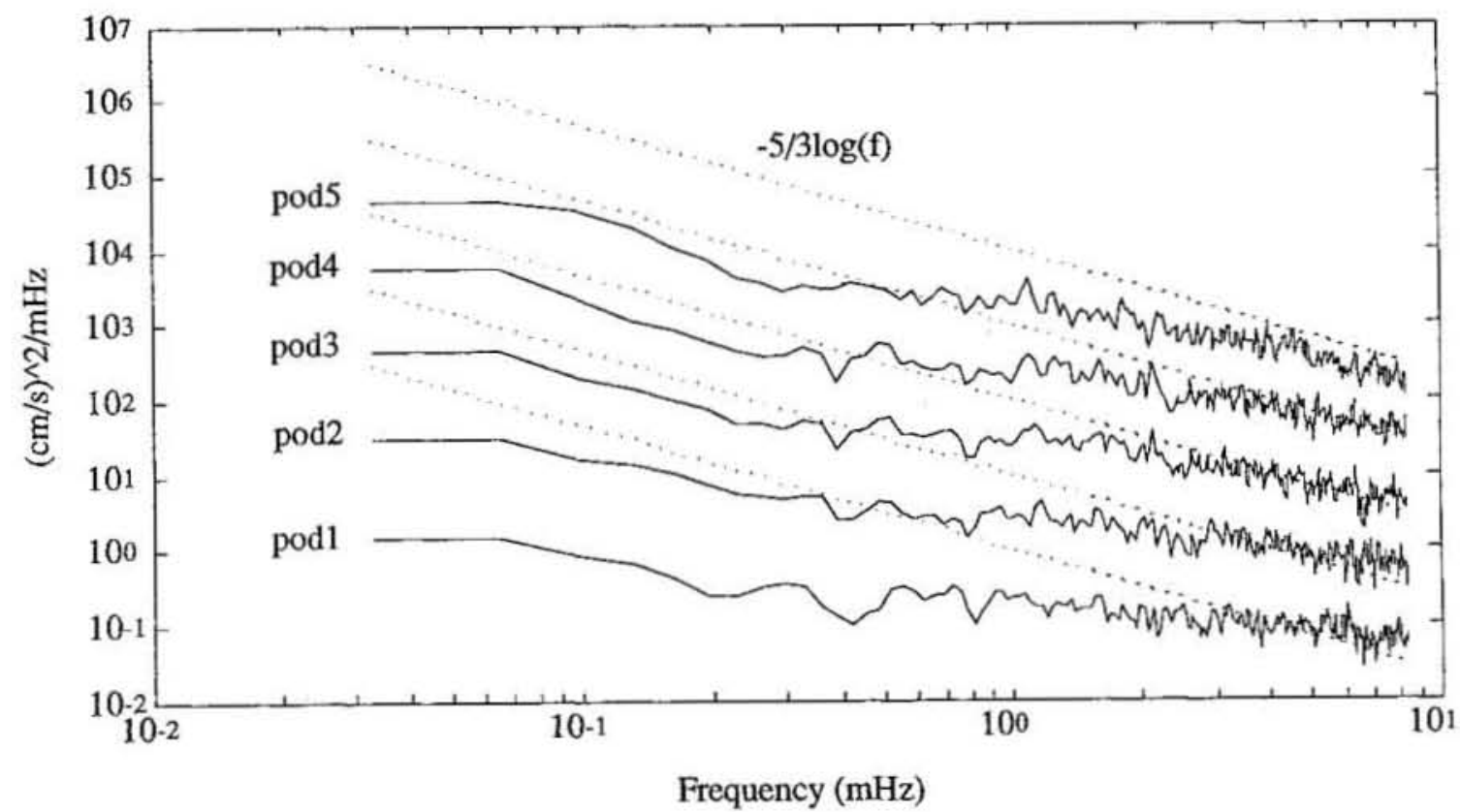

Figure 4.22: Power spectrum of vertical velocity from BS3. The top pods (3-5) show the $-5 / 3$ Log(f) behaviour at high frequencies, whereas the lower two pods do not. The spectra were offset in the vertical the same as in figure 4.21 . 
Spectra for temperature at BS3 are shown in figure 4.23. The flattening of the spectra evident at frequencies higher than $0.005 \mathrm{~Hz}$ is due to the noise floor of temperature measurement. The temperature fluctuations corresponding to this level are :

$$
\left(\frac{T^{2}}{f}\right)=2 \times 10^{-7} \mathrm{o}^{2} / \mathrm{mHz}, \mathrm{T}=0.0015^{\circ} \mathrm{C}
$$

This noise level approximately corresponds to the digitization noise floor for the temperature estimation $\left(0.0005^{\circ} \mathrm{C}\right.$, from section 3$)$.

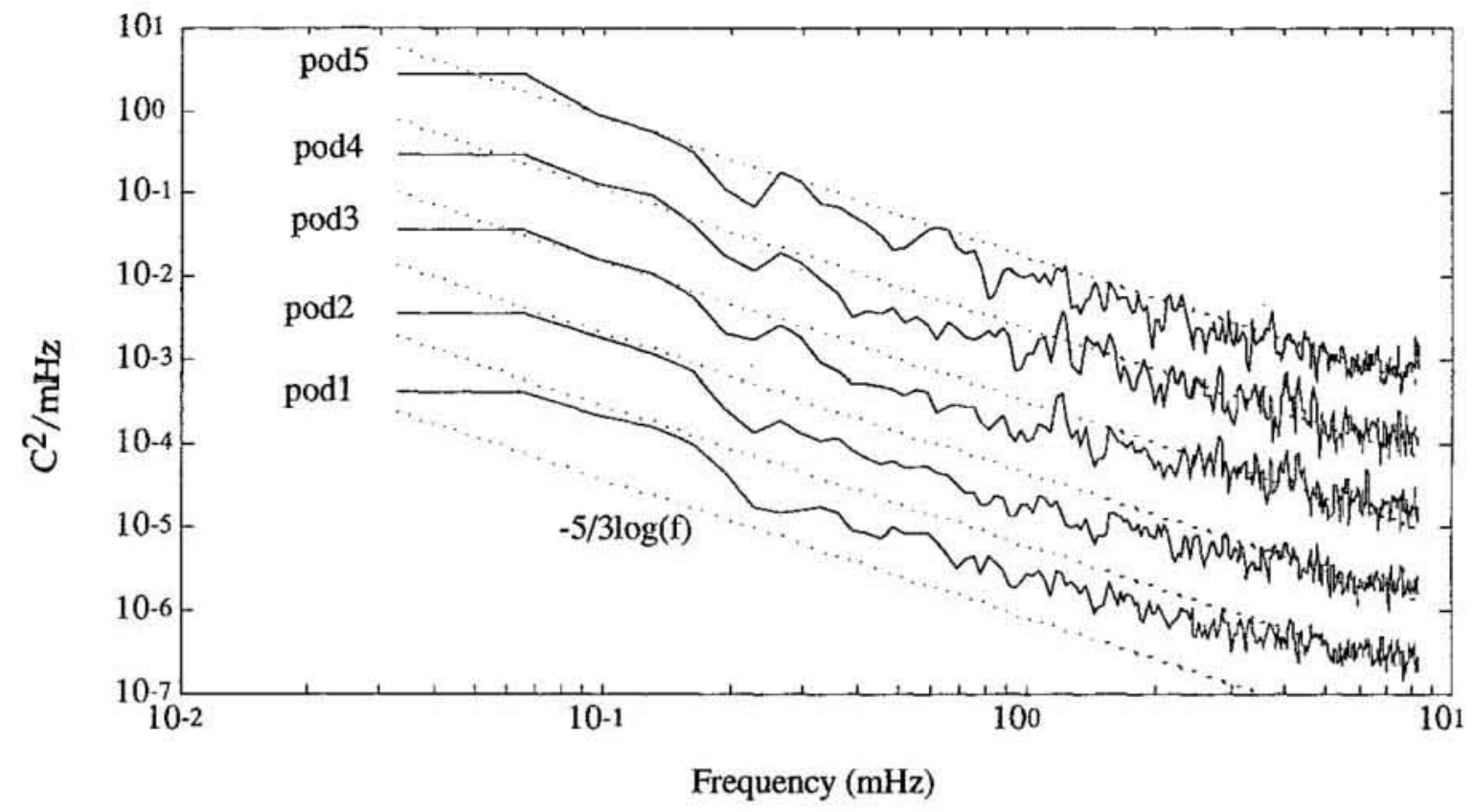

Figure 4.23: Power spectra of temperature (travel-time estimates) from BS3. All pods show the $-5 / 3$ $\log (f)$ behaviour at high frequencies. At frequencies higher than $0.004 \mathrm{~Hz}$, the spectra level off due to digitization noise at the resolution of $0.0005-0.0015^{\circ} \mathrm{C}$. The spectra were offset in the vertical the same as in figure 4.21 .

Spectra for M2 are shown in figure 4.24. The sample rate of all the MTR's was $1 / 3.75$ minutes, so the spectra do not extend as high in frequency as those from BS3 and BS4. The spectra from all sensors on all three moorings exhibit the $-5 / 3 \log (f)$ behaviour. 


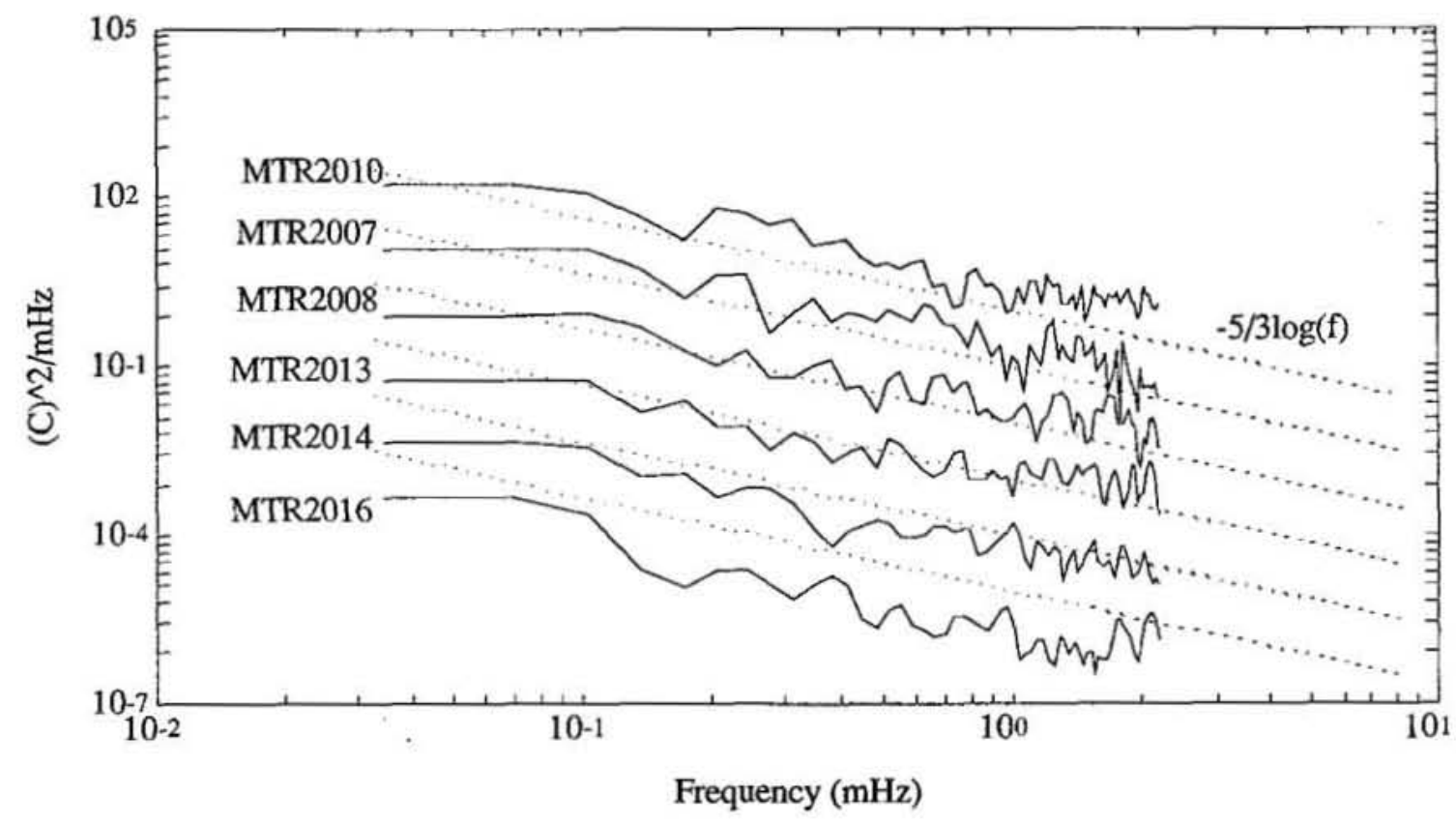

Figure 4.24: Power spectra of temperature from M2. All sensors show the $-5 / 3 L o g(f)$ behaviour over the entire spectrum. The spectra were offset in the vertical the same as in figure 4.21.

I have described measurements of velocity from BASS tripods, temperature profiles from all six instruments, mean heat flux and turbulent heat diffusion, turbulent kinetic energy, and finally power spectra of the time-series of temperature and velocity. The primary goal in acquiring all this information was to attempt to detect a plume from diffuse hydrothermal flow. I will show in the next section that the data indicates that I did in fact observe diffuse hydrothermal effluent. I will use some of the measurements to make an integrated estimate of the heat output from diffuse hydrothermal flow. 


\section{Interpretation of Field Measurements}

In this discussion of the VENTS90 measurements, I will try to:

- prove that the instruments detected diffuse hydrothermal flow that was advected horizontally along the seafloor,

- identify the source of diffuse hydrothermal flow,

- estimate the total heat output by the diffuse vents, and

- point out some additional measurements which showed interesting plume properties.

I will address each of these points in the order that they are shown above.

\section{Was Diffuse Hydrothermal Flow Detected?}

Temperature anomalies at M2 are the most striking evidence to suggest that hydrothermal flow was observed. There were six major peaks over a three day period, each almost $0.100^{\circ} \mathrm{C}$ above the background temperature (figure 4..11). These peaks coincide with local minima in the turbulent kinetic energy (figure 4.18), with a 10-hour delay (figure 4.25). The cross-correlation function is shown in Appendix C.

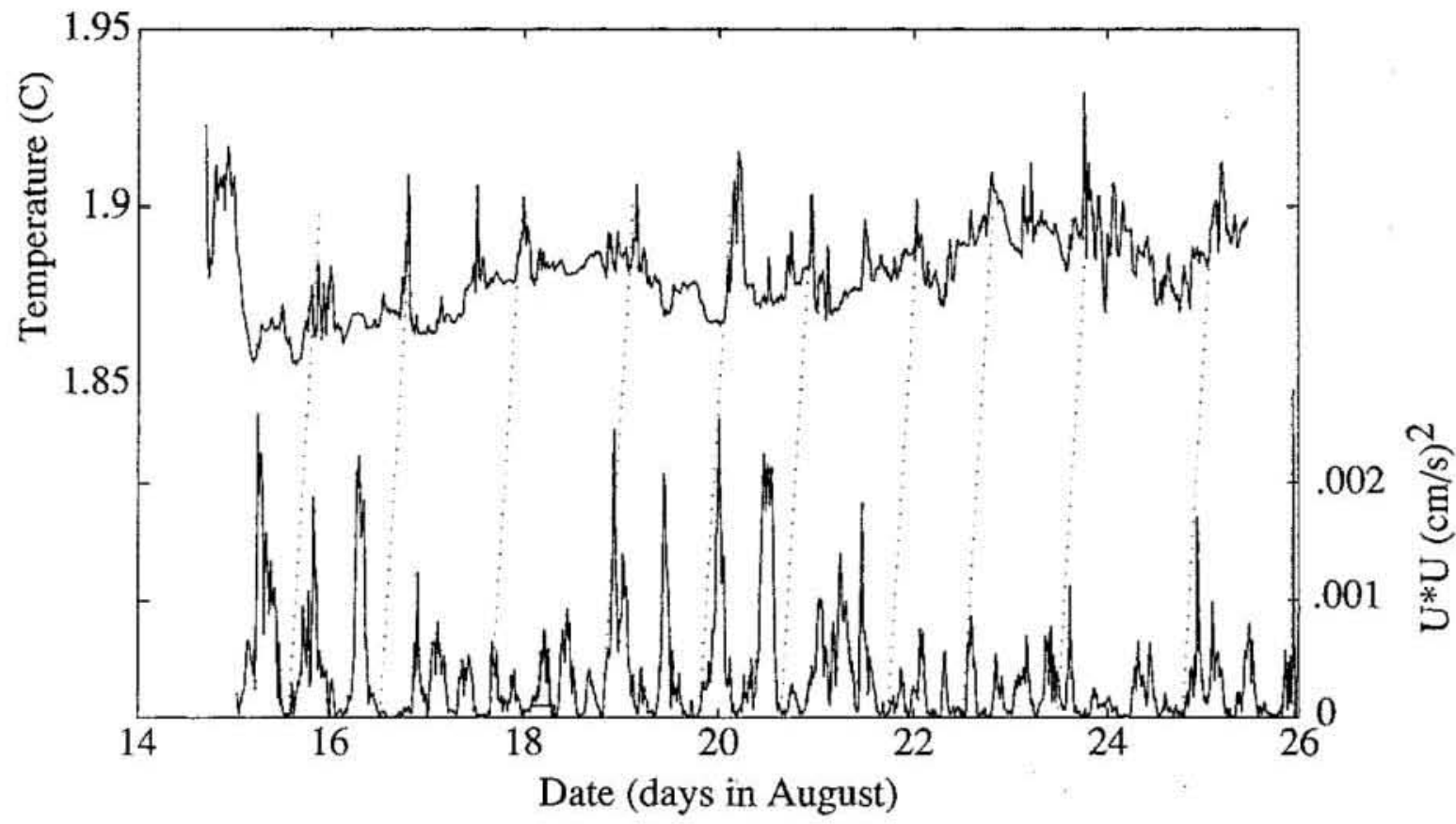

Figure 4.25: The temperatures at the lowest sensor on $M 2$ is plotted along with the turbulent kinetic energy from BS3, pod3. The turbulent kinetic energy is plotted below the temperature. The vertical scale for temperature is shown to the left, and the scale for kinetic energy is to the right. I have indicated segments of these curves which are correlated. The turbulence leads the temperature by about 10 hours, Suggestiing a causal relationship between turbulence or current, and plume temperature. 
I will play "devil's advocate" for a moment, and try to explain these measurements without involving hydrothermal flow. A temperature anomaly at the seafloor could be created if water was somehow brought down from shallower depths by topography north of M2. This water would appear warmer than the surroundings during low-mixing conditions. When the turbulence increased, the warm fluid would be diluted with bottom water, and the temperature anomaly would disappear. In order for this to be plausible, a very large topographic feature must be present. The nearest major topographic feature to $\mathrm{M} 2$ is a $100 \mathrm{~m}$ cliff on the western edge of the axial valley. The temperature gradient was on the order of $5 \times 10^{-5} \mathrm{C} \mathrm{C} / \mathrm{m}$ (Baker, 1991). Therefore, the water that could be entrained from $100 \mathrm{~m}$ above the axial valley would produce a temperature anomaly of only $0.005^{\circ} \mathrm{C}$. This would not yield the observed temperature anomalies, which were on the order of $0.050-0.100^{\circ} \mathrm{C}$. Thus, ambient temperature gradients could not have created the temperature anomalies seen on $\mathrm{M} 2$.

Suppose that the effluent from a diffuse hydrothermal source was advected past M2. How can I account for the episodic nature of the measurements, and for the correlation between M2 temperatures and turbulence measurements (figure 4.25, and the drosscorrelation functions in Appendix C)? Consider what would happen if the hydrothermal source built up a large bolus of warm water above the vent field during low-current, lowmixing conditions. When the horizontal current increased, this large volume of relatively concentrated fluid would be advected downstream, sometimes past M2. Such a scenario would require periods of slack tide to store up a large volume of concentrated vent fluid. The hydrothermal output would appear episodic at M2, and would be related to the periods of low tidal current.

In figure 4.25, there are several times when a plume should have been observed (based on the flow direction and correlation with turbulence), but none was seen. Looking at the history of the current direction and magnitude (figure $4.5,4.6$ ), the times when plumes were not seen correspond to periods when the duration of the slack tide, or the southward flow was not long enough to build up a bolus of fluid, and then transport it to M2.

The above mechanism for creating the temperature anomalies at M2 is dependent upon the presence of hydrothermal flow. There were many sources of active venting north of M2 which had temperature anomalies in excess of those observed at M2 (from both Alvin and 
towed camera surveys; Embley, 1991; Baker, 1991). If I were solving a detective novel, I would say that the suspect (diffuse hydrothermal flow) had the means, and the opportunity to create the temperature anamalies at M2 (sorry, I can't find a motive). Let's apprehend the suspect.

\section{Where did the Diffuse Flow Originate?}

Figure 4.26 shows the map of the VENTS90 deployment site with the heat flux direction plotted over the position of each of the moorings. The directions of maximum heat flux at M2 indicate that there were two different heat sources. One of these was to the north of M2, and the other was to the east. I will consider the northern source first.

The mean velocity during the first three days of deployment was $3-4 \mathrm{~cm} / \mathrm{s}$ to the south. Velocity was correlated (with no time lag ) over the entire field. BS3, BS4, and Cannon's moored current meters (several kilometers to south of the BASS tripods) showed very similar velocities (Cannon, 1991). Assuming the current north of M2 was behaving the same as observed at BS3 at the same time, then the 10-hour time lag between the turbulence minima and the temperature spikes on M2 suggest that a heat source $1 \mathrm{~km}$ north of M2 could have built up a bolus of warm water, given an advection velocity of $3-4 \mathrm{~cm} / \mathrm{s}$.

Careful comparison between the bottom temperatures on all instruments reveal a striking similarity. Figures 4.11 through 4.13 show this very clearly. The dashed lines in figure 4.11 show some examples of features which appear correlated between the instruments. Figure 4.13 shows the bottom temperature gradient at each instrument. The increase in bottom temperature gradient appears to be correlated between instruments, except for the second deployment of BS4. This may have been due to BS4's relocation near the top of a large mound, where it would have encountered a different part of the diffuse plume, having a different temperature gradient. The decay in temperature gradient fluctuations in figure 4.13 is an indication of the plume dilution from the northern source. This quantity represents the difference between vent fluid and eddies of ambient water entrained near the location of the sensor 


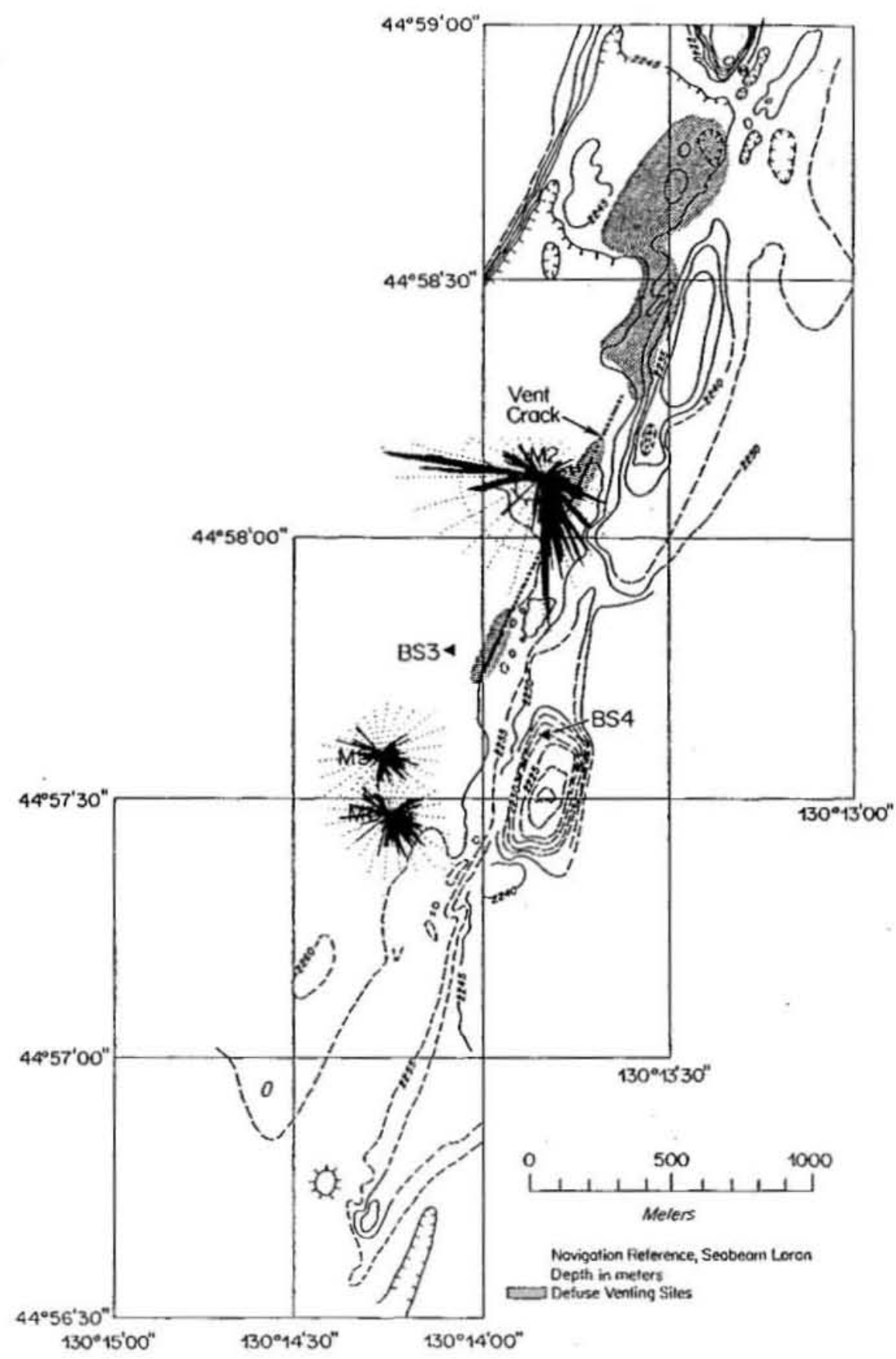

Figure 4.26: Map of the VENTS90 deployment site showing the direction and magnitude of average heat flux at the location of each of the moorings. The heat flux plots were copied from figure 4.15 
There were three temperature spikes in figure 4.12 which occurred during periods of westward flow. These are represented by the large heat flux spike shown in figure 4.26. Examination of the temperature profile at M2 (figures 4.12 and 4.27) reveals that these temperature anomalies are substantially different in appearance from those during southward flow. These anomalies exhibited maximum temperatures at the $10 \mathrm{~m}$ elevation rather than at the top of the mooring. The map of the deployment field (figure 4.26) shows that Alvin observed a small area of diffuse flow $100 \mathrm{~m}$ east of M2. This segment of the crack vent was the most likely source for diffuse flow observed during westward flow.

The two sources of hydrothermal activity were; one large source approximately $1 \mathrm{~km}$ north of M2, and a smaller source $100 \mathrm{~m}$ east of M2. The two sources were identified by two independent measurements; the temperature profile at $\mathrm{M} 2$, and the velocity direction at BS3. Temperature profiles on the other instruments indicate that the northern heat source was large enough that the temperature anomaly was detectable as far as $\mathbf{2} \mathbf{~ k m}$ downstream. In my detective novel, this would be the time when the hero would cry "book' im", and the crook (diffuse hydrothermal flow) would be hauled off to be fingerprinted.

\section{How much Energy was Output in Diffuse Plumes?}

The two sources of diffuse flow produced plumes of different heights. Due to the observations from submersibles, I expect that this difference in height was due to the size of the sources. The northern source was probably several hundred meters across, while the eastern source was less than $100 \mathrm{~m}$ long by $5 \mathrm{~m}$ wide. The horizontal dimensions of these diffuse sources is the biggest unknown in estimating heat flux. I will calculate the heat flux from the eastern source first, since it was closer to M2, and the size of its plume was thus better defined than the plume from the northern source.

Figure 4.15 shows an estimate of the heat transfer rate (the enrgy that is advected with the plume) from the eastern source to be $10 \mathrm{~kW} / \mathrm{m}^{2}$. The plume appears to have a maximum height on the order of $20 \mathrm{~m}$ above bottom (figure 4.12 ). Within this $20 \mathrm{~m}$ plume, the vertical temperature profile reaches a maximum at $10 \mathrm{~m}$. The equivalent thickness for

a plume with constant properties would be approximately $10 \mathrm{~m}$. DSV Alvin observations 
suggest that the source of this plume extended for $50-100 \mathrm{~m}$ along the central crack (figure 4.26). Heat flux from this source is:

$$
H=\left(\rho c_{p} \Delta T U\right) Z 2 Y,
$$

where the quantity in brackets was from figure 4.16. $\mathrm{Z}$ is the vertical thickness of the plume, and $\mathrm{Y}$ is the half-width. The most speculative part of this calculation is the estimate of plume width. Temperature anomaly is accurate to $\pm .005^{\circ} \mathrm{C}(= \pm 10 \%)$, velocity is known within $\pm .4 \mathrm{~cm} / \mathrm{s}(= \pm 15 \%)$ of the mean value, vertical rise height may be underpredicted by $5 \mathrm{~m}(=+50 \%)$, and the physical coefficients are no worse than $\pm 10 \%$ in error. The plume width may be as large as $100 \mathrm{~m}$, or as small as $50 \mathrm{~m}$. The range of heat flux is thus 5-20 MW from the eastern source, with the most probable value from 10-15MW, based on DSV Alvin surveys of the diffuse source (DSV Alvin dive \# 2267).

Estimating the output from the northern source is more difficult than for the eastern source. The geometry of the eastern source was fairly well defined, since it was near M2, and there is only one potential origin for the plume. The northern plume could come from any, or all of a large number of diffuse patches of venting north of M2. DSVAlvin dives revealed many segments of the central crack where warm fluid was observed for hundreds of meters. In addition, there was a high-temperature vent field $1.5 \mathrm{~km}$ north of M2 (figure 4.26).

The specific heat flux (the downstream heat transport) at M2 during southward flow was $10 \mathrm{~kW} / \mathrm{m}^{2}$ (figure 4.15 ). The plume centerline may have been higher than the $45 \mathrm{~m}$ thermistor on M2, but there are some events on M2 which appear to show the temperature leveled off near the top. Figure 4.27 shows the temperature profile at M2 during the southward and westward plume events. I will assume that the plume centerline is in fact $50 \mathrm{~m}$ from the seafloor. This makes the equivalent plume thickness equal to $50 \mathrm{~m}$. The width of the plume may be as small as $100 \mathrm{~m}$, but it is more likely to be much larger. The plume was detected at M2 during flow from almost $60^{\circ}$ of heading between south and southeast flow. This leads me to expect the plume to be very wide. BS4 detected temperature anomalies which matched those at BS3, and the tripods were separated by approximately $400 \mathrm{~m}$ in the east-west direction. An upper bound on the plume width would be to say that it covered the whole of the axial valley, appearing as smog does over Los 
Angeles in the summer. Such a plume would have a width on the order of one kilometer. Thus, the range of heat flux from this source was 50-500MW for plume width from 100$1000 \mathrm{~m}$.

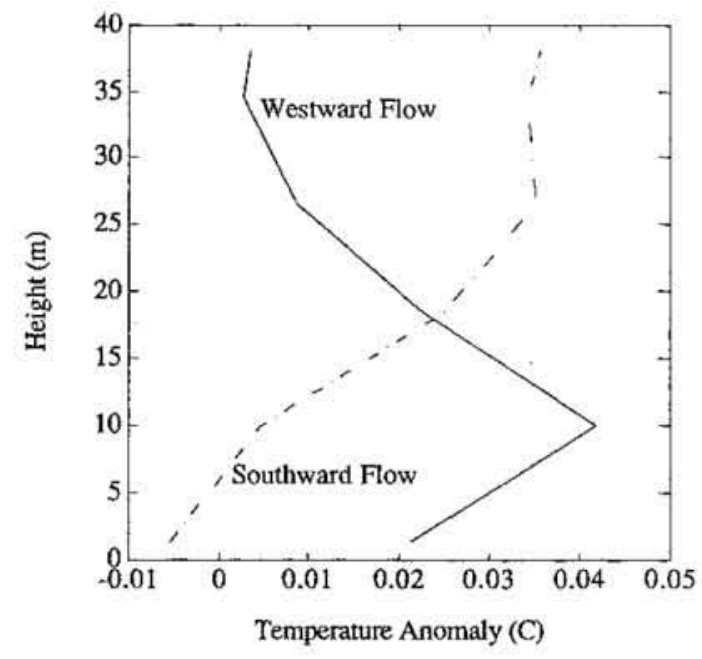

Figure 4.27: Profiles of the temperature anomalies from M2 during the westward and northward flow. The maximum temperature during westward flow was at the $10 \mathrm{~m}$ elevation, whereas the maximum temperature occurs at $40 \mathrm{~m}$ during southward flow.

More information about this plume can be found by analyzing the drop in temperature anomaly seen at all the sensors. Figure 4.28 shows a plot of temperature fluctuation versus distance from a hypothetical source $1 \mathrm{~km}$ north of M2.

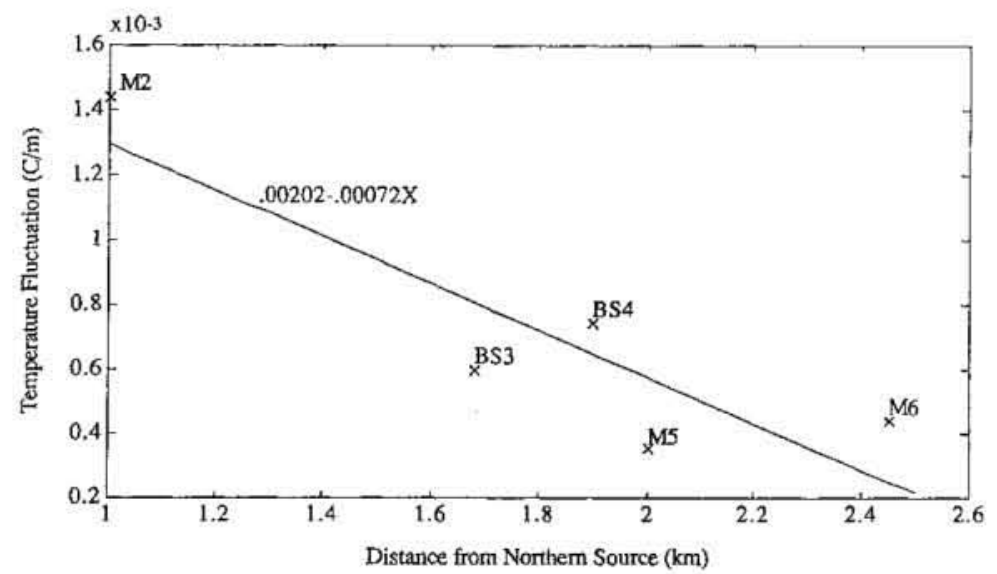

Figure 4.28 : Standard deviation of the bottom temperature gradient at each instrument in the VENTS 90 array. The data comes from calculating the stanadard deviation of fluctuations in the bottom temperature gradient shown in figure 4.13 for the times when a plume was advecting in the southward direction. The fluctuations correspond to the difference between the temperature of plume fluid versus local measurements of ambient fluid which is being entrained into the plume. 
The data plotted in figure 4.28 represents variation in local temperature gradient at each sensor during the first day of the deployment, when the flow was southward. I chose this to estimate the plume temperature decay because; it was detected at the BASS tripods as well as at the moorings, and it eliminates the effects of local temperature offsets between sensors by only comparing the magnitude of fluctuations. The fluctuations in temperature gradient at the seafloor are created by alternate sampling of plume water, and bursts of cool entrained water as the plume is advected past an instrument. A linear fit to the data is shown in the figure. This fit corresponds to the equation 2.33.

$$
\rho^{*} \approx \rho_{\mathrm{o}}^{*}\left[1-\frac{\mathrm{V}_{\mathrm{e}} W_{\mathrm{e}}}{U W_{\mathrm{O}}} \frac{\mathrm{x}}{\mathrm{Y}_{\mathrm{O}}}\right]=\beta \frac{\Delta \mathrm{T}}{\mathrm{T}_{\mathrm{o}}} .
$$

The regression in figure 4.28 shows;

$$
\Delta \mathrm{T}=0.10-0.036 \mathrm{x} .
$$

Replacing 4.2 into the density anomaly equation 4.1 yields:

$$
\begin{gathered}
\rho_{\mathrm{o}}{ }^{*}=\beta \frac{0.10}{2}{ }^{\circ} \mathrm{C}=5 \times 10^{-7} \text {, so } \\
\rho_{\mathrm{o}} \frac{{ }_{\mathrm{V}} \mathrm{V}_{\mathrm{e}}}{\mathrm{UW}_{\mathrm{O}}} \frac{1}{\mathrm{Y}_{\mathrm{o}}}=\beta \frac{0.36}{2}=1.8 \times 10^{-6} \text {, and } \\
\mathrm{Y}_{\mathrm{O}}=280 \frac{\mathrm{V}_{\mathrm{e}} \mathrm{W}_{\mathrm{e}}}{\mathrm{UW}_{\mathrm{O}}} \mathrm{m} .
\end{gathered}
$$

$V_{e}$ and $W_{e}$ are the entrainment velocities into the plume for ambient water. I will assume the ratio of $W_{e}$ to $W_{0}$ is equal to unity. This is a zeroth-order estimate, and these two velocities are of the same order of magnitude (section 2.5). A reasonable estimate for the entrainment velocity $V_{\mathrm{e}}$ is based on the turbulent kinetic energy measured by BASS. A measured value for the $\overline{U^{\prime} U^{\prime}}$ kinetic energy in a plume at $5 \mathrm{~m}$ was $0.01 \mathrm{~cm}^{2} / \mathrm{s}^{2}$. The entrainment velocity using this measurement as a basis would therefore be $0.1 \mathrm{~cm} / \mathrm{s}$. For buoyant plumes, it is common to take the entrainment velocity to be $10 \%$ of the plume centerline velocity (J.S. Turner; 1973). This is equivalent to assuming the entrainment to be proportional to the velocity shear on the boundary of a plume. For a boundary layer flow, the analogous velocity scale is the "shear velocity" (Tennekes and Lumley, 1972) which is often taken as $10 \%$ of the mean flow velocity. Thus, it is not unreasonable to assume that 
the entrainment velocity is between $0.1-0.4 \mathrm{~cm} / \mathrm{s}$ for an average horizontal current of $1 \mathrm{~cm} / \mathrm{s}$. Thus, the above relation becomes:

$$
\mathrm{Y}_{\mathrm{O}}=30-110 \mathrm{~m}
$$

where $\mathrm{Y}_{\mathrm{o}}$ is the half-width of the actual plume source. The spreading of this source is:

$$
Y=Y_{o}+\frac{V_{e}}{U} x=(30-110 m)+(.1-4) x
$$

At $1.5 \mathrm{~km}$ downstream from the source, the plume width would be $360-1,420 \mathrm{~m}$. Using the above plume width, the heat flux would be :

$$
\mathrm{H}=\left(\rho c_{\mathrm{p}} \Delta \mathrm{T}_{\mathrm{o}} \mathrm{U}\right) \mathrm{Z}_{\mathrm{o}} 2 \mathrm{Y}_{\mathrm{o}}=180-710 \mathrm{MW}
$$

This calculation would be improved dramatically if more were known of the horizontal dimensions of the diffuse plume.

\section{Additional Plume Properties}

BASS measured much more than just mean current direction and magnitude. In the VENTS'90 deployment, observations of sound speed, turbulent mixing, and turbulent heat diffusion were made. Some of this data has been discussed in connection with the estimate of hydrothermal heat output. There are aspects of these measurements which do not easily fit into a simple model for hydrothermal flow.

\section{Turbulence Measurements}

Grant, Williams and Glenn (1984) and Gross, Williams and Grant (1986) discussed measurements of benthic boundary layer phenomena in detail. In these papers, BASS was used to measure bottom turbulence for comparison with flow models. Gross, Williams and Grant (1986) measured turbulent kinetic energy of $1 \mathrm{~cm}^{2} / \mathrm{s}^{2}$ in $10 \mathrm{~cm} / \mathrm{s}$ flow . The ratio of $\overline{U^{\prime} U^{\prime}}$ to $\mathrm{U}^{2}$ was approximately $0.001-0.01$. VENTS'90 data shows this ratio to be $0.0004-0.001$. Gross, Williams and Grant comment that turbulence measured when the mean velocity was less than $5 \mathrm{~cm} / \mathrm{s}$ were in error by $\pm 40 \%$ due to resolution limits in the vertical velocity component. Mean flow during VENTS' 90 was never higher than $6-8 \mathrm{~cm} / \mathrm{s}$, and was 
typically 3-4 cm/s. At such low velocities, the Reynolds stress and turbulent kinetic energy estimates may be in error by a substantial magnitude.

The vertical profiles of Reynolds stress and turbulent kinetic energy shown in figure 4.20 indicate that turbulent mixing increases with distance from the bottom. This is observed primarily during high velocity mean flow. Such behaviour contradicts turbulent boundary layer theory (such as Monin and Yaglom, 1971). One explanation could be that mixing was caused by a mechanism not related to the boundary layer. This mechanism may be dependent upon hydrothermal flow. The turbulence generated by horizontally advected buoyant flow could be a topic for further study.

\section{Turbulent Heat Diffusion}

Figure 4.15 shows a scatter plot of the turbulent heat diffusion estimates. These plots show that the peak turbulent diffusion was $0.6 \mathrm{~W} / \mathrm{m}^{2}$. This diffusion of heat was directed primarily downward, into the seafloor. Over a $1000 \mathrm{~m}$ distance downstream from a hydrothermal source, a plume that is $200 \mathrm{~m}$ wide will transport $120 \mathrm{~kW}$ of heat into the boundary layer if this diffusion rate is constant throughout the plume. Given a total heat flux on the order of $100 \mathrm{MW}$, this is only $0.12 \%$ of the total transport. The measurement of this quantity by BASS shows that plume models which neglect the heat loss to a boundary layer on the seafloor are justified.

- Salinity Changes

Figures 3.15 and 3.16 show the comparison between temperature estimated from traveltime measurements (as described in section 3), and those estimated from a thermistor. BS4 shows excellent agreement between the two estimates. BS3, however, shows a significant discrepancy. This error cannot be explained by any straightforward electronic drift or fault in the measurement circuit. Since BS4 and BS3 were identical instruments, it is very odd that one should behave so well, while the other shows a cyclic offset with a period of two weeks.

One explanation for the offset is to suppose that the assumption of constant salinity is not correct. The salinity fluctuation necessary to produce the discrepancy shown was 
plotted in figure 3.17. The times when this function was high correspond to periods of southward flow, while the low levels correspond to northward flow. This would imply that the northern plumes were high in salinity (by 200ppm) when compared with flow from the south, where no plumes were found (Embley, 1991). BS4 may have been above the layer where salinity variations were detectable. This may expalin why BS4 did not record large salinity fluctuations. The salinity in 3.17 is not correlated with temperature fluctuations from the plume, however. I would expect that salinity and temperature should be similar since both are conservative plume properties. This is one serious inconsistency with interpretting the supposed salinity fluctuations.

Data from Baker ( 1991) shows that a CTD towed across the crack vent near this site recorded elevated salinity (by $30-60 \mathrm{ppm}$ ) at the same time as $0.100^{\circ} \mathrm{C}$ temperature spikes were observed. His data was uncertain due to a difference in conductivity and thermistor response times. Massoth (1991) has also noted some observations of elevated salinity in diffuse and black smoker hydrothermal fluids in this area.

The accuracy of BASS sound-speed measurement for estimating fluctuations in salinity has not been calibrated. I present this data as an intriguing side issue which bears further investigation into the behavior of the Juan de Fuca ridge vents, and into the potential of simultaneous travel-time and temperature measurement for long-term measurement of salinity.

\section{Conclusion: Diffuse Hydrothermal Flow during VENTS90}

I have shown that the instrument array deployed during VENTS90 successfully detected effluent from two patches of diffuse hydrothermal flow. One of these was $100 \mathrm{~m}$ to the east, and was transporting 5-20MW of heat into the bottom $20 \mathrm{~m}$ layer of water on the seafloor. The other source was $1.5 \mathrm{~km}$ north of the array, and was transporting $180-710 \mathrm{MW}$ of thermal energy into the ocean.

Additional measurements during the VENTS90 deployment have led to intriguing questions regarding the salinity of diffuse plumes, and the interaction between diffuse plume flow and mixing processes. 


\section{References}

Baker, E.T., telephone conversation and subsequent FAX of unpublished graphs of CTD data, February, 1991.

Cannon, G.A., telephone conversation, and subsequent transmission of unpublished plots of current meter data from the Juan de Fuca ridge during VENTS90, February, 1991

Cannon, G.A. , D.J. Pashinski, Circulation Near Axial Seamount, J. Geophys. Res., Vol.95, No. B8, pp. 12,823-12,828, 1990

Embley, R.W., telephone conversation, March, 1991

Grant, W.D. , A.J. Williams III, S.M. Glenn, Bottom Stress Estimates and their Prediction on the Northern California Continental Shelf during CODE-1: The Importance of Wave-Current Interaction, J. Phys. Oc., Vol.14, pp.506-527, 1984

Gross, T.F. , A.J. Williams III and W.D. Grant, Long-term in situ Calculations of Kinetic Energy and Reynolds Stress in a Deep-Sea Boundary Layer, J. Geo. Res., Vol.91, No.C7, pp.8461-8469, 1986

Little, J.N. , L. Shure, Signal Processing Toolbox for use with MATLAB: User's Guide, The Mathworks Inc., South Natick, MA, 1988

Massoth, G.J., telephone conversation, March, 1991

Monin, A.S. and A.M. Yaglom, Statistical Fluid Mechanics: Mechanics of Turbulence, Volume 1, The MIT Press, Cambridge, MA, 1971

Oppenheim, A.V. and R.W. Schafer, Digital Signal Processing, Prentice-Hall, 1975

Tennekes, H. and J.L. Lumley, A First Course in Turbulence, MIT Press, Cambridge, MA., 1972

Turner, J.S. , Buoyancy Effects in Fluids, Cambridge Univ. Press, Cambridge, 1973

YSI Incorporated, YSI Precision Thermistors catalog, Yellow Springs, Ohio, 1990 


\section{Section 5}

\section{Conclusions and Recommendations}

I have attempted to present a simple model for predicting the behaviour of flow from hydrothermal sources which are not sufficiently intense to form spectacular jets on the seafloor. Such diffuse flow covers very large portions of an active ridge crest. The total energy output from these diffuse sources has been the subject of much speculation over the past ten years. Theoretical, laboratory and numerical simulations show that it is appropriate to look for the effluent from these sources near the seafloor, quite some distance downstream of the vent source.

I selected specific instruments, and a measurement strategy was developed based on lessons that I learned from laboratory modelling. The key aspects of my measurement strategy were to obtain vertical profiles of both temperature and horizontal velocity at several locations downstream from the vent source. These measurements were compared with ones made when no hydrothermal sources were evident. The results showed that hydrothermal activity is detectable on the seafloor $1-2 \mathrm{~km}$ downstream of the vent source. 
Different sources of flow could be distinguished from one another by flow direction, and by the character of the vertical temperature profiles. A reasonable estimate of the energy output from the vents was shown using the velocity and temperature profiles.

The biggest unknown was the horizontal extent of detected vent plumes. Some assumptions were made based on observation of dilution in one of the plumes observed, and based on known source dimensions for the other plume. In both cases, the errors due to the assumptions were much larger than in any of the measured variables. Even with this limitation, the estimates of heat flux ( $450 \pm 270 \mathrm{MW}$ and $12 \pm 8 \mathrm{MW}$ for the northern and eastern sources, respectively) were reasonably reliable. A cartoon of the larger of the two diffuse plumes is shown in figure 5.1.

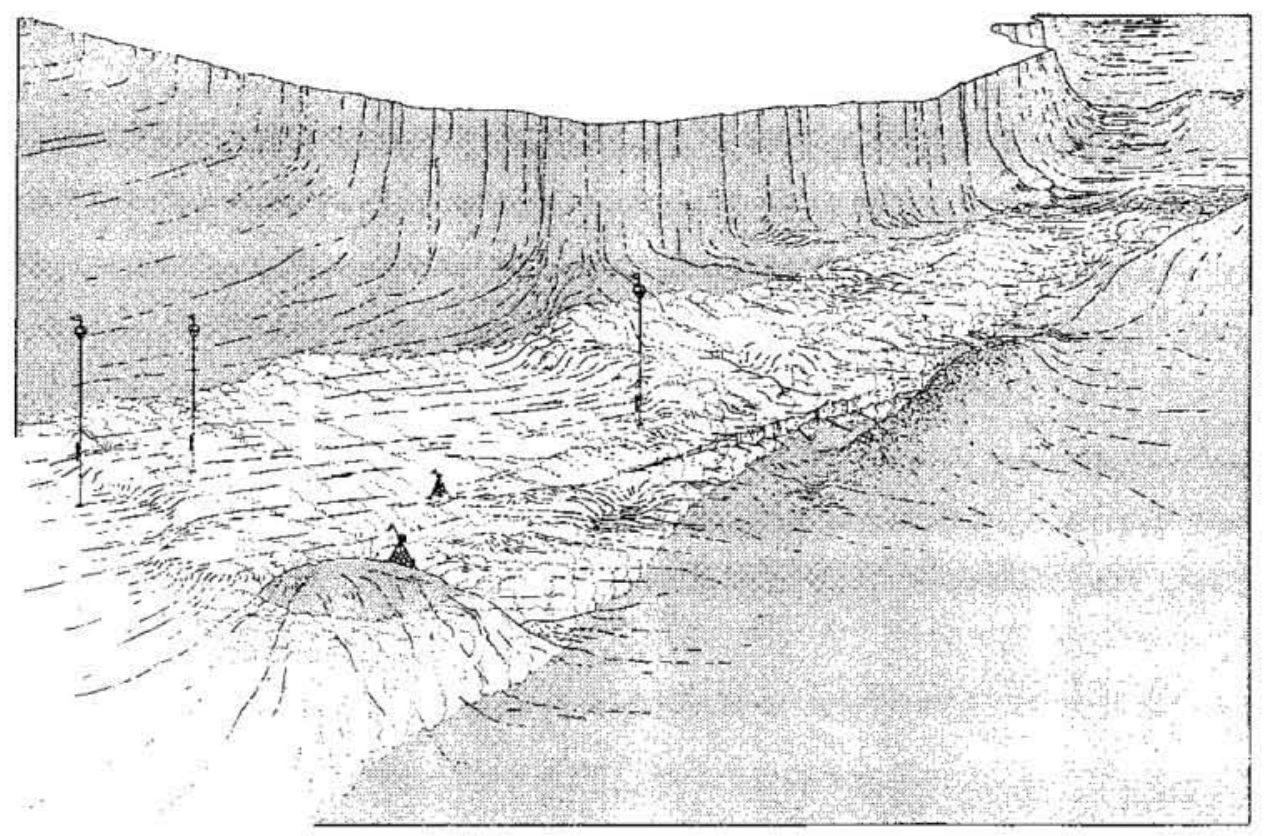

Figure 5.1: A sketch of the northern plume source at the Juan de Fuca ridge. The VENTS90 instruments are depicted in the figure. The white "smog" is shown here hugging the axial valley, at a rise height of no more than $50 \mathrm{~m}$ above the bottom. The BS4 tripod was $32 \mathrm{~m}$ above the valley floor.- The salinity evidence from 3.17 for BS3 and BS4 showed that BS3 experienced large changes in salinity, while BS4 (on top of the hil) did not experience any long-term salinity trend. 
Baker and Massoth (1987) estimated the heat flux from tow-yo surveys over the southern Juan de Fuca ridge to be $580 \mathrm{MW} \pm 351 \mathrm{MW}$. My estimate from the northern patch of diffuse flow was comparable to their estimate integrated over the plumes found in the water column.

The next step in the measurement of diffuse hydrothermal plumes will be to map the plume width as well as height and temperatrue anomaly. A field experiment which would eliminate the uncertainty in plume width would require deployment of a crossstream array as well as an instrument array aligned parallel to the ridge axis. An array to accurately monitor the total diffuse vent output could be assembled with as few as 20 small thermistor moorings deployed in two transects perpendicular to the axial crack, with each line spaced by $500-1000 \mathrm{~m}$ along the crack. This would map both the temperature field in diffuse plumes, and the spreading or dilution of the effluent.

This thermistor array would need to be punctuated with several velocity sensors which could measure low-velocity flow for long periods. Current measurement has turned out to be less crucial than originally thought, however it was very important to get good 1-hour time resolution of flow direction to correctly identify sources. Current meters used in future must be accurate to within $.5 \mathrm{~cm} / \mathrm{s}$ at velocities down to $1 \mathrm{~cm} / \mathrm{s}$. This precludes use of any existing mechanical flowmeters.

Ideally, the plume field monitor would be deployed in a region which could be surveyed to map out locations of known sources. I was fortunate to benefit from the extensive surveys of the southern Juan de Fuca ridge conducted by the NOAA VENTS program over the past ten years. The site where the experiment discussed in this thesis was deployed was very well mapped by numerous towed camera surveys, side-scan sonar tracks, SeaBeam mapping, and Alvin dives.

An array as descibed above may have the sensitivity to monitor fluctuations in vent output neccessary to relate the heat flux to other measurements such as micro-seismicity, or long-term fluid chemistry. This measurement could be made without development of new sensors, but by deploying commercially available instruments. The field measurement described in this thesis was accomplished at a total cost which was less than the fees for four days of Atlantis II/ DSV Alvin use. 
My modelling and measurement of diffuse vents shows them to be a large component of the heat budget of a seafloor hydrothermal system. This was known already. The really interesting result of my research was to show that the temperature anomaly from the diffuse venting can remain very close to the seafloor. Efforts to catalog the energy output from hydrothermal systems must not neglect the bottom $20-50 \mathrm{~m}$ of the water column. There is a lot of hydrothermal heat at that height.

\section{Reference}

Baker, E.T.,G.J. Massoth, Characteristics of hydrothermal plumes from two vent fields on the Juan de Fuca Ridge, northeast Pacific Ocean, Earth and Planet. Sci. Lett., 85, 59,1987 


\title{
Appendix A : "Discrete and Diffuse Heat Transfer at ASHES Vent Field, Axial Volcano, Juan de Fuca Ridge"
}

\author{
Peter A. Rona and D. Andrew Trivett
}

Submitted to Earth and Planetary Science Letters, 1991 


\begin{abstract}
Field measurements are used to estimate the heat flux and dispersal patterns of the discrete component of hydrothermal discharge from individual vents as point sources and the diffuse component from relatively large areas of the seafloor in the ASHES vent field located in the caldera of Axial volcano. The investigation centered on the high-temperature portion of the field, a $100 \times 100 \mathrm{~m}$ area encompassing discrete discharge $\left(\leq 326^{\circ}\right)$ from individual vents at four sulfide edifices, two anhydrite edifices, and a zone of intersecting fractures, and diffuse flow from intervening areas. Fractured lobate and sheet lava flows form the substrate. Direct measurements of effluent temperature, flow rate, and orifice diameter at all the known individual vents were made from DSV ALVIN in September 1987. A total value of $4.4 \times 10^{6} \mathrm{~W}$ was estimated for the discrete component of heat flux based on the direct measurements. A grid of temperature measurements at altitudes of $1 \mathrm{~m}$ and $20 \mathrm{~m}$ above the study area using a $1 \mathrm{~m}$-long vertical array of temperature sensors mounted at the front of DSV ALVIN's instrument platform delineated the water temperature field as a basis for estimation of the diffuse component of heat flux. Positive temperature anomalies over principal areas of diffuse flow at the $1 \mathrm{~m}$ altitude were correlated with anomalies at the $20 \mathrm{~m}$ altitude using a standard plume model. Measured water column properties, source area temperatures and diameters were used with flow rate calculated from the model to estimate a diffuse heat flux of $15-75 \times 10^{6} \mathrm{w}$. The study indicates that the diffuse component of convective heat flux is an order of magnitude greater than the discrete component in the high-temperature portion of the ASHES vent field.
\end{abstract}




\section{Introduction}

Observations of hydrothermal fields at seafloor spreading centers reveal that transfer of heat and mass from the seafloor into the water column occurs by discrete and diffuse flow (Fig. 1) $[1,2,3]$. Discrete flow comprises the focused discharge of hydrothermal solutions through individual orifices as point sources, primarily in mineralized chimneys. Heat flux from discrete sources can be calculated from direct measurements $[4,1]$, and by modeling based on jet and plume theory $[5,6,7,8,9]$.

Diffuse flow comprises the disseminated discharge of hydrothermal solutions through larger areas of the seafloor made permeable primarily by networks of fractures. Hydrothermal areas are permeated with microplumes which are individually insignificant, but collectively comprise significant thermal and mass fluxes. Areas of diffuse flow can be sufficiently extensive that their total thermal output may equal or exceed that of discrete sources such as black smokers. Although the thermal output of the diffuse component of discharge in seafloor hydrothermal fields has been hypothesized to be at least as large as the discrete component, quantification is difficult. Fluxes from diffuse sources are elusive to measure because flow velocities and fluid temperatures are low and discharge is unevenly distributed over a wide area $[2,3]$.

In this paper we describe the results of a field experiment to delineate the discrete and diffuse convective heat sources in a known hydrothermal field, the ASHES vent field in the caldera of Axial volcano on the Juan de Fuca Ridge (Fig. 2). We then estimate the total convective heat flux at a seafloor hydrothermal field based on our data. Direct measurements were employed to estimate the discrete component. A direct estimate of diffuse heat flux requires measurement of temperature and flow velocity over relatively large areas of the seafloor. This has not been technically feasible to date. In the work presented here, we measured the temperature field at 
altitudes of about $1 \mathrm{~m}$ and $20 \mathrm{~m}$ in the water column and vertical velocity of diffuse flow at points within the ASHES vent field. We use these measurements and the results of laboratory tank simulations, in conjunction with a standard buoyant plume model to estimate the diffuse component of heat flux. The laboratory tank simulations show relations between plume rise height, horizontal current, stratification, and source intensity for diffuse flow $[10,11]$. The measurements and observations reported were made from DSV ALVIN on a dive series (dive numbers 1916-1927) in September 1987.

\section{ASHES Vent Field}

The ASHES (Axial Seamount Hydrothermal Emissions study) vent field is located in the caldera of Axial volcano at the spreading axis of the central segment of the Juan de Fuca Ridge. This site is well suited for our heat flux investigation because the field has been mapped in detail (Fig. 2) $[12,13,14)$, exhibits both discrete and diffuse flow, and is limited in area and number of vents to facilitate its characterization (Fig. 1). The caldera of Axial Volcano is $8 \mathrm{~km}$ long along azimuth $020^{\circ}$ and is $3 \mathrm{~km}$ wide. The ASHES vent field occupies an area of approximately $200 \mathrm{~m} \times 1200 \mathrm{~m}$ centered at $45^{\circ} 56^{\prime} \mathrm{N}$, $130^{\circ} 01^{\prime} \mathrm{W}$ adjacent to the faulted southwest wall of the caldera. The field is situated in a subtle $4 \mathrm{~m}$ depression between depths of $1540 \mathrm{~m}$ and $1544 \mathrm{~m}$ (Fig. 2) within the shoalest region of the caldera floor which increases in depth northward to $1600 \mathrm{~m}$ at its northeast wall [14]. The depression is more-or-less rectangularly shaped and floored by fractured lobate flows, fractured sheet flows, and jumbled sheet flows [14]. The fractures in the sheet flows form an intersecting set with predominantly $\mathrm{N} 20^{\circ} \mathrm{W}$ and $\mathrm{N} 10^{\circ} \mathrm{E}$ orientations corresponding to a caldera-wide pattern of tectonic lineations parallel and transverse to the long axis of the caldera $\left(\mathrm{N} 20^{\circ} \mathrm{W}\right)$ and a subsidiary set of orthogonal intersections [13]. The location of the ASHES vent field in the caldera may be controlled by higher permeability at prin- 
cipal intersections of these tectonic lineations which channelize upwelling hydrothermal solutions, as observed at other sites on oceanic ridges [15].

Our investigation centered on the $100 \times 100$ m portion of the ASHES field that contains the seven known high-temperature sources (Fig. 2). Four of the sources are sulfide edifices (Inferno, Hell, Hillock and Mushroom) that rise 1-4 m above nearly sediment-free fractured, lobate basalt flows. The sulfide edifices incorporate multiple orifices discharging fluids that are either black or clear, are generally chloride-enriched (480-540 mnol/kg; ambient seawater $539 \mathrm{mmol} / \mathrm{kg}) \quad[16]$, and attain temperatures of $326^{\circ} \mathrm{C}$ (Table 1). Clear, high-temperature, chloride-depleted fluids (chlorinity 176-258 mnol/ kg) [16] discharge from two other sources: Virgin Mound ( $\left.\max =299^{\circ} \mathrm{C}\right)$, a $0.4-\mathrm{m}$ tall group of several white anhydrite chimneys at the boundary between jumbled and fractured sheet flows, Crack Vents $\left(T \max =226^{\circ} \mathrm{C}\right)$, a zone of anhydritefilled fractures each several meters long, $7-$ to $10-\mathrm{cm}$ wide, and about $1 \mathrm{~m}$ apart in basalt sheet flows, and an unsampled, unnamed source (New) similar in appearance to virgin Mound. The chloride-enriched (high metals) and depleted (low metals) solutions are interpreted as the brine and vapor phases, respectively, of solutions phase-separated by boiling beneath the seafloor and partially mixed with ambient seawater $[16,17]$.

A relation exists between vent types, lava flow morphology and fracture patterns [14]. The four sulfide edifices with chloride-enriched black smokers all occur in fractured lobate flows (Table 1; Inferno, Hell, Hillock, Mushroom). The two sulfate mounds and the zone of fractures that vent clear, chloride-enriched solutions occur either in jumbled sheet flows (Table 1; New), fractured sheet flows (Crack Vents), or at the boundary between jumbled and fractured sheet flows (Virgin). The distribution of low- and high-chlorinity venting is consistent with segregation of the separated brine and vapor phases by mechanisms based on differential buoyancy or relative permeability [17]. A qualitative model for the distribution of fluids 
observed at ASHES vent field suggests that brine-phase fluids are confined within flow conduits by a surrounding relative permeability barrier related to conduit diameter, while vapor-phase fluids flow diffusely into the surrounding host rock [18]. The segregation mechanism apparently favors discrete discharge of chloride-enriched fluids through sulfide edifices on fractured lobate flows and both discrete and diffuse discharge of chloride-depleted fluids partially mixed with ambient seawater through anhydrite deposits on jumbled and fractured sheet flows.

Diffuse flow is unevenly distributed in the ASHES vent field, as determined by direct observations from DSV ALVIN of schlieren effects and the temperature survey in the near-bottom water column presented in this paper (Figs. 3-5). Patches of diffuse flow with measured temperatures up to $27^{\circ} \mathrm{C}$ emanate from the four sulfide edifices between discrete orifices. Vestimentiferan tubeworms cover the four sulfide edifices, evidencing the pervasive nature of the diffuse flow through the edifices based on the association of the tubeworms with chemosynthetic bacteria that grow in the hydrothermal solutions. An area of diffuse flow (Clump vent) occurs around the base of the sulfide edifice of Hell vent. Patchy areas of diffuse flow occur in the areas between all of the seven chimney complexes and at Crack Vents. Lowtemperature diffuse venting extends intermittently to the caldera wall to the west and south of the high-temperature portion of the field.

\section{Measurement Methods}

Water temperature, flow rates, and orifice diameter were measured at discrete vents in the various chimneys described (Table 1). Water temperature was directly measured using a platinum resistance temperature detector (RTD) mounted in a probe (Yellow Springs International Model 19377), as part of an in-situ sensing and sampling system [19]. The probe was held in the centerline of flow at each vent orifice by a manipulator arm of the submersible. 
RTD specifications are a range of 0 to $500^{\circ} \mathrm{C}$, an accuracy of $1.0^{\circ} \mathrm{C}$, a resolution of $0.01^{\circ} \mathrm{C}$, and a time constant of $2 \mathrm{~s}$. Flow rates were measured by placing a vertical rod, marked at $10 \mathrm{~cm}$ intervals, at the orifice of each vent or in an area of diffuse flow. A five-minute video of the flow was made with a camera mounted on an arm of the submersible and held as nearly orthogonal to the rod as feasible within about $1.5 \mathrm{~m}$ of the vent. Flow velocities were measured by advancing the video image frame-by-frame $(0.033 \mathrm{~s}$ per frame) and timing the rise of eddies or particles in the initial $10 \mathrm{~cm}$ interval above the orifice; each flow rate reported (Table 1 ) is the average of ten determinations by this method and has an estimated error of \pm 15 percent. To test the accuracy of determinations, we compared flow velocities from the same video of one of the vents (Table 1, Hell, top: east) using our method and a method based on digital correlation of eddy images [20]. The flow velocities determined by the two different methods agree within measurement error $(30 \pm$ $5 \mathrm{~cm} / \mathrm{s}$, Table 1; $32 \mathrm{~cm} / \mathrm{s}$ with standard deviation of $13 \mathrm{~cm} / \mathrm{s}$ ) [21]. Orifice diameter was measured directly by laying a marked rod horizontally at each orifice using a manipulator arm of the submersible. Temperature measurements made with the same RID at areas of diffuse flow on and at the base of chimneys (Table 1) are considered to be minima owing to dilution by rapid mixing with ambient seawater.

Near-bottom water temperature at the hydrothermal field was measured using a vertical array of three thermistors (Fenwal part number K2365; accuracy $0.02^{\circ} \mathrm{C}$; precision $0.004^{\circ} \mathrm{C}$; time constant $2 \mathrm{~s}$ spaced $0.5 \mathrm{~m}$ apart mounted on a $1 \mathrm{~m}$ long pipe secured to the front of an instrument basket at the forward end of DSV ALVIN. The resistance of each of the four thermistors was recorded sequentially at a $0.5 \mathrm{~s}$ interval every $10 \mathrm{~s}$ in the solid state memory of a digital recorder (Sea Data model 4-TDR-1). The thermistors were calibrated from $-2^{\circ}$ to $+8^{\circ} \mathrm{C}$ in two-degree increments before and after the experiment. Water depth was obtained from the output of a pressure transducer 
(accuracy 5 dbar) which recorded continuously in the solid state memory of another digital recorder (Sea Data model 4-TDR-1) housed in a pressure case also mounted in the instrument basket.

Submersible navigation was done with a Sonatrack acoustic navigation system operated from the support vessel with an estimated positional accuracy of $20 \mathrm{~m}$ for the submersible relative to a net of four bottom-mounted acoustic transponders with 5-km baselines. The horizontal flow velocity and direction of a current prevailing during the water temperature survey was estimated at $7 \pm 3 \mathrm{~cm} / \mathrm{s}$ to the north based on the set of the submersible along lines steered east-west at a speed of 1 knot $(1.85 \mathrm{~km} / \mathrm{h})$ within the acoustic navigation net. This estimate is consistent with the nearest current meter array moored at a depth of $1855 \mathrm{~m}$ on a sill on the western side of Axial Volcano about $10 \mathrm{~km}$ from the caldera, which recorded 7-15 cm/s to the north throughout the day of our temperature survey (September 23, 1987) [22].

\section{Discrete Component of Heat Flux}

Measurements of fluid temperature, diameter, and flow rate, were made at each of the orifices on six of the seven chimney complexes known in the ASHES vent field. The measurements were used to calculate heat flux with the following equation [4]:

$$
\mathrm{H}=\pi \mathrm{r}^{2} \text { vp Cp } \Delta \mathrm{T}
$$

where $\mathrm{H}$ is the hydrothermal heat loss (W), $\mathrm{r}$ is the radius of the vent orifice (cm; measured), $\mathrm{v}$ is the flow rate $(\mathrm{cm} / \mathrm{s}$; measured in the initial $10 \mathrm{~cm}$ above the orifice), $p$ the density of the vent water (Table 1; Bischoff and Rosenbauer, 1985), Cp the heat capacity (Table 1; Bischoff and Rosenbauer, 1985), and $\Delta T$ the temperature difference between the ambient water and the hydrothermal fluid $\left({ }^{\circ} \mathrm{C}\right.$; temperature measured at orifice). An inventory of the 
measurements and heat fluxes is presented in Table 1 . Ranges of values measured at individual orifices are 20 to $90 \mathrm{~cm} / \mathrm{s}$ for flow rate, 108 to $326^{\circ} \mathrm{C}$ for fluid temperature, and 1 to $7.5 \mathrm{~cm}$ for orifice diameters. These individual measurements yield a range of heat outputs between $0.019 \times 10^{6}$ and $1.540 \times 10^{6} \mathrm{~W}$. The seventh chimney complex is a previously unknown source, similar in appearance to Virgin Mound, that was observed from the submersible (Dive 1927) several meters southeast of Hillock, but was not measured. Heat output of this source (New) is assumed to be equivalent to that of Virgin Mound. The sum of the convective heat flux of each of the known discrete orifices is $4.4 \times 10^{6} \mathrm{~W}$ (Table 1). A video of the ASHES vent field made in August 1986, one year prior to the measurements reported here [23], showed a visibly higher intensity of venting from the two orifices at the top of the Hell sulfide edifice indicating significant changes of mass flow rate in a period of one year or less.

\section{Diffuse Component of Heat Flux}

A near-bottom temperature survey was carried out to record the anomalies associated with diffuse discharge. Temperature measurements were made with the $1 \mathrm{~m}$-Iong array of temperature sensors mounted on DSV ALVIN along two grids. The grids were laid out as sets of orthogonal lines $100 \mathrm{~m}$ long spaced $20 \mathrm{~m}$ apart at altitudes of about $1 \mathrm{~m}$ and $20 \mathrm{~m}$ above the seafloor. The $1 \mathrm{~m}$ altitude was maintained visually by the submersible pilot; the $20 \mathrm{~m}$ altitude was maintained using the digital readout of the pressure depth sensor (accuracy $1 \mathrm{db})$ on the submersible. To run the grids the submersible pilot was directed from the support ship by underwater telephone. The actual tracklines are skewed by prevailing currents, as noted, and shortened owing to time constraints (Figs. 3, 4).

The temperature survey conducted from ALVIN was merged with navigation data. A computer contouring routine was used to construct isotherm maps of the 
study site at the $1 \mathrm{~m}$ and $20 \mathrm{~m}$ altitudes above the seafloor (Figs. 3,4 ). It is clear that the contouring algorithm has introduced artifacts. For example, some of the warm anomalies have been formed into roughly circular patches by contouring based on data along single tracklines. For the purpose of estimating heat output from the three diffuse vent patches identified, we have extracted the approximate characteristic plume diameter, plume average temperature anomaly, and rough downstream displacement between the $1 \mathrm{~m}$ and $20 \mathrm{~m}$ altitude anomalies on the isotherm maps.

The $1 \mathrm{~m}$ survey is below the level of discharge of the major discrete sources from the sulfide edifices (Table 1). The discrete sources were observed to rise rapidly above the survey level without much lateral spreading, consistent with tank experiments by Trivett [10] (Fig. 1). The $1 \mathrm{~m}$ altitude map shows three principle areas of diffuse venting primarily located around the Hell, Hillock and Mushroom sulfide edifices (Fig. 3). This corresponds with visual observation from the submersible of areas of noticeable diffuse discharge. The maximum temperature anomalies associated with the diffuse sources occurred on the northwest side of these three edifices. Vertical velocities of diffuse flow measured in five areas within ASHES vent field near the sulfide edifices and crack vents ranged between 5 and $10 \mathrm{~cm} / \mathrm{s}$ (Table 2).

The temperature anomalies identified in the $1 \mathrm{~m}$ altitude isotherm map are matched with their corresponding anomalies on the $20 \mathrm{~m}$ altitude map based on consideration of spatial patterns and source parameters. Three areas of diffuse flow are identified on the $1 \mathrm{~m}$ altitude map (Fig. $3 ; \mathrm{A}_{1}, \mathrm{~B}_{1}, \mathrm{C}_{1}$ ). The three areas form a right triangle with sides $B C$ and $A B$ oriented north-south and east-west, respectively. Area $\mathrm{C}$ is the largest area with the highest temperature anomaly; area $B$ is the smallest area with the lowest temperature anomaly. The three areas of highest temperature anomalies on the $20 \mathrm{~m}$ altitude map (Fig. $4 ; \mathrm{A}_{20}, \mathrm{~B}_{20}, \mathrm{C}_{20}$ ) lie to the north-northwest of areas $\mathrm{A}_{1}, \mathrm{~B}_{1}$, and $\mathrm{C}_{1}$ 
(Fig. 3), as expected for corresponding anomalies under the prevailing current flow. The three areas at $20 \mathrm{~m}$ altitude are oriented and configured with respect to one another in a pattern similar to the three areas at $1 \mathrm{~m}$ altitude. However, the sides $A B$ and $B C$ at $20 \mathrm{~m}$ altitude are not aligned east-west and north-south, but have apparently rotated clockwise relative to the $1 \mathrm{~m}$ altitude triangle. Different offsets are observed between the three areas at the two altitudes.

The observed changes in orientation and offset may result from differences in source parameters (temperature anomaly, area of anomalous temperature, and vertical flow velocity) at the three areas. The Environmental Protection Agency (EPA) UMERGE model designed to model buoyant plumes from sewage outfalls in the ocean $[24,25,26]$ was applied to calculate the relation between plume trajectories and source parameters. UMERGE, as described in [25], calculates plume properties in a linearly stratified cross-flow using a Lagrangian formulation of the conservation equations for mass, vertical momentum, horizontal momentum, temperature, and salinity. The model deals exclusively with two-dimensional problems. We have assumed uniform velocity profiles and a linear density gradient in the application of this model to our problem. We have neglected any contribution from salinity differences between the vent fluid and the ambient seawater. Our sensitivity analysis showed that the salinity difference produced by dilution with ambient seawater of an undiluted, high-temperature hydrothermal fluid to attain the state of the source fluid for diffuse venting is too small to have a measurable impact on our results.

A stable density gradient positive downward for the water column was used in the model based on a Brunt-Vaisala frequency of $0.005-0.012 \mathrm{rad} / \mathrm{s}$ calculated from three vertical conductivity-temperature-depth (CTD) profiles. The profiles were recorded with a Seabird CTD mounted on DSV ALVIN during dives to the ASHES vent field in 1988 [27]. The trajectories of the three 
buoyant plumes were calculated using the UMERGE model to reproduce the horizontal offsets, diameters, and temperature anomalies at 1 and $20 \mathrm{~m}$ altitudes observed at areas $A, B$ and $C$ on the isotherm maps (Figs. 3, 4). The plot of the three plume trajectories (Fig. 6) and source parameters derived from the model calculations are in reasonable agreement with the observed offsets and measured source parameters (source diameter and temperature) for the three plumes (Table 2); the calculated source vertical velocities (5.5$14 \mathrm{~cm} / \mathrm{s}$ ) are close to the range measured at other points in the hydrothermal field (Table 1; 5-10 cm/s). The source vertical velocity representative of an area may be less than that of individual microplumes within the area. The calculated effective dilution of the plume by mixing during its rise from 1 to $20 \mathrm{~m}$ is similar to that estimated from the measured data (Table 2).

The calculated trajectories (Fig. 6) and source parameters help to explain the difference in offsets of the three areas of temperature anomalies at the $20 \mathrm{~m}$ altitude (Table 2). The larger offset of plume $A$ than that of $B$ or $C$ may result if the vertical flow velocity of $A$ is relatively small despite its larger area limiting its upward penetration as it drifts downcurrent. Plume B originates from a smaller area with a lower temperature anomaly than A, so that its vertical velocity would have been high to penetrate to the $20 \mathrm{~m}$ altitude. A relatively large source area and temperature anomaly at $1 \mathrm{~m}$ altitude at area C corresponds to the largest area of warm water observed at $20 \mathrm{~m}$ altitude and the highest rise calculated by the model for plume $\mathrm{C}$. Anomalies $\mathrm{A}, \mathrm{B}$, and $\mathrm{C}$ at $20 \mathrm{~m}$ altitude are situated in the northwest quadrant of the isotherm map where the temperature field is highest, consistent with coalescing at that altitude of diffuse flow from the source areas of these anomalies at $1 \mathrm{~m}$ altitude (Figs. 3,4 ). The explanation of plume trajectories offered can only be confirmed by knowledge of the maximu rise height of the three plumes, such as may have been obtained by additional temperature surveys at higher altitudes. 
A profile of temperatures recorded on the three sensors of the $1 \mathrm{~m}$ long vertical array at the $1 \mathrm{~m}$ altitude shows stable temperature gradients (neutral to cooling downward) over the Crack Vents area and unstable gradients (mixed and warming downward) over the areas of diffuse venting to the northwest of Hillock and Inferno (Fig. 5). These gradients are consistent with the observation that the temperature anomalies recorded over the diffuse venting areas around the sulfide edifices buoyantly rise. A temperature anomaly corresponding to diffuse venting in the crack Vents area does not appear in the $20 \mathrm{~m}$ altitude survey. Either the area traversed over the crack vents lacks the buoyancy flux to penetrate to $20 \mathrm{~m}$ as suggested by the stable gradient measured at $1 \mathrm{~m}$ altitude (Fig. 5), or the sampling grid missed a corresponding area of anomalous temperature.

Convective heat flux was calculated for the three diffuse source areas with plumes at $20 \mathrm{~m}$ altitude using equation 1 (Table 2). Average temperature anomaly and area of anomalous temperature were taken from the $1 \mathrm{~m}$ altitude isotherm map (Fig. 3). Diffuse flow rate (v) in equation 1 was estimated with UMERGE (Table 2) and is consistent with diffuse flow rate measured at other areas of ASHES vent field (Table 1). Measured and calculated source characteristics are presented in Table 2. Source area $\mathrm{C}$ has the largest flux related to size of its area and magnitude of temperature anomaly $\left(54.5 \times 10^{6} \mathrm{~W}\right)$. The heat flux from source areas $A$ and $B$ is proportionally smaller $\left(6.9 \times 10^{6} \mathrm{~W}\right.$ and $3.2 \times 10^{6} \mathrm{~W}$, respectively) for a total estimated convective heat flux from the three diffuse source areas of $65 \times 10^{6} \mathrm{~W}$ for the prevailing current velocity of $7 \mathrm{~cm} / \mathrm{s}$.

\section{Discussion}

Several uncertainties exist in our estimate of heat flux from diffuse sources in the ASHES vent field. It was implicitly assumed that stratification was entirely due to temperature and that salinity was constant in the ambient 
environment. This assumption was justified by comparing the Brunt-Vaisala frequency calculated using temperature data from the measured temperature field with that calculated from CID measurements. The frequency based on temperature alone is comparable to that based on CID measurements. This observation implies that salinity differences play a minor role in the ambient stratification. The source velocity necessary to produce the observed anomalies would decrease if lower salinities based on a separate chloridedepleted phase $[16,17]$ were used for the diffuse flow.

Another concern is whether the $20 \mathrm{~m}$ altitude temperature anomalies were indeed matched with their corresponding sources at $1 \mathrm{~m}$ altitude. Typical trackline spacing of the $20 \mathrm{~m}$ altitude survey in the area of interest is $30 \mathrm{~m}$. The UMERGE plume model shows that the observed source conditions could have produced the temperature anomalies measured at $20 \mathrm{~m}$ altitude. The UMERGE plume model further shows that offsets between discharge at the orifices of discrete sources and the $20 \mathrm{~m}$ altitude (c. $10 \mathrm{~m}$ ) would be less than for diffuse sources (Table 2) owing to the greater buoyancy flux and smaller mixing cross-section of the discrete sources. Gaps in coverage at $20 \mathrm{~m}$ altitude precluded recording of anomalies from the discrete sources (Fig. 4). The presence of additional anomalies is suggested by a CID/rosette tow over the north end of the ASHES vent field which recorded and sampled four separate areas of thermal and chemical anomalies within $15 \mathrm{~m}$ of the seafloor in August $1987[28]$.

Not all the diffuse sources in the study area contributed to the temperature anomalies at $20 \mathrm{~m}$ altitude. Stable temperature gradients measured at about $1 \mathrm{~m}$ altitude over the portion of the Crack Vents area traversed (Fig. 5) indicate that a component of the diffuse flow is being advected by the prevailing current at less than $20 \mathrm{~m}$ above the seafloor. The presence of this weak diffuse flow, the tendency noted to underestimate the areas of diffuse sources owing to limited trackline control for the isotherm contouring 
routine, and the presence of diffuse sources outside of the study area, all contribute to underestimation of the diffuse component of convective heat transfer in ASHES vent field.

An additional uncertainty in the diffuse heat flux estimate comes from the plume model itself. Laboratory tank simulations of relations between plume rise height, horizontal current, density stratification, and source Intensity for diffuse flow show that standard plume models such as UMERGE agree well with the simulations when the rise height of the plume is greater than the source area diameter [10]. As plume rise height approaches source area diameter, the standard model over-predicts the source intensity necessary to produce the rise height. Comparison between simulations and laboratory data indicates that this over-prediction is within a factor of two for the weakest diffuse plumes. For the worse case estimate that UMERGE over-predicts the necessary source intensity to produce a given plume by a factor of two, our calculated source vertical velocities between 5.5 and $14 \mathrm{~cm} / \mathrm{s}$ would reduce to 3-7 cm/s (Table 2). The total diffuse heat flux from the three source areas would decrease to $15-38 \times 10^{6} \mathrm{~W}$ as a lower estimate. Alternatively, if all three source areas (Fig. 3, A, B, C) exhibited the same heat flux/area ratio as area $c$, then the total diffuse heat flux from these areas would be $75 \times 10^{6} \mathrm{~W}$, as an upper estimate.

\section{Conclusions}

The convective heat flux from discrete vents on four sulfide edifices (Inferno, Mushroom, Hell, Hillock) and two anhydrite mounds (Virgin and New) in the high-temperature portion of the ASHES vent field is $4.4 \times 10^{6} \mathrm{~W}$ based on an inventory of direct measurements made from DSV ALVIN in September 1987. Prior observations suggest that the mass flow rate of venting at individual sulfide edifices may fluctuate substantially on an annual or shorter term basis. We have applied a standard plume model to facilitate estimation of 
heat flux from the three principal areas of diffuse flow observed at the high-temperature portion of the ASHES vent field using measurements of near-bottom water temperature field and prevailing current velocity. Diffuse heat flux from these three areas is shown to be between 15 and $75 \times 10^{6} \mathrm{~W}$ with intervening areas of weaker diffuse flow unaccounted for.

The diffuse flow does not merge to form a single plume that rises to one level, but separates at various levels related to a balance between buoyancy flux, ambient density stratification, and prevailing current velocity. The areas of most intense diffuse flow distinctly occur around and between discrete high-temperature vents (Figs. 3, 4).

The evidence presented indicates that convective heat transfer of diffuse flow from areas of the seafloor exceeds that of discrete flow from point sources in the high-temperature portion of the ASHES vent field by an order of magnitude [29]. Similar work is needed at other seafloor hydrothermal fields to test the hypothesis that diffuse flow is the dominant process of convective heat transfer at oceanic ridges. 


\section{Acknowledgments}

We thank Captain R. Baker and complement of RV ATIANTIS II and Expedition Leader R. Hollis and group of DSRV ALVIN, and Chief Scientist S. Hammond for support on NOAA VENTS Program 1987 cruise to Axial Volcano. J. Morton of the U.S. Geological Survey directed the acquisition and processing of acoustic navigation data. Thanks for help in making vent observations to members of the dive team B. Applegate, D. Butterfield, A. DeBevoise, R. Embley, R. Feely, C. Fox, J. Franklin, S. Little, J. Lupton, G. Massoth, R. McDuff, K. Murphy and v. Tunnicliff. W. Frick provided EPA software and advice on the UMERGE program. G. Massoth and R. Feely provided CID data. G.A. Cannon provided current meter data. J. Bischoff and R. Rosenbauer provided information on seawater properties at high temperatures and pressures. We appreciate helpful reviews by E. Baker and J. Cann. PAR thanks the NOAA VENTS Program for support. The work of DAT is the result of research sponsored by NOAA National Sea Grant College office, U.S. Department of Commerce, under grant number NA86-AA-D-SG090, wHOI Sea Grant Project number R10-11-PD. The U.S. Government is authorized to produce and distribute reprints for governmental purposes, notwithstanding any copyright notation that may appear herein. 


\section{References}

1. Converse, D.R., H.D. Holland, and J.M. Edmond, Flow rates in the axial hot springs of the East Pacific Rise $21^{\circ} \mathrm{N}$ : Implications for the heat budget and the formation of massive sulfide deposits, Earth planet. Sci. Lett., 69, 159-175, 1984.

2. Little, S.A., K.D. Stolzenbach, and F.J. Grassle, Tidal current effects on temperature in diffuse hydrothermal flow: Guaymas Basin, Geophys. Res. Lett., 15, 1491-1494, 1988.

3. Rona, P.A., and K.G. Speer, An Atlantic hydrothermal plume: Trans-Atlantic Geotraverse (TAG) area, Mid-Atlantic Ridge crest near $26^{\circ} \mathrm{N}$, J. Geophys. Res., 94, 13,879-13,893, 1989.

4. Macdonald, K.C., K. Becker, F.N. Spiess, and R.D. Ballard, Hydrothermal heat flux of the "black smoker" vents on the East Pacific Rise, Earth Planet. Sci. Lett., 48, 1-7, 1980.

5. Rouse, H., C.-S. Yih, and H.W. Humphreys, Gravitational convection from a boundary source, Tellus, 4, 201-210, 1952.

6. Morton, B.R., G.I. Taylor, and J.S. Turner, Turbulent gravitational convection from maintained and instantaneous sources, Proc. ‥ Soc. London, Ser. A, 234, 1-23, 1956.

7. Turner, J.S., Buoyancy Effects in Fluids, 367 pp., Cambridge University Press, New York, 1973.

8. Lowell, R.P, and P.A. Rona, On the interpretation of near-bottom water temperature anomalies, Earth planet. Sci. Lett., 32, 18-24, 1976.

9. Little, S.A., K.D. Stolzenbach, and R.P. Von Herzen, Measurements of plume flow from a hydrothermal vent field, I. Geophys. Res, $\underline{92}$, 2587-2593, 1987.

10. Trivett, D.A., A.J. Williams, III, and J.R. Cann, Measurement and modeling of diffuse flow at seafloor hydrothermal fields, in prep. 
11. Cann, J.R., D.A. Trivett, and A.J. Williams III, A practical model of diffuse hydrothermal flow, EOS, Trans. Amer. Geophys. Union, 71, 143, 1990.

12. Malahoff, A., G. McMurtry, S. Hammond, and R. Embley, High-temperature hydrothermal fields - Juan de Fuca Ridge - Axial Volcano, EOS, Trans. Amer. Geophys. Union, 65, 1112, 1984.

13. Embley, R.W., K.M. Murphy, and C.G. Fox, High resolution studies of the summit of Axial Volcano, ‥ Geophys. Res., 95, 12,785-12,812, 1990.

14. Hammond, S.R., Relationships between lava types, seafloor morphology, and the occurrence of hydrothermal venting in the ASHES vent field of Axial Volcano, J. Geophys. Res.., 95, 12,875-12,893, 1990.

15. Rona, P.A., R.P. Denlinger, M.R. Fisk, K.J. Howard, G.L. Taghon, K.D. Klitgord, J.S. MCClain, G.R. MCMurray, and J.C. Wiltshire (Federal/State Gorda Ridge Technical Task Force Working Group B), Major off-axis hydrothermal activity on the northern Gorda Ridge, Geology, 18, 493-496, 1990.

16. Massoth, G.J., D.A. Butterfield, J.E. Lupton, R.E. McDuff, M.D. Lilley, and I.R. Jonasson, Submarine venting of phase-separated hydrothermal fluids at Axial Volcano, Juan de Fuca Ridge, Nature, 340, 702-705, 1989.

17. Butterfield, D.S., G.J. Massoth, R.E. MCDuff, J.E. Lupton, and M.D. Lilley, The geochemistry of hydrothermal fluids from ASHES vent field, Axial Seamount, Juan de Fuca Ridge: Subseafloor boiling and subsequent fluid-rock interaction, J. Geophys. Res., 95, 12,895-12,921, 1990.

18. Fox, C.G., The consequences of phase separation on the distribution of hydrothermal fluids at ASHES vent field, Axial Volcano, Juan de Fuca Ridge, J. Geophys. Res.., 95, 12,923-12,926, 1990.

19. Massoth, G.J., H.B. Milburn, S.R. Hammond, D.A. Butterfield, R.E. McDuff, and J.E. Jupton, The geochemistry of submarine venting fluids at Axial Volcano, Juan de Fuca Ridge: New sampling methods and program rationale. 
M.B. De Luca and I Babb, Editors, Global Venting, Midwater and Benthic Ecological Processes; National Undersea Research Program, Research Report $88-4,29-59,1988$.

20. Wells, J.T., M.O. Smith, V.A. Atnipp, and R.E. McDuff, Determinating fluid velocity of black smoker jets from digital correlation of video images, EOS, Trans. Amer. Geophys. Union, 70, 1383, 1989.

21. J.T. Wells, personal comminication.

22. Cannon, G.A., and D.J. Pashinski, Circulation near Axial Seamount, J. Geophys. Res.., 95, 12,823-12,828, 1990.

23. R.W. Embley, personal commication.

24. Frick, W.E., Non-empirical closure of the plume equations, Atmos. Envir., $\underline{18}, 653-662,1984$.

25. Muellenhoff, W.P., A.M. Soldate, Jr., D.J. Baumgartner, M.D. Schuldt, L.R. Davis, and W.E. Frick, Initial mixing characteristics of municipal ocean discharges; Volume 1 - Procedures and Applications, U.S, Environmental Protection Agency Report, EPA-600/3-85-073a, 1985.

26. EPA (Environmental Protection Agency), Initial mixing characteristics of municipal ocean discharges: Volume I. Procedures and applications: EPAV 600/3-85 073a, 77 p., 1985.

27. G.J. Massoth and R.A. Feely, personal communication.

28. Baker, E.T., R.E. MCDuff, and G.J. Massoth, Hydrothermal venting from the summit of a ridge axis seamount: Axial Volcano, Juan de Fuca Ridge, J. Geophys. Res.. 95, 12,843-12,854, 1990.

29. Rona, P. A., and D. A. Trivett, Discrete and diffuse heat transfer at ASHES Vent Field, Axial Volcano, Juan de Fuca Ridge, EOS, Trans. Amer. Geophys. Un., 71, 1570, 1990. 
Figure Captions

Figure 1. Cartoon showing how plumes from discrete and diffuse sources in a seafloor hydrothermal field achieve density equilibrium with surrounding seawater at different altitudes above the seafloor in a stably stratified water column. Diffuse source areas comprised of multiple microplumes actually exhibit a patchy distribution on the seafloor and coalesce to produce larger plumes that rise to different heights generally lower than rise heights of plumes from discrete sources. The plumes are deflected by a prevailing current.

Figure 2. Bathymetric map of ASHES vent field based on DSRV ALVIN pressure sensor (accuracy $1 \mathrm{dbar}$ ) and altimeter (isobath interval $0.5 \mathrm{~m}$; modified from [14]). The map shows locations of the seven known high-temperature vents (solid triangles). Three areas of positive temperature anomalies related to diffuse flow are noted (A, B, C). $A-A^{\prime}$ is the line of the temperature profile shown in Figure 5. An index map shows the location of ASHES vent field in the caldera of Axial volcano at the axis of the central Juan de Fuca Ridge.

Figure 3. Isotherm map (interval $0.020^{\circ} \mathrm{C}$ ) of water temperature measured at an altitude of about $1 \mathrm{~m}$ above the seafloor at the high-temperature portion of ASHES vent field with temperature sensors mounted on DSV ALVIN. Tracklines (dotted) and positions of discrete hightemperature vents (solid triangles) are shown. Three areas of positive temperature anomalies associated with diffuse sources are delineated by closures of the $2.40^{\circ} \mathrm{C}$ isotherm $\left(A_{2}, B_{1}, C_{1}\right) . A-A^{\prime}$ is the line of the temperature profile shown in Figure 5.

Figure 4. Isotherm map (interval $0.005^{\circ} \mathrm{C}$ ) of water temperature measured at an altitude of about $20 \mathrm{~m}$ above the seafloor over the high-temperature portion of ASHES vent field as shown in Figure 3. Three areas of 
positive temperature anomalies are delineated by closures of the $2.39^{\circ} \mathrm{C}$ isotherm $\left(A_{20}, B_{20}, C_{20}\right)$. Tracklines (dotted) and positions of discrete high-temperature vents (solid triangles) are shown.

Figure 5. Potential temperature profiles measured with a $1 \mathrm{~m}$-long vertical array of three sensors mounted on the front of the submersible with the lowermost sensor 1 at an altitude of about $1 \mathrm{~m}$ above the seafloor along trackline A-A' (Figure 3 ).

Figure 6. Plot of trajectories of three plumes corresponding to areas of diffuse sources in the ASHES vent field (A, B, C in Figures 3, 4; Table 2) calculated from EPA UMERGE plume model $[24,25,26]$. 


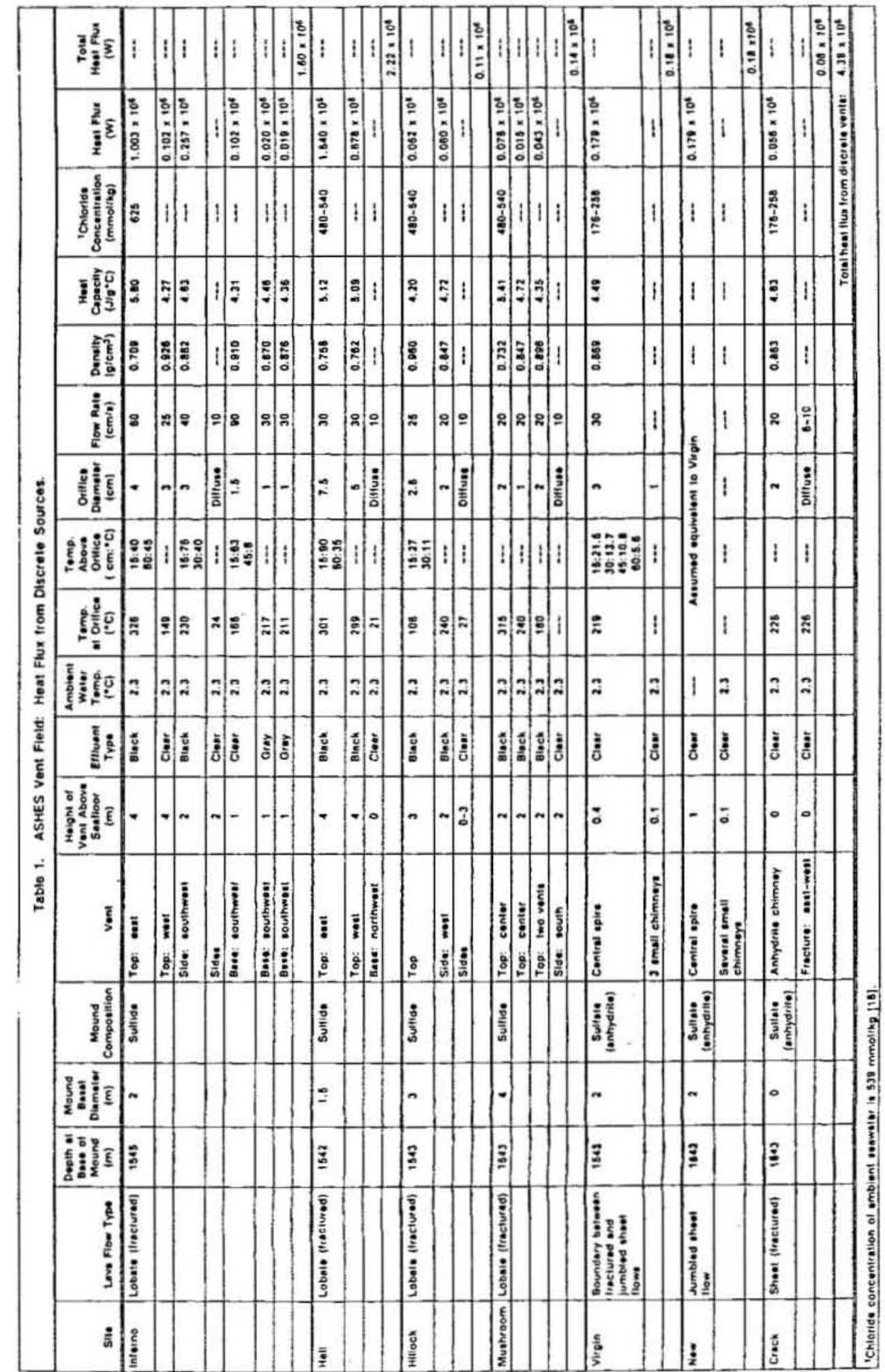




\begin{tabular}{|c|c|c|c|}
\hline Sources (Figs. 3, 4) & A & B & c \\
\hline $\begin{array}{l}\text { Source Diameter } \\
\text { ( 1 } \mathrm{m} \text { altitude })\end{array}$ & $20 \mathrm{~m}$ & $10 \mathrm{~m}$ & $35 \mathrm{~m}$ \\
\hline $\begin{array}{l}\text { Source Temperature } \\
(\sim 1 \mathrm{~m} \text { altitude })\end{array}$ & $2.4^{\circ} \mathrm{C}$ & $2.4^{\circ} \mathrm{C}$ & $2.575^{\circ} \mathrm{C}$ \\
\hline $\begin{array}{l}\text { Ambient Temperature } \\
\text { @ } 1 \mathrm{~m} \\
\text { @a } 20 \mathrm{~m}\end{array}$ & $\begin{array}{l}2.33^{\circ} \mathrm{C} \\
2.35^{\circ} \mathrm{C}\end{array}$ & $\begin{array}{l}2.33^{\circ} \mathrm{C} \\
2.35^{\circ} \mathrm{C}\end{array}$ & $\begin{array}{l}2.33^{\circ} \mathrm{C} \\
2.35^{\circ} \mathrm{C}\end{array}$ \\
\hline Brunt-Vaisala Frequency & $.0012 \mathrm{rad} / \mathrm{s}$ & $.0012 \mathrm{rad} / \mathrm{s}$ & $.0012 \mathrm{rad} / \mathrm{s}$ \\
\hline $\begin{array}{l}\text { Offset @ } 20 \text { m* } \\
\text { (measured) } \\
\text { (calculated) }\end{array}$ & $\begin{array}{l}63.4 \mathrm{~m} \\
64.5 \mathrm{~m}\end{array}$ & $\begin{array}{l}29.4 \mathrm{~m} \\
33.7 \mathrm{~m}\end{array}$ & $\begin{array}{l}31.7 \mathrm{~m} \\
32.0 \mathrm{~m}\end{array}$ \\
\hline $\begin{array}{c}\text { Dilution@20 m } \\
\text { (measured) } \\
\text { (calculated) }\end{array}$ & $\begin{array}{l}2.3 \\
9.2\end{array}$ & $\begin{array}{c}2.3 \\
10.2\end{array}$ & $\begin{array}{l}6.4 \\
5.5\end{array}$ \\
\hline $\begin{array}{l}\text { Source Vertical Velocity } \\
\text { (calculated) }\end{array}$ & $7.5 \mathrm{~cm} / \mathrm{s}$ & $14 \mathrm{~cm} / \mathrm{s}$ & $5.5 \mathrm{~cm} / \mathrm{s}$ \\
\hline $\begin{array}{l}\text { Current Horizontal Velocity } \\
\text { (measured) }\end{array}$ & $7 \mathrm{~cm} / \mathrm{s}$ & $7 \mathrm{~cm} / \mathrm{s}$ & $7 \mathrm{~cm} / \mathrm{s}$ \\
\hline $\begin{array}{l}\text { Heat Flux } \\
\text { (calculated) }\end{array}$ & $6.9 \times 10^{6} \mathrm{~W}$ & $3.2 \times 10^{6} \mathrm{~W}$ & $54.5 \times 10^{6} \mathrm{~W}$ \\
\hline $\begin{array}{l}\text { Rise Height } \\
\text { (calculated; Fig. 6) }\end{array}$ & $18 \mathrm{~m}$ & $21 \mathrm{~m}$ & $46 \mathrm{~m}$ \\
\hline
\end{tabular}

- Matched using the model to give estimated vertical velocity at source. 


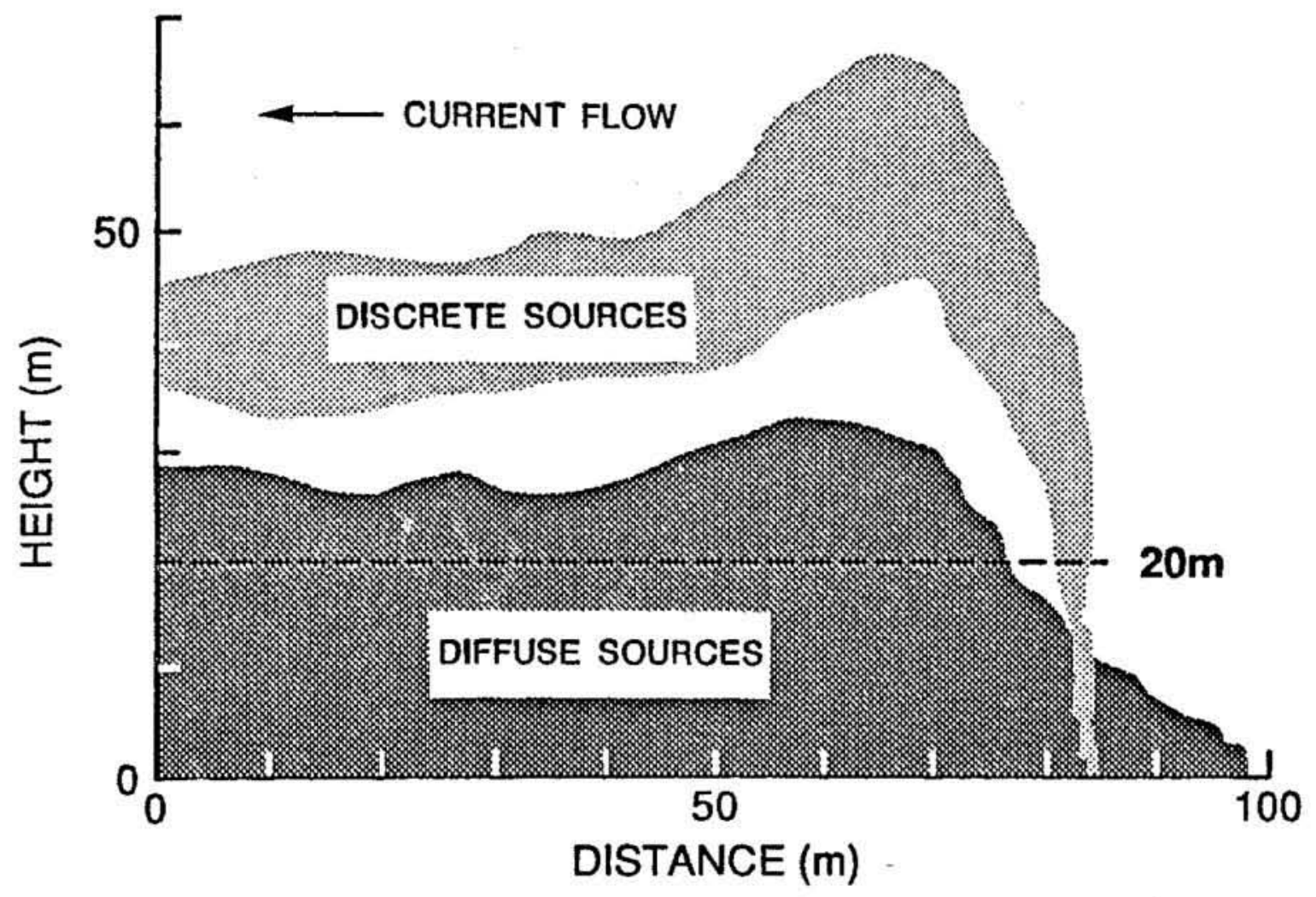

Figure 1 


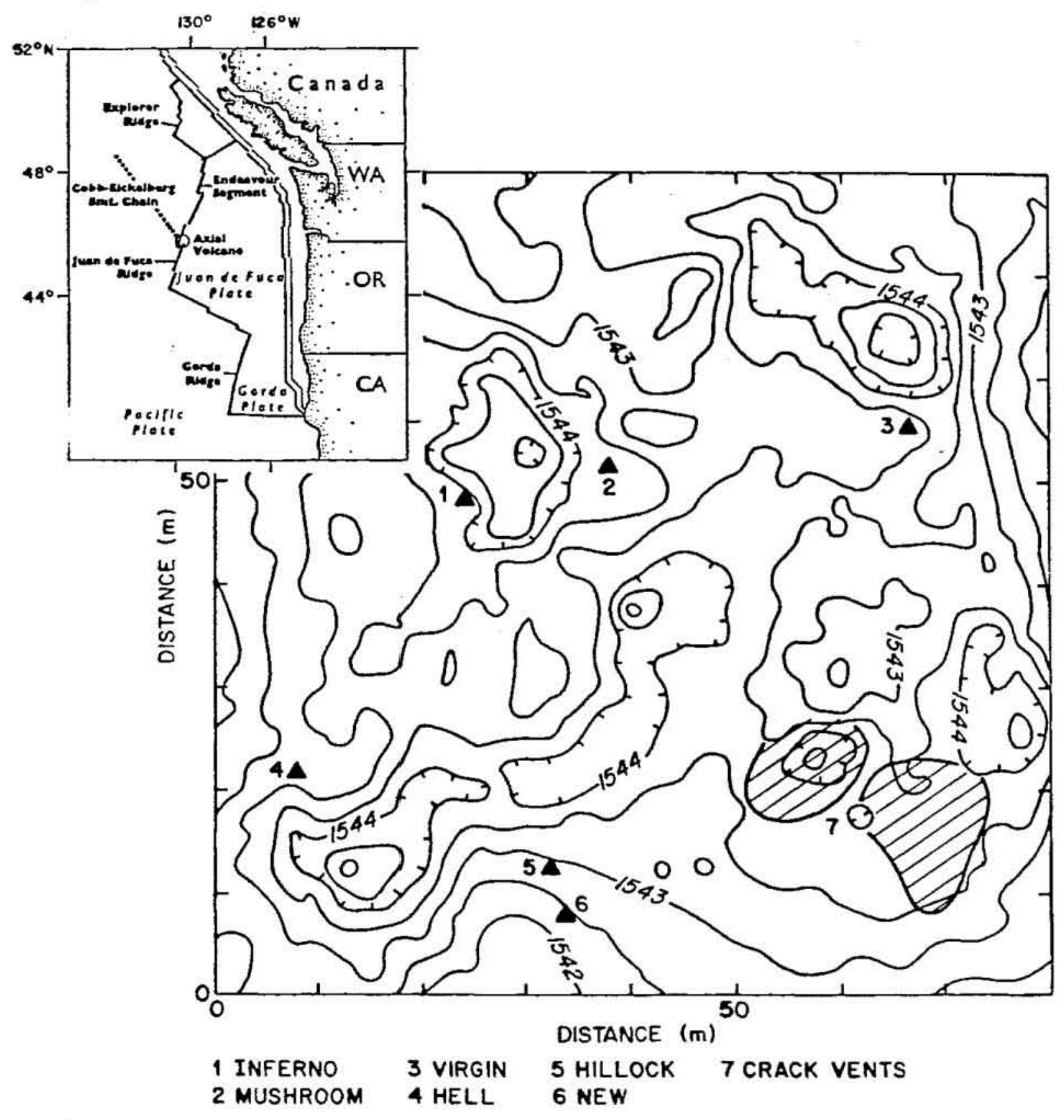




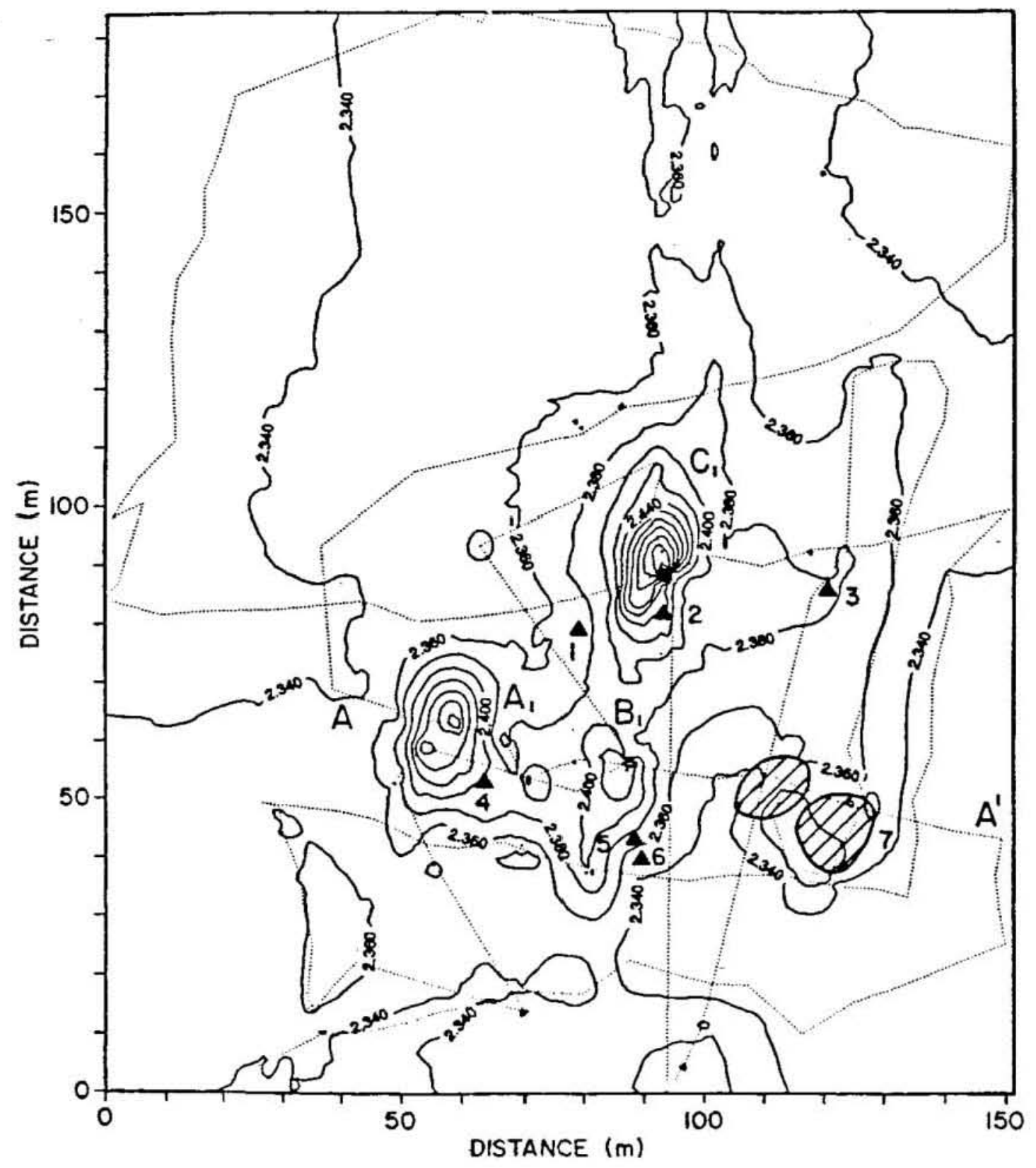

$\begin{array}{lll}1 \text { INFERNO } & 3 \text { VIRGIN } & 5 \text { HILLOCK } 7 \text { CRACK VENTS } \\ 2 \text { MUSHROOM } & 4 \text { HELL } & 6 \text { NEW }\end{array}$

Figure 3 


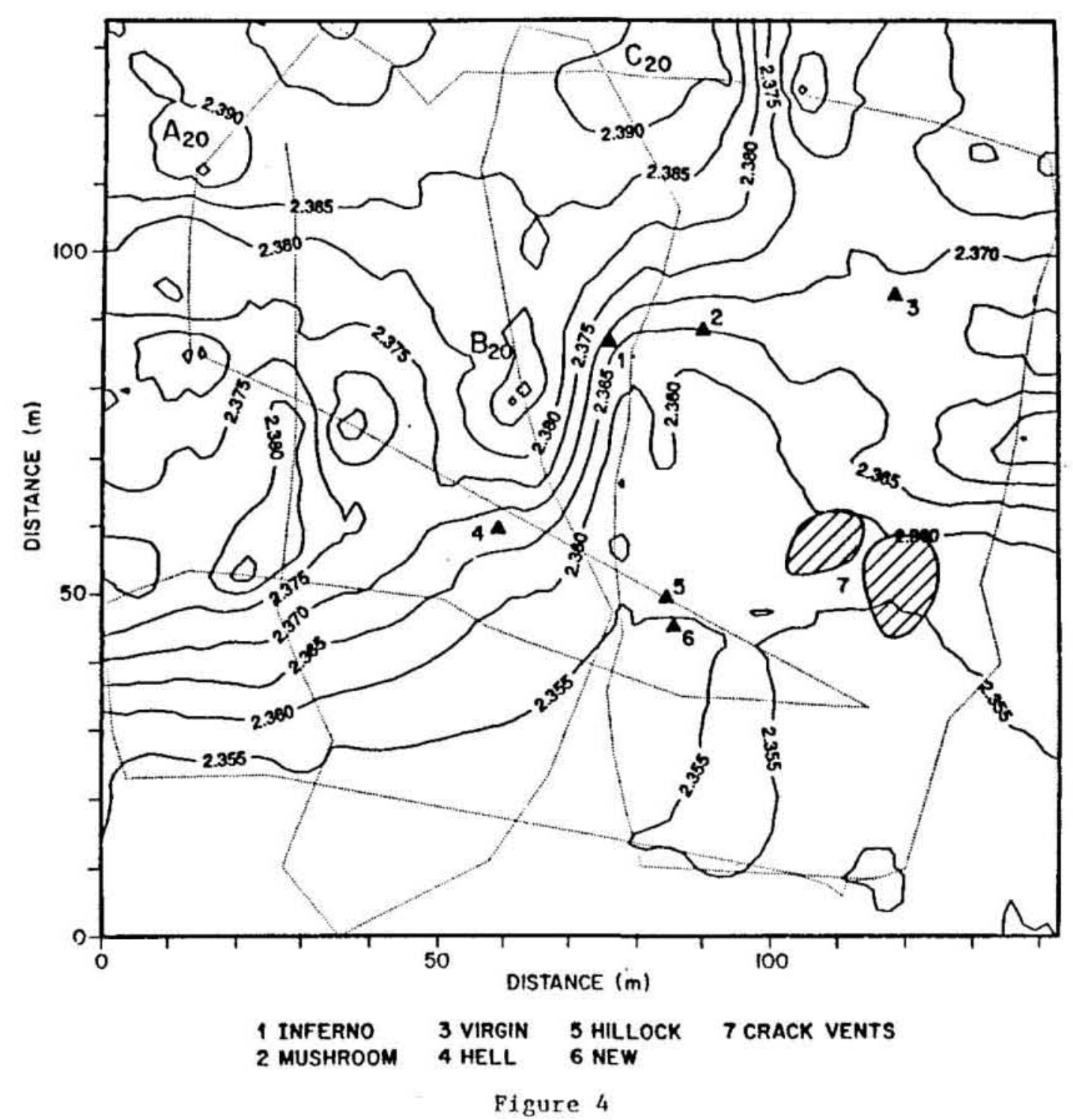




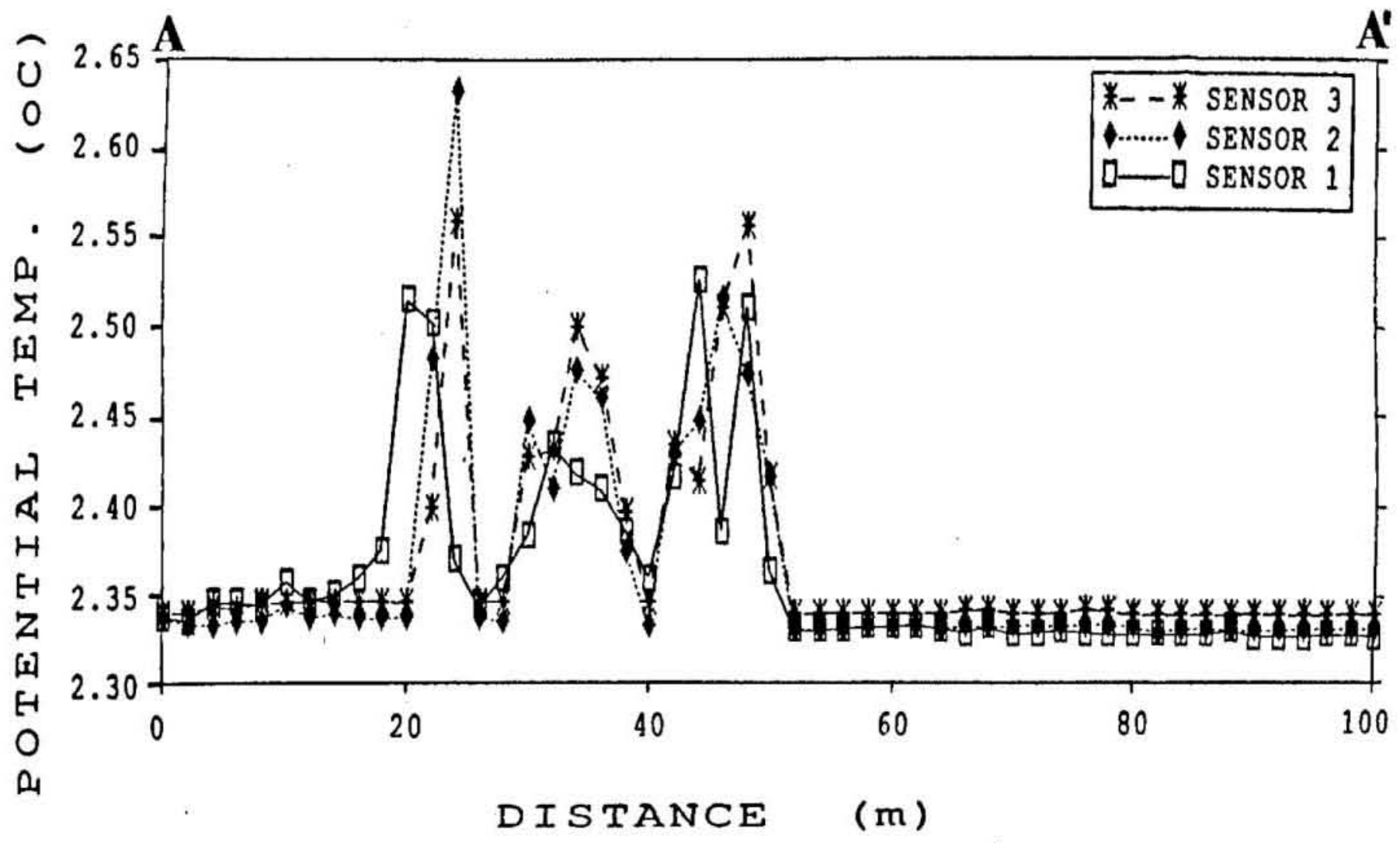

Figure 5 
TRAJECTORY OF ASHES DIFFUSE PLUME MODELS

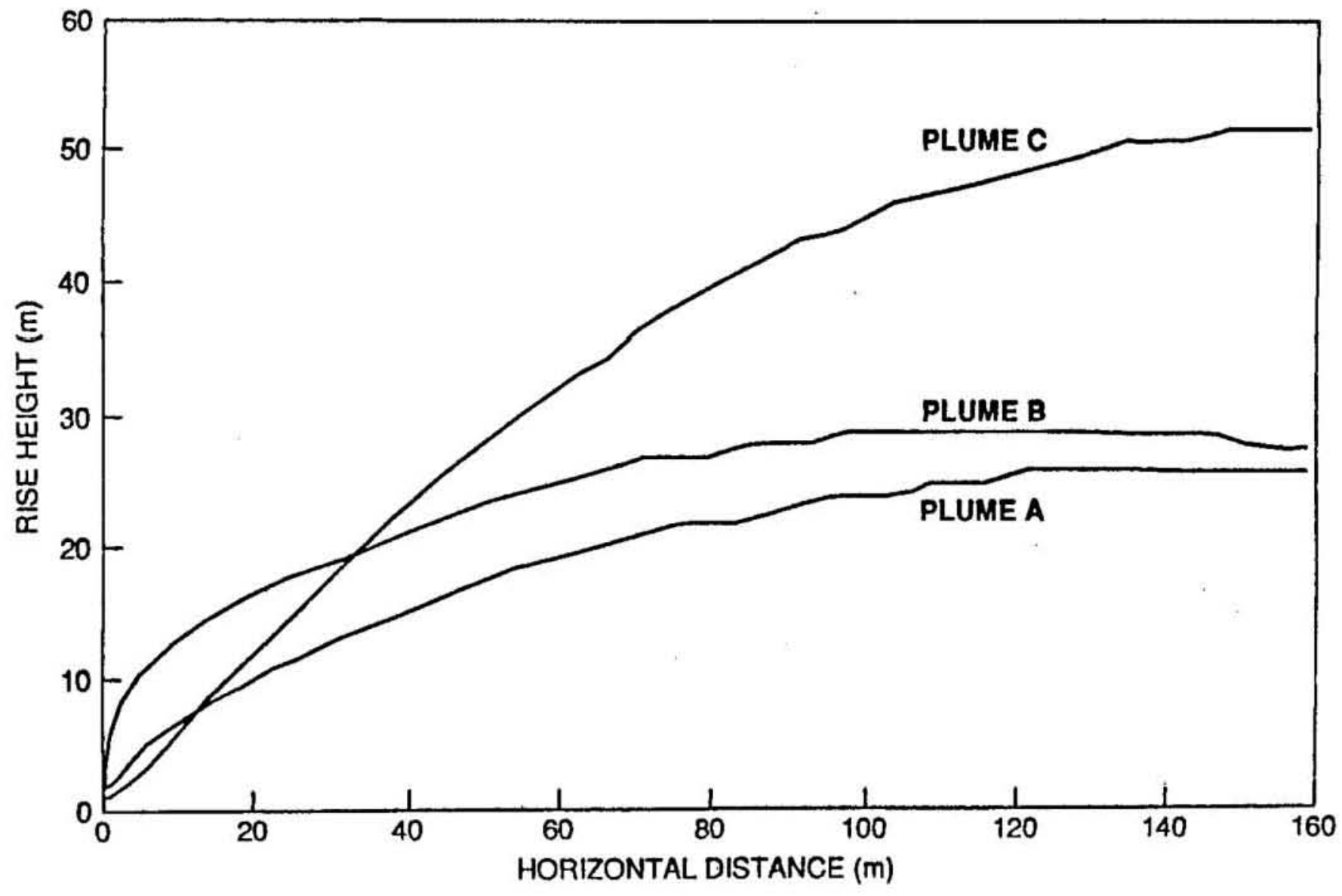

Figure 6 
Appendix B : "Error Analysis of an Acoustic Current Meter"

D.A. Trivett, E.A. Terray, and A.J. Williams III

Accepted for publication in IEEE Journal of Oceanic Engineering,

Oct. 1991 


\title{
Error Analysis of an Acoustic Current Meter
}

\author{
D. Andrew Trivett, Eugene A. Terray, Albert J. Williams III
}

Applied Ocean Physics and Engineering Department

Woods Hole Oceanographic Institution

Woods Hole, Massachusetts

\begin{abstract}
Accuracy of the Benthic Acoustic Stress Sensor (BASS) and the proposed Modular Acoustic Velocity Sensor (MAVS) is evaluated in this paper. A simple model of the hydrodynamic sources of error for acoustic current meters is presented and compared with the measured performance of BASS in a tow-tank, and in field deployments.

The sources of error addressed in this paper include those due to ideal flow around the sensor cage, wake effects from the support structure and transducers, vortex shedding from the cage, and electronic zero-point offsets. Electronic error dominates at velocities less than $5-10 \mathrm{~cm} / \mathrm{s}$, while flow disturbance dominates at higher speeds.
\end{abstract}

Keywords: Current meter, acoustic, flow disturbance

\section{INTRODUCTION}

In this paper, we model the principal errors in BASS (Benthic Acoustic Stress Sensor), a 3-dimensional vector acoustic current meter, using simple "back of the envelope" calculations. This error analysis leads to a reasonable match with the observed performance of BASS in tank tests and in deep-sea deployments. Based on this prioritization of error sources, we are designing a prototype MAVS (Modular Acoustic Velocity Sensor) which will be a small, high-performance acoustic current meter useful in a wide range of ocean applications. A sketch of the MAVS is shown in figure 1. Details of the MAVS design are not the subject of this paper. However, we will estimate the performance of the proposed sensor using our simple error analysis. The approach to estimating flow errors presented in this paper will be useful to designers of other flow sensors. 
We address self-generated flow disturbance from the acoustic current meter, and leave the topic of flow disturbance from support structures such as a mooring cable, or tripod base for future work. There are so many potential deployment schemes with individual support constraints that a general discussion would not be helpful. A very accurate current meter such as the one under development will allow effects from a poor support configuration to be separated from the true flow. Less precise current meters may give the user a false sense of measurement quality by showing no difference between good measurements, and those corrupted by nearby flow disturbers. For this reason, it is essential to understand selfinduced errors which may corrupt velocity measurements.

Six primary sources for self-induced error will be presented in this paper. They are:

- Ideal flow effects

- Wake effects

- Vortex shedding

- Sample aliasing

- Zero offset bias

- Sound speed errors

Each of these will be addressed in the succeeding sections. A brief overview of the BASS and improvements to be incorporated in MAVS will be presented. We will finish with an estimate of the errors from BASS, discussion of observed BASS performance, and a performance projection for MAVS.

\section{MEASUREMENT OF FLOW VELOCITY BY BASS}

The velocity measurement in BASS (figure 2) is made by eight high frequency acoustic transducers. They are arranged in four pairs. Each pair of transducers face one another and form an axis along which a component of velocity is measured. Only three axes are needed for a vector measurement, but four are used for redundancy [4]. When a measure of velocity is requested, both transducers of a pair transmit at the same time, then both listen. When one return is detected, an electric current source is steered to an integrating capacitor. When the 
second return is detected, another current source is steered to a second capacitor. After a set interval, the voltage across both capacitors is compared. This voltage difference is proportional to the difference in travel time between two directions of propagation along an acoustic path. Differential travel-time is proportional to the component of fluid velocity along the path. Three such acoustic axes allow a vector velocity to be constructed. Absolute and differential travel-time have been measured with a sensitivity of $7 \mathrm{nS}$ and $40 \mathrm{pS}$, respectively.

We estimate the flow velocity and sound speed along the axis of an acoustic path as:

$$
\begin{aligned}
\mathrm{U}_{\mathrm{m}} & =\frac{\mathrm{c}^{2}}{2 \mathrm{~L}}\left(\mathrm{t}_{1}-\mathrm{t}_{2}\right) \\
\mathrm{c} & =\frac{2 \mathrm{~L}}{\mathrm{t}_{1}+\mathrm{t}_{2}}
\end{aligned}
$$

Where $t_{1}$ and $t_{2}$ are the measured travel-times in opposite directions, $\mathrm{L}$ is the acoustic path length, $\mathrm{c}$ is the speed of sound, and $U_{m}$ is the measured velocity. The fractional error in this approximation is on the order of $\frac{U^{2}}{c^{2}}$. Assuming typical values for $U$ and $c$, the error in this approximation will be on the order of $4 \times 10^{-7}$.

By measuring acoustic travel-time in two directions, we get two independent parameters for calculating flow velocity $(U)$ and sound speed $(c)$. Measuring sound speed allows us to estimate the temperature using an equation of state for seawater, such as found in [11]. We can use the $\mathrm{U}$ and c estimates to calculate a function proportional to convective heat flux, or simply use the c estimate to give a better prediction of velocity if the heat flux is not desired. Recently, a BASS sensor array was deployed near a deep-sea hydrothermal vent to measure $c$ and $U$ in order to estimate convective heat flux in the field [12]. Estimates of temperature based on c measurements compared with simultaneous thermistor data showed errors of less than ${ }^{ \pm} 0.005^{\circ} \mathrm{C}$ [12]. Turbulent heat diffusion was resolved to $0.6 \mathrm{~W} / \mathrm{m}^{2}$.

Measurement of differential travel time to a precision of 40 picoseconds has been demonstrated in BASS [1]. This time resolution corresponds to a velocity resolution of 0.03 
$\mathrm{cm} / \mathrm{s}$. Zero-velocity calibrations of BASS between deployments have shown bias errors on the order of 0.1 to $0.3 \mathrm{~cm} / \mathrm{s}$, with large variability from one transducer pair to another. For velocities less than approximately $5 \mathrm{~cm} / \mathrm{s}$, this offset bias dominates the error budget for BASS. Flow disturbances created by struts and supports which position the acoustic transducers exceed other sources of error for velocities greater than $5 \mathrm{~cm} / \mathrm{s}$. In order to quantify the relative errors inherent in acoustic current meters, we will outline the six largest sources of error seen in BASS, and then apply those errors to the proposed MAVS.

\section{ERRORS DUE TO IDEAL FLOW}

As an example of the minimum flow disturbance attainable with an intrusive sensor, we consider a sphere in an infinite, inviscid fluid. We will use the spherical geometry to represent any component of a flow sensor which has similar length scales in all three dimensions. Two-dimensional struts will be modelled as cylinders. In real fluids, ideal flow solutions such as this are valid upstream of an object. This means that acoustic axes which are supposed to be in "undisturbed" flow on the upstream side of a sensor are still influenced by the presence of supports.

Figure 4 shows the streamlines around the cross-section of a sphere in ideal flow. The velocity at any point in such an axisymmetric flow field is given by:

$$
\begin{gathered}
U_{r}=U\left(1-\frac{D^{3}}{8 r^{3}}\right) \cos \theta \\
U_{\theta}=-U\left(1+\frac{D^{3}}{16 r^{3}}\right) \sin \theta
\end{gathered}
$$

For $\mathrm{D} / \mathrm{r}<1$, the relative velocity error will be:

$$
\frac{\mathrm{U}_{\mathrm{m}}-\mathrm{U}}{\mathrm{U}}=\frac{\Delta \mathrm{U}_{\mathrm{m}}}{\mathrm{U}} \approx \frac{\mathrm{D}^{3}}{16 \mathrm{r}^{3}}\left(3 \sin ^{2} \theta-2\right)
$$


where $\mathrm{U}$ is the undisturbed velocity, $\mathrm{U}_{\mathrm{m}}$ is the velocity in the presence of a sphere, $\mathrm{r}$ is the radius from the center of the body pictured in figure $4, \mathrm{D}$ is the diameter of the sphere, and $\theta$ is the angle from the horizontal axis. In order for the velocity magnitude error to be less than $1 \%$, we must look at least 2 diameters away from the center of the sphere.

An acoustic current meter measures the integrated velocity along a straight-line path between two transducers (the distance between transducers is $L$ ). By assuming that $D / L<1$, the integrated velocity error along a path with spherical flow disturbers at both ends is:

$$
\frac{\left\langle\Delta U_{m}\right\rangle}{U}=\frac{2}{L} \int_{0}^{L / 2} \frac{\Delta U_{m}}{U} d r \approx \frac{D^{3}}{2 L^{3}}
$$

This velocity error represents the best possible performance from an acoustic current meter. True performance will be worse, since transducers are not spherical, and flow is not inviscid. The transducers for BASS are $1 \mathrm{~cm}$ diameter, and the path length is $15 \mathrm{~cm}$. The resulting error due to ideal flow would therefore be on the order of $0.015 \%$.

We can perform an identical analysis of errors induced by a two-dimensional strut in ideal flow. The sensor pod shown in figure 2 has several struts near the acoustic axes. We will calculate the velocity error induced by one strut supporting each of the the sensor pods comprising an acoustic axis. Making the same assumptions as above, the error in velocity due to the presence of a cylinder will be approximately:

$$
\frac{\left\langle\Delta \mathrm{U}_{\mathrm{m}}\right\rangle}{\mathrm{U}} \approx \frac{\mathrm{D}^{2}}{\mathrm{~L}^{2}}
$$

The struts for BASS are $1 / 8^{\prime \prime}$ diameter $(0.3175 \mathrm{~cm})$, and the path length is $15 \mathrm{~cm}$. The resulting potential flow error would therefore be on the order of $0.05 \%$. Other acoustic current meters are in existence with $12 \mathrm{~cm}$ paths, and $1 \mathrm{~cm}$ diameter supports [8]. The simple potential flow error for these sensors will be more on the order of $0.7 \%$. 
Comparing the two results above shows that struts of a given diameter cause a great deal more flow disturbance than similar sized spheres. This forces the design of an acoustic current meter toward geometries which use very small supports, rather than mounting transducers around a large diameter central support which will cause comparatively more flow disturbance.

\section{WAKE EFFECTS}

The self-induced wake from cylinders supporting transducers has been studied by other investigators ( for example [2],[3],[8] ). A strut produces a shadow zone in which the velocity is less than that in the surrounding flow. This zone occupies a region roughly as shown in figure 5 . The far-field wake velocity defect and half-width are:

$$
\begin{aligned}
& \frac{\mathrm{U}_{1}}{\mathrm{U}}=0.94\left(\frac{\mathrm{CDD}^{\mathrm{D}}}{\mathrm{x}}\right)^{1 / 2} \\
& \frac{\delta}{\mathrm{D}}=0.25\left(\frac{\mathrm{CD}^{\mathrm{x}}}{\mathrm{D}}\right)^{1 / 2}
\end{aligned}
$$

In these equations, $D$ is the strut diameter, $C D$ is the drag coefficient, $x$ is the downstream coordinate, $\delta$ is the half-width of the wake, and $U_{1}$ is the centerline velocity defect in the wake of the cylinder. These equations are formulated after [3]. We are assuming that the wake sources are two-dimensional. An analysis for three-dimensional bodies would produce similar relations except the exponents would be $1 / 3$ and $2 / 3$ [13][14]. We will limit this analysis to only the two-dimensional case.

The above equations require that the velocity defect in the wake be small compared to the free-stream velocity, and are valid only in the far field downstream where pressure fluctuations due to the body are negligible (100 D according to [3], $50 \mathrm{D}$ according to [14]). This second restriction is violated in all acoustic current meters, including BASS and the proposed MAVS. These functions are plotted in figure 6. It is possible to add higher order 
terms to correct the solution in the near-field [14], but doing so would introduce only a small correction. We will use the above wake functions in our error estimate.

The worst-case for mean-wake interference with acoustic paths is shown in figure 6. Here, the wake crosses an acoustic axis at some angle $\theta$, obscuring a portion of the path such that the integrated velocity will be:

$$
\begin{gathered}
\mathrm{L} \mathrm{U}_{\mathrm{m}} \cos \theta=\left(\mathrm{L}-\frac{2 \delta}{\sin \theta}\right) \mathrm{U} \cos \theta+\frac{2 \delta}{\sin \theta}\left(\mathrm{U}-\mathrm{U}_{1}\right) \cos \theta \\
\frac{\Delta \mathrm{U}_{\mathrm{m}}}{\mathrm{U}}=-\frac{2 \mathrm{D}}{\mathrm{L} \sin \theta} \frac{\delta}{\mathrm{D}} \frac{\mathrm{U}_{1}}{\mathrm{U}}
\end{gathered}
$$

Assuming that the position in the wake is on the order of $L / 2$ downstream, $\theta$ is approximately $45^{\circ}$, the error is:

$$
\frac{\Delta U_{m}}{U}=-0.33 C_{D} \frac{D}{L}
$$

We only consider the case where the acoustic axis is intersected by a wake at an acute angle. The geometry of BASS permits us to choose three paths which are not entirely shadowed by the wake. The selective use of redundant acoustic axes has been discussed in [10], and applied to measurements under surface waves in [16]. Given a sensor geometry where the included angle between acoustic axes is $90^{\circ}$, the worst case will occur when the angle of incidence with the flow is $45^{\circ}$.

Given a $1 \mathrm{~cm}$ diameter strut, and a $15 \mathrm{~cm}$ path, assuming a drag coefficient of 1 , the error due to intersection between an acoustic path and a cylinder wake will be on the order of $2.2 \%$. A $0.3 \mathrm{~cm}$ strut coupled with a $15 \mathrm{~cm}$ path will yield errors on the order of $0.66 \%$.

\section{VORTEX SHEDDING}

Figure 7 shows frequency components from BASS records of tow-tank runs at six cart speeds. The data is a sample of more than 300 separate tows conducted in a calibration 
facility at the Canada Centre for Inland Waters in Burlington, Ontario. In each spectrum, the four separate curves represent the four acoustic axes in a single BASS pod. The spectra are averaged over all angles of orientation with the flow. The first spectrum shows fluctuations in recorded velocity at a tow speed of $1 \mathrm{~cm} / \mathrm{s}$. The spectrum is extremely flat out to the Nyquist frequency of $2.5 \mathrm{~Hz}$.

The peak observed at $0.1 \mathrm{~Hz}$ is evident in all tow data at all speeds. At $2 \mathrm{~cm} / \mathrm{s}$ a spectral peak appears centered on $0.5 \mathrm{~Hz}$. In the subsequent spectra, this peak is seen to move higher in frequency until it is beyond the Nyquist frequency, and begins to alias the measurement, eventually raising the noise floor. The frequencies of this peak correspond to vortex shedding frequencies calculated using [5]:

$$
\mathrm{f}_{\mathrm{S}}=0.2 \frac{\mathrm{U}}{\mathrm{D}}
$$

The shedding frequency from a $1 \mathrm{~cm}$ diameter body corresponds with observed peaks up to $10 \mathrm{~cm} / \mathrm{s}$, beyond which the sampling rate was no longer sufficient to resolve the phenomena. The BASS sensor cage contains $1 \mathrm{~cm}$ diameter acoustic transducers and support rings (figure 2). We expect that the shedding most likely occurred from these components.

Figure 8 shows the mean energy of each spectrum plotted against tow speed. This plot can be interpreted as magnitude of the noise floor for each tow speed. The second plot in figure 8 shows the variability in the spectra as a function of speed. For any given mean velocity, vortex shedding will create a peak in the spectrum of measured velocity at a frequency given above, and with a fractional error approximated by:

$$
\frac{\Delta \mathrm{U}_{\mathrm{f}}}{\mathrm{U}}=0.0004 \mathrm{U}
$$

Where $U$ is expressed in $\mathrm{cm} / \mathrm{s}$. This relation was estimated from figure 8 .

The surprising aspect of vortex-induced errors is that the effect seems to come from eddies which are much smaller than the path length of the acoustic current meter. There are 
two ways that velocity anomalies created by small vortex shedding can corrupt BASS towtank data:

- by causing the entire support structure to vibrate in a strumming resonance, thereby producing relative motion between the sensor cage and the flow;

- through spatial aliasing of the velocity measurements due to the sensor geometry.

The first possibility requires that at least one natural frequency of the support cage (figure 2) or the mounting structure be excited by the shedding frequency. This seems unlikely because the BASS cage and its mount are quite stiff, with reasonably high natural frequencies of vibration. It would be useful to mount accelerometers on a BASS cage in a tow-tank to observe the structural response to flow disturbance.

Figures 8 and 9 show that the magnitude of the spectral peaks at each tow speed are monotonically increasing up to $80 \mathrm{~cm} / \mathrm{s}$. There are no obvious speeds where the structural resonance is hit, causing greater vibration than other speeds. Anyone who has driven an old car will recognize that some rattles are produced at particular speeds when the forcing frequency matches a structural resonance, while wind noises simply get louder as speed increases. The latter case is analogous to our spectra from BASS.

Tows at greater than $90 \mathrm{~cm} / \mathrm{s}$ seem to show a drop in the noise floor. This may be due to structural resonance at $80-90 \mathrm{~cm} / \mathrm{s}$, but there is not enough data at that speed to support such a conclusion. The shedding frequency from a $1 \mathrm{~cm}$ diameter body at this speed is approximately $16-20 \mathrm{~Hz}$.

Assuming that the BASS cage is not undergoing structural resonance at speeds less than $80 \mathrm{~cm} / \mathrm{s}$, we need to justify how eddies formed in the wake of a $1 \mathrm{~cm}$ diameter body have corrupted velocity which was integrated over a $15 \mathrm{~cm}$ path. If we assume that the received signal is the summation of ray paths resembling a bundle of straws of length $L$ all fitting in a tube of diameter $\mathrm{D}$ (the transducer diameter), then consider the velocity measurement in a field as shown in figure 9a and 9b. In 9a, an eddy is advecting through the acoustic path, and the velocity measured will be equal to the mean flow component along the axis, minus 
the velocity along the axis due to the vortex. In $9 \mathrm{~b}$, the velocity will be similar, except that the vortex will increase the measured velocity.

As a progression of eddies are advected through the acoustic path, the velocity measured will appear to fluctuate around the mean $U$, and the fluctuations will have a frequency equal to that of vortex shedding. In this way, an acoustic current meter is corrupted by eddies on the scale of 2D. Thus, there are two length scales important in any discussion of spatial sampling for an acoustic current meter. In contrast, a mechanical flowmeter averages over a large volume, relying upon inertial effects to minimize aliasing due to high frequency fluctuations.

\section{SAMPLE FREQUENCY}

Both the path length and beam diameter of an acoustic current meter have a large impact on the resolvable eddy scales. For greater sensitivity and smaller errors due to flow disturbance, we tend to demand long paths. Spatial and temporal resolution of small eddies demands short paths. The minimum resolvable travel-time difference in BASS is 40 picoseconds. Using the relation :

$$
\Delta t=\frac{2 U L}{c^{2}}
$$

Path lengths on the order of $15 \mathrm{~cm}$ give velocity sensitivity of $0.03 \mathrm{~cm} / \mathrm{s}$. Spatial resolution based on path length is governed by:

$$
\mathrm{U}^{2}=\mathrm{Lf}_{\text {samp }}
$$

Where $\mathrm{f}_{\text {samp }}$ is the sampling frequency required to avoid aliasing, and $\mathrm{U}$ is the mean flow velocity. For mean flow on the order of $100 \mathrm{~cm} / \mathrm{s}$, the sampling frequency required for a $15 \mathrm{~cm}$ path sensor is $3.3 \mathrm{~Hz}$, while for a $5 \mathrm{~cm}$ path sensor it is $10 \mathrm{~Hz}$. 
This takes into account scales based on the acoustic path length. As outlined above, beam diameter is an equally important dimension. To avoid aliasing from eddies the size of the transducer diameter (in effect, the cross-beam dimension) then we must sample significantly faster. This is illustrated in the spectra for 20 and $30 \mathrm{~cm} / \mathrm{s}$ tows in figure 7 . The vortex induced peak has exceeded the Nyquist frequency, and has been folded over into the measured spectra, increasing the noise floor. To avoid this cross-beam aliasing, sample frequency must be higher than:

$$
\mathrm{f}_{\text {samp }}=0.4 \frac{\mathrm{U}}{\mathrm{D}}
$$

\section{ZERO OFFSET}

At low velocity, the zero offset of the electronics dominates error. In BASS, errors in velocity estimation at tow-speeds under $5 \mathrm{~cm} / \mathrm{s}$ are on the order of $0.3 \mathrm{~cm} / \mathrm{s}$, due entirely to the uncertainty in zero velocity offset. This comes about because of small differences in the electrical properties of the signal path between one direction versus the other. In BASS, this error may be due to the fact that the sensor cages are separated from signal generation and reception electronics through 18 feet of coaxial cable which is constantly being flexed and stretched. This mechanical deformation changes the capacitance of the cables enough to skew the zero measurement by up to $0.3 \mathrm{~cm} / \mathrm{s}$. Figure 10 shows the difference between preand post deployment zeros from two separate BASS arrays deployed recently in $2000 \mathrm{~m}$ of water. Of 48 acoustic axes shown in figure 10, nine were not used because the two sets of zero calibrations differed by more than $0.3 \mathrm{~cm} / \mathrm{s}$.

Transducers themselves may change the zero offset through aging, and moisture absorption [1]. The effects can be reduced in BASS by careful in situ zero calibration. In MAVS, the electronics will be much closer to the transducers, so the relative capacitance of the conductors between sensor and electronics will only be a minor part of the circuit. In addition, the conductors will be fixed in a rigid support, and will not be subjected to flexing 
and stretching. Thus, the zero offset of MAVS is expected to be substantially better than $0.3 \mathrm{~cm} / \mathrm{s}$.

\section{SPEED OF SOUND FLUCTUATIONS}

Unmeasured changes in the acoustic speed of sound will result in errors in flow velocity measurement. Since the speed of sound is used to convert time difference to velocity, and velocity is proportional to $c^{2}$, errors in $c$ are significant. The velocity error due to sound speed uncertainty is:

$$
\frac{\Delta U_{m}}{U}=\frac{c^{2}-c_{m^{2}}}{c^{2}}
$$

For example, if the true and assumed speed of sound differ by $4 \mathrm{~m} / \mathrm{s}$ (equivalent to a $1^{\circ} \mathrm{C}$ change in temperature [11]), the calculated velocity will be in error by $0.6 \%$. By measuring the speed of sound, we can minimize this error. The difference in sound speed from the surface layer to the SOFAR channel axis is on the order of $30 \mathrm{~m} / \mathrm{s}$ [11]. Thus, velocity error possible from this source could be as great as $4 \%$.

The sensitivity to which fluctuations in the speed of sound have been measured in the ocean with BASS was sufficient for temperature estimates stable to within $\pm 0.005{ }^{\circ} \mathrm{C}$ [12]. Thus, the sensitivity in speed of sound was $0.025 \mathrm{~m} / \mathrm{s}$. The absolute accuracy was not known, since no independent measure of sound speed was done at the same time. The stability of this measure was excellent over a 14 day deployment of BASS [12].

\section{PRELIMINARY MAVS SENSOR CONFIGURATION}

The error sources discussed above have been considered in the preliminary design of a sensor head for MAVS. The design includes construction of a new support cage, new transducers, new instrument housing and mounting, and redesigned electronics.

Transducers 
The large signal-to-noise ratio achieved in BASS using $1 \mathrm{~cm}$ diameter piezo-ceramic transducers indicates that substantially smaller transducers can be used in MAVS. This will provide several advantages including lower flow disturbance due to the transducers, a wider beam pattern allowing coarser tolerance on alignment, and a simple mounting configuration. We have bench-tested $3 \mathrm{~mm}$ disk transducers to show that sufficient received power is possible over a $15 \mathrm{~cm}$ range at $1.75 \mathrm{MHz}$.

\section{Cage Design}

Transducer support geometry has been addressed by numerous authors (reviewed by [8]). There is no clear consensus as to which best combines structural stiffness, low flow disturbance, and manufacturability. Many support cages used in previous instruments had mooring stress carried through the sensor cage itself. This had a devastating impact on the cage design. In MAVS, we are designing a cage which will not carry any foreign loads, making it possible to use very small diameter structural elements, as well as optimizing the geometry for the single purpose of minimum flow measurement error.

Our approach to minimize velocity error due to wake vortices in MAVS is to reduce the size of the transducers and the horizontal rings. The struts themselves will begin to dominate the vortex shedding. It may be possible to improve the performance even further by modifying the strut cross-section to break up eddies, creating more broad-banded vortices with smaller intensity. This is analogous to the approach taken in the design of antistrumming cables for ocean applications [6].

Strut size must be chosen carefully to avoid structural resonances in the frequency bands of interest. This may be a very restrictive condition, forcing an extremely stiff structure with resonances higher than perhaps a hundred Hertz. One option involves the use of carbon fibre struts molded into a cage structure. The carbon fibre has the advantage of high stiffness, low weight, ease of fabrication using molding procedures, plus the option to tailor the thermal expansion coefficient by adding other types of fibres to the matrix. It may be possible to manufacture a composite cage with nearly zero thermal expansion. $3 \mathrm{~mm}$ diameter struts have been tested with magnet-wire conductors molded into the core of the structure to be connected to the transducers. A sketch of the prototype sensor cage is shown in figure 3 . 


\section{Zero Offset}

We have attempted to minimize the zero offset error by incorporating two features in the new sensor: 1) the cables between electronics and transducers will be shorter than 1 meter; 2) they will be housed in a rigid strut. The former will reduce the impact of the cables on measurements since the equivalent circuit of the transmitting and receiving system will not be dominated by the cable capacitance, as it is with BASS [1]. Likewise, the transmitted waveform will not be distorted before reaching the transducer. The new design will also prevent the cables from being flexed.

Using an equivalent circuit model proposed for BASS in [1], we estimate the offset sensitivity of MAVS relative to BASS. To keep offset errors small, the source and load impedance should be much less than the transducer and cable impedance. Using small transducers and short cables yields lower capacitance, and thus higher impedance relative to the source and load. From a preliminary circuit design, MAVS will be half as sensitive to capacitance changes in the cables and transducer as BASS. Thus, MAVS should have zero offset drift on the order of 0.05 to $0.15 \mathrm{~cm} / \mathrm{s}$.

The MAVS cage is being designed to allow simple and repeatable zero calibration by placing the sensor head in as small a container as possible to limit large scale fluid motion while performing a calibration. This calibration is presently done with BASS by taping up the sensor volume using polyethylene bags and duct tape to block flow, and deploying the instrument off a dock for a brief period.

\section{CONCLUSION : AN ERROR BUDGET}

The discussion above regarding first the sources of error in an acoustic current meter, and the subsequent section on design of the MAVS leads us to estimate the magnitudes of error in BASS, and the projected performance of MAVS.

The errors discussed above are summarized in Table 1. Assuming that the errors are independent, the total error for the current meters is the root-mean-square of the 
independent errors. Table 2 presents a comparison between the performance of BASS and MAVS. When summing the errors, we include potential flow effects from all struts, rings and transducers. When evaluating wake effects, we only sum the disturbances from bodies that are upstream.

Figures 11 and 12 show error measured from tow-tank testing of BASS. The sensor was towed at several speeds from 1 to $120 \mathrm{~cm} / \mathrm{s}$ in the Canada Centre for Inland Waters testing facility in Burlington, Ontario. Runs were done with the sensor oriented in 20 different ways, including rotations about the long vertical axis of the pod, and about the horizontal axis. The rotations ranged from -20 to $+20^{\circ}$ about the horizontal axis, and for all $360^{\circ}$ about the vertical axis. The data shown includes all orientations.

At low speeds, a $0.3 \mathrm{~cm} / \mathrm{s}$ constant bias dominates the error. Figure 12 shows the probability density of the velocity error for the data from figure 11. The Gaussian distribution plotted in figure 12 has had the mean error removed $(-4 \%)$, and a standard deviation equal to $3.5 \%$.

The breakdown of error contributions from the components of the BASS cage clearly shows the mount rings to be the largest contributor. They are the only component with sharp corners, and their dimensions are $0.3 \mathrm{~cm} \times 1.0 \mathrm{~cm}$. The drag coefficient of a rectangular crosssection strut is approximately double that of a circular cylinder, as is the wake halfwidth[13]. In addition to the larger wake resulting from the rectangular cross-section, the rings are axisymmetric about the vertical axis of the sensor. The wake from the rings will interfere with measurement regardless of rotation about this axis. Wake from the vertical struts only interfere for certain flow directions.

If the BASS sensor is tilted about a horizontal axis, thereby presenting a larger ring cross-section to the flow, the wake will get much larger, interfering with more of the measurement volume. Small angles of tilt have a large impact on the error, whereas rotation about the vertical axis is much more subtle (figure 13). The top graph shows normalized velocity measured for rotations about the vertical axis from $0-90^{\circ}$. The circles represent $80 \%, 90 \%, 100 \%$, and $110 \%$ of free-stream velocity . Ideal response would follow the $100 \%$ line. The error due to rotation about the vertical axis appears to be on the order of $5 \%$ in the 
figure. The lower plot in figure 13 shows the error for tilt angles up to $20^{\circ}$. The increase in error is much more sensitive to change in tilt than in rotation about the vertical axis.

Based on the comparison between estimated and measured error for BASS, we consider the $1.6 \%$ error estimate for MAVS to be reasonable. For speeds less than $5 \mathrm{~cm} / \mathrm{s}$, a constant error of $.05-.15 \mathrm{~cm} / \mathrm{s}$ is expected. This represents a refinement of the prediction made in [15].

\section{ACKNOWLEDGEMENT}

The authors wish to thank M.J. Santala , R. Gopalkrishnan and Neil Brown for their helpful advice and critique. The staff of the Canada Centre for Inland Waters provided support services for tank tests. We also thank Gerald Appell and anonymous reviewers for their prompt reviews and helpful comments. We gratefully acknowledge the WHOI Education office for support (DAT), and the National Science Foundation for funding of recent field work under OCE-8917448. Tank tests were supported by NSF grant OCE-8716937. This paper is WHOI contribution \#7626.

\section{REFERENCES}

[1] A.J. Williams et al., Measurement of turbulence in the Oceanic Bottom Boundary Layer with an Acoustic Current Meter Array, J. Atmos. Oceanic Tech., Vol.4, No.2, pp.312-327, June 1987

[2] J. Wucknitz, Flow Distortion by Supporting Structures, in Air-Sea Interaction: Instruments and Methods, Ed. by F.Dobson, L.Hasse, R.Davis, Plenum Press, New York, 1980, pp.605-626

[3] W.C. Reynolds and T. Cebeci, Calculation of Turbulent Flows, in Iurbulence,Vol.12, Topics in Applied Physics, Ed. P. Bradshaw, Springer-Verlag, 1976, pp.193-229

[4] J.S. Tochko, A Study of the Velocity Structure in a Marine Boundary Layer, Ph.D thesis, MITWHOI Joint Program in Oceanographic Engineering, 1978

[5] R.D. Blevins, Flow Induced Vibration, Van Nostrand, 1977

[6] T.R. Cummings, SAIC Quiet Cable, proceedings of Marine Instrumentation '90, February 27March 1, 1990, San Diego, CA

[7] W.D. Grant, A.J. Williams, S.M. Glenn, Bottom Stress Estimates and their Prediction on the Northern California Continental Shelf during the CODE-1: the Importance of Wave-Current Interaction, J. Phys. Oceanogr., 14, 1984, 506-527 
[8] J.R. McCullough and W. Graeper, Moored Acoustic Travel Time (ATT) Current Meters: Evolution, Performance, and Future Designs, WHOI Report, WHOI-79-92, Dec. 1979

[9] A.J. Williams III, BASS, An acoustic current meter array for benthic flow-field measurements, Mar. Geo., 66, pp.345-355, 1985

[10] H. Botma, The VEKTOR-AKWA, An Acoustic Current Meter for Use in 3-Dimensional Dynamic Flows, in Proceedings of the IEEE Fourth Working Conference on Current Measurement, G.F. Appell and T.B. Curtin, eds., 1990, pp. 120- 128

[11] C.S. Clay, H. Medwin, Acoustical Oceanography: Principles and Applications, John Wiley \& Sons, New York, 1977

[12] D.A. Trivett, Measuring Flow from Diffuse Hydrothermal Activity, Sc.D. Thesis, Massachussetts institute of Technology/ Woods Hole Oceanographic Institution Joint Program in Ocean Engineering, 1991

[13] H. Schlichting, Boundary Laver Theory, 7th ed., McGraw-Hill, 1979

[14] A.S. Monin, A.M. Yaglom, Statistical Fluid Mechanics: Mechanics of Turbulence, Volume 1, MIT Press, 1971

[15] D.A. Trivett, A.J. Williams, E.A. Terray, Modular Acoustic Velocity Sensor: A General-Purpose Flow Meter, in Proceedings of the IEEE Fourth Working Conference on Current Measurement, G.F. Appell and T.B. Curtin, eds., 1990, pp. 80-89

[16] M.J. Santala, Ph.D. Thesis, Massachussetts Institute of Technology/ Woods Hole Oceanographic Institution Joint Program in Ocean Engineering, 1991 


\section{FIGURE CAPTIONS}

Figure 1: MAVS General Configuration

Figure 2: BASS Sensor Cage

Figure 3: MAVS Sensor Cage

Figure 4 : Potential Flow Around a Sphere

Figure 5: Velocity Defect and Half-Width of a Cylinder Wake

Figure 6: Interference of Acoustic Path due to Wake

Figure 7: Spectra of Velocity for Several Tow Speeds of BASS

Figure $8:$ Noise Floor and Variance of Spectra of BASS

Figure 9A \& B : An Eddy advecting through the acoustic beam;

9A: Eddy moving into the Beam

9B: Eddy Passing Out of the Beam

Figure 10: Zero Offset between two successive calibrations of BASS

Figure 11 : BASS Accuracy from Tow-Tank Data

Figure 12: Probability Distribution for BASS Tow-Tank Data

Figure 13: Cosine Response of BASS 
T able 1: Summary of Errors from various sources

\begin{tabular}{|l|c|}
\hline Error Source & Error Function \\
\hline Potential Flow: Sphere & $\left(\frac{D}{\mathrm{~L}}\right)^{3}$ \\
Potential Flow: Cylinder & $\left(\frac{\mathrm{D}}{\mathrm{L}}\right)^{2}$ \\
Cylinder Wake & $0.33\left(\frac{\mathrm{C}_{\mathrm{D}} \mathrm{D}}{\mathrm{L}}\right)$ \\
Vortex shedding & $\mathrm{f}_{\mathrm{S}}=0.2 \frac{\mathrm{U}}{\mathrm{D}}, \frac{\Delta \mathrm{U}}{\mathrm{U}}=0.0004 \mathrm{U}$ \\
Zero Offset & $0.1-0.3 \mathrm{~cm} / \mathrm{s}$ \\
Sound Speed & $\frac{\mathrm{c}^{2}-\mathrm{c}_{\mathrm{m}}^{2}}{\mathrm{c}^{2}}$ \\
\hline
\end{tabular}


$T$ able 2: Summary of Errors from various sources and their impact on BASS and MAVS

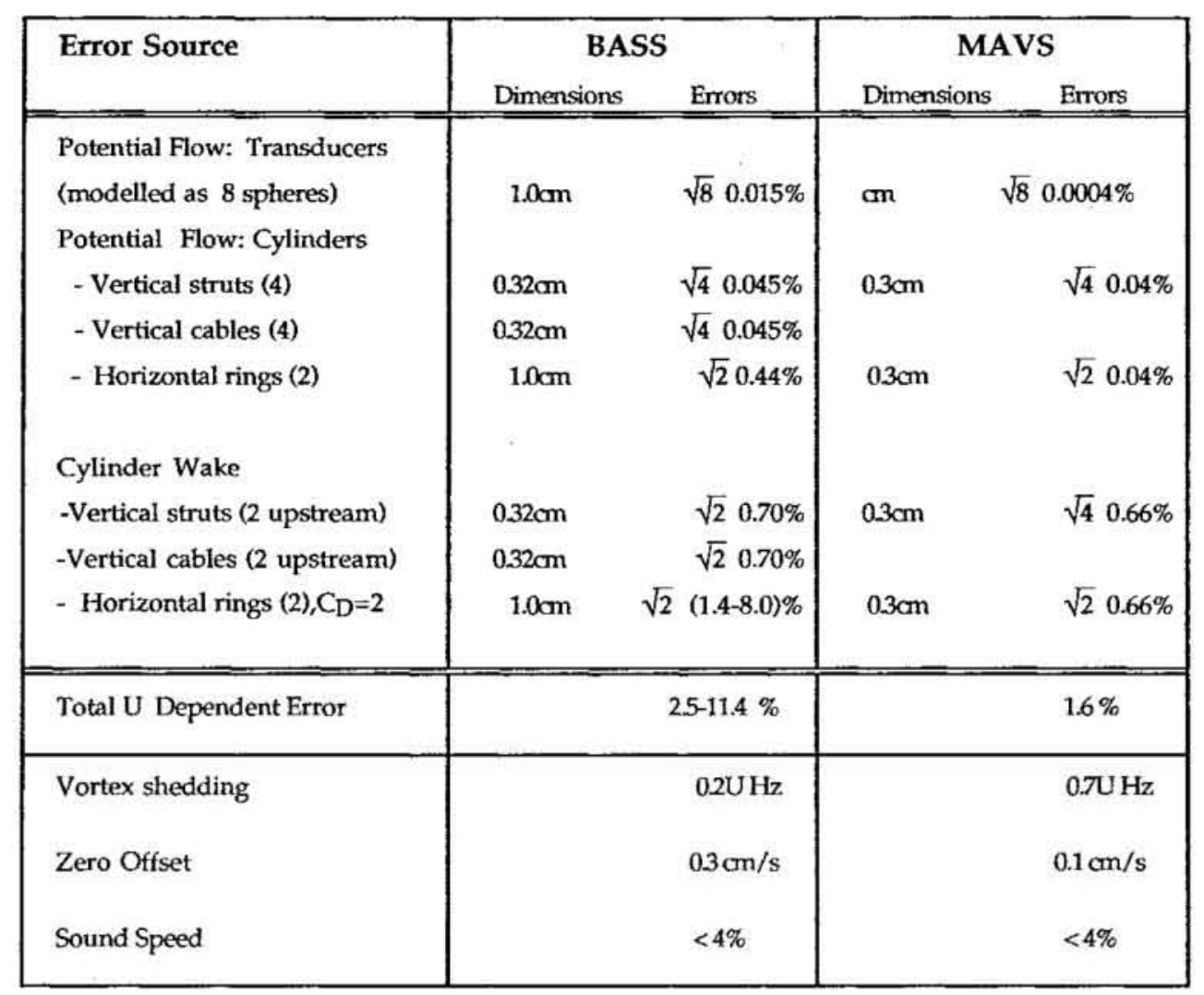




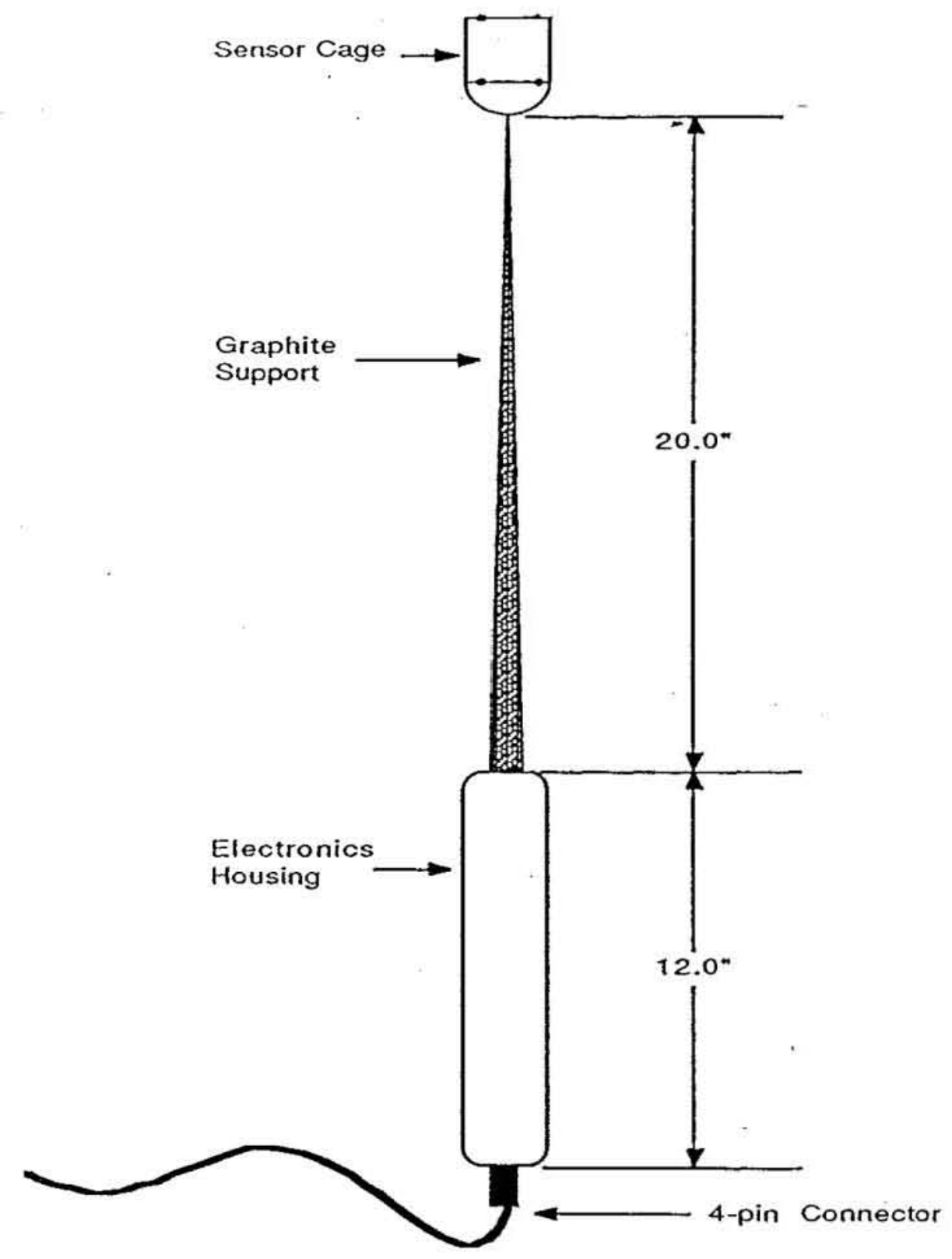

Figure 1: MAVS General Configuration 


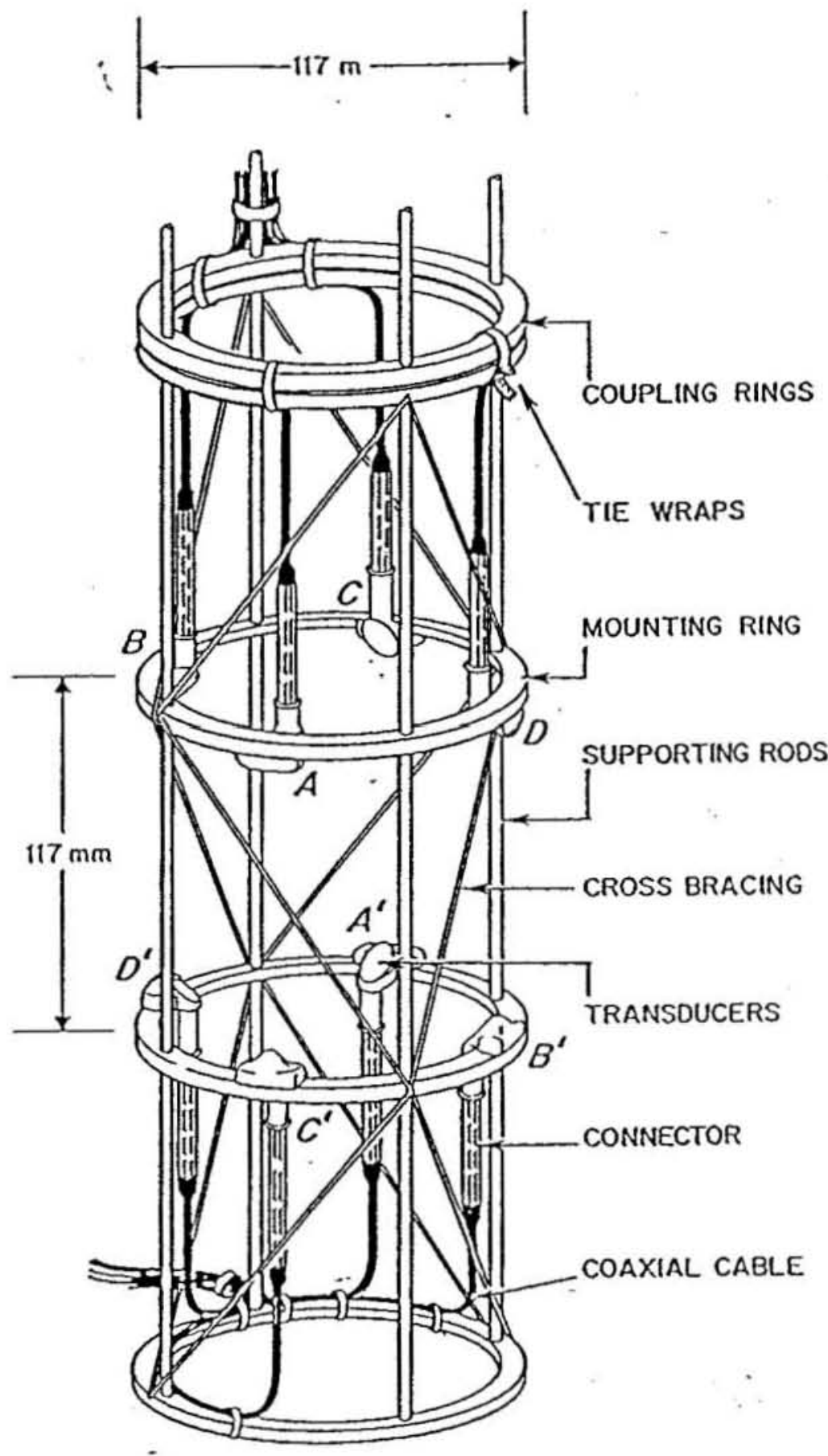

Figure 2: BASS Sensor Cage 


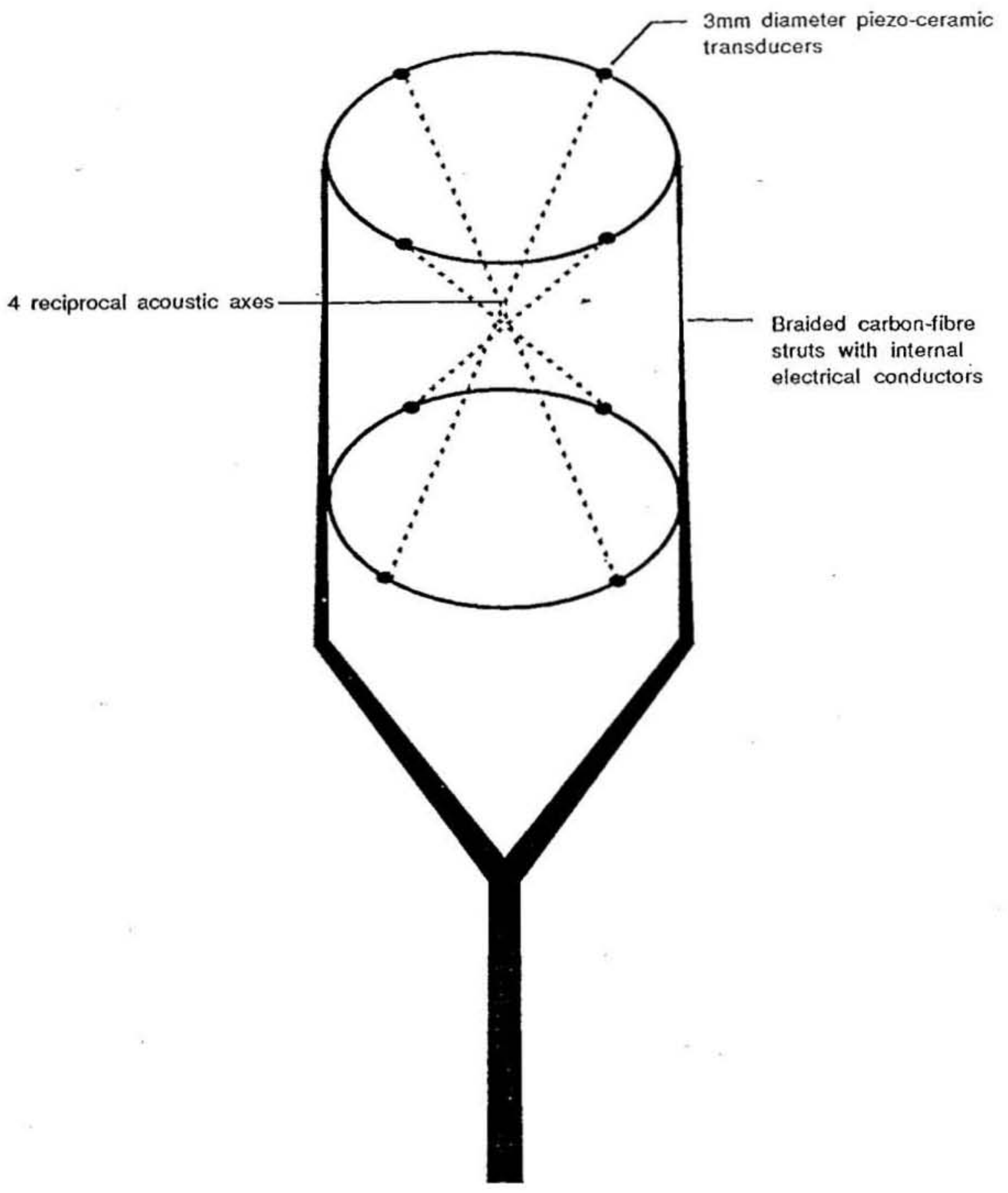

1

Figure 3: MAVS Sensor Cage 


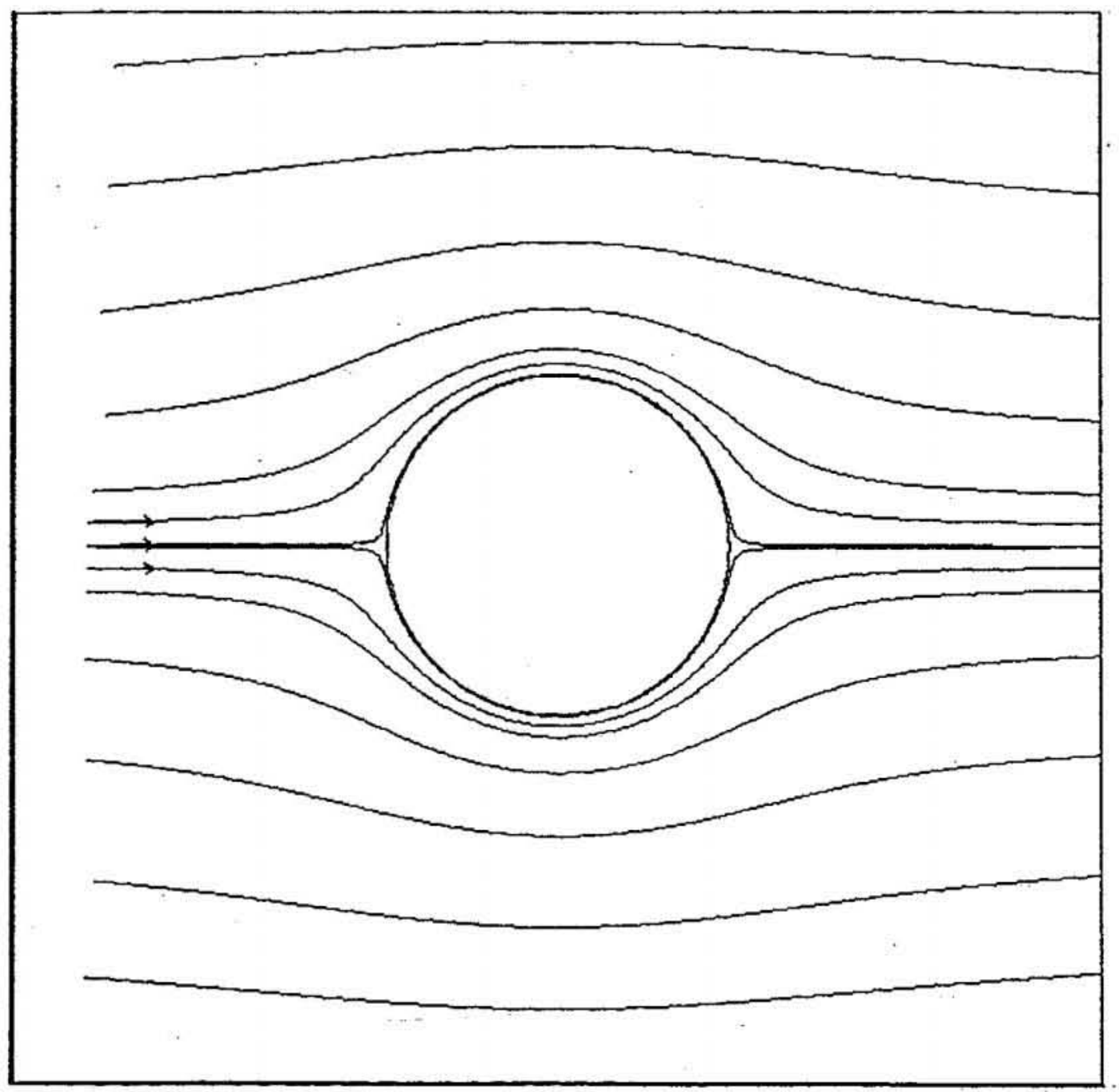

Figure 4: Potential Flow Around a Sphere 


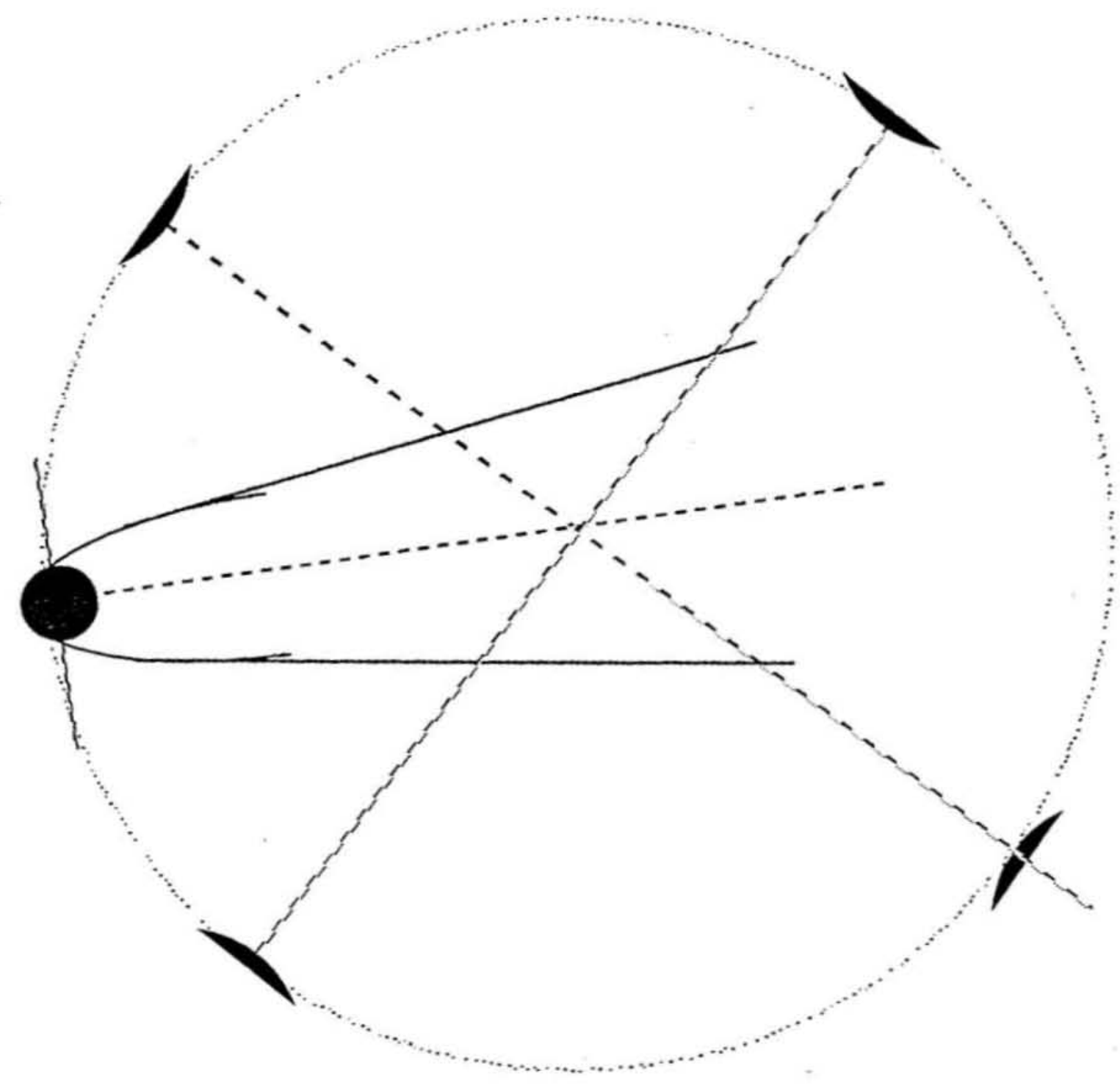

Figure 5: Interference of Acoustic Path due to Wake 

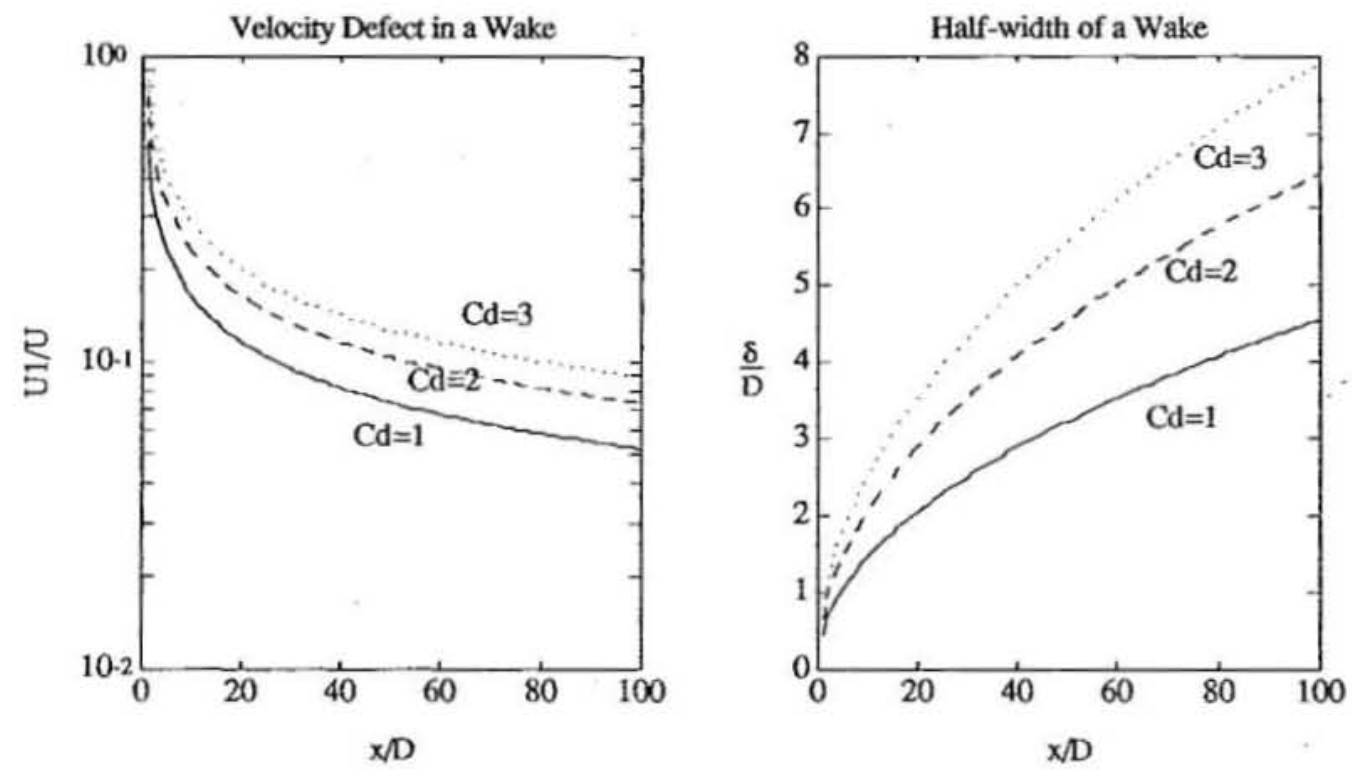

Figure 6: Velocity Defect and Half-Width of a Cylinder Wake 

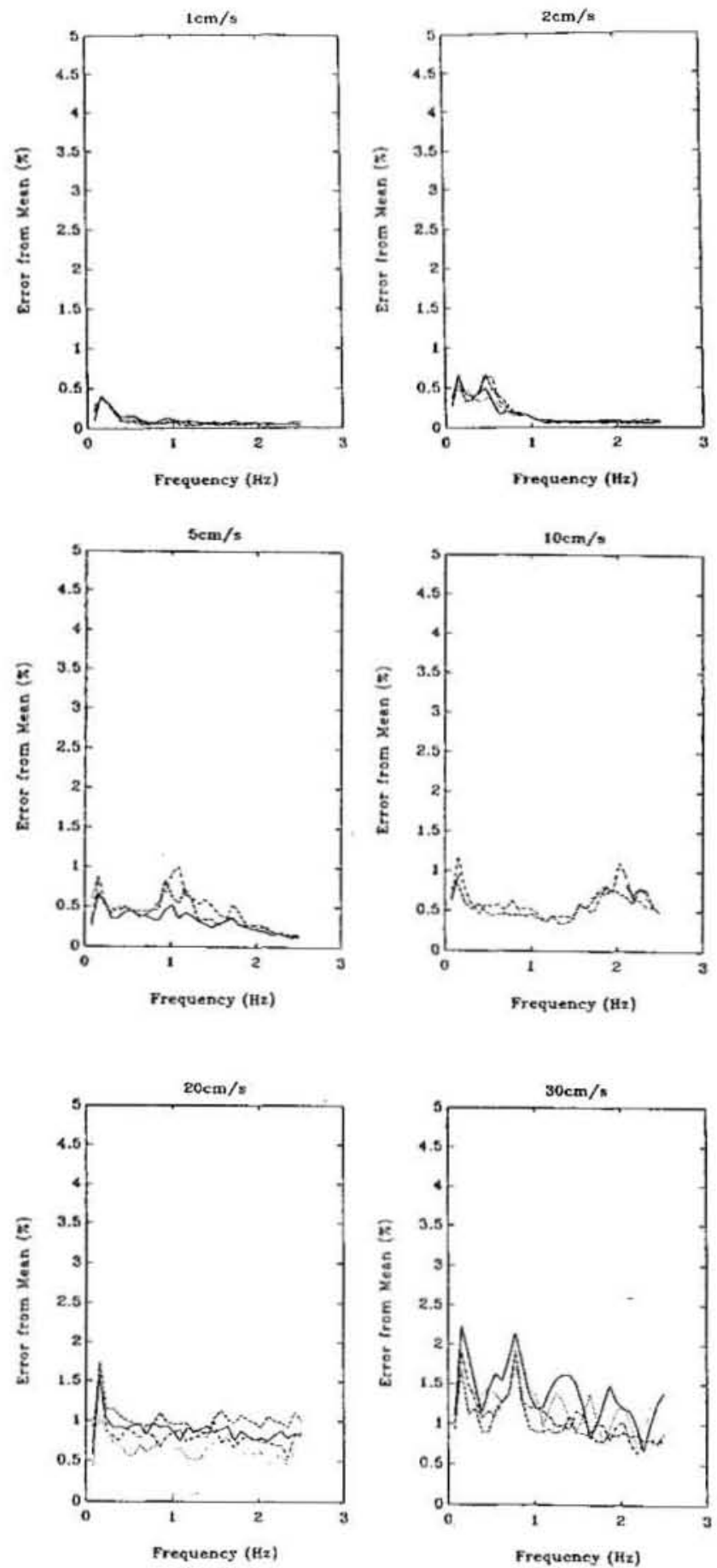

Figure 7: Spectra of Velocity for Several Tow Speeds of BASS 

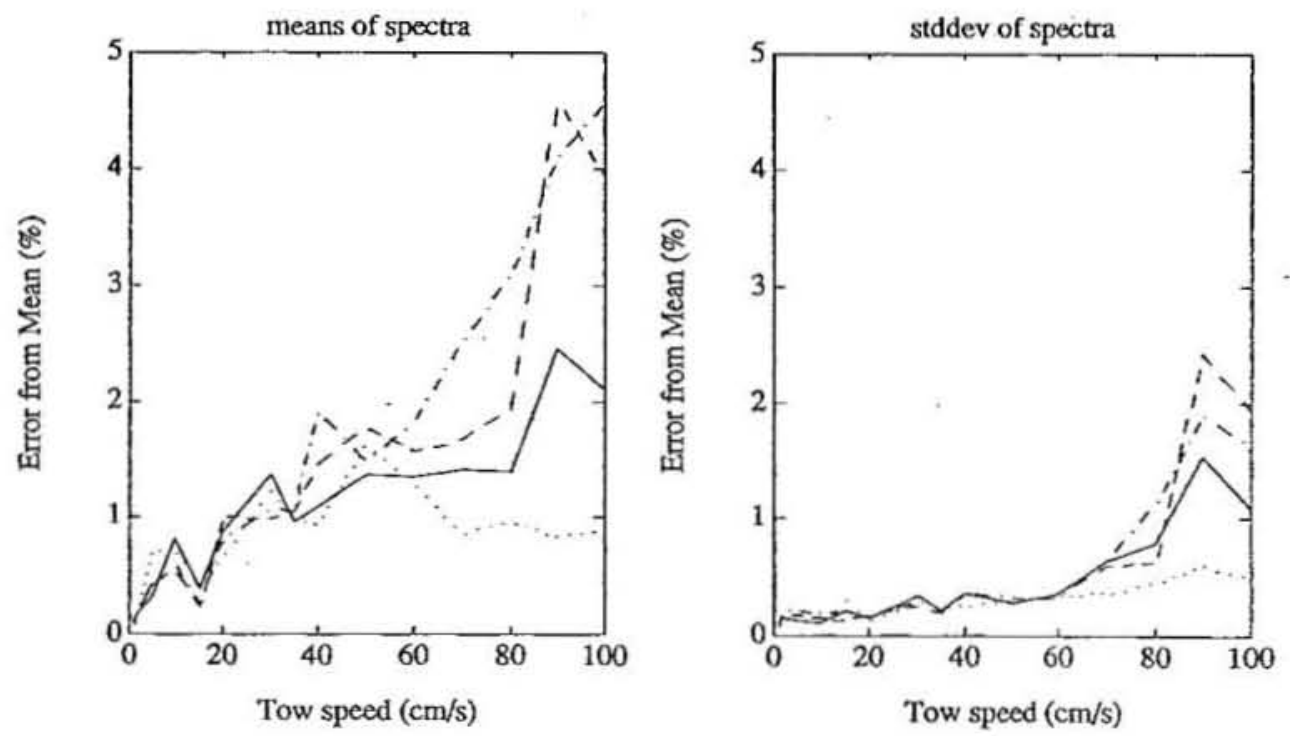

Figure 8 : Noise Floor and Variance of Spectra of BASS 


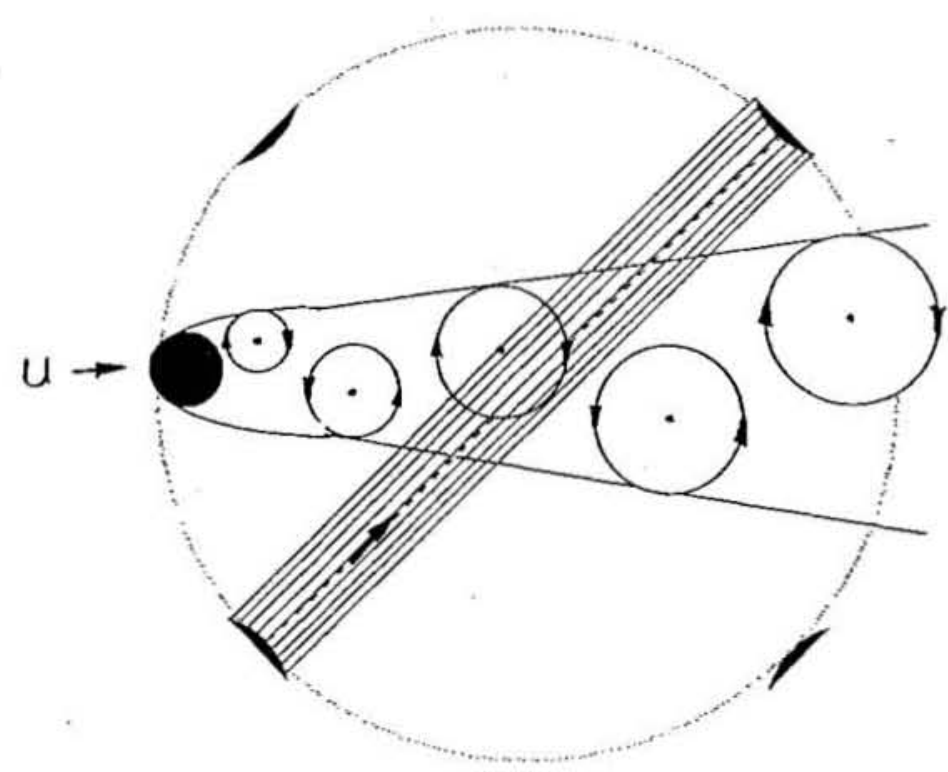

9A: moving into the Beam

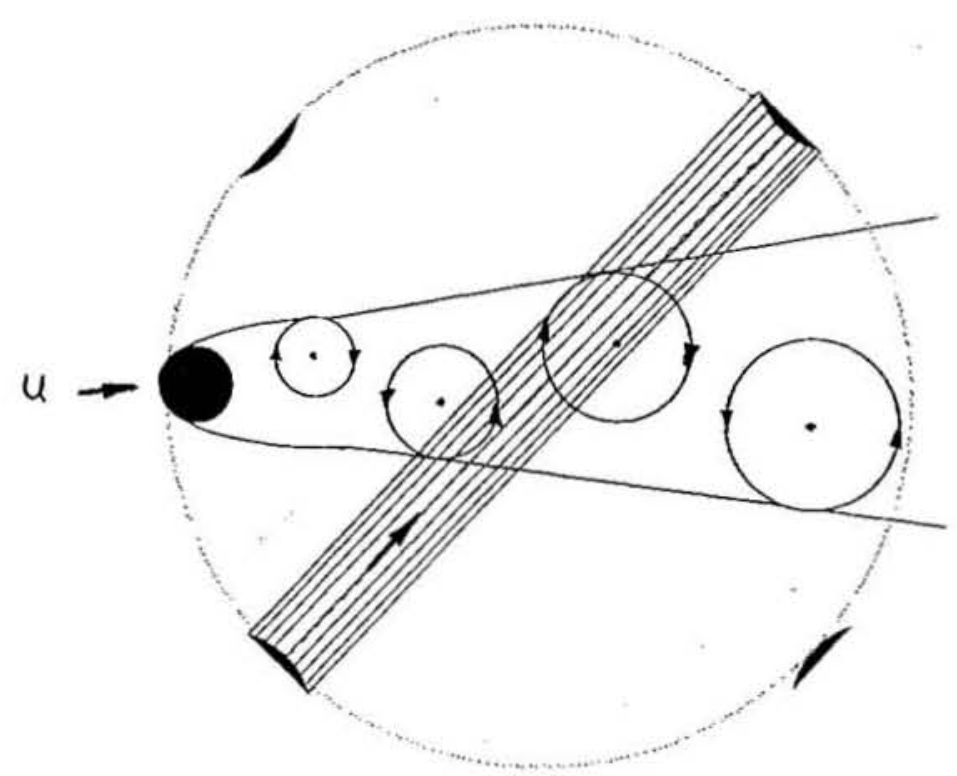

9 B: Passing Out of the Beam

Figure 9A \& B : An Eddy advecting through the acoustic beam; 


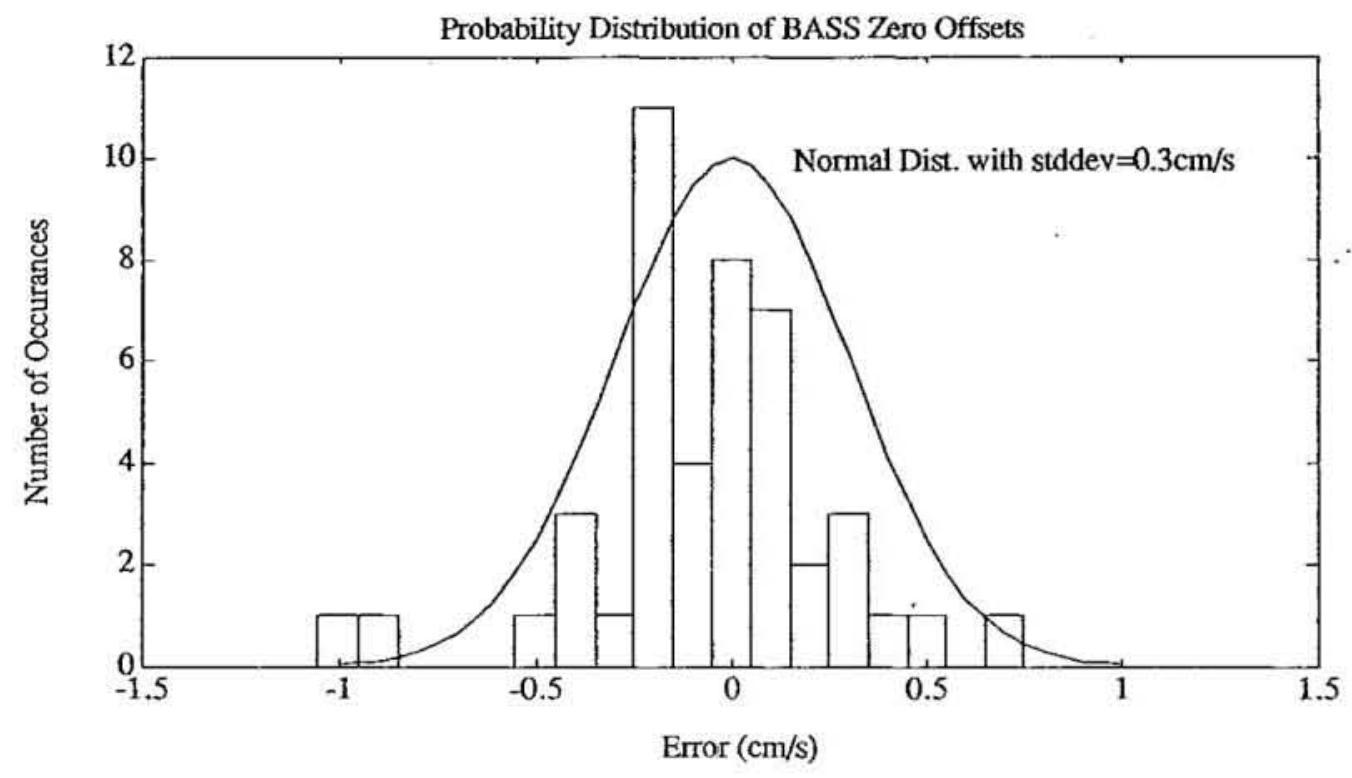

Figure 10: Zero Offset between two successive calibrations of BASS 


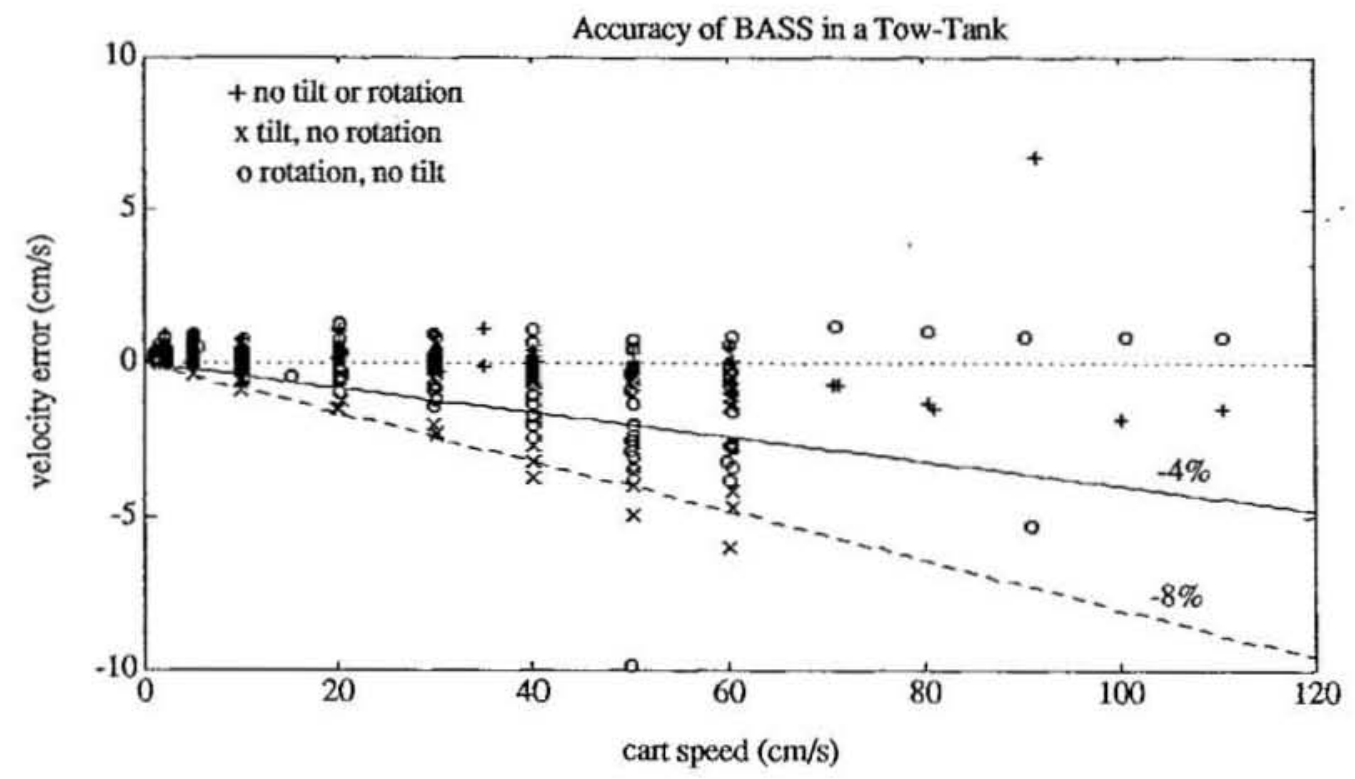

Figure 11 : BASS Accuracy from Tow-Tank Data 


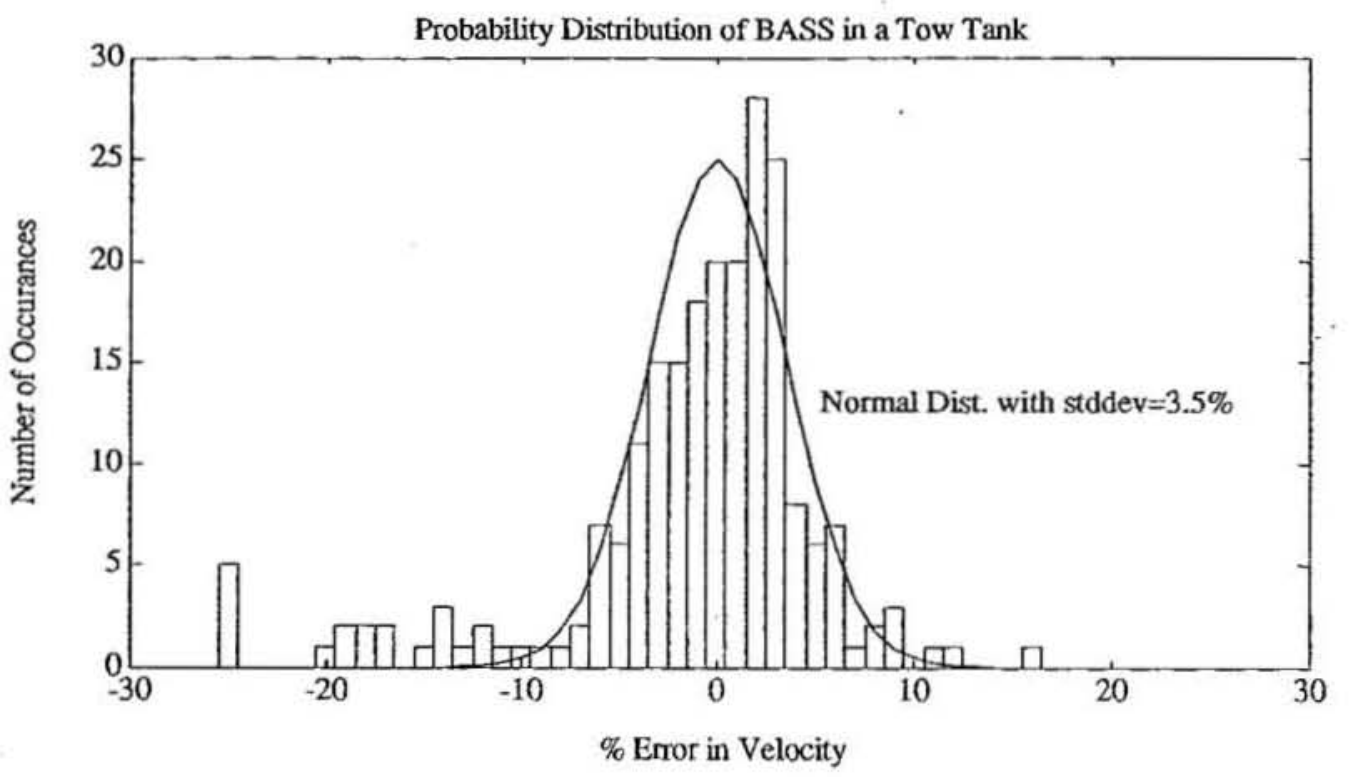

Figure 12: Probability Distribution for BASS Tow-Tank Data 

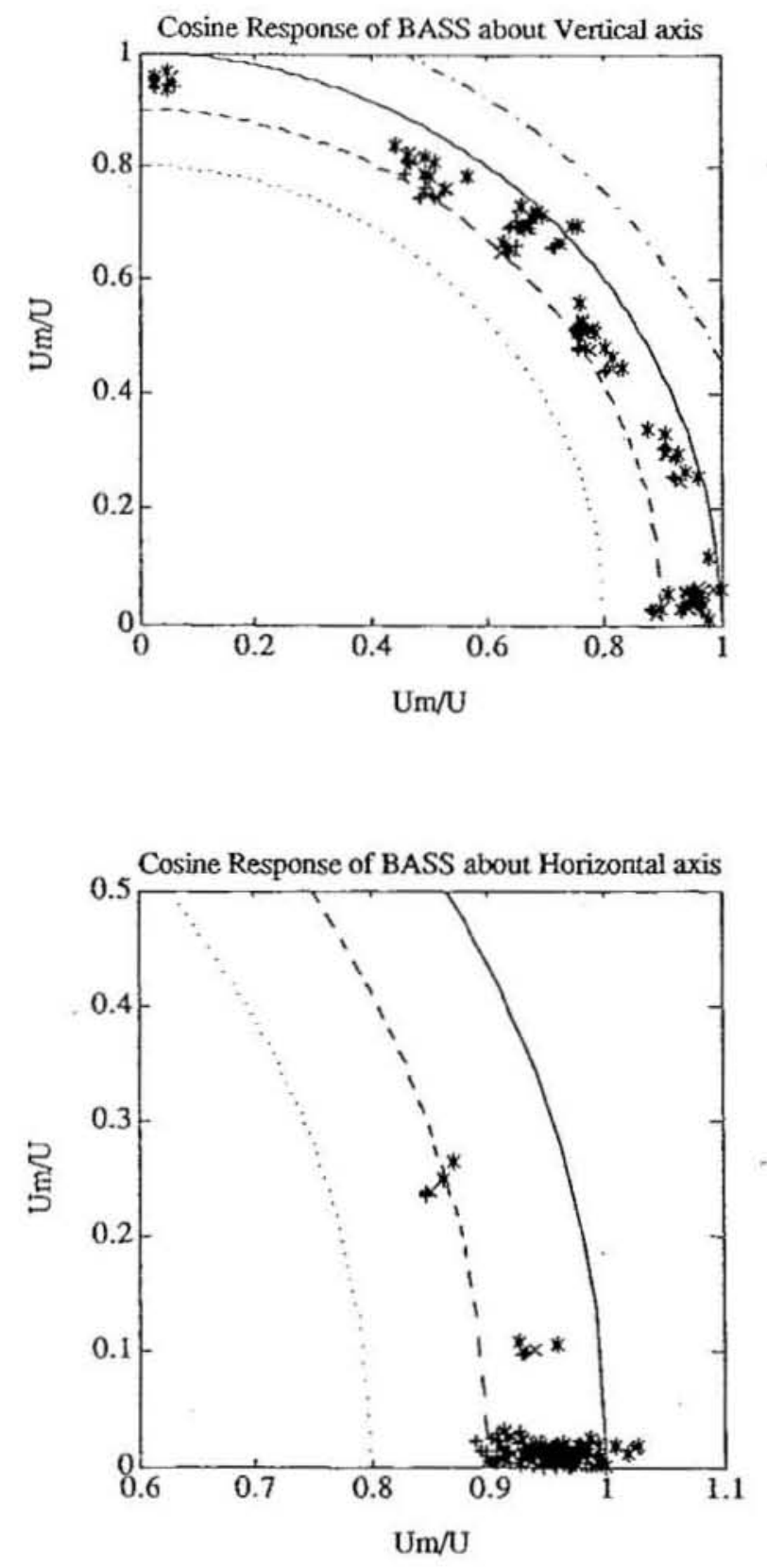

Figure 13: Cosine Response of BASS 
Appendix C : Time-Series and Cross-correlations from VENTS90 


\section{Additional Data Plots from VENTS90}

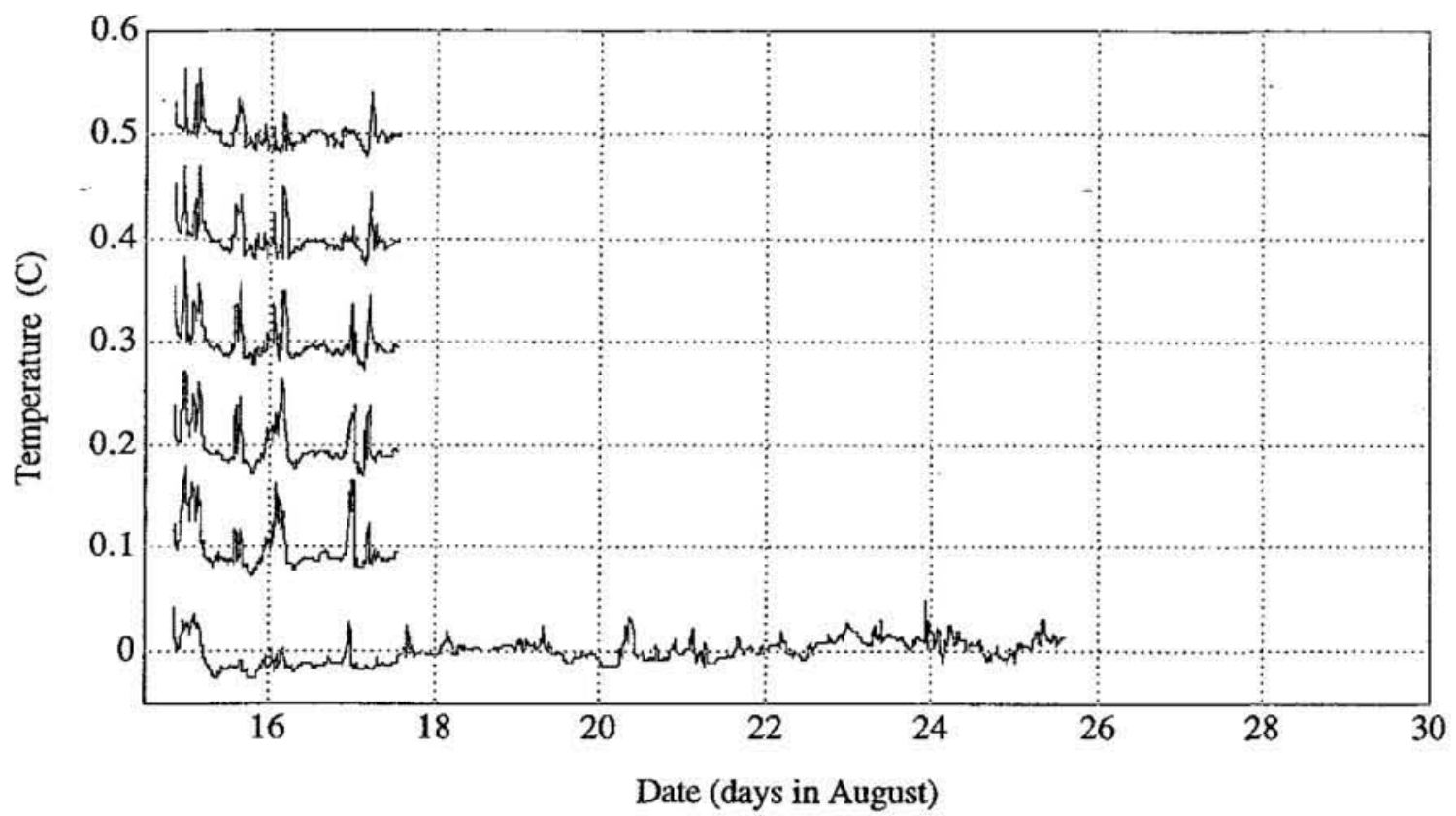

Figure C.1: Temperature from all the thermistors on M2. Each temperature time-series is offset vertically by $.1^{\circ} \mathrm{C}$. The bottom time series is from MTR2016, which logged data for longer than the others.

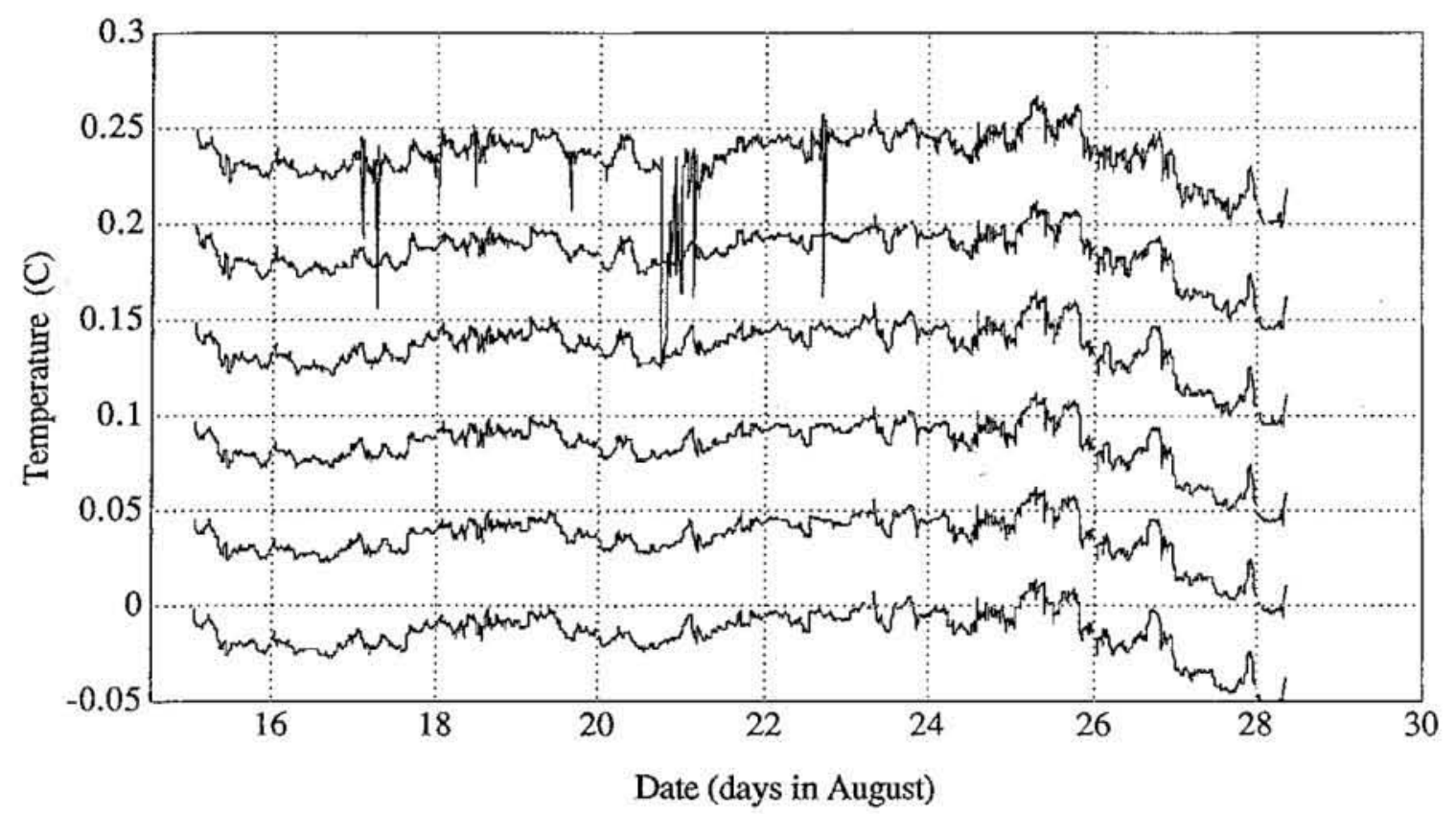

Figure C.2: Temperature from all the pods on BS3. Each temperature time-series is offset vertically by $.05^{\circ} \mathrm{C}$. The bottom time series is from the lowermost pod, and the top is from the highest pod. The top pod had one bad acoustic axis, which is reflected in the large spikes in temperature. 


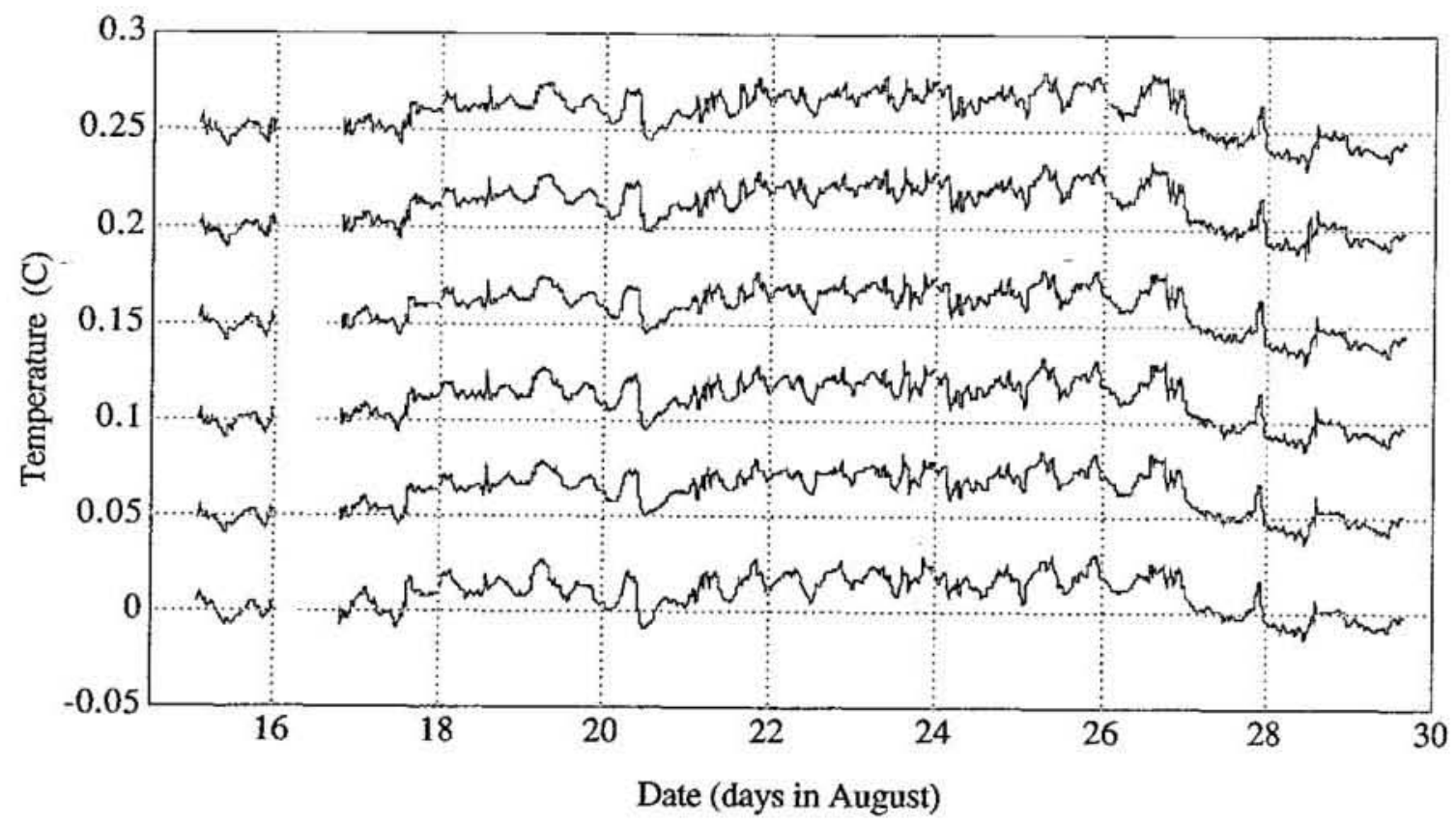

Figure C.3: Temperature from all the pods on BS4. Each temperature time-series is offset vertically by $.05^{\circ} \mathrm{C}$. The bottom time series is from the lowermost pod, and the top is from the highest pod.

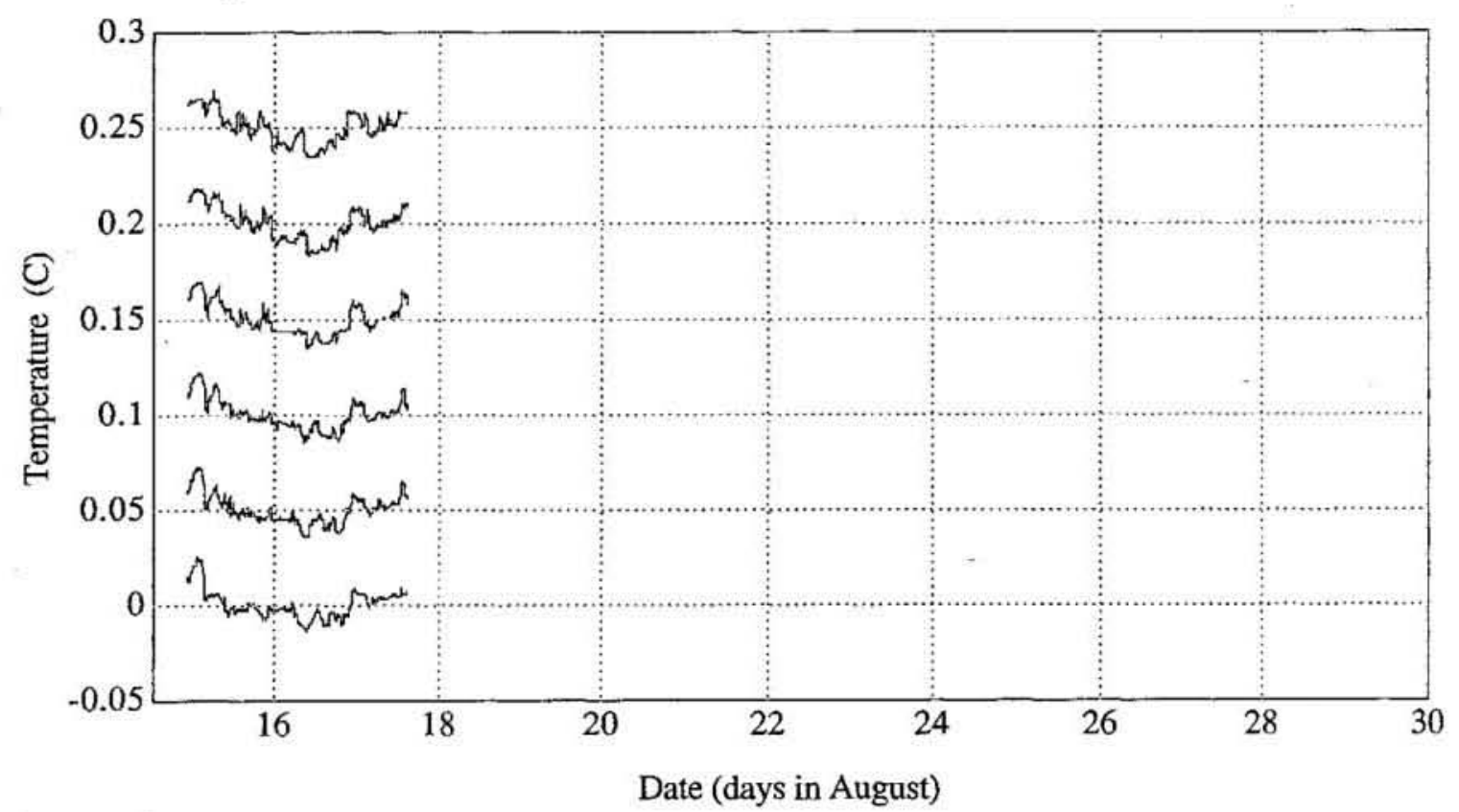

Figure C.4: Temperature from all the thermistors on M5. Each temperature time-series is offset vertically by $.05^{\circ} \mathrm{C}$. The bottom time series is from the lowermost sensor, and the top is from the highest sensor. 


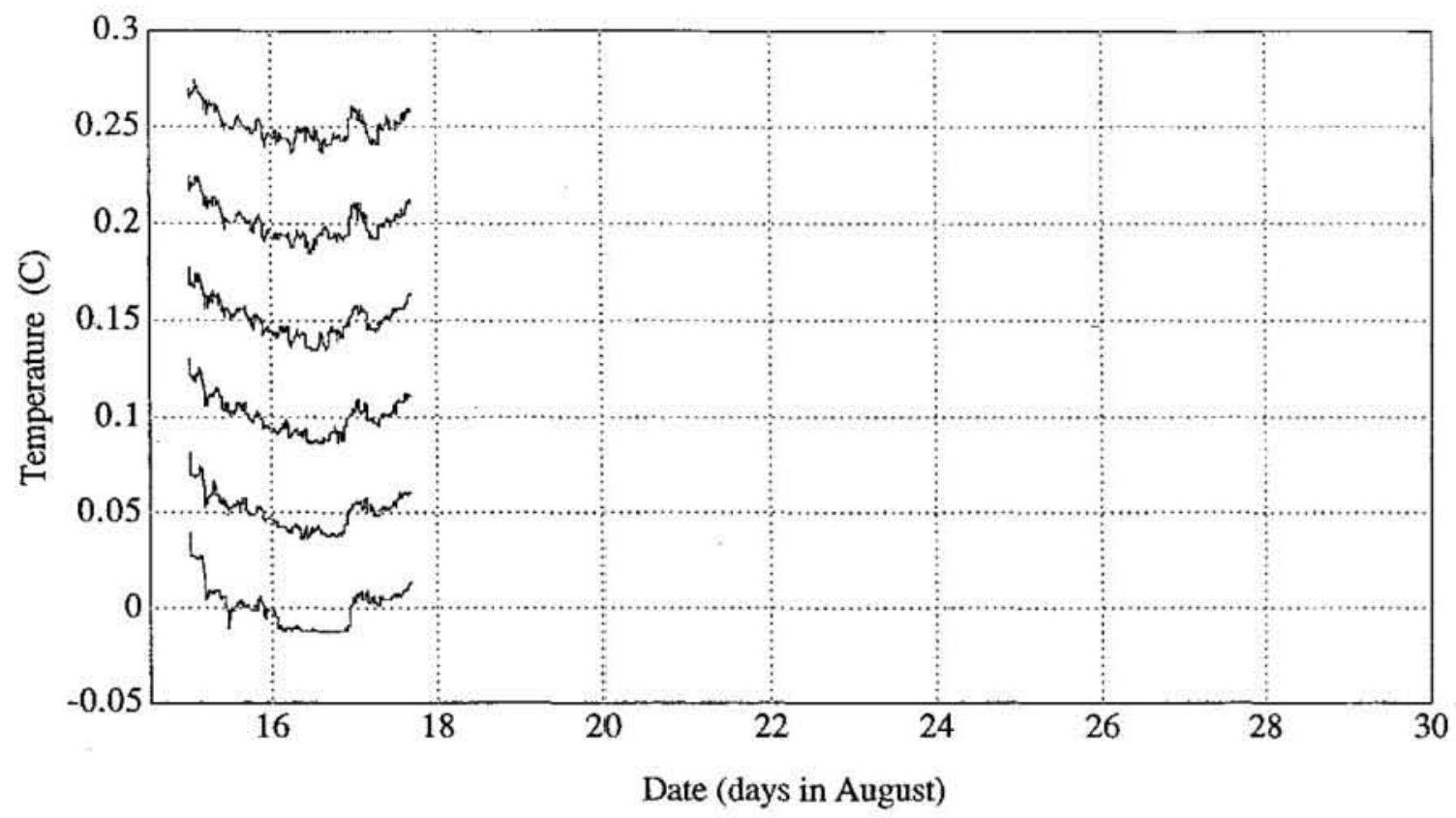

Figure C.5: Temperature from all the thermistors on M6. Each temperature time-series is offset vertically by $.05^{\circ} \mathrm{C}$. The bottom time series is from the lowermost sensor, and the top is from the highest sensor.

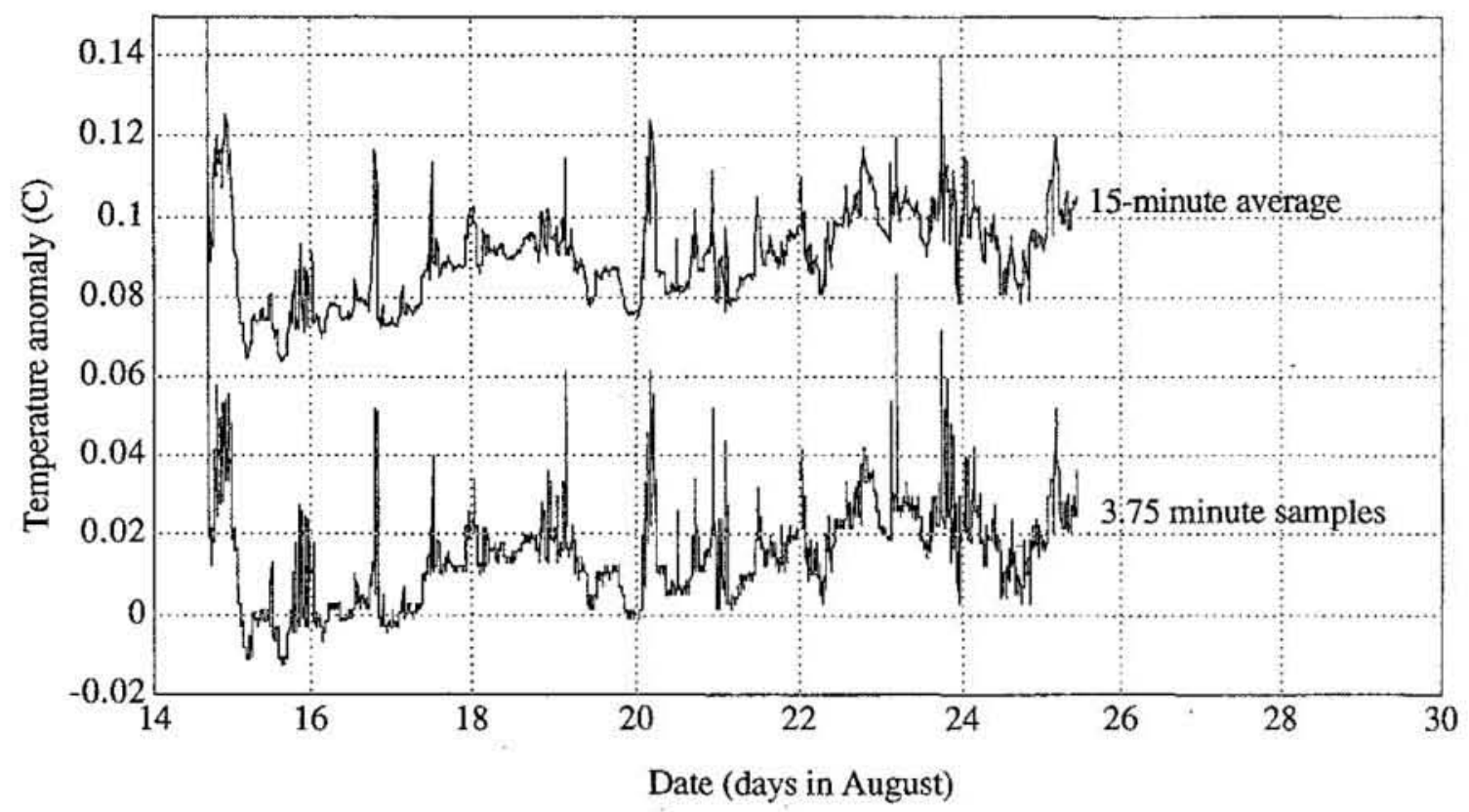

Figure C.6: Temperature from the bottom thermistor on M2. Each temperature time-series is offset vertically by $.08^{\circ} \mathrm{C}$. The bottom time series is raw data which was recorded at a sample rate of once per 3.75 minutes. The upper time-series shows the same data after it was decimated to 15-minute averages. 

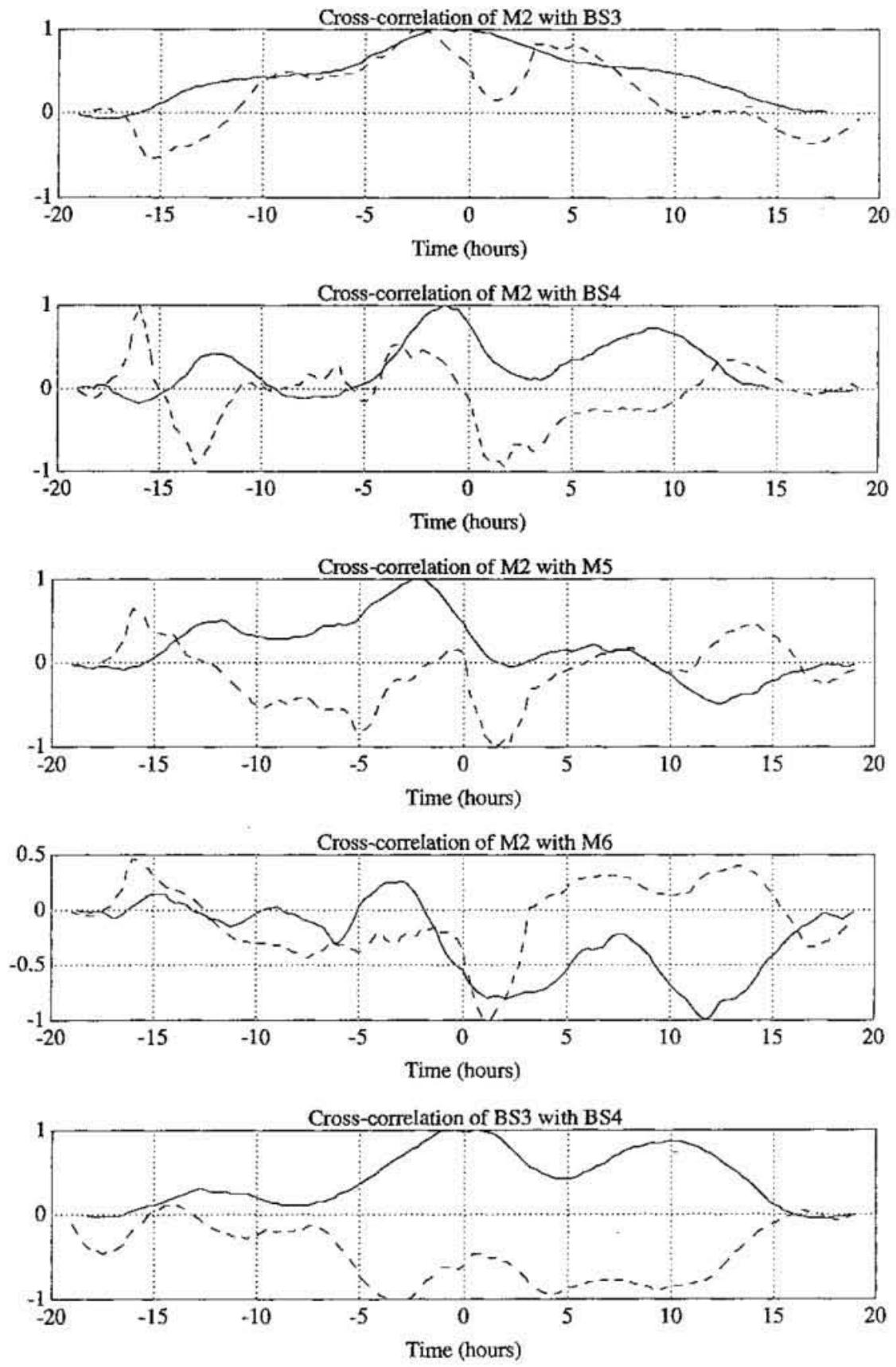

Figure C.7: Cross-correlation between temperatures from the moorings and tripods. The solid line is the correlation between temperatures on the first day of deployment, and the dashed line is the correlation between temperatures on the third day. 

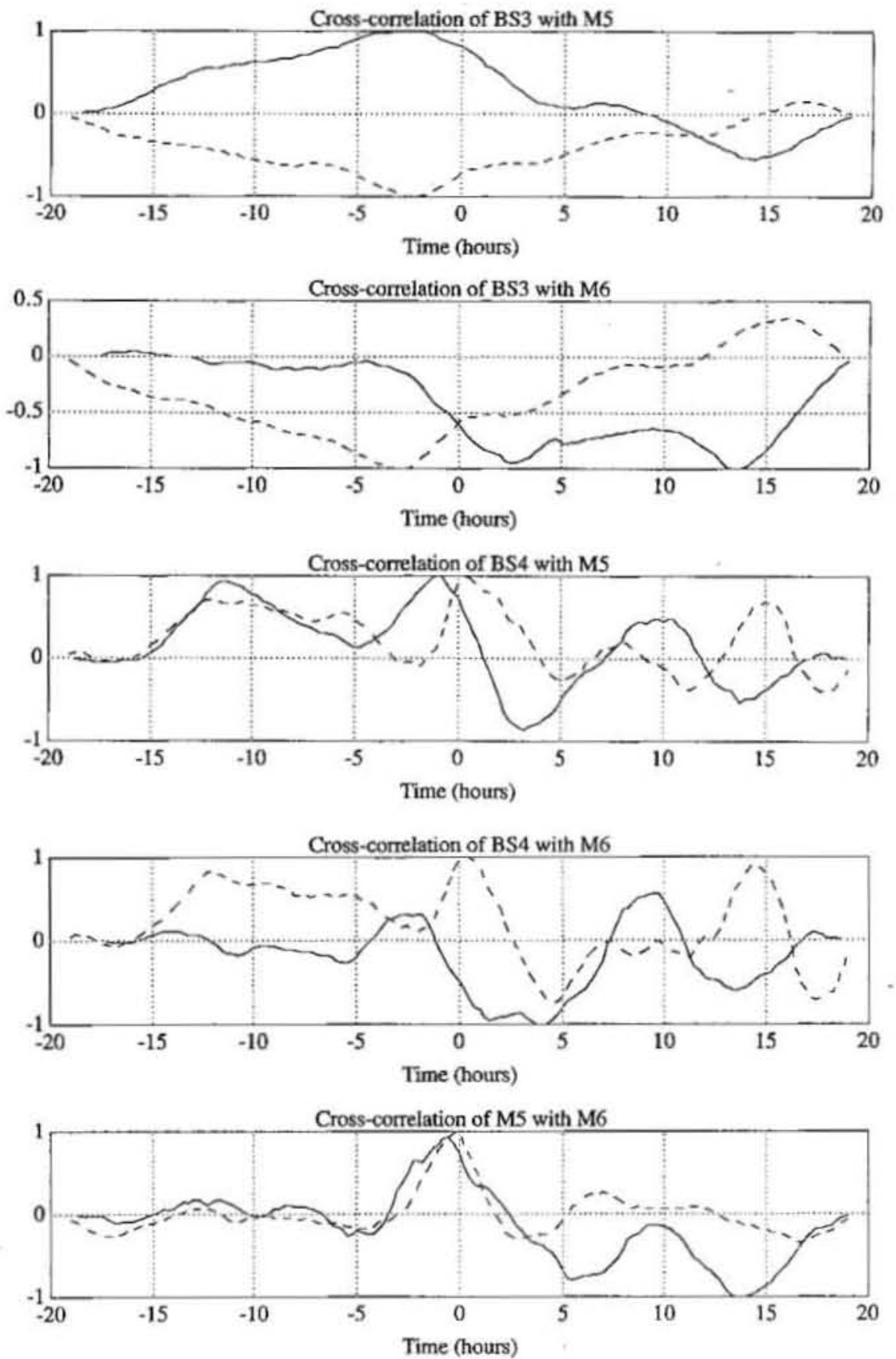

Figure C.8: Cross-correlation between temperatures from the moorings and tripods. The solid line is the correlation between temperatures on the first day of deployment, and the dashed line is the correlation between temperatures on the third day. This is a continuation of the plots from C.7. 


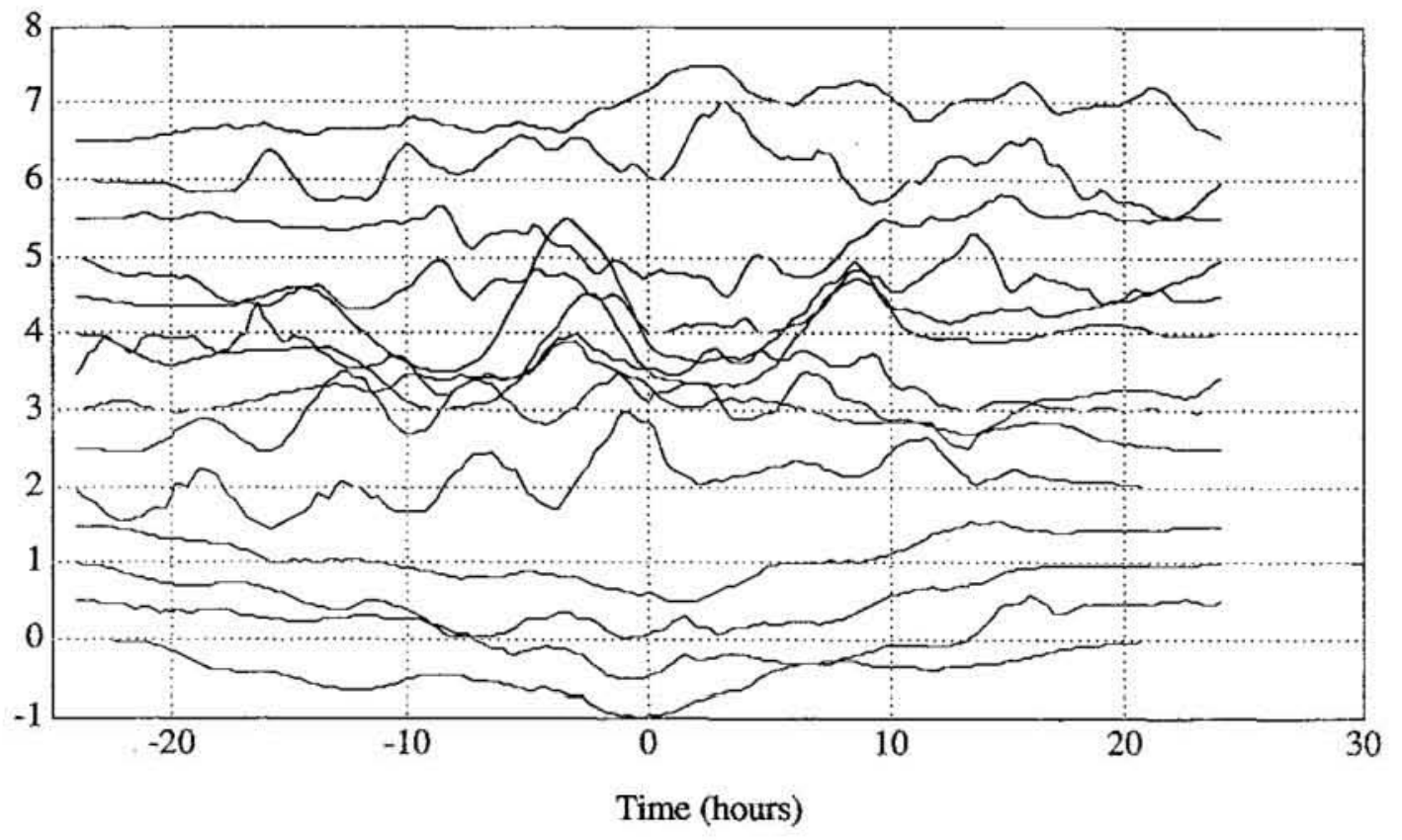

Figure C.7: Cross-correlation between the bottom sensor on M2 and the turbulent kinetic energy measured at BS3. The bottom line represents the correlation for the first day, and each other line moving upwards on the figure represents the correlation for a subsequent 12-hour period. The correlation changes depending on flow conditions, indicating that the relation is not purely a function of tidal forcing, but is probably a result of flow direction and magnitude also. The correlation peak around 10-hours (between 8-14 hours there appears to be a peak in several of the correlations) was used as a representative time-scale for the relation between M2 and the turbulent intensity. 

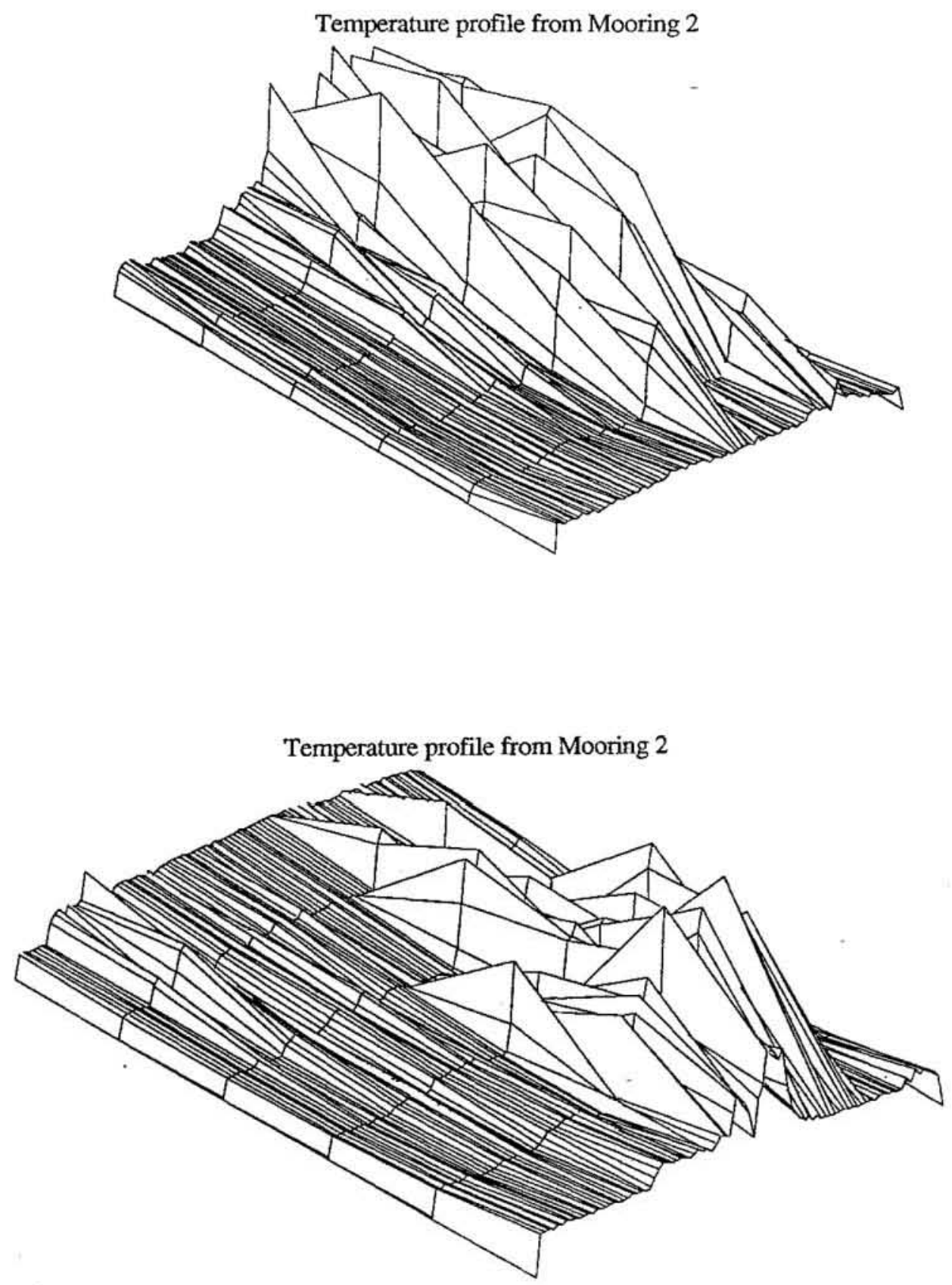

Figure C.8: Temperature profiles from M2 showing 3.75-minute samples of plumes going to the southward (top) and to the westward (bottom). The vertical scale on both plots is temperature, and the horizontal axes are time (to the right) and height (to the left). The figure 4.14 shows the complete time-series of this representation similar to this that has been averaged to one-hour samples. 